\title{
Prophylactic platelet transfusion for prevention of bleeding in patients with haematological disorders after chemotherapy and stem cell transplantation (Review)
}

Estcourt L, Stanworth S, Doree C, Hopewell S, Murphy MF, Tinmouth A, Heddle N
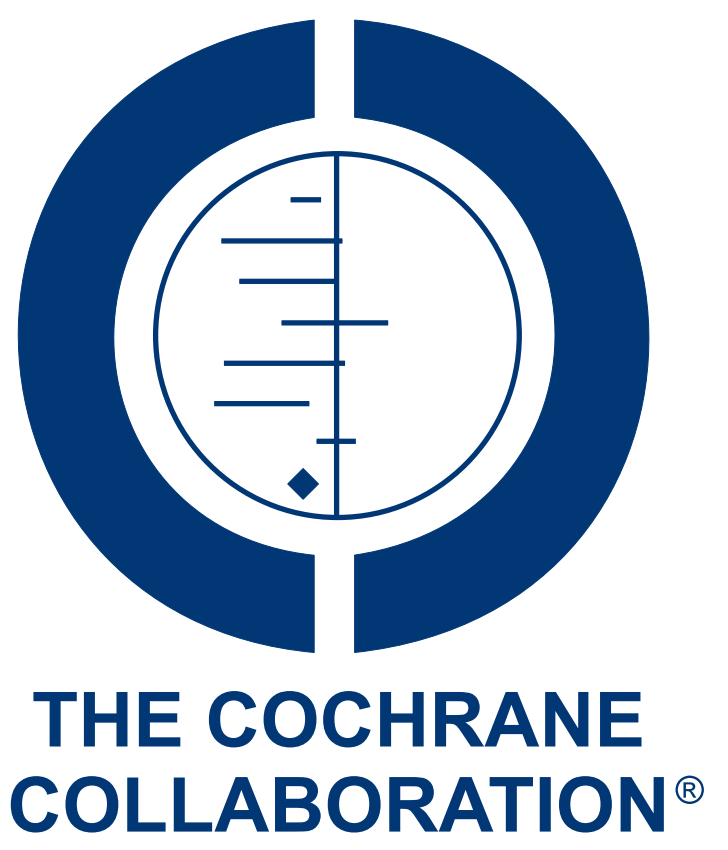

This is a reprint of a Cochrane review, prepared and maintained by The Cochrane Collaboration and published in The Cochrane Library 2012, Issue 5

http://www.thecochranelibrary.com

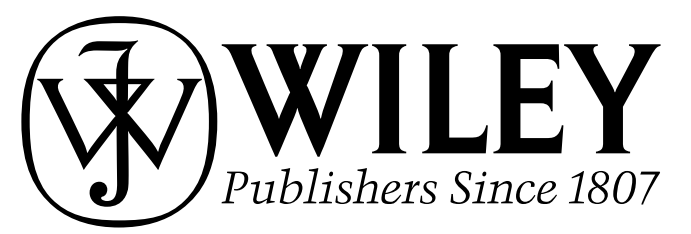

Prophylactic platelet transfusion for prevention of bleeding in patients with haematological disorders after chemotherapy and stem cell transplantation (Review)

Copyright ( 2012 The Cochrane Collaboration. Published by John Wiley \& Sons, Ltd. 
TABLE OF CONTENTS

HEADER . . . . . . . . . . . . . . . . . . . . . . . . . . . . . . 1

ABSTRACT .. . . . . . . . . . . . . . . . . . . . . . . . . . . . . . . . . . . . . . . . . . . . . . . . .

PLAIN LANGUAGE SUMMARY . . . . . . . . . . . . . . . . . . . . . . . . . . . . . . . . . . . . . . . . $\quad . \quad 2$

SUMMARY OF FINDINGS FOR THE MAIN COMPARISON . . . . . . . . . . . . . . . . . . . . . .

BACKGROUND . . . . . . . . . . . . . . . . . . . . . . . . . . . . . . . . . . . . . . 6

OBJECTIVES . . . . . . . . . . . . . . . . . . . . . . . . . . . . . . . . . . . . . . . . . 8

METHODS . . . . . . . . . . . . . . . . . . . . . . . . . . . . . . . . . . . . . . 8

RESULTS . . . . . . . . . . . . . . . . . . . . . . . . . . . . . . . . . . . . . . . 12

Figure 1. . . . . . . . . . . . . . . . . . . . . . . . . . . . . . . . . . . . . . 13

Figure 2. . . . . . . . . . . . . . . . . . . . . . . . . . . . . . . . . . . . . . 18

Figure 3. . . . . . . . . . . . . . . . . . . . . . . . . . . . . . . . . . . . . . 24

Figure 4. . . . . . . . . . . . . . . . . . . . . . . . . . . . . . . . . . . . . . 24

Figure 5. . . . . . . . . . . . . . . . . . . . . . . . . . . . . . . . . . . . . . 25

Figure 6. . . . . . . . . . . . . . . . . . . . . . . . . . . . . . . . . . . . . . 26

Figure $7 . \quad$. . . . . . . . . . . . . . . . . . . . . . . . . . . . . . . . . . . . . 27

Figure 8. . . . . . . . . . . . . . . . . . . . . . . . . . . . . . . . . . . . . . 28

Figure 9. . . . . . . . . . . . . . . . . . . . . . . . . . . . . . . . . . . . . . 29

Figure 10. . . . . . . . . . . . . . . . . . . . . . . . . . . . . . . . . . . . . . 30

ADDITIONAL SUMMARY OF FINDINGS . . . . . . . . . . . . . . . . . . . . . . . . . . . . . .

DISCUSSION . . . . . . . . . . . . . . . . . . . . . . . . . . . . . . . . . . . . . . 40

AUTHORS' CONCLUSIONS . . . . . . . . . . . . . . . . . . . . . . . . . . . . . . . . . . . . . 42

ACKNOWLEDGEMENTS . . . . . . . . . . . . . . . . . . . . . . . . . . . . . . . . . . . . . . . . . . 43

REFERENCES . . . . . . . . . . . . . . . . . . . . . . . . . . . . . . . . . . . . . 43

CHARACTERISTICS OF STUDIES . . . . . . . . . . . . . . . . . . . . . . . . . . . . . . . 52

DATA AND ANALYSES . . . . . . . . . . . . . . . . . . . . . . . . . . . . . . . . . . . . . . . . . . . . . . . $\quad$.

Analysis 1.1. Comparison 1 Prophylactic platelet transfusion versus non prophylactic or therapeutic transfusion, Outcome

1 Numbers of participants with a significant bleeding event. . . . . . . . . . . . . . . . . . . . . . . 88

Analysis 1.2. Comparison 1 Prophylactic platelet transfusion versus non prophylactic or therapeutic transfusion, Outcome

2 Number of days with significant bleeding. . . . . . . . . . . . . . . . . . . . . . . . . . . . 89

Analysis 1.3. Comparison 1 Prophylactic platelet transfusion versus non prophylactic or therapeutic transfusion, Outcome

3 Mortality from all causes. . . . . . . . . . . . . . . . . . . . . . . . . . . . . . 90

Analysis 1.4. Comparison 1 Prophylactic platelet transfusion versus non prophylactic or therapeutic transfusion, Outcome 4 Mortality from bleeding. . . . . . . . . . . . . . . . . . . . . . . . . . . . . .

Analysis 1.5. Comparison 1 Prophylactic platelet transfusion versus non prophylactic or therapeutic transfusion, Outcome

5 Mean number of platelet transfusions per course of chemotherapy. . . . . . . . . . . . . . . . . 91

Analysis 1.6. Comparison 1 Prophylactic platelet transfusion versus non prophylactic or therapeutic transfusion, Outcome 6 Mean number of red cell transfusions per patient. . . . . . . . . . . . . . . . . . . . . . . . . . . . 9

Analysis 1.7. Comparison 1 Prophylactic platelet transfusion versus non prophylactic or therapeutic transfusion, Outcome

7 Remission rates. . . . . . . . . . . . . . . . . . . . . . . . . . . . . . . . . 92

Analysis 1.8. Comparison 1 Prophylactic platelet transfusion versus non prophylactic or therapeutic transfusion, Outcome 8 Number of participants with platelet refractoriness. . . . . . . . . . . . . . . . . . . . . . . . 92

Analysis 2.1. Comparison 2 Prophylactic platelet transfusion at one trigger level versus another trigger level, Outcome 1

Number of participants with any bleeding event. . . . . . . . . . . . . . . . . . . . . . .

Analysis 2.2. Comparison 2 Prophylactic platelet transfusion at one trigger level versus another trigger level, Outcome 2

Numbers of participants with a significant bleeding event.

Analysis 2.3. Comparison 2 Prophylactic platelet transfusion at one trigger level versus another trigger level, Outcome 3

Number of participants with WHO Grade 3 or 4 bleeding. . . . . . . . . . . . . . . . . . . . . . . . . . .

Analysis 2.4. Comparison 2 Prophylactic platelet transfusion at one trigger level versus another trigger level, Outcome 4

Number of participants with bleeding requiring a red cell transfusion. . . . . . . . . . . . . . . . .

Analysis 2.5. Comparison 2 Prophylactic platelet transfusion at one trigger level versus another trigger level, Outcome 5

Number of days with any bleeding.

Prophylactic platelet transfusion for prevention of bleeding in patients with haematological disorders after chemotherapy and stem cell transplantation (Review) 
Analysis 2.6. Comparison 2 Prophylactic platelet transfusion at one trigger level versus another trigger level, Outcome 6 Number of days with a significant bleed.

Analysis 2.7. Comparison 2 Prophylactic platelet transfusion at one trigger level versus another trigger level, Outcome 7

Mortality from all causes. . . . . . . . . . . . . . . . . . . . . . . . . . . . . . .

Analysis 2.8. Comparison 2 Prophylactic platelet transfusion at one trigger level versus another trigger level, Outcome 8

Mortality from bleeding. . . . . . . . . . . . . . . . . . . . . . . . . . . . . . .

Analysis 2.9. Comparison 2 Prophylactic platelet transfusion at one trigger level versus another trigger level, Outcome 9

Mean number of platelet transfusions per patient. . . . . . . . . . . . . . . . . . . . . . . . .

Analysis 2.10. Comparison 2 Prophylactic platelet transfusion at one trigger level versus another trigger level, Outcome 10

Mean number of red cell transfusions per patient. . . . . . . . . . . . . . . . . . . . . . . . .

Analysis 2.11. Comparison 2 Prophylactic platelet transfusion at one trigger level versus another trigger level, Outcome 11

Remission rates. . . . . . . . . . . . . . . . . . . . . . . . . . . . . . . . . .

Analysis 2.12. Comparison 2 Prophylactic platelet transfusion at one trigger level versus another trigger level, Outcome 12

Numbers of participants with platelet transfusion reactions. . . . . . . . . . . . . . . . . . .

Analysis 2.13. Comparison 2 Prophylactic platelet transfusion at one trigger level versus another trigger level, Outcome 13

Number of participants with thromboembolic disease. . . . . . . . . . . . . . . . . . . . . . . . . .

Analysis 2.14. Comparison 2 Prophylactic platelet transfusion at one trigger level versus another trigger level, Outcome 14

Number of participants requiring HLA-matched platelets. . . . . . . . . . . . . . . . . . . 10

Analysis 2.15. Comparison 2 Prophylactic platelet transfusion at one trigger level versus another trigger level, Outcome 15

Number of participants with platelet refractoriness. . . . . . . . . . . . . . . . . . . . . . 101

Analysis 3.1. Comparison 3 Prophylactic platelet transfusion with one dose schedule versus another dose schedule, Outcome

1 Number of participants with any bleeding event. . . . . . . . . . . . . . . . . . . . . . 102

Analysis 3.2. Comparison 3 Prophylactic platelet transfusion with one dose schedule versus another dose schedule, Outcome

2 Number of participants with a significant bleeding event. . . . . . . . . . . . . . . . . . .

Analysis 3.3. Comparison 3 Prophylactic platelet transfusion with one dose schedule versus another dose schedule, Outcome

3 Number of participants with WHO Grade 3 or 4 bleeding. . . . . . . . . . . . . . . . . . 104

Analysis 3.4. Comparison 3 Prophylactic platelet transfusion with one dose schedule versus another dose schedule, Outcome

4 Number of participants with WHO grade 4 bleeding. . . . . . . . . . . . . . . . . . . .

Analysis 3.5. Comparison 3 Prophylactic platelet transfusion with one dose schedule versus another dose schedule, Outcome

5 Number of participants with bleeding requiring a red cell transfusion. . . . . . . . . . . . . . . 106

Analysis 3.6. Comparison 3 Prophylactic platelet transfusion with one dose schedule versus another dose schedule, Outcome

6 Number of participants with bleeding causing cardiovascular compromise. . . . . . . . . . . . . . . . . . 106

Analysis 3.7. Comparison 3 Prophylactic platelet transfusion with one dose schedule versus another dose schedule, Outcome

7 Number of days with significant bleeding. . . . . . . . . . . . . . . . . . . . . . . . . 107

Analysis 3.8. Comparison 3 Prophylactic platelet transfusion with one dose schedule versus another dose schedule, Outcome

8 Mortality from all causes. . . . . . . . . . . . . . . . . . . . . . . . . . . . . . 108

Analysis 3.9. Comparison 3 Prophylactic platelet transfusion with one dose schedule versus another dose schedule, Outcome

9 Mortality from bleeding. . . . . . . . . . . . . . . . . . . . . . . . . . . . . .

Analysis 3.10. Comparison 3 Prophylactic platelet transfusion with one dose schedule versus another dose schedule,

Outcome 10 Number of participants with platelet transfusion reactions. . . . . . . . . . . . . . .

Analysis 3.11. Comparison 3 Prophylactic platelet transfusion with one dose schedule versus another dose schedule,

Outcome 11 Thromboembolic disease.

Analysis 3.12. Comparison 3 Prophylactic platelet transfusion with one dose schedule versus another dose schedule,

Outcome 12 Number of participants with a significant bleeding episode.

Analysis 3.13. Comparison 3 Prophylactic platelet transfusion with one dose schedule versus another dose schedule,

Outcome 13 Time to first significant bleeding event.

Analysis 3.14. Comparison 3 Prophylactic platelet transfusion with one dose schedule versus another dose schedule,

Outcome 14 Number of days with WHO grade 2 or above bleeding per patient.

Analysis 4.1. Comparison 4 Prophylactic platelet transfusion versus platelet-poor plasma, Outcome 1 Number of participants with a significant bleeding event. . . . . . . . . . . . . . . . . . . . . . . .

Analysis 4.2. Comparison 4 Prophylactic platelet transfusion versus platelet-poor plasma, Outcome 2 Time to first

bleed. 100 01

.
"s (n) (ns) .

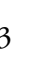
14 
Analysis 4.3. Comparison 4 Prophylactic platelet transfusion versus platelet-poor plasma, Outcome 3 Number of participants with bleeding requiring a red cell transfusion. . . . . . . . . . . . . . . . . . . Analysis 4.4. Comparison 4 Prophylactic platelet transfusion versus platelet-poor plasma, Outcome 4 Number of participants with bleeding causing cardiovascular compromise. . . . . . . . . . . . . . . . . . . . . .

Analysis 4.5. Comparison 4 Prophylactic platelet transfusion versus platelet-poor plasma, Outcome 5 Mortality from bleeding.

Analysis 4.6. Comparison 4 Prophylactic platelet transfusion versus platelet-poor plasma, Outcome 6 Complete remission. . . . . . . . . . . . . . . . . . . . . . . . . . .

Analysis 4.7. Comparison 4 Prophylactic platelet transfusion versus platelet-poor plasma, Outcome 7 Development of HLA

Antibodies. . . . . . . . . . . . . . . . . . . . . . . . . . . . . . . . . . . . 119

ADDITIONAL TABLES . . . . . . . . . . . . . . . . . . . . . . . . . . . . . . . 119

APPENDICES . . . . . . . . . . . . . . . . . . . . . . . . . . . . . . . . . . . . 127

WHAT'S NEW . . . . . . . . . . . . . . . . . . . . . . . . . . . . . . . . . . . . . 131

HISTORY . . . . . . . . . . . . . . . . . . . . . . . . . . . . . . . . . . . . . . . 131

CONTRIBUTIONS OF AUTHORS . . . . . . . . . . . . . . . . . . . . . . . . . . . . . 131

DECLARATIONS OF INTEREST . . . . . . . . . . . . . . . . . . . . . . . . . . . . . . . . . . . . . . . . 131

SOURCES OF SUPPORT . . . . . . . . . . . . . . . . . . . . . . . . . . . . . . . . . . . . . . . . . . . . . . . . . 132

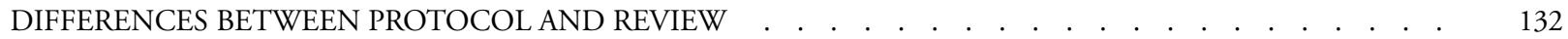

INDEX TERMS . . . . . . . . . . . . . . . . . . . . . . . . . . . . . . . . . . . 132

Prophylactic platelet transfusion for prevention of bleeding in patients with haematological disorders after chemotherapy and stem cell iii transplantation (Review)

Copyright $\odot 2012$ The Cochrane Collaboration. Published by John Wiley \& Sons, Ltd. 


\title{
[Intervention Review]
}

\section{Prophylactic platelet transfusion for prevention of bleeding in patients with haematological disorders after chemotherapy and stem cell transplantation}

\author{
Lise Estcourt ${ }^{1}$, Simon Stanworth ${ }^{1}$, Carolyn Doree ${ }^{2}$, Sally Hopewell ${ }^{3}$, Michael F Murphy ${ }^{2}$, Alan Tinmouth ${ }^{4}$, Nancy Heddle ${ }^{5}$ \\ ${ }^{1}$ Haematology/Transfusion Medicine, NHS Blood and Transplant, Oxford, UK. ${ }^{2}$ Systematic Review Initiative, NHS Blood and \\ Transplant, Oxford, UK. ${ }^{3}$ Centre for Statistics in Medicine, University of Oxford, Oxford, UK. ${ }^{4}$ Medicine (hematology) and Pathology \\ Centre for Transfusion Research, The Ottawa Health Research Institute and the University of Ottawa, Ottawa, Canada. ${ }^{5}$ McMaster \\ University, Hamilton, Canada \\ Contact address: Lise Estcourt, Haematology/Transfusion Medicine, NHS Blood and Transplant, Level 2, John Radcliffe Hospital, \\ Headington, Oxford, OX3 9BQ, UK. lestcourt@doctors.org.uk.
}

Editorial group: Cochrane Haematological Malignancies Group.

Publication status and date: New search for studies and content updated (conclusions changed), published in Issue 5, 2012.

Review content assessed as up-to-date: 14 November 2011.

Citation: Estcourt L, Stanworth S, Doree C, Hopewell S, Murphy MF, Tinmouth A, Heddle N. Prophylactic platelet transfusion for prevention of bleeding in patients with haematological disorders after chemotherapy and stem cell transplantation. Cochrane Database of Systematic Reviews 2012, Issue 5. Art. No.: CD004269. DOI: 10.1002/14651858.CD004269.pub3.

Copyright (C) 2012 The Cochrane Collaboration. Published by John Wiley \& Sons, Ltd.

\begin{abstract}
A B S T R A C T
Background

Platelet transfusions are used in modern clinical practice to prevent and treat bleeding in thrombocytopenic patients with bone marrow failure. Although considerable advances have been made in platelet transfusion therapy in the last 40 years, some areas continue to provoke debate especially concerning the use of prophylactic platelet transfusions for the prevention of thrombocytopenic bleeding.

Objectives

To determine the most effective use of platelet transfusion for the prevention of bleeding in patients with haematological disorders undergoing chemotherapy or stem cell transplantation.
\end{abstract}

Search methods

This is an update of a Cochrane review first published in 2004. We searched for randomised controlled trials (RCTs) in the Cochrane Central Register of Controlled Trials (CENTRAL Issue 4, 2011), MEDLINE (1950 to Nov 2011), EMBASE (1980 to Nov 2011) and CINAHL (1982 to Nov 2011), using adaptations of the Cochrane RCT search filter, the UKBTS/SRI Transfusion Evidence Library, and ongoing trial databases to 10 November 2011.

Selection criteria

RCTs involving transfusions of platelet concentrates, prepared either from individual units of whole blood or by apheresis, and given to prevent bleeding in patients with haematological disorders. Four different types of prophylactic platelet transfusion trial were included.

Data collection and analysis

In the original review one author initially screened all electronically derived citations and abstracts of papers, identified by the review search strategy, for relevancy. Two authors performed this task in the updated review. Two authors independently assessed the full text of all potentially relevant trials for eligibility. Two authors completed data extraction independently. We requested missing data from the original investigators as appropriate.

Prophylactic platelet transfusion for prevention of bleeding in patients with haematological disorders after chemotherapy and stem cell transplantation (Review)

Copyright ( 2012 The Cochrane Collaboration. Published by John Wiley \& Sons, Ltd. 


\section{Main results}

There were 18 trials that were eligible for inclusion, five of these were still ongoing. Thirteen completed published trials (2331 participants) were included for analysis in the review. The original review contained nine trials (718 participants). This updated review includes six new trials (1818 participants). Two trials (205 participants) in the original review are now excluded because fewer than $80 \%$ of participants had a haematological disorder.

The four different types of prophylactic platelet transfusion trial, that were the focus of this review, were included within these thirteen trials.

Three trials compared prophylactic platelet transfusions versus therapeutic-only platelet transfusions. There was no statistical difference between the number of participants with clinically significant bleeding in the therapeutic and prophylactic arms but the confidence interval was wide (RR 1.66; $95 \%$ CI 0.9 to 3.04). The time taken for a clinically significant bleed to occur was longer in the prophylactic platelet transfusion arm. There was a clear reduction in platelet transfusion usage in the therapeutic arm. There was no statistical difference between the number of participants in the therapeutic and prophylactic arms with platelet refractoriness, the only adverse event reported.

Three trials compared different platelet count thresholds to trigger administration of prophylactic platelet transfusions. No statistical difference was seen in the number of participants with clinically significant bleeding (RR 1.35; 95\% CI 0.95 to 1.9), however, this type of bleeding occurred on fewer days in the group of patients transfused at a higher platelet count threshold (RR 1.72; 95\% CI 1.33 to 2.22). The lack of a difference seen for the number of participants with clinically significant bleeding may be due to the studies, in combination, having insufficient power to demonstrate a difference, or due to masking of the effect by a higher number of protocol violations in the groups of patients with a lower platelet count threshold. Using a lower platelet count threshold led to a significant reduction in the number of platelet transfusions used. There were no statistical differences in the number of adverse events reported between the two groups.

Six trials compared different doses of prophylactic platelet transfusions. There was no evidence to suggest that using a lower platelet transfusion dose increased: the number of participants with clinically significant (WHO grade 2 or above) (RR 1.02; $95 \%$ CI 0.93 to 1.11 ), or life-threatening (WHO grade 4) bleeding (RR 1.87; $95 \%$ CI 0.86 to 4.08). A higher platelet transfusion dose led to a reduction in the number of platelet transfusion episodes, but an increase in total platelet utilisation. Only one adverse event, wheezing after transfusion, had a significantly higher incidence when standard and high dose transfusions were compared but this difference was not seen when low dose and high dose transfusions were compared. It is therefore likely to be a type I error (false positive).

One small trial compared prophylactic platelet transfusions versus platelet-poor plasma. The risk of a significant bleed was decreased in the prophylactic platelet transfusion arm (RR 0.47 ; 95\% CI 0.23 to 0.95 ) and this was statistically significant.

All studies had threats to validity; the majority of these were due to methodology of the studies not being described in adequate detail.

Although it was not the main focus of the review, it was interesting to note that in one of the pre-specified sub-group analyses (treatment type) two studies showed that patients receiving an autologous transplant have a lower risk of bleeding than patients receiving intensive chemotherapy or an allogeneic transplant (RR $0.73,95 \%$ CI 0.65 to 0.82 ).

\section{Authors' conclusions}

These conclusions refer to the four different types of platelet transfusion trial separately. Firstly, there is no evidence that a prophylactic platelet transfusion policy prevents bleeding. Two large trials comparing a therapeutic versus prophylactic platelet transfusion strategy, that have not yet been published, should provide important new data on this comparison. Secondly, there is no evidence, at the moment, to suggest a change from the current practice of using a platelet count of $10 \times 10^{9} / \mathrm{L}$. However, the evidence for a platelet count threshold of $10 \times 10^{9} / \mathrm{L}$ being equivalent to $20 \times 10^{9} / \mathrm{L}$ is not as definitive as it would first appear and further research is required. Thirdly, platelet dose does not affect the number of patients with significant bleeding, but whether it affects number of days each patient bleeds for is as yet undetermined. There is no evidence that platelet dose affects the incidence of WHO grade 4 bleeding.Prophylactic platelet transfusions were more effective than platelet-poor plasma at preventing bleeding.

\section{PLAIN LANGUAGE SUMMARY}

Platelet transfusions are used to prevent bleeding in patients with low platelet counts due to treatment-induced bone marrow failure

Prophylactic platelet transfusion for prevention of bleeding in patients with haematological disorders after chemotherapy and stem cell 
This review was undertaken to determine the best use of platelet transfusions for the prevention of bleeding in patients who have haematological disorders and are receiving intensive (myelosuppressive) chemotherapy or stem cell transplantation. The review aimed to look at three main topics. One, what is the evidence to indicate if platelet transfusions should be given to prevent bleeding as compared to a strategy aimed at transfusion when bleeding occurs? Second, if platelet transfusions are given to prevent bleeding, when should they be given, for example, at what level of platelet count when measured in a blood sample? Three, if platelet transfusions are given what platelet dose should be used? We are unable to answer the first question, however new data from two large studies should be available when this review is updated in approximately two years time. With regard to the second question, there is no evidence to suggest a change from the current practice of using a platelet count of $10 \times 10^{9} / \mathrm{L}$ to trigger the use of platelet transfusions to prevent bleeding. However, more research is required to clarify this issue. The final question can be answered. Using a lower platelet dose did not lead to an increased risk of bleeding and fewer platelets were required. The reduction in the number of platelets used should, theoretically, reduce the risk of adverse events although no true differences were seen in the studies. However, adverse events are uncommon and therefore a statistically significant difference may not be seen. 


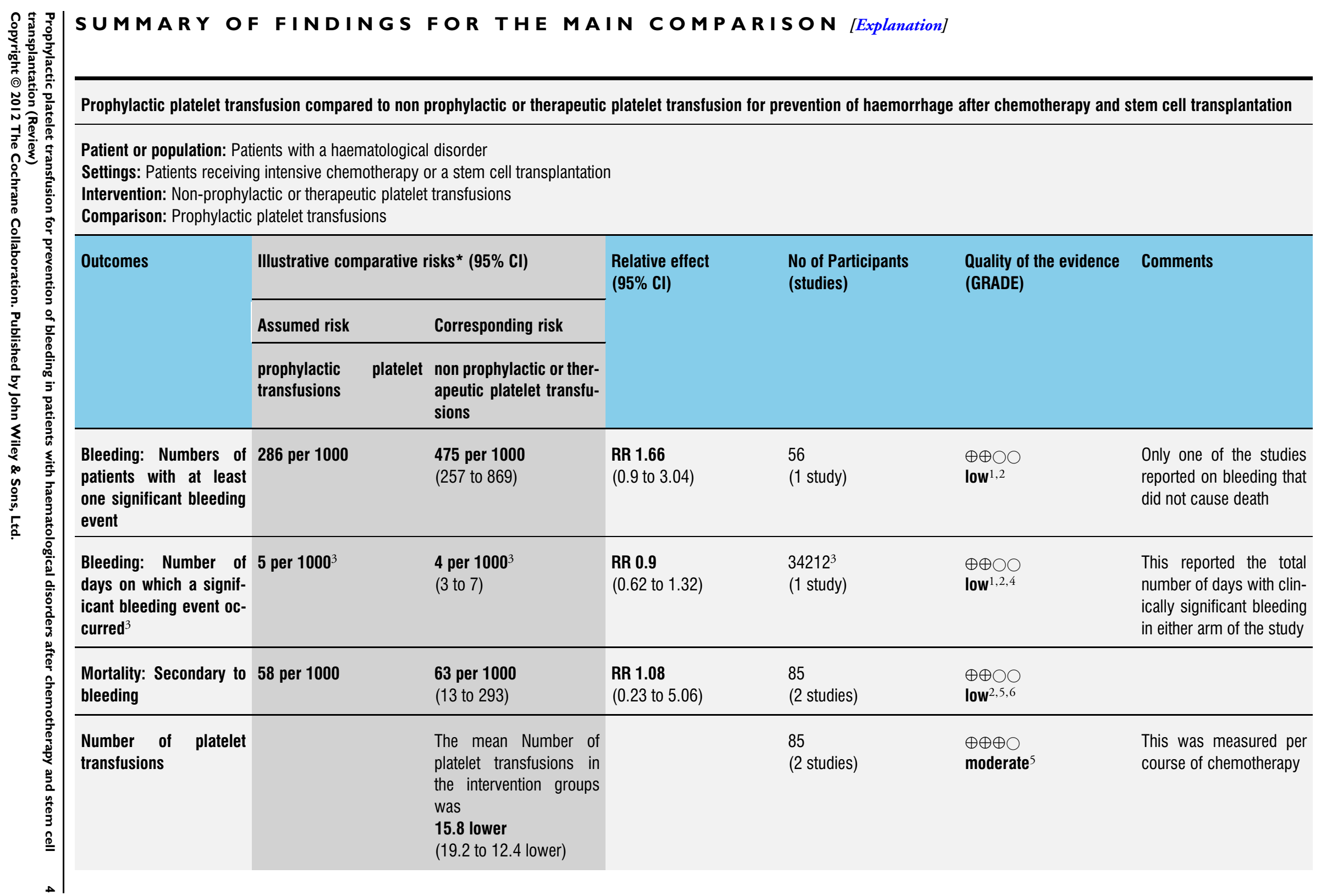


*The basis for the assumed risk (e.g. the median control group risk across studies) is provided in footnotes. The corresponding risk (and its $95 \%$ confidence interval) is based on the assumed risk in the comparison group and the relative effect of the intervention (and its $95 \% \mathrm{Cl}$ ).

Cl: Confidence interval; RR: Risk ratio;

GRADE Working Group grades of evidence

High quality: Further research is very unlikely to change our confidence in the estimate of effect.

Moderate quality: Further research is likely to have an important impact on our confidence in the estimate of effect and may change the estimate.

Low quality: Further research is very likely to have an important impact on our confidence in the estimate of effect and is likely to change the estimate

Very low quality: We are very uncertain about the estimate.

${ }^{1}$ This study was conducted over 30 years ago and there have been dramatic changes in patient management since that time

2 This was a small study

3 This was the total number of days recorded within the study rather than participants

${ }^{4}$ There were only a small number of events leading to imprecision

5 These studies were conducted over 30 years ago and there have been major changes to patient management in that time

${ }^{6}$ These were small studies and this may have led to some inconsistency in the results 


\section{B A C K G R O U N D}

\section{Description of the condition}

Platelet transfusions are used in modern clinical practice to prevent and treat bleeding in thrombocytopenic patients with bone marrow failure secondary to chemotherapy or stem cell transplantation. The ready availability of platelet concentrates has undoubtedly made a major contribution in allowing the development of intensive treatment regimens for haematological disorders (malignant and non-malignant) and other malignancies.

The first demonstration of the effectiveness of transfusions of platelets was performed in 1910 (Duke 1910). However, it was not until the 1970s and 1980s that the use of platelet transfusions became standard treatment for thrombocytopenic patients with bone marrow failure (Blajchman 2008). Alongside changes in supportive care, the routine use of platelet transfusions in patients with haematological disorders since that time has led to a marked decrease in the number of haemorrhagic deaths associated with thrombocytopenia (Slichter 1980), however this has led to a considerable increase in the demand for platelet concentrates. Currently, platelet concentrates are the second most frequently used blood component. About 266,000 adult doses per year are transfused in the UK (Taylor 2010), costing about $£ 50$ million per year. Administration of platelet transfusions to patients with haematological disorders now constitute a significant proportion (up to 67\%) of all platelets issued (Cameron 2007; Greeno 2007; Pendry 2011), and the majority of these (69\%) are given to prevent bleeding (Estcourt 2011a).

\section{Description of the intervention}

Despite the obvious beneficial effect that platelet transfusions have had on the management of patients with haematological malignancies with severe thrombocytopenia who are actively bleeding, questions still remain on how this limited resource should be used to prevent severe and life-threatening bleeding (Estcourt 2011b). Prophylactic platelet transfusions for patients with chemotherapy-induced thrombocytopenia became standard practice following the publication of several, small, randomised controlled trials in the late 1970s and early 1980s (Higby 1974; Murphy 1982; Solomon 1978). This review does not focus on the absolute need for platelet transfusions in this patient population but instead reviews the transfusion strategies that most effectively balance the benefits of their use against their risks. This review focused on four different types of prophylactic platelet transfusion trial.

\section{Prophylactic platelet transfusions versus therapeutic- only platelet transfusions}

The standard practice in most haematology units across the developed world has been to use prophylactic transfusions, in line with guidelines (BCSH 2003, Slichter 2007). The experimental intervention was to only give platelet transfusions when bleeding occurred.

\section{Prophylactic platelet transfusion threshold}

Prophylactic platelet transfusions are typically given when blood platelet counts fall below a given trigger level. Studies compared different platelet count thresholds to trigger the administration of prophylactic platelet transfusions. The current consensus is that patients should receive a platelet transfusion when the platelet count is $<10 \times 10^{9} / \mathrm{L}$, unless there are other risk factors for bleeding, such as sepsis, concurrent use of antibiotics or other abnormalities of haemostasis (BCSH 2003; Schiffer 2001; Slichter 2007). The experimental interventions were higher or lower platelet transfusion thresholds.

\section{Dose of prophylactic platelet transfusions}

This is the number of platelets given (platelet dose) during a standard platelet transfusion. For adults, the usual dose given is a single apheresis unit or a pool of four to six whole blood-derived platelets, with the absolute number of platelets in the range of $300 \times 10^{9}$ to $600 \times 10^{9}$ (Stanworth 2005). The experimental interventions were low dose or high dose platelet transfusion strategies.

Platelet transfusions versus alternative treatments (such as artificial platelet substitutes/platelet-poor plasma/ recombinant factor VIla (rFVIla)/ fibrinogen)

The standard practice in most haematology units across the developed world has been to use prophylactic transfusions, in line with guidelines (BCSH 2003; Slichter 2007). The experimental intervention was to give an alternative treatment, such as artifical platelet substitutes, platelet-poor plasma, rFVIIa or fibrinogen.

\section{How the intervention might work}

\section{Prophylactic platelets versus therapeutic-only platelet transfusions}

A retrospective review of almost 3000 thrombocytopenic adult patients over a 10-year period showed no relationship between the first morning platelet count, or the lowest platelet count of the day, and the risk of bleeding (Friedmann 2002). This has raised the question as to whether a threshold-defined prophylactic platelet transfusion approach is appropriate.

Further support for the absence of a relationship between the severity of thrombocytopenia and bleeding came from a review of case reports of severe intracranial haemorrhage. These cases were described in trials of prophylactic platelet transfusions. No clear evidence could be found for an association between the occurrence of 
major intracranial bleeding and absolute platelet count just prior to the onset of severe bleeding (Stanworth 2005).

Thus, the overall benefit of a prophylactic platelet transfusion policy over a policy to use platelets only therapeutically, using a platelet count threshold, has not been established.

A recent study, using an historical control, assessed a therapeutic platelet transfusion strategy after autologous transplantation. Only $19 \%$ of the patients had clinically relevant bleeding of minor or moderate severity, and no severe or life-threatening bleeding was documented, this was a comparable rate to the historical control (20\%). One-third of all transplants, and $47 \%$ after high-dose melphalan, were performed without any platelet transfusion. The numbers of platelet transfusions were reduced by $50 \%$ compared with their historical control (Wandt 2006). In an interim report of a randomised controlled trial (Wandt 2009), platelet transfusions could be significantly reduced (by $27 \%$ ) in the therapeutic transfusion arm compared with prophylactic transfusion. $46 \%$ of patients in the therapeutic arm did not need any platelet transfusions. However, the incidence of clinically relevant bleeding was significantly higher $(28.7 \%$ vs $9.5 \%)$, this is not surprising as this was the trigger for transfusion in the experimental arm.

Therefore a therapeutic platelet transfusion strategy may be safe and feasible. A large randomised controlled trial that hopes to answer this question has just completed recruitment of patients TOPPs trial (Blajchman 2008; Stanworth 2010).

\section{Optimal dose of prophylactic platelets}

The dose of the platelet product transfused was based upon the perceived need to raise the patient's platelet count above a certain safe threshold. Over the years, our understanding of bleeding in thrombocytopenic patients has advanced and there is now evidence to suggest that patients require only approximately 7100 platelets/ $\mu \mathrm{L}$ per day to maintain haemostasis (Hanson 1985). Platelets have been shown to provide an endothelial supportive function by plugging gaps in the endothelium of otherwise intact blood vessels. Animal studies have shown that thrombocytopenia is associated with the gradual thinning of the vessel wall endothelium over time, and that, if thrombocytopenia persists, gaps gradually occur between adjacent endothelial cells (Blajchman 1981; Kitchens 1975; Nachman 2008). This thinning and fenestration of the endothelium is accompanied with the on-going and increased use of circulating platelets to prevent the loss of red blood cells (RBCs) through these gaps.

A mathematical model predicted that smaller, more frequent doses of platelets would be as effective as higher doses of platelets in maintaining patients' platelet counts above an agreed threshold (Hersh 1998). This raised the question of whether thrombocytopenic bleeding could be prevented with a lower platelet dose (Tinmouth 2003). Such a strategy has potential economic and resource advantages, as fewer platelet transfusions might be required and donor exposures might be reduced.
Several smaller studies tried to address this question but only one of them used bleeding as a primary outcome measure (Tinmouth 2004). This showed that the low-dose prophylactic regimen was just as effective as the standard dose and resulted in a $25 \%$ reduction in the number of platelets transfused.

There have been two recent larger trials. One was stopped early because of an excess of WHO grade 4 bleeding (Heddle 2009), and the large PLADO trial confirmed the earlier finding by Tinmouth (Slichter 2010).

\section{Prophylactic platelet threshold}

Efforts were also made to establish a threshold for the use of prophylactic transfusions based on the platelet count. It became standard practice to transfuse platelets at platelet counts below $20 \mathrm{x}$ $10^{9} / \mathrm{L}$, in an attempt to prevent bleeding (Beutler 1993). This practice was partly based on the findings of non-randomised studies, such as Gaydos 1962. This showed that gross haemorrhage (haematuria, haematemesis and melaena) was present more frequently at platelet counts below $5 \times 10^{9} / \mathrm{L}$ than when the platelet count was between $5 \times 10^{9} / \mathrm{L}$ and $100 \times 10^{9} / \mathrm{L}$. This study and others like it did not clearly support the use of a threshold for prophylactic platelet transfusion of $20 \times 10^{9} / \mathrm{L}$, nor was any threshold effect seen.

The routine use of platelet transfusions from the 1970s, in patients with haematological malignancies, resulted in a decreased mortality rate due to bleeding (less than $1 \%$ of patients) (Slichter 1980). However, the widespread use of a threshold platelet count of $20 \times 10^{9} / \mathrm{L}$ for prophylactic platelet transfusions led to a marked growth in demand for platelet concentrates (Sullivan 2002).

This stimulated research to address whether the threshold could be safely lowered to $10 \times 10^{9} / \mathrm{L}$ (Rebulla 1997, reviewed in Stanworth 2004). The consensus formulated from these trials was that patients should receive a platelet transfusion when the platelet count is $<10 \times 10^{9} / \mathrm{L}$, unless there are other risk factors for bleeding, such as sepsis, concurrent use of antibiotics or other abnormalities of haemostasis (BCSH 2003; Schiffer 2001; Slichter 2007).

There have been calls for a further reduction in the threshold to 5 x $10^{9} / \mathrm{L}$. In the 1970s it had been shown, using faecal blood loss as an indicator of bleeding, that the increased risk of bleeding was at the $5 \times 10^{9} / \mathrm{L}$ threshold (Slichter 1978). However, the ability to decrease the platelet threshold to this level may be compromised by the inaccuracy of automated platelet counters at very low platelet counts (Segal 2005).

Although platelet mass has been used as a transfusion trigger for neonatal platelet transfusions (Gerday 2009), different platelet count thresholds have been the only known trigger used in patients with a haematological disorder.

\section{Platelet transfusions versus alternative treatments (such as artificial platelet substitutes/platelet-poor plasma/ rFVIIa/ fibrinogen)}


Most clinical research has focused on the optimal dose for platelet transfusion or the threshold level of platelet counts for prophylactic platelet transfusions, rather than questioning the underlying assumption that prophylactic platelet transfusions are necessary or effective. The most recent RCTs have established that many patients develop bleeding at some stage during the period of greatest risk, frequently defined as a period of thrombocytopenia (Heddle 2009; Slichter 2010). This bleeding covers a spectrum of bleeding, from skin changes to, less commonly, intracranial haemorrhage. In Slichter 2010, patients had similar rates of bleeding (17\%) with morning platelet counts within the range of 6 to $80 \times 10^{9} / \mathrm{L}$. This means that there are a significant number of bleeding episodes that are not being effectively treated by prophylactic platelet transfusions. Treatments that target other parts of the clotting cascade may be as effective at treating bleeding as prophylactic platelet transfusions.

\section{Assessment of bleeding}

A bleeding assessment has been seen as a more clinically relevant measure of the effect of platelet transfusions than surrogate markers such as platelet increment.

Any review that uses bleeding as a primary outcome measure needs to assess the way that the trials have recorded bleeding. Unfortunately, the way bleeding has been recorded and assessed has varied markedly between trials (Cook 2004; Heddle 2003).

Retrospective analysis of bleeding leads to a risk of bias because bleeding events may be missed, and only more severe bleeding is likely to have been documented. Prospective bleeding assessment forms provide more information and are less likely to miss bleeding events. However, different assessors may grade the same bleed differently and it is very difficult to blind the assessor to the intervention.

The majority of trials have used the WHO system for grading bleeding, or a modification of this system (Koreth 2004). One limitation of all the scoring systems that have been based on the WHO system is that the categories are relatively broad and subjective. This means that a small change in a patient's bleeding risk may not be detected. Another limitation is that the modified WHO categories are partially defined by whether a bleeding patient requires a blood transfusion. The threshold for intervention may vary between clinicians and institutions and so the same level of bleeding could be graded differently in different institutions. The definition of what constitutes clinically significant bleeding has varied between studies, although the majority of more recent platelet transfusion studies (Heddle 2009; Stanworth 2010; Slichter 2010) now classify it as WHO grade 2 or above there has been greater heterogeneity in the past (Cook 2004; Koreth 2004). The difficulties with assessing and grading bleeding may limit the ability to compare results between studies and this needs to be kept in mind when reviewing the evidence for the effectiveness of prophylactic platelet transfusions.

\section{Why it is important to do this review}

Although considerable advances have been made in platelet transfusion therapy in the last 40 years, three major areas continue to provoke debate.

Firstly, what is the optimal prophylactic platelet dose to prevent thrombocytopenic bleeding?

Secondly, which threshold should be used to trigger the transfusion of prophylactic platelets?

Thirdly, are prophylactic platelet transfusions superior to therapeutic platelet transfusions for the prevention and/or control of life-threatening thrombocytopenic bleeding?

The initial formulation of this Cochrane review attempted to answer these questions, but there was insufficient evidence available at the time for any definitive conclusions to be drawn (Stanworth 2004). This update of the review reassessed the literature, to ascertain whether any recent studies can provide us with the evidence to answer those questions. There has been another recent systematic review of the optimal dose for prophylactic platelets (Cid 2007), but this is now out-dated because several new large studies have recently been completed.

This review did not assess whether there are any differences in the efficacy of apheresis versus whole-blood derived platelet products, nor did it assess differences between $\mathrm{ABO}$ identical and $\mathrm{ABO}$ nonidentical platelet transfusions. This is because both these topics have been covered by recent systematic reviews (Heddle 2008; Shehata 2009).

\section{O B J E C T I VES}

To determine the most effective use of platelet transfusion for the prevention of bleeding (prophylactic platelet transfusion) in patients with haematological disorders and undergoing myelosuppressive chemotherapy or stem cell transplantation.

\section{METHODS}

\section{Criteria for considering studies for this review}

\section{Types of studies}

Only randomised controlled trials (RCTs) have been included in this review.

\section{Types of participants}

Patients with haematological disorders receiving treatment with myelosuppressive chemotherapy and/or stem cell transplantation. All ages were included. If trials consisted of mixed populations 
of patients, with diagnoses of solid tumours, only data from the haematological subgroups were used. If subgroup data for haematological patients was not provided (after contacting the authors of the trial), the trial was excluded if fewer than $80 \%$ of participants had a haematological disorder. Any patients that are not being treated with intensive chemotherapy or a stem cell transplant are by definition excluded. Patients with non-malignant haematological disorders (e.g. aplastic anaemia, congenital bone marrow failure syndromes) that are being treated with an allogeneic stem cell transplant are therefore included within the study.

\section{Types of interventions}

Transfusions of platelet concentrates, prepared either from individual units of whole blood or by apheresis, and given prophylactically to prevent bleeding. Prophylactic platelet transfusions are typically given when blood platelet counts fall below a given trigger level. There was no restriction on dose or frequency of platelet transfusion but we took this information into account in the analysis, where available. Similarly, there was no restriction on trigger level, although again we took this information into account in the analysis where available.

We included the following comparisons:

- prophylactic platelet transfusions versus therapeutic platelet transfusions (on-demand triggered by bleeding)

- prophylactic platelet transfusion with one trigger level versus prophylactic platelet transfusion with another trigger level

- prophylactic platelet transfusion with one dose schedule versus prophylactic platelet transfusion with another dose schedule

- platelet transfusions (prophylactic or on-demand) versus alternative treatments (such as artificial platelet substitutes/ platelet-poor plasma/ rFVIIa/ fibrinogen).

\section{Types of outcome measures}

\section{Primary outcomes}

Number and severity of bleeding episodes.

- The number of patients with at least one bleeding episode.

- The number of days on which bleeding occurred.

\section{Secondary outcomes}

- Mortality (all causes)

- Mortality secondary to bleeding

- Number of platelet transfusions

- Number of red cell transfusions

- Disease-free survival

- Proportion of patients achieving complete remission

- Time in hospital
- Adverse effects of treatments (transfusion reactions, thromboembolism, development of platelet antibodies).

\section{Search methods for identification of studies}

We formulated search strategies in collaboration with the Cochrane Haematological Malignancies Group.

\section{Electronic searches}

\section{Bibliographic databases}

We searched for randomised controlled trials in the following databases:

- MEDLINE (Ovid, 1950 to 10 November 2011)

- EMBASE (Ovid, 1980 to 10 November 2011)

- CENTRAL (The Cochrane Library, Issue 4, 2011)

- CINAHL (NHS Evidence, 1982 to 10 November 2011)

- UKBTS/SRI Transfusion Evidence Library ( www.transfusionevidencelibrary.com) (1980 to 10 November 2011)

- LILACS ( BIREME/PAHO/WHO, 1982 to 10 November 2011)

- KoreaMed (KAMJE, 1997 to 10 November 2011)

- PakMediNet (2001 to 10 November 2011)

- IndMed (ICMR-NIC, 1985 to 10 November 2011)

- Conference Proceedings Citation Index-Science (CPCI-S) (Web of Science (Thomson Reuters), 1990 to 10 November 2011)

Searches were updated from the original search in January 2002, first in November 2009, then in May 2010, then in March 2011 and finally on 10 November 2011. Searches in MEDLINE, EMBASE and CINAHL were combined with adaptations of the Cochrane RCT search filters, as detailed in the Cochrane Handbook for Systematic Reviews of Interventions (Lefebvre 2011). Search strategies for both the original and update searches are presented in Appendix 1, Appendix 2, Appendix 3, Appendix 4, Appendix 5, Appendix 6 and Appendix 7.

\section{Databases of ongoing trials}

We also searched ClinicalTrials.gov (http://clinicaltrials.gov/ct2/ search), the ISRCTN Register (http://www.controlled-trials.com/ isrctn/) and the World Health Organization International Clinical Trials Registry (ICTRP) (http://apps.who.int/trialsearch/) on 10 November 2011 in order to identify ongoing trials.

\section{Searching other resources}

We augmented database searching by: 


\section{Handsearching of references}

We checked references of all identified trials, relevant review articles, and current treatment guidelines for further literature. These searches were limited to the first generation reference lists.

\section{Personal contacts}

We contacted authors of relevant studies, study groups and experts worldwide known to be active in the field for unpublished material or further information on ongoing studies.

\section{Data collection and analysis}

\section{Selection of studies}

Two independent review authors (LE, CD) initially screened all electronically derived citations and abstracts of papers identified by the review search strategy for relevancy. Studies clearly irrelevant were excluded at this stage.

The full texts of all potentially relevant trials were then formally assessed for eligibility by two independent review authors (LE, SS) against the criteria outlined above. All disagreements were resolved by discussion with a third review author (MM). Further information was sought from a study author because the article contained insufficient data to make a decision about eligibility (Zumberg 2002). This study was excluded after the author supplied the additional information. A study eligibility form was designed for trials of platelet transfusion to help in the assessment of relevance, which included ascertaining whether the participants had haematological disorders, and whether two groups could be defined in the trial on the basis of differences in symptomatic triggers, platelet count triggers, or platelet dose schedules. The reasons why studies failed to meet the eligibility criteria were recorded.

\section{Data extraction and management}

Two review authors (LE, SS) conducted data extraction according to the guidelines proposed by the Cochrane Collaboration (Higgins 2011a). Potential disagreements between the review authors were resolved by consensus. The review authors were not blinded to names of authors, institutions, journals, or the outcomes of the trials. The data extraction forms were piloted on three studies with all disagreements resolved by consensus, thereafter the two authors (LE, SS) extracted data independently for all the studies. The following data were extracted:

\section{General information}

Review author's name, date of data extraction, study ID, reference manager number, first author of study, author's contact address (if available), citation of paper, objectives of the trial.

\section{Trial details}

Trial design, location, setting, sample size, power calculation, treatment allocation, randomisation, blinding, inclusion and exclusion criteria, reasons for exclusion, comparability of groups, length of follow up, stratification, stopping rules described, statistical analysis, results, conclusion, and funding.

\section{Characteristics of participants}

Age, gender, ethnicity, total number recruited, total number randomised, total number analysed, types of haematological disease, lost to follow-up numbers, drop outs (percentage in each arm) with reasons, protocol violations, previous treatments, current treatment, prognostic factors.

\section{Interventions}

Experimental and control interventions, type of platelet given, timing of intervention, dosage of platelet given, compliance to interventions, additional interventions given especially in relation to red cell transfusions, any differences between interventions.

\section{Outcomes measured}

Number and severity of bleeding episodes. Mortality (all causes), and mortality due to bleeding. Disease-free survival. Proportion of patients achieving complete remission. Time in hospital. Number of platelet transfusions. Number of red cell transfusions. Adverse effects of treatments (e.g. transfusion reactions, thromboembolism, development of platelet antibodies)

Both full-text versions and abstracts including additional information (for example slides) of eligible studies were used to retrieve the data. Publications reporting on more than one trial were extracted using one data extraction form for each trial. Trials reported in more than one publication were extracted on one form only. Nine study authors were contacted for additional information, two study authors no longer had access to the original data and two study authors supplied the information requested.

\section{Assessment of risk of bias in included studies}

Two review authors (LE, SS) assessed all included studies for possible risk of bias (as described in the Cochrane Handbook (Higgins 2011c)). The assessment included information about the design, conduct and analysis of the trial. Each criterion was evaluated on a three-point scale: low risk of bias, high risk of bias, or unclear. To assess risk of bias, the following questions were included in the risk of bias table for each included study:

- Was the allocation sequence adequately generated?

- Was allocation adequately concealed?

- Was knowledge of the allocated intervention adequately prevented during the study?

- Were incomplete outcome data adequately addressed (for every outcome separately)? 
- Are reports of the study free of selective outcome reporting?

- Was the study apparently free of other problems that could put it at risk of bias?

\section{Measures of treatment effect}

For dichotomous outcomes the number of outcomes in treatment and control groups were recorded and the treatment effect measures across individual studies were estimated as the relative effect measures (relative risk (RR) with 95\% confidence intervals (CI)). For continuous outcomes, the mean and standard deviations were recorded. For continuous outcomes measured using the same scale the effect measure was the mean difference (MD) with $95 \%$ confidence intervals, or the standardised mean difference (SMD) for outcomes measured using different scales.

\section{Dealing with missing data}

This was performed according to the recommendations in the Cochrane Handbook (Higgins 2011b). Nine authors were contacted in order to obtain information not reported in the publications of the trials. Four authors supplied the missing data (Heckman 1997; Heddle 2009; Rebulla 1997; Tinmouth 2004). Two further authors searched for missing data but it was no longer available (Diedrich 2005; Sintnicolaas 1982).

In trials that included patients with haematological disorders as well as patients with solid tumours or non-malignant haematological disorders. Data were extracted for the malignant haematology subgroup from the general trial data; This could not be done in one study (Zumberg 2002). The author was contacted in order to retrieve information on malignant haematology patients but was unable to supply the requested data.

All five authors of the ongoing trials were contacted, two responded (Stanworth 2010; Wandt 2009).

Within an outcome, when there was missing data, the preferred analysis was an intention-to-treat analysis (ITT). The number of patients lost to follow-up was recorded for each trial.

\section{Assessment of heterogeneity}

The decision about whether or not to combine the results of individual studies depended on an assessment of heterogeneity. If studies were considered sufficiently homogenous in their study design, a meta-analysis was carried out and the statistical heterogeneity assessed. Statistical heterogeneity of treatment effects between trials was assessed using a $\mathrm{Chi}^{2}$ test with a significance level at $\mathrm{P}<0.1$. The $\mathrm{I}^{2}$ statistic was used to quantify possible heterogeneity $\left(\mathrm{I}^{2}>\right.$ $30 \%$ moderate heterogeneity, $\mathrm{I}^{2}>75 \%$ considerable heterogeneity). Potential causes of heterogeneity were explored by sensitivity and subgroup analyses if possible.

\section{Assessment of reporting biases}

None of the meta-analyses contained more than 10 trials, therefore potential publication bias (small trial bias) was not explored by the generation of a funnel plot (Sterne 2011).

\section{Data synthesis}

Analyses were performed according to the recommendations of the Cochrane Collaboration (Deeks 2011). Aggregated data was used for analysis. For statistical analysis, data was entered into Review Manager 2011. Data entry into software was done by one review author and was checked for accuracy by a second review author. Meta-analyses were performed using a fixed-effect model (for example the generic inverse variance method for survival data outcomes and Mantel-Haenszel method for dichotomous data outcomes); results of the random-effects model were also examined. GRADEprofiler was used to create summary of finding tables as suggested in the Cochrane Handbook (Schünemann 2011).

The following types of comparisons were performed separately:

1. Prophylactic platelet transfusions versus therapeutic platelet transfusions (on-demand triggered by bleeding)

2. Prophylactic platelet transfusion with one trigger level versus prophylactic platelet transfusion with another trigger level 3. Prophylactic platelet transfusion with one dose schedule versus prophylactic platelet transfusion with another dose schedule

4. Platelet transfusions (prophylactic or on-demand) versus alternative treatments (such as artificial platelet substitutes/ platelet-poor plasma/rFVIIa/fibrinogen concentrate) In the discussion, consideration was taken into translating the results of the included studies into recommendations for action. All review authors were involved in drawing conclusions and making specific recommendations for future research.

\section{Subgroup analysis and investigation of heterogeneity}

Two sub-group analyses were pre-specified prior to updating the review, these were fever and patients' diagnostic and treatment sub-groups.

The pre-specified sub-group analyses were only reported on in a minority of studies. If data were available it has been reported. Meta-regression was not performed because no sub-group contained more than ten studies (Deeks 2011). Differences between sub-groups were compared using a random-effects model when the two sub-groups were independent following the guidance in Chapter 9 of the Cochrane Handbook (Deeks 2011). If this was not possible then differences would be commented on narratively.

\section{Sensitivity analysis}

Robustness of the overall results were assessed by sensitivity analysis with respect to those trials deemed at high risk of bias. 
RES U L T S

\section{Description of studies}

See: Characteristics of included studies; Characteristics of excluded studies; Characteristics of ongoing studies.

See Characteristics of included studies; Characteristics of excluded studies; and Characteristics of ongoing studies.

\section{Results of the search}

See PRISMA Flow Diagram Figure 1The original search (conducted January 2002) identified a total of 3196 potentially relevant citations. There were 2380 citations after duplicates were removed. 2343 records were able to be excluded on the basis of the abstract. This was performed by one review author. 
Figure I. PRISMA Flow Diagram

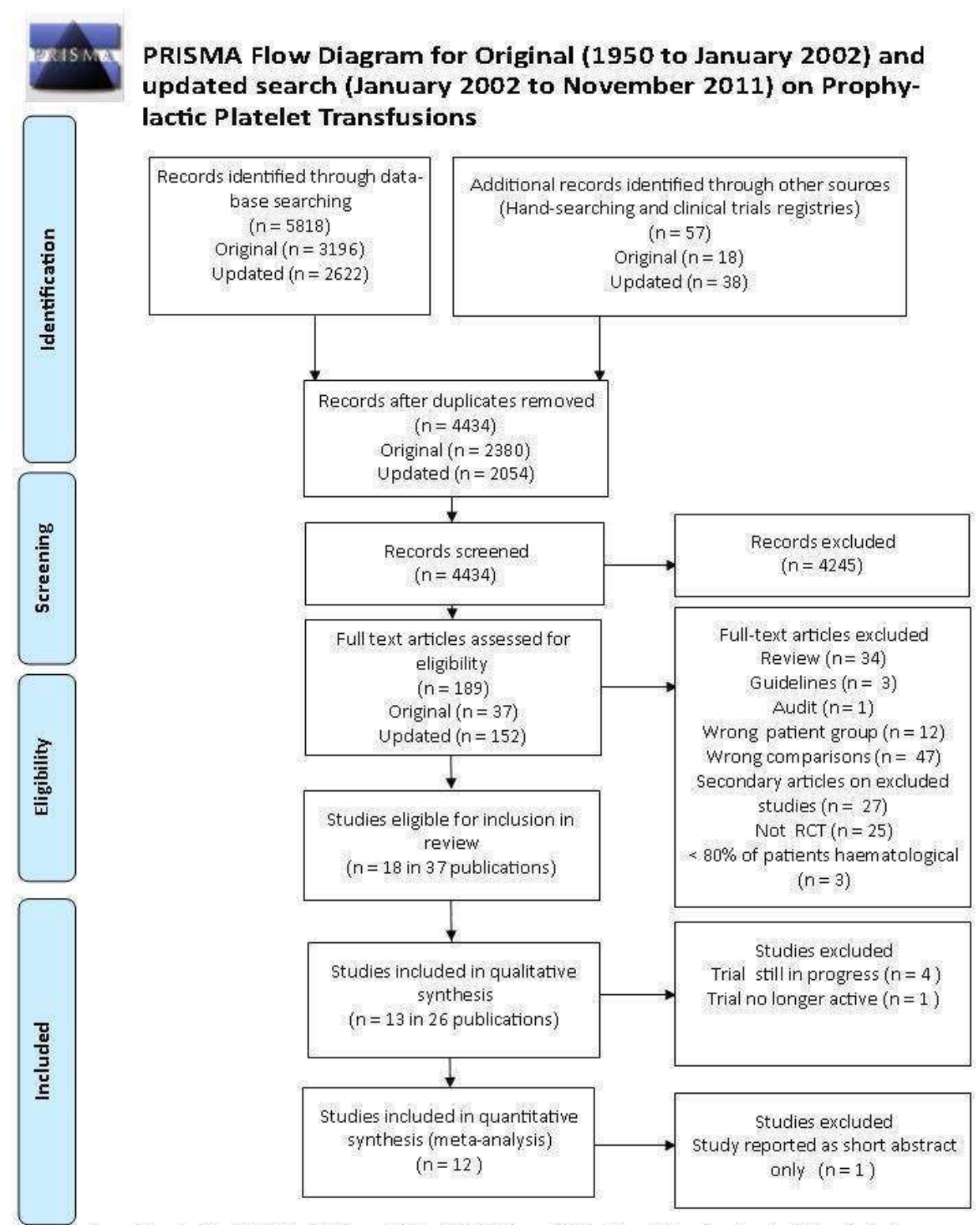

From: Moher D, Liberati A, TetzlaffJ, Atman DG, The PRISMA Grou (2009). Referred Reporting terns for S/sternatic Revews 
The update searches (conducted November 2009, May 2010, March 2011 and November 2011) identified a total of 2622 potentially relevant citations. There were 2054 citations after duplicates were removed. 1865 records were able to be excluded on the basis of the abstract by two review authors (CD \& LE). In this update, 152 full text articles were retrieved for relevance and the previous systematic review (Stanworth 2004) identified 37 studies which appeared relevant on the basis of their full text of abstract or paper using the original inclusion/exclusion criteria Stanworth 2004. These 189 citations were reviewed by two review authors (LE \& SS).

\section{Included studies}

See Characteristics of included studies for full details of each study.There were 18 studies eligible for inclusion, five of these studies were ongoing studies.

\section{Ongoing studies}

The updated review identified five ongoing studies within 11 abstracts or database records. The original review identified one ongoing study that is not currently recruiting patients (Franklin 1995). However, no further information were available from the trialists. Searches of databases of ongoing trials and abstracts identified four further potentially relevant trials (Lu 2011; NCT00180986; Stanworth 2010; Wandt 2009). NCT00180986 is not actively recruiting patients at the moment (no further information available from the author). Lu 2011; Stanworth 2010; Wandt 2009 have now completed recruitment of patients but results have not yet been published. See Characteristics of ongoing studies for further details.

\section{Studies contributing to the main outcome}

The 13 remaining RCTs (26 publications) were published between 1973 and 2010. There were 13 secondary citations of included studies (cited as secondary references for the relevant included studies).

There were six new studies (Diedrich 2005; Heddle 2009; Sensebe 2004; Slichter 2010; Steffens 2002; Tinmouth 2004) included in this updated review, and they were published between 2002 and 2010. Nine studies were identified in the original review (Heckman 1997; Higby 1974; Klumpp 1999; Murphy 1982; Rebulla 1997; Roy 1973; Sintnicolaas 1982; Solomon 1978; Zumberg 2002). Two studies that had previously been included in the review were excluded because fewer than $80 \%$ of participants had a haematological disorder and no subgroup data could be identified (Klumpp 1999; Zumberg 2002).

The thirteen RCTs included were distributed across the four review sub-categories as follows:
- Three trials evaluated the effect of a prophylactic platelet transfusion policy versus a therapeutic platelet transfusion policy (Murphy 1982; Sintnicolaas 1982; Solomon 1978);

- Three trials evaluated the effect of a prophylactic platelet transfusion policy with one trigger level versus a prophylactic platelet transfusion policy with another trigger level (Diedrich 2005; Heckman 1997; Rebulla 1997);

- Six trials evaluated the effect of a prophylactic platelet transfusion with one dose schedule versus a prophylactic platelet transfusion with another dose schedule (Heddle 2009; Roy 1973; Sensebe 2004; Slichter 2010; Steffens 2002; Tinmouth 2004);

- One trial evaluated the effect of prophylactic platelet transfusions versus platelet-poor plasma (Higby 1974).

In the remainder of this review these sub-categories will be described in separate sections.

\section{Prophylactic platelet transfusions versus therapeutic platelet transfusions}

See Table 1 for study characteristics, including number and type of participants, type of intervention, duration of study, type of platelet product and primary outcome.

Three RCTs were identified in this comparison. All were single centre parallel RCTs. The number of patients randomised ranged from 12 in Sintnicolaas 1982 to 56 in Murphy 1982. Two studies were conducted in the USA in the 1970's, although one study was not published until 1982, some years after recruitment had been completed (Murphy 1982). One study was conducted in the Netherlands (Sintnicolaas 1982).

Sintnicolaas 1982 was only reported as a short abstract, and no further information was available from the author, therefore this study will be excluded from any quantitative analysis (12 participants were randomised, but the numbers in each arm of the study were not stated).

\section{Participants}

In total 99 participants were randomised, and of these, 97 were included in the analysis. Two patients were excluded from Solomon 1978 because they died from an intra-cranial haemorrhage on the first day of the study. The study populations varied slightly. In Solomon 1978, patients were previously untreated adults with acute myeloid leukaemia (AML); patients with acute promyelocytic leukaemia (APL) were excluded. In Murphy 1982, patients were previously untreated children with either AML or acute lymphoblastic leukaemia (ALL); no exclusion criteria were reported. In Sintnicolaas 1982, patients had acute leukaemia and were severely thrombocytopenic; no exclusion criteria were reported. 


\section{Intervention}

All three studies compared prophylactic platelet transfusions with a platelet threshold of $20 \times 10^{9} / \mathrm{L}$ with a therapeutic platelet transfusion regime (platelet transfusion given for clinically significant bleeding). However, in Solomon 1978, platelet transfusions were also given in the therapeutic ("specific indications") arm if there had been a $50 \%$ fall in platelets to below $20 \times 10^{9} / \mathrm{L}$ over the previous $24 \mathrm{hrs}$.

\section{Co-interventions}

None of the studies had any reported co-interventions. None of the studies reported a red cell transfusion policy.

\section{Outcomes}

Only one of the three studies defined a primary outcome; this was survival (Murphy 1982). Only one study commented on bleeding outcomes apart from death from bleeding (Murphy 1982). Two studies reported on platelet transfusion requirements (Murphy 1982; Solomon 1978). Two studies commented on adverse events (platelet refractoriness) (Murphy 1982; Sintnicolaas 1982). None of the studies commented on transfusion reactions or thromboembolic disease.

\section{Prophylactic platelet transfusion with one trigger level versus prophylactic platelet transfusion with another trigger level}

See Table 2 for study characteristics including: number and type of participants; type of intervention (actual thresholds used); duration of study; type of platelet product; and primary outcome . Three parallel RCTs were identified in this comparison. Two were single-centre studies (Diedrich 2005; Heckman 1997), and one was a multicentre study (Rebulla 1997). The number of patients randomised ranged from 78 in Heckman 1997 to 276 in Rebulla 1997. The studies were conducted in Italy, Sweden and the USA.

\section{Participants}

In total 520 participants were randomised, of these, 499 were included in the analysis. Twenty one patients randomised in Rebulla 1997 were excluded from analysis (16 no study records received; two received non-myeloablative chemotherapy; three died (two within 24 hours of enrolment into the study). Two of the studies examined adult patients with acute leukaemia; one included ALL and AML patients (Heckman 1997); and the other included only patients with AML (Rebulla 1997). Both excluded patients with APL. The third study included both adults and children undergoing an allogeneic stem cell transplant (Diedrich 2005).

\section{Intervention}

Two studies compared a prophylactic transfusion threshold of 10 x $10^{9} / \mathrm{L}$ with a threshold of $20 \times 10^{9} / \mathrm{L}$ (Heckman 1997; Rebulla 1997). One study compared a threshold of $10 \times 10^{9} / \mathrm{L}$ with a threshold of $30 \times 10^{9} / \mathrm{L}$ (Diedrich 2005).

\section{Co-interventions}

In two of the three studies (Diedrich 2005; Rebulla 1997) a red cell transfusion policy was stated. Both studies transfused red cells when the haemoglobin was less than $80 \mathrm{~g} / \mathrm{L}$.

\section{Outcomes}

Two of the three studies defined a primary outcome (Diedrich 2005; Rebulla 1997). Rebulla 1997 defined the frequency and severity of bleeding as the primary outcome, with the number of platelet transfusions as a secondary outcome. Whereas tDiedrich 2005 defined the number of platelet transfusions as the primary outcome with bleeding as one of the secondary outcomes. The third study, Heckman 1997, stated that its main aims were to look at platelet use and bleeding complications. All three studies commented on adverse events associated with platelet transfusions.

\section{Prophylactic platelet transfusion with one dose schedule versus prophylactic platelet transfusion with another dose schedule}

See Table 3 for study characteristics including number and type of participants, type of intervention (actual doses used), prophylactic platelet transfusion thresholds used, duration of study, type of platelet product and primary outcome .

Six RCTs were identified in this type of platelet transfusion study. Three were single-centre studies (Roy 1973; Steffens 2002; Tinmouth 2004) and three were multi-centre studies (Heddle 2009; Sensebe 2004; Slichter 2010). The number of patients randomised ranged from 54 in Steffens 2002) to 1351 in Slichter 2010. The studies were conducted in Canada, France, UK and USA.

\section{Participants}

In total 1808 participants were randomised, of these, 1714 were included in the analysis. Ninety one patients (7 in Heddle 2009, 5 in Sensebe 2004, and 79 in Slichter 2010) were excluded from these studies because they did not receive a platelet transfusion. Three further patients were excluded from the Heddle 2009 study because there were no bleeding assessment data available. Three of the studies included only adult patients (Heddle 2009; Steffens 2002; Tinmouth 2004). Two of the studies included both adults and children (Sensebe 2004; Slichter 2010). One study included only children with acute leukaemia (Roy 1973). All of the patients

Prophylactic platelet transfusion for prevention of bleeding in patients with haematological disorders after chemotherapy and stem cell 15 transplantation (Review) 
had hypoproliferative thrombocytopenia but the cause of this varied between studies. All of the studies included patients with acute leukaemia, however only four of the studies specifically stated that APL was an exclusion criteria (Heddle 2009; Sensebe 2004; Slichter 2010; Tinmouth 2004). Four of the studies included patients receiving an autologous stem cell transplant (Heddle 2009; Sensebe 2004; Slichter 2010; Tinmouth 2004). Three of the studies included patients receiving an allogeneic stem cell transplant (Heddle 2009; Slichter 2010; Steffens 2002).

\section{Intervention}

Two studies (Heddle 2009; Tinmouth 2004) compared low versus standard dose platelet transfusions (as defined by the individual studies). Three studies compared standard versus high dose platelet transfusions (Roy 1973; Sensebe 2004; Steffens 2002). Slichter 2010 performed a comparison between low dose, standard dose, and high dose platelet transfusions.

\section{Co-interventions}

There were no reported co-interventions in any of the studies. Four of the six studies did not report a red cell transfusion policy and two studies (unpublished data of Heddle 2009; Slichter 2010) reported that local practice at each centre determined the red cell transfusion policy.

\section{Outcomes}

Four of the six studies defined a primary outcome (Heddle 2009; Sensebe 2004; Slichter 2010; Tinmouth 2004). In three of these studies bleeding was the primary outcome measure (Heddle 2009; Slichter 2010; Tinmouth 2004), whereas in the fourth study the primary outcome was the time between the first platelet transfusion and the daily platelet count reaching $20 \times 10^{9} / \mathrm{L}$ (Sensebe 2004), with bleeding reported as an adverse event. Only one of the six studies reported on adverse events associated with platelet transfusions (Slichter 2010).

\section{Prophylactic platelet transfusions versus alternative treatments (such as artificial platelet substitutes/platelet- poor plasma/ rFVIla/ fibrinogen)}

There was only one study in this sub-category (Higby 1974). It was a small (21 patients) parallel RCT conducted in the USA in the 1970 s.

\section{Participants}

In total 21 participants were randomised (18 patients were randomised once and three were randomised twice). Three of the randomisation episodes were not included in the analysis because patients had spontaneous recovery of their platelet counts within 48 hours of study entry. The study included adults with AML.

\section{Intervention}

Patients received either platelets $\left(3\right.$ units $/ \mathrm{m}^{2}$ ) or an equivalent volume of platelet-poor plasma twice weekly. The study stopped if the patient had a significant bleed, developed significant sepsis or there was recovery of the platelet count.

\section{Co-interventions}

This study had no reported co-interventions.

\section{Outcomes}

No primary outcome was mentioned, but outcomes mentioned were the frequency of bleeding and average platelet count during the study. This study commented on the development of HLA antibodies as an adverse effect of platelet transfusions.

\section{Excluded studies}

See Characteristics of excluded studies for further details.

- Twelve studies compared different participant groups

(Andrew 1993; Arnold 2006; Bai 2004; Fanning 1995; Gajic 2006; Gerday 2009; Hilbom 2008; Johansson 2007; Julmy 2009; Reed 1986; Speiss 2004; Vadhan-Raj 2002).

- Forty seven studies compared different types of platelet formulations with outcome measures not relevant to the eligibility criteria

(Agliastro 2006; Akkök 2007; Anderson 1997; Arnold 2004; Bentley 2000; Blumberg 2002; Blundell 1996; Carr 1990; Couban 2002; de Wildt-Eggen 2000; Diedrich 2009; Dumont 2011; Gmur 1983; Goodrich 2008; Gurkan 2007; Harrup 1999; Heal 1993; Heddle 1994; Heddle 1999; Heddle 2002; Kakaiya 1981; Kerkhoffs 2010; Lapierre 2003; Leach 1991; Lee 1989; Lozano 2010; Lozano 2011; ISRCTN49080246; McCullough 2004; Messerschmidt 1988; Mirasol 2010; Murphy 1986; Oksanen 1991; Oksanen 1994; Schiffer 1983; Shanwell 1992; Singer 1988; Sintnicolaas 1995; Slichter 2006; Strindberg 1996; Sweeney 2000; TRAP 1997; Van Marwijk 1991; van Rhenen 2003; Wang 2002; Williamson 1994; Zhao 2002).

- Three citations were guidelines (Follea 2004; Samama 2005; Tosetto 2009).

- One citation was an audit (Qureshi 2007).

- Thirty four citations were reviews (including 3 systematic reviews: Cid 2007; Heddle 2003; Shehata 2009).

- Twenty five studies were not randomised controlled trials

(Aderka 1986; Callow 2002; Cameron 2007; Chaoui 2005; Decaudin 2004; Eder 2007; Elting 2002; Elting 2003; Friedmann 2002; Gil-Fernandez 1996; Gmur 1991; Greeno 2007; Hardan 1994; Lawrence 2001; Navarro 1998; Nevo 2007; Norol 1998; Paananen 2009; Sagmeister 1999; Verma 2008; Wandt 1998; Wandt 2005; Wandt 2006; Weigand 2009; Zahur 2002). 
- Twenty seven were secondary citations of excluded studies (cited as secondary references for the relevant excluded studies).

- Three studies were studies in which fewer than $80 \%$ of the participants were haematological patients and no data were available on the haematological subgroup (Goodnough 2001; Klumpp 1999; Zumberg 2002). Klumpp 1999 and Zumberg 2002 had been included in the previous review Stanworth 2004 but have now been excluded because these were studies in which fewer than $80 \%$ of the participants were haematological patients and no data were available on the haematological subgroup.

\section{Risk of bias in included studies}

See Figure 2 for further details. 
Figure 2. Risk of bias summary: review authors' judgements about each risk of bias item for each included study.

\begin{tabular}{|c|c|c|c|c|c|c|c|c|}
\hline & 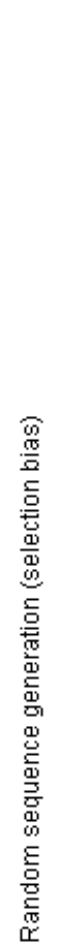 & 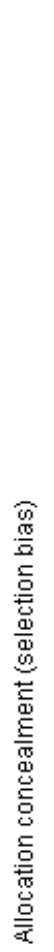 & 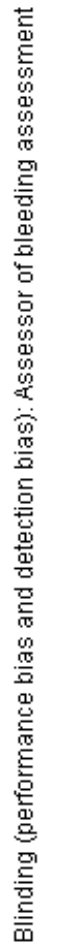 & 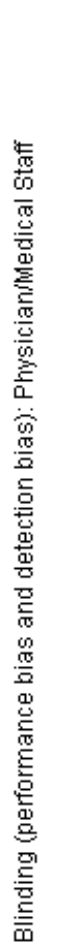 & 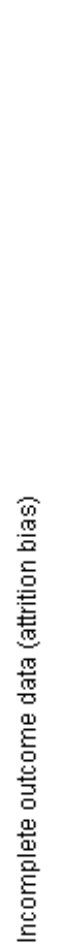 & 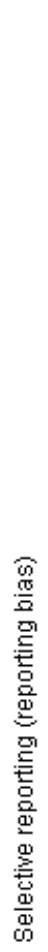 & 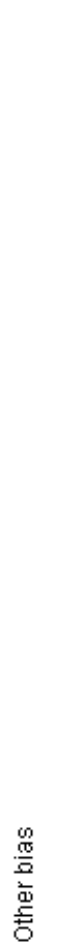 & 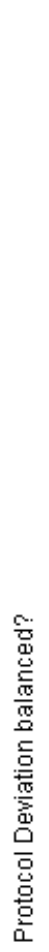 \\
\hline Diedrich 2005 & $?$ & $?$ & $\odot$ & $\odot$ & $?$ & $?$ & $\odot$ & $?$ \\
\hline Heckman 1997 & $?$ & $?$ & $\odot$ & $\odot$ & $?$ & $?$ & $?$ & $\odot$ \\
\hline Heddle 2009 & $\odot$ & + & $\odot$ & - & $\odot$ & - & $\odot$ & $\odot$ \\
\hline Higby 1974 & $?$ & 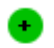 & $?$ & + & $\odot$ & $?$ & $\odot$ & $?$ \\
\hline Murphy 1982 & $?$ & $?$ & $?$ & $?$ & $?$ & - & $\odot$ & $?$ \\
\hline Rebulla 1997 & $\odot$ & + & - & $\odot$ & + & $?$ & $\odot$ & $\odot$ \\
\hline Roy 1973 & $?$ & $?$ & $\odot$ & $?$ & $\odot$ & - & $\odot$ & $?$ \\
\hline Sensebe 2004 & $?$ & $?$ & $?$ & - & $\odot$ & $?$ & $\odot$ & $?$ \\
\hline Sintnicolaas 1982 & $?$ & $?$ & $?$ & $?$ & $?$ & $?$ & $?$ & $?$ \\
\hline Slichter 2010 & $\odot$ & $?$ & $\odot$ & $\odot$ & $\odot$ & + & $\odot$ & $\odot$ \\
\hline Solomon 1978 & $?$ & $?$ & $?$ & $?$ & $?$ & $?$ & $?$ & $?$ \\
\hline Steffens 2002 & $?$ & $?$ & $?$ & $?$ & $?$ & - & $?$ & $?$ \\
\hline Tinmouth 2004 & $\odot$ & $\odot$ & - & $\odot$ & $\odot$ & $?$ & $\odot$ & - \\
\hline
\end{tabular}

Prophylactic platelet transfusion for prevention of bleeding in patients with haematological disorders after chemotherapy and stem cell 
Prophylactic platelet transfusions versus therapeutic platelet transfusions

All studies (Murphy 1982; Sintnicolaas 1982; Solomon 1978) had some threats to validity. The majority of these potential risks were due to a lack of detail provided on the specific criteria and were thus judged as "unclear" using the Cochrane grading system.

\section{Sequence generation and allocation concealment}

None of the studies reported on the method of sequence generation or allocation concealment.

\section{Blinding}

All studies were likely to be at risk of detection bias. No mechanisms were mentioned to blind outcome assessors or clinicians to the intervention. This might have been particularly problematic with respect to outcomes with potentially very high levels of subjectivity - such as enumerating significant bleeding events.

\section{Incomplete outcome data}

Loss to follow-up was generally low. In Solomon 1978 analysis was not by intention-to-treat as two patients (randomised to the prophylactic arm) that died from cerebral haemorrhages on day one of the study were not included in the analysis.

\section{Selective reporting}

It was unclear whether any of the studies were free of selective reporting as study protocols were not available.

\section{Protocol deviation}

No study reported on protocol deviation.

\section{Other potential sources of bias}

The small numbers of participants in the studies compromised the likelihood that there was equivalence of participants at baseline. All studies are therefore potentially at risk of significant bias.

\section{Prophylactic platelet transfusion with one trigger level versus prophylactic platelet transfusion with another trigger level}

All three studies had some threats to validity (Diedrich 2005; Heckman 1997; Rebulla 1997). The majority of these potential risks were due to a lack of detail provided on the specific criteria and were thus judged as "unclear" using the Cochrane grading system.

\section{Sequence generation}

Only one of the studies had adequate sequence generation (Rebulla 1997), the methods used in the other two studies were unclear.

\section{Allocation concealment}

Only one of the studies had adequate allocation concealment ( Rebulla 1997), whether this was achieved in the other studies was unclear.

\section{Blinding}

In one of the studies there was adequate blinding of the bleeding assessor (Diedrich 2005), but other medical staff were unblinded to the treatment arm. In the other two studies (Heckman 1997; unpublished data of Rebulla 1997), the bleeding assessors and medical staff were unblinded.

\section{Incomplete outcome data}

Rebulla 1997 did not perform an intention to treat analysis. Twenty one of the randomised patients were excluded from analysis (16 no study records received; two received non-myeloablative chemotherapy. Three died (two within 24 hours of enrolment into the study); two of the three deaths were due to an intra-cerebral haemorrhage. However, the number of participants with missing outcome data were balanced across the intervention groups.

\section{Selective reporting}

It was unclear whether any of the studies were free of selective reporting as study protocols were not available.

\section{Protocol deviation}

In two of the three studies there were more protocol deviations in the intervention arm of the study (Heckman 1997; Rebulla 1997). The third study was insufficiently reported for an adequate assessment to be made (Diedrich 2005). In Heckman 1997, there was a statistically significant difference between the two arms. 14 out of 37 patients with a transfusion threshold of $10 \times 10^{9} / \mathrm{L}$ were affected by protocol deviations whereas only 6 out of 41 patients with a transfusion threshold of $20 \times 10^{9} / \mathrm{L}$ were affected. In Rebulla 1997, the pre-transfusion platelet count was higher than indicated in the protocol in $5.4 \%$ of platelet transfusions with a transfusion threshold of $10 \times 10^{9} / \mathrm{L}$, but only $2 \%$ of platelet transfusions with a higher transfusion trigger were transfused outside 
the protocol guidelines, whether this was statistically significant was not reported.

\section{Other potential sources of bias}

Two of the three studies (Diedrich 2005; Rebulla 1997) appeared to be free of other sources of significant bias. The third study was insufficiently reported for an adequate assessment to be made (Heckman 1997).

Two of the three studies are potentially at risk of bias due to the higher numbers of protocol violations in the intervention arms of the studies. The third study could not be adequately assessed for this risk.

\section{Prophylactic platelet transfusion with one dose schedule versus prophylactic platelet transfusion with another dose schedule}

All six studies had some threats to validity (Heddle 2009; Roy 1973; Sensebe 2004; Slichter 2010; Steffens 2002; Tinmouth 2004).

\section{Sequence generation}

Three of the studies described reliable methods of sequence generation with computer generated block design (Heddle 2009; Slichter 2010; Tinmouth 2004). The other three studies were insufficiently reported for an adequate assessment to be made (Roy 1973; Sensebe 2004; Steffens 2002).

\section{Allocation concealment}

Two of the studies described adequate allocation concealment ( Heddle 2009; Tinmouth 2004). Heddle 2009 used a secure webbased randomisation system and Tinmouth 2004 used a sealed envelope system administered by blood bank staff. The other four studies were insufficiently reported for an adequate assessment to be made.

\section{Blinding}

In two of the six studies (Sensebe 2004; Tinmouth 2004), the medical staff were not blinded to the intervention. A further two studies could not be assessed for blinding of medical staff due to lack of information (Roy 1973; Steffens 2002). The final two studies had been designed as blinded studies, but the authors of both of these studies raised the suspicion that blinding was inadequate (Heddle 2009; Slichter 2010). In Heddle 2009 this suspicion was raised because of unbalanced early withdrawal of patients from the study by physicians (seven patients were withdrawn early from the study; one in the standard dose arm and six in the low dose arm). In Slichter 2010 it was noted that differences in the volume of platelets transfused led to loss of blinding.
Three studies were designed so that the bleeding assessors were blinded to the intervention (Heddle 2009; Roy 1973; Slichter 2010), but the authors of two of these studies (Heddle 2009; Slichter 2010) raised the suspicion that blinding was inadequate. Two studies did not provide sufficient information to determine whether bleeding assessors were blinded to the intervention (Sensebe 2004; Steffens 2002). In one study (Tinmouth 2004), the bleeding assessor was unblinded to the outcome measure.

In four of the six studies (Heddle 2009; Roy 1973; Slichter 2010; Tinmouth 2004), the final allocation of bleeding grade was performed by individuals blinded to the intervention (Heddle 2009; Roy 1973; Tinmouth 2004), or by the use of a computer algorithm (Slichter 2010). Sensebe 2004 and Steffens 2002 did not provide sufficient information to determine whether individuals who graded bleeding were blinded to the intervention.

\section{Incomplete outcome data}

Two of the studies were at risk of significant bias due to an imbalance in the amount of missing data between the arms of the study (Heddle 2009; Slichter 2010). In Slichter 2010 complete data were available on $71 \%, 82 \%$ and $83 \%$ of platelet transfusions in the low, medium and high dose arms of the study respectively (this was a statistically significant difference). In Heddle 2009 more participants were withdrawn early from the study in the low dose arm.

Three of the studies were not at risk of bias due to incomplete outcome data (Roy 1973; Sensebe 2004; Tinmouth 2004). The sixth study was not reported in enough detail for this to be assessed (Steffens 2002).

\section{Selective reporting}

Only one of the six studies was free of selective reporting (Slichter 2010). In two further studies (Sensebe 2004; Tinmouth 2004), an assessment could not be made due to a lack of information. Three of the studies were at risk of significant bias due to selective reporting (Heddle 2009; Roy 1973; Steffens 2002). In Heddle 2009 not all of the pre-specified outcomes were reported (including platelet response; pre- and post-transfusion bleeding grade in response to dose of therapeutic platelets transfused; cost analysis). In Roy 1973 a large amount of data had been collected as demonstrated by the sentence that states: "No correlation of the incidence of bleeding with sex, pre-transfusion haematocrit, concomitant corticosteroid therapy or the use of anti-neoplastic drugs was found"

However, none of these results were reported. Steffens 2002 has only ever been reported as an abstract, however, it mentions within this that further outcomes (such as clinical efficacy and bleeding episodes) would be reported in more detail in the future.

\section{Protocol deviation}

Three of the six studies were at risk of bias due to an imbalance in protocol deviations between the different arms of the studies

Prophylactic platelet transfusion for prevention of bleeding in patients with haematological disorders after chemotherapy and stem cell 20 transplantation (Review) 
(Heddle 2009; Slichter 2010; Tinmouth 2004). The other three studies were not reported in enough detail for an assessment to be made (Roy 1973; Sensebe 2004; Steffens 2002).

In Heddle 2009, the platelet count that triggered a transfusion was higher in the low-dose treatment group (35.9\% of transfusions $(158 / 440)$ given at a trigger of $16 \times 10^{9} / \mathrm{L}$ or more) than in the standard dose group (24.7\% of transfusions $(66 / 267)$ given at a trigger of $16 \times 10^{9} / \mathrm{L}$ or more). In Slichter 2010 , a significantly smaller proportion of transfusions were within the assigned dose range when platelet counts were compared between low dose and medium dose groups ( $71 \%$ vs. $80 \%)$ and between high dose and medium dose groups ( $70 \%$ vs. $80 \%$ ). In Tinmouth 2004 , a total of 15 out of 164 transfusions contravened the protocol in the low dose arm but only 3 out of 147 transfusions contravened the protocol in the standard dose arm.

\section{Other potential sources of bias}

Only two of the six studies had further potential sources of bias (Roy 1973; Heddle 2009). Three of the studies were free of any other obvious sources of bias (Sensebe 2004; Slichter 2010; Tinmouth 2004), and the sixth study was reported in insufficient detail for an assessment to be made (Steffens 2002).

In Roy 1973, there was a marked difference in population age groups between the two arms of the study, other baseline characteristics were not reported in sufficient detail for an assessment to be made. In Heddle 2009, discrepancies in the adjudication of bleeding grade occurred in 39\% (433 out of 1150) of the bleeding days analysed with most of these discrepancies occurring between the grade 1 and grade 2 classifications. Although, through consensus, agreement could eventually be reached in most cases. Heddle 2009 was also stopped early due to a pre-specified stopping guideline.

All of these studies were therefore at risk of bias.

\section{Prophylactic platelet transfusions versus alternative treatments (such as artificial platelet substitutes/platelet- poor plasma/ $\mathrm{rFVIla/}$ fibrinogen)}

Higby 1974 had some significant threats to validity, with differences in the baseline characteristics between the two arms of the study.

\section{Sequence generation and allocation concealment}

Methods of randomisation and allocation concealment were not stated.

\section{Blinding}

Physicians were blinded to the treatment regimen.

\section{Incomplete outcome data}

Analysis was not performed on an intention-to-treat basis. Only 21 of the 24 randomisations were included because an as-treated analysis was performed instead.

\section{Selective reporting}

No protocol was available to comment on whether selective reporting had occurred.

\section{Protocol deviation}

No protocol deviations were reported.

\section{Other potential sources of bias}

There was a difference in baseline characteristics between the two groups of patients. Patients in the platelet-poor plasma arm of the study were significantly younger than those patients in the prophylactic platelet arm of the study.

\section{Risk of bias in the assessment and grading of bleeding}

There were ten studies in which bleeding outcomes were reported (Table 4). In four of these it was the primary outcome (Heddle 2009; Rebulla 1997; Slichter 2010; Tinmouth 2004). These four studies all reported the method of assessing bleeding and the bleeding severity scale used. However, although in three of these four studies red blood cell usage was used to partially grade bleeding severity, only one study reported a definitive red cell transfusion policy (Rebulla 1997), and two studies left the decision to transfuse up to local policies (Heddle 2009; Slichter 2010). Variations in red cell transfusion policies across centres within a trial could affect the assessment of bleeding grade and therefore lead to bias. Also, variations in the use of transfusions between studies could affect the results of any meta-analysis.

\section{Effects of interventions}

See: Summary of findings for the main comparison Prophylactic platelet transfusion compared to non prophylactic or therapeutic platelet transfusion for prevention of haemorrhage after chemotherapy and stem cell transplantation; Summary of findings 2 Prophylactic platelet transfusion at threshold of 10,000 compared to higher transfusion threshold $(20,000$ or 30,000$)$ for patients with a haematological disorder; Summary of findings 3 Prophylactic platelet transfusion with one dose schedule compared to prophylactic platelet transfusions with another dose schedule for patients with a haematological disorder; Summary of findings 4 Prophylactic platelet transfusion compared to platelet-poor plasma for patients with a haematological disorder In all the included studies, the study's own definition of clinically significant bleeding was used, unless otherwise stated. If the study

Prophylactic platelet transfusion for prevention of bleeding in patients with haematological disorders after chemotherapy and stem cell 21 transplantation (Review)

Copyright ( 2012 The Cochrane Collaboration. Published by John Wiley \& Sons, Ltd. 
did not explicitly define clinically significant bleeding it was assumed that WHO grade 2 or above bleeding was clinically significant bleeding because the majority of newer studies have used this as the definition of clinically significant bleeding (Heddle 2009; Slichter 2010; Stanworth 2010).

\section{Prophylactic platelet transfusions versus therapeutic platelet transfusions.}

Three studies were included in this type of platelet study (Murphy 1982; Sintnicolaas 1982; Solomon 1978).

\section{Number and severity of bleeding episodes}

Bleeding outcomes were only reported for one of the three studies (Murphy 1982).

\section{Number of participants with a significant bleeding event}

The number of participants with a significant bleeding event showed a trend towards an increased risk of bleeding in the therapeutic arm (RR 1.66; 95\% CI 0.90 to 3.04), however the confidence intervals included 1.0 (no effect) i.e. this was not statistically significant (Analysis 1.1). Murphy 1982 also reported this outcome for cases of AML and ALL separately (Analysis 1.1), but this subgroup analysis also showed no significant difference between the two arms of the study.

\section{Number of days with a significant bleeding event}

There was no significant difference between the two arms in the number of days on which significant bleeding occurred (RR 0.9; 95\% CI 0.62 to 1.32 ) (Analysis 1.2). Murphy 1982 also reported this outcome for cases of AML and ALL separately (Analysis 1.2), but this subgroup analysis also showed no significant difference between the two arms of the study.

\section{Time to first significant bleeding event}

The time to the first significant bleeding event was only reported graphically (Murphy 1982). Murphy 1982 also reported this outcome for cases of AML and ALL separately. The time to the first significant bleeding event was significantly longer for ALL patients in the prophylactic platelet transfusion arm but there was no significant difference between the two arms of the study for AML patients.

\section{Severity of bleeding episodes}

None of the studies reported the number of patients with bleeding that required a red cell transfusion.

None of the studies reported the number of patients with bleeding that caused cardiovascular compromise.

\section{Mortality}

\section{All-cause mortality}

This was reported in two of the three studies (Murphy 1982; Solomon 1978). Meta-analysis of the data was performed and no significant difference in all-cause mortality (RR 0.97; 95\% CI 0.48 to 1.93) was seen between prophylactic and therapeutic platelet transfusions. There was no evidence of heterogeneity in all cause mortality.

\section{Mortality secondary to bleeding}

This was reported for all of the studies (Murphy 1982; Sintnicolaas 1982; Solomon 1978). A meta-analysis of the data from two of the studies (Murphy 1982; Solomon 1978) was performed and no significant difference in mortality due to bleeding (RR 1.08, 95\% CI 0.23 to 5.06) was seen between prophylactic and therapeutic platelet transfusions (Analysis 1.4). There was the possibility of moderate heterogeneity in mortality due to bleeding $\left(I^{2}=41 \%\right)$, however this may be explained by the small size of both studies (this could not be explored further using formal statistical analysis due to a lack of data). Although no deaths due to bleeding occurred in Sintnicolaas 1982, a meta-analysis could not be performed because it was unknown how many patients were randomised to each arm of the study.

\section{Number of platelet transfusions}

Two of the three studies reported the number of platelet units given (Murphy 1982; Solomon 1978) (see Table 5), but a meta-analysis was unable to be performed because the figures were reported in different units and SDs were not reported by Murphy (Murphy 1982). Despite this limitation, there was evidence of a clear reduction in platelet usage between the prophylactic and therapeutic arms. In Solomon 1978 there was a mean difference (MD) (fixedeffect) of -15.8 platelet units per course of chemotherapy $(95 \%$ CI -19.2 to -12.4$)$.

\section{Number of red cell transfusions}

Only Solomon 1978 reported the mean number of red cell units given per patient (Table 5). There was a small reduction in red

Prophylactic platelet transfusion for prevention of bleeding in patients with haematological disorders after chemotherapy and stem cell 22 transplantation (Review) 
cell usage in the prophylactic arm, but this was not statistically significant (MD (fixed-effect) -0.6 units, $95 \%$ CI -1.34 to 0.14 ).

\section{Disease free survival}

Only Murphy 1982 reported disease free or all cause survival rates. However, this was only reported graphically. There was no significant difference seen between the two arms. At 10 months, average survival rate in the therapeutic arm was approximately $86 \%$ SD $\pm 8 \%$ and in the prophylactic arm was approximately $91 \% \mathrm{SD} \pm$ $8 \%$.

\section{Complete remission}

Only Solomon 1978 reported complete or partial remission rates. There was no significant difference between complete remission rates between the two arms of the study (RR 1.06, 95\% CI 0.50 to 2.27 ).

\section{Time in hospital}

None of the studies reported the length of time that the patients were in hospital.

\section{Adverse events}

Two of the three studies reported any adverse events (Murphy 1982; Sintnicolaas 1982). The only adverse event reported was platelet refractoriness.

\section{Transfusion reactions}

None of the studies reported transfusion reactions.

\section{Thromboembolic disease}

None of the studies reported thromboembolic disease.

\section{HLA antibodies/platelet refractoriness}

Platelet refractoriness was defined in Murphy 1982 as bleeding for more than 4 days in which thrombocytopenia persists in the face of repeated platelet transfusions. This showed a trend towards a decreased risk of developing platelet refractoriness in patients in the therapeutic arm but this was not statistically significant (RR 0.33, 95\% CI 0.04 to 2.66). In Sintnicolaas 1982, two patients became refractory to platelets (no definition given) one in each arm of the study but it was unknown how many patients were randomised to each arm of the study.

\section{Pre-specified subgroup analysis}

\section{Treatment and diagnostic subgroups}

These were only reported in Murphy 1982 (see paragraph on number and severity of bleeding episodes above). There was no statistically significant difference between the subgroups of AML and ALL when number of participants with a significant bleeding event were compared $\left(\mathrm{P}=0.1 ; \mathrm{I}^{2}=64.1 \%\right)$.

\section{Fever}

None of the studies commented on an association between fever and bleeding risk.

\section{Prophylactic platelet transfusion with one trigger level versus prophylactic platelet transfusion with another trigger level}

Three studies were included in this type of platelet transfusion study (Diedrich 2005; Heckman 1997; Rebulla 1997).

\section{Number and severity of bleeding episodes}

Bleeding outcomes were reported for all three studies.

\section{Number of participants with a significant bleeding event}

This was reported for two of the three studies (Diedrich 2005; Rebulla 1997), and data from the third study was supplied by the author (Heckman 1997). A meta-analysis of this data showed no significant difference between a lower versus a higher transfusion trigger level (RR 1.35, 95\% CI 0.95 to 1.90) (Figure 3), nor was any significant difference seen if the studies comparing a threshold of $10 \times 10^{9} / \mathrm{L}$ versus $20 \times 10^{9} / \mathrm{L}$ were analysed separately (RR 1.41; 95\% CI 0.95 to 2.1) (Heckman 1997; Rebulla 1997), to that compared a threshold of $10 \times 10^{9} / \mathrm{L}$ versus $30 \times 10^{9} / \mathrm{L}$ (RR $1.19,95 \%$ CI 0.59 to 2.37 ) (Diedrich 2005). 
Figure 3. Forest plot of comparison: 2 Prophylactic platelet transfusion at one trigger level versus another trigger level, outcome: 2.2 Numbers of participants with a significant bleeding event.

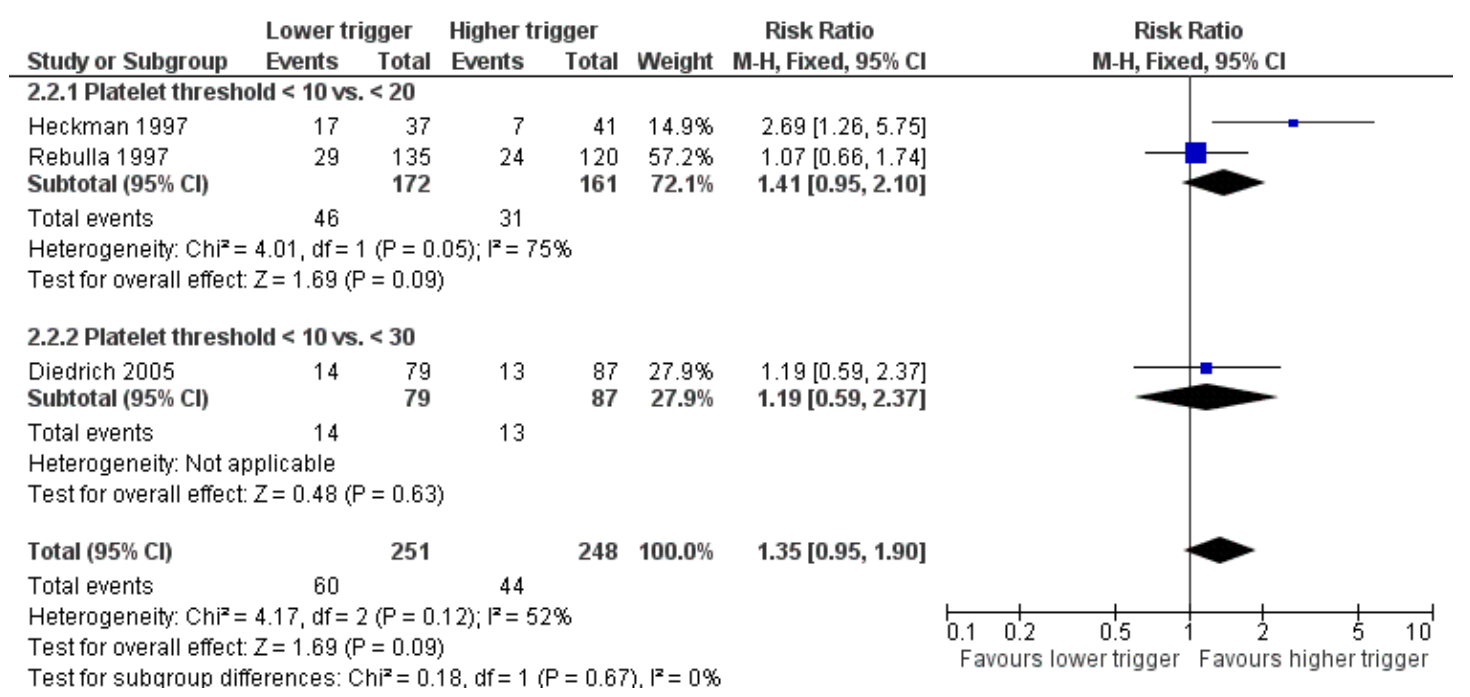

\section{Number of days with a significant bleeding event}

This was reported in Rebulla 1997; data from a second study was supplied by the author (Heckman 1997). The author of the third study was contacted but this data was no longer available (Diedrich 2005). A meta-analysis of the available data showed that there was a higher number of days with clinically significant bleeding in the arm with a lower transfusion trigger level and that this result was statistically significant (RR $1.72,95 \%$ CI 1.33 to 2.22 ) (Figure 4).

Figure 4. Forest plot of comparison: 2 Prophylactic platelet transfusion at one trigger level versus another trigger level, outcome: 2.4 Number of days with a significant bleed.

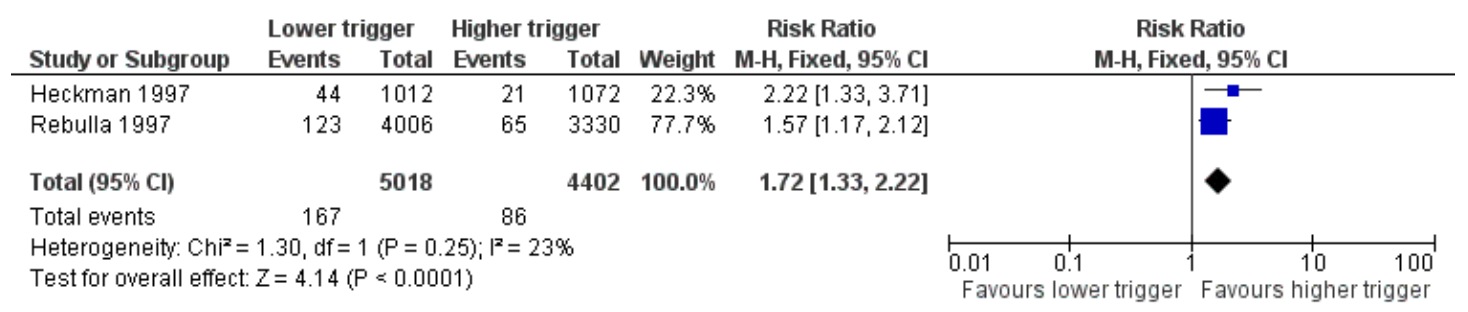

\section{Time to first significant bleeding event}

None of the studies reported the time to first significant bleeding event.

\section{Severity of bleeding episodes}

Only Diedrich 2005 reported the number of patients with bleeding that required a red cell transfusion. There was no significant difference between a lower versus a higher transfusion trigger level

Prophylactic platelet transfusion for prevention of bleeding in patients with haematological disorders after chemotherapy and stem cell 24 transplantation (Review)

Copyright ( 2012 The Cochrane Collaboration. Published by John Wiley \& Sons, Ltd. 
(RR $0.65,95 \%$ CI 0.15 to 2.8 ).

None of the studies reported the number of patients with bleeding that caused cardiovascular compromise.

Two of the studies (Diedrich 2005; Rebulla 1997) reported the number of patients with WHO grade 3 and 4 bleeding. A metaanalysis of this data showed no statistically significant difference between a lower versus a higher trigger level (RR 0.99, 95\% CI 0.52 to 1.88 ).

None of the studies reported the number of patients with WHO grade 4 bleeding alone.

\section{Mortality}

\section{All-cause mortality}

This was reported for two of the three studies (Heckman 1997; Rebulla 1997). In Heckman 1997, the number of study participants who had died was reported at the time of data analysis rather than those that occurred during the initial study period (Rebulla 1997) because of these differences a meta-analysis was not performed. In Heckman 1997, 25 out of 37 patients died in the lower threshold arm and 29 out of 41 patients died in the higher threshold arm, this was not a statistically significant difference. In Rebulla 1997, 18 out of 135 patients died in the lower threshold arm and 9 out of 120 patients died in the higher threshold arm, this was not a statistically significant difference.

\section{Mortality secondary to bleeding}

Death due to bleeding was reported for all three studies, but it was only in the largest study that any deaths occurred (Rebulla 1997). One death due to intracerebral haemorrhage in the lower trigger arm was included in the analysis (RR 2.67, 95\% CI 0.11 to 64.91), however two further deaths due to intracerebral haemorrhage (one in each arm of the study) were in patients who were randomised but not included in the analysis. If analysis of the data included all patients randomised then there was still no evidence of a statistically significant difference in death rate between the two arms of the study (RR 1.86, 95\% CI 0.17 to 20.26) (assuming that those patients on which no data forms were returned did not die secondary to bleeding).

\section{Number of platelet transfusions}

All three studies reported on the number of platelet transfusions required. Diedrich 2005 reported the results as medians and ranges and showed a statistically significant decrease in the median number of platelet transfusions required in the lower trigger level arm (median 4; range 0 to 32 versus median 10; range 0 to 48). A metaanalysis of the other two studies. unpublished data of Heckman 1997 and Rebulla 1997, showed a statistically significant reduction in the mean number of platelet transfusions required in the low threshold arm (MD (fixed-effects) -2.09, 95\% CI -3.20 to 0.99) (Figure 5).

Figure 5. Forest plot of comparison: 2 Prophylactic platelet transfusion at one trigger level versus another trigger level, outcome: 2.8 Mean number of platelet transfusions per patient.

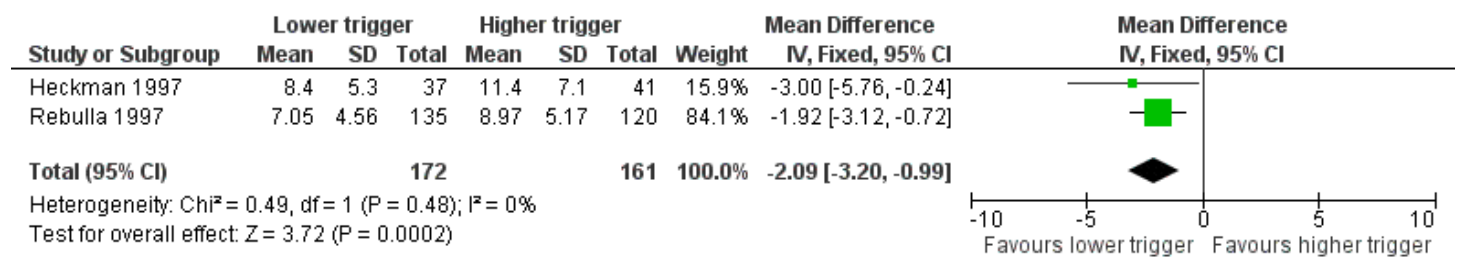




\section{Number of red cell transfusions}

All three studies reported on the number of red cell transfusions required. One of the studies reported the results as medians and ranges and showed no difference in the red cell transfusion requirement (median 4; range 0 to 26 in the lower trigger arm versus median 4; range 0 to 31 in the higher trigger arm). A meta-analysis of the other two studies, unpublished data of Heckman 1997 and Rebulla 1997, showed no statistically significant difference between the two arms in the mean number of red cell transfusions required (MD (fixed effects) $0.66,95 \% \mathrm{CI}-0.43$ to 1.76 ) (Figure $6)$.

Figure 6. Forest plot of comparison: 2 Prophylactic platelet transfusion at one trigger level versus another trigger level, outcome: 2.9 Mean number of red cell transfusions per patient.

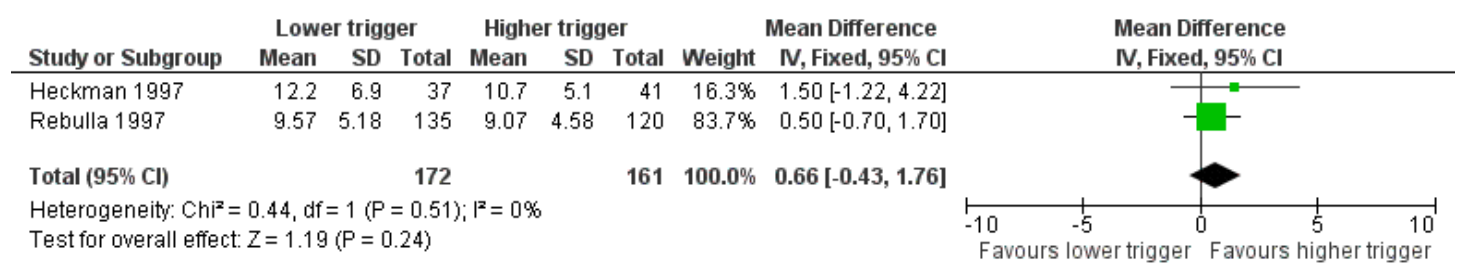

\section{Disease free survival}

Only Diedrich 2005 reported a Kaplan-Meier probability at 3 years of disease-free survival; and reported no significant difference between the two arms of the study.The three studies reported all-cause survival in various ways and none showed a significant difference between the two arms of the study.

\section{Complete remission}

Two of the studies reported the number of patients who had achieved a complete remission (Heckman 1997; Rebulla 1997). A meta-analysis of this data showed no evidence of a difference between the two arms (RR 0.92, 95\% CI 0.78 to 1.09 ) (Figure 7). 
Figure 7. Forest plot of comparison: 2 Prophylactic platelet transfusion at one trigger level versus another trigger level, outcome: 2.10 Remission rates.

\begin{tabular}{|c|c|c|c|c|c|c|c|}
\hline \multirow[b]{2}{*}{ Study or Subgroup } & \multicolumn{2}{|c|}{ Lower trigger } & \multicolumn{2}{|c|}{ Higher trigger } & \multirow[b]{2}{*}{ Weight } & \multirow{2}{*}{$\begin{array}{c}\text { Risk Ratio } \\
\text { M-H, Fixed, 95\% Cl }\end{array}$} & \multirow{2}{*}{$\begin{array}{c}\text { Risk Ratio } \\
\text { M-H, Fixed, 95\% Cl }\end{array}$} \\
\hline & Events & Total & Events & Total & & & \\
\hline Heckman 1997 & 25 & 37 & 27 & 41 & $24.1 \%$ & $1.03[0.75,1.40]$ & \\
\hline Rebulla 1997 & 76 & 135 & 76 & 120 & $75.9 \%$ & $0.89[0.73,1.09]$ & \\
\hline Total (95\% Cl) & & 172 & & 161 & $100.0 \%$ & $0.92[0.78,1.09]$ & \\
\hline Total events & 101 & & 103 & & & & \\
\hline $\begin{array}{l}\text { Heterogeneity: } \mathrm{Chi}^{2}= \\
\text { Test for overall effect }\end{array}$ & $\begin{array}{l}0.57, \mathrm{df}= \\
Z=0.94\end{array}$ & $\begin{array}{l}(P=0 . \\
=0.35)\end{array}$ & $45) ; 1^{2}=0$ & & & & 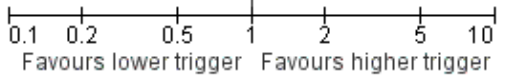 \\
\hline
\end{tabular}

\section{Time in hospital}

All of the studies reported the length of time that the patients were in hospital. These were all reported as medians with ranges or interquartile ranges (IQR) (Table 6). Therefore, a meta-analysis could not be performed. Two of the studies reported no statistically significant difference in hospital stay between the arms of the study (Diedrich 2005; Heckman 1997), whereas the third study did not report any P values (Rebulla 1997).

\section{Adverse events}

All of the studies reported at least one adverse event of platelet transfusions.

\section{Transfusion reactions}

Only Heckman 1997 reported on transfusion reactions secondary to platelet transfusions. There was no statistically significant difference between the two arms of the study (RR $0.07,95 \%$ CI 0.00 to 1.09$)$.

\section{Thromboembolic disease}

Only Rebulla 1997 reported deaths due to thromboembolic disease. There was one death in each arm of the study.

\section{HLA antibodies/platelet refractoriness.}

Only Diedrich 2005 reported on the development of HLA antibodies. There was no statistically significant difference between the two arms of the study (RR $1.10,95 \%$ CI 0.07 to 17.31 ). Two of the studies reported on the development of platelet refractoriness (Diedrich 2005; Heckman 1997). A meta-analysis of this data showed no significant difference between the different transfusion trigger levels (RR $0.66,95 \%$ CI 0.16 to 2.67 ).

\section{Pre-specified subgroup analysis}

Heterogeneity between the subgroups could not be assessed formally due to a lack of data.

\section{Treatment and diagnostic subgroups}

Heckman 1997 performed a subgroup analysis that compared newly diagnosed versus relapsed acute leukaemia patients. The relapsed patients had 2.1 fewer bleeding episodes during the study. However, in a multivariate analysis, performed by the study authors, that included age, disease status and arm of the study this difference was not statistically significant.

\section{Fever}

Two of the studies commented on an association between fever and bleeding risk (Heckman 1997; Rebulla 1997).

In Heckman 1997, the authors reported a statistically significant association between the number of febrile days and an increase in the number of platelet transfusions but not between the number of febrile days and the total number of bleeding events.

A retrospective multivariate analysis of the data from Rebulla 1997 by Webert 2006 showed that an increase in body temperature increased the risk of clinically significant bleeding (WHO grade 2 to 4) the following day. After they had controlled for the platelet count (which was the only other factor in their analysis that significantly affected bleeding risk), the presence of an elevated body temperature was associated with an $87 \%$ increase in the risk of clinically significant bleeding. This effect was more pronounced at higher body temperatures $\left(>38.5^{\circ} \mathrm{C}\right)$. However, this effect was not seen when they analysed only WHO grade 3 and 4 bleeding events.

Prophylactic platelet transfusion with one dose schedule versus prophylactic platelet transfusion with another dose schedule

Prophylactic platelet transfusion for prevention of bleeding in patients with haematological disorders after chemotherapy and stem cell 27 transplantation (Review) 
Six studies were included in this type of platelet transfusion study (Heddle 2009; Roy 1973; Sensebe 2004; Slichter 2010; Steffens 2002; Tinmouth 2004).

\section{Number and severity of bleeding episodes}

Five of the six studies reported bleeding as an outcome.

Three studies compared a low dosage versus standard dosage platelet transfusion. Two studies showed no significant difference in the number or severity of bleeding episodes between low dosage versus standard dosage platelet transfusions (Slichter 2010;
Tinmouth 2004). The third study was stopped early according to a pre-defined stopping rule because of an excessive number of severe bleeding episodes in the low dosage arm (Heddle 2009). Three studies compared standard dosage versus high dosage platelet transfusions (Roy 1973; Sensebe 2004; Slichter 2010). None of these studies showed any significant difference in the number or severity of bleeding episodes.

\section{Number of participants with a significant bleeding event}

This was reported for four of the six studies (Figure 8). Figure 8. Forest plot of comparison: 3 Prophylactic platelet transfusion with one dose schedule versus
another dose schedule, outcome: 3.2 Number of participants with a significant bleeding event.

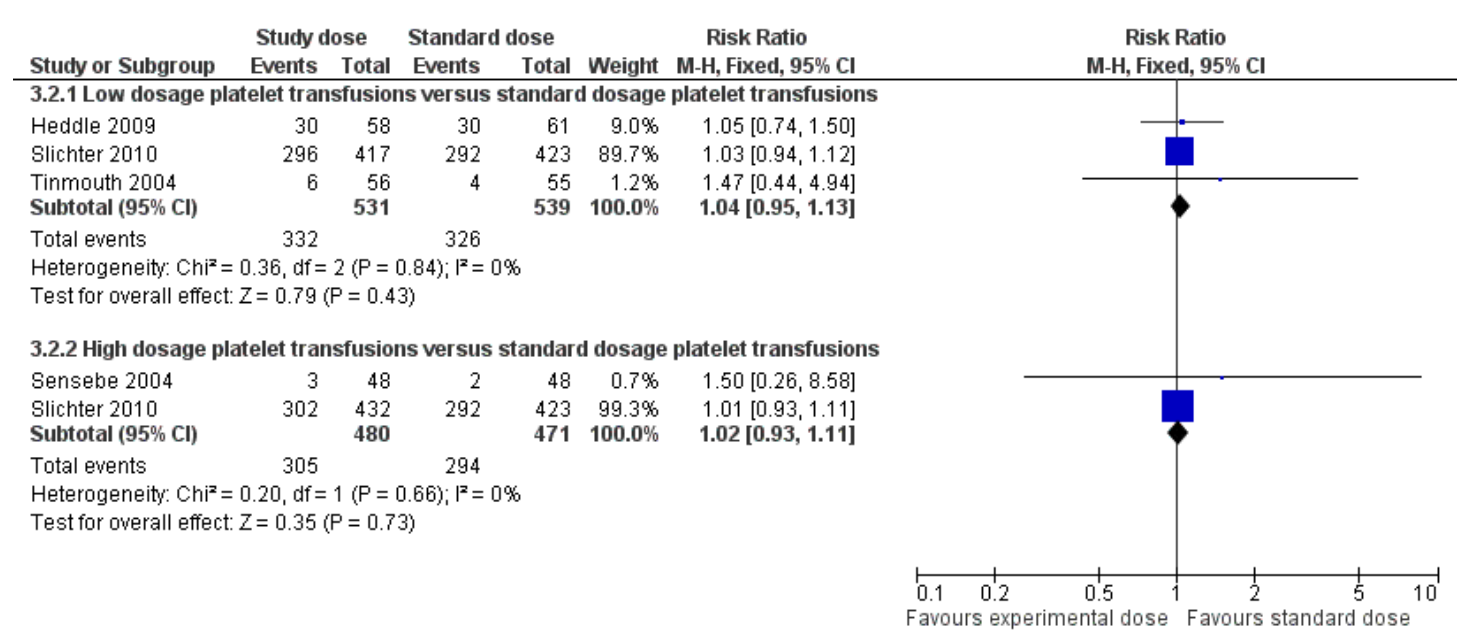

Three studies compared a low dosage versus standard dosage platelet transfusion (Heddle 2009; Slichter 2010; Tinmouth 2004). A meta-analysis of this data showed no statistically significant difference in the number of participants who had clinically significant bleeding (RR $1.04,95 \%$ CI 0.95 to 1.13 ) with relatively narrow $95 \%$ confidence intervals.

Two studies compared a high dosage versus standard dosage platelet transfusion (Sensebe 2004; Slichter 2010). A meta-analysis of this data showed no statistically significant difference in the number of participants who had significant bleeding (RR 1.02, $95 \%$ CI 0.93 to 1.11 ) with relatively narrow $95 \%$ confidence intervals.

\section{Number of days with a significant bleeding event}

Three of the studies reported on the number of days with a sig- nificant bleeding event (Roy 1973; Heddle 2009; Slichter 2010, and a fourth study provided unpublished data (Tinmouth 2004). In Slichter 2010, it was reported as the median number of days with WHO grade 2 or above bleeding per patient (Table 7), and no significant difference was seen between the arms of the study. Authors of Heddle 2009 and Tinmouth 2004 studies provided unpublished data on the mean number of days with bleeding. Despite re-classifying significant bleeding in Tinmouth 2004 as the number of days with bleeding that required an intervention or a therapeutic platelet transfusion (rather than the study definition - in an attempt to decrease the differences in how bleeding events were defined between studies) there was still substantial heterogeneity $\left(\mathrm{I}^{2}=64 \%\right)$ when an attempt was made to combine the data. A formal analysis of the reasons for this could not be performed but there were several possible reasons. Firstly, Tinmouth

Prophylactic platelet transfusion for prevention of bleeding in patients with haematological disorders after chemotherapy and stem cell 28 transplantation (Review) 
2004 included 24 patients who never received a platelet transfusion, these were specifically excluded from analysis of Heddle 2009. Secondly, Tinmouth 2004 randomised patients at initiation of chemotherapy and the study was stopped when they had a clinically significant bleed, whereas in Heddle 2009, patients were randomised when they received their first prophylactic platelet transfusion and they remained within the study until platelet count recovery or discharge from hospital. Thirdly, the majority of patients in Tinmouth 2004 were patients receiving an autologous stem cell transplant (77/111) whereas in Heddle 2009 the majority of patients had acute leukaemia (103/119). The data was also skewed and therefore a meta-analysis was not performed. In Roy 1973, Heddle 2009 and Tinmouth 2004 (unpublished data), the total number of days in each arm in which significant bleeding occurred was reported. Again these studies showed substantial heterogeneity (for the reasons above). In Heddle 2009, it showed a significantly larger number of days with bleeding in the low dosage arm of the study (RR 1.41, 95\% CI 1.07 to 1.87). In Tinmouth 2004 , there was no significant difference between the two arms of the study (RR $0.6,95 \%$ CI 0.35 to 1.02 ) (in the number of days with bleeding that required an intervention or a therapeutic platelet transfusion) (Figure 9).

Figure 9. Forest plot of comparison: 3 Prophylactic platelet transfusion with one dose schedule versus another dose schedule, outcome: 3.3 Number of days with significant bleeding.

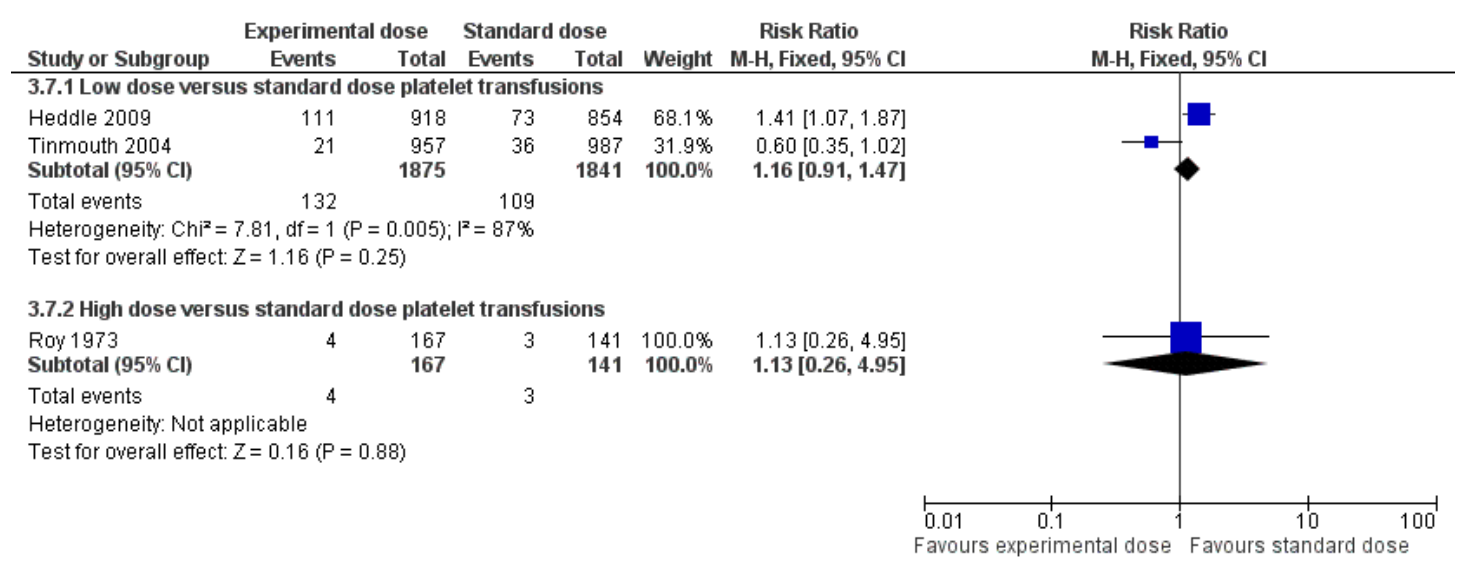

\section{Time to first significant bleeding event}

This was reported for two of the six studies (Heddle 2009; Slichter 2010). A meta-analysis was unable to be performed because the data were reported in different formats. In Heddle 2009, there was no significant difference seen in the time taken for patients receiving low dosage or standard dosage platelets to develop bleeding of WHO grade 2 or above. In Slichter 2010, there was no significant difference in the time to first significant bleeding event (Table 8).

\section{Severity of bleeding}

Two of the studies reported the number of patients with WHO grade 3 or 4 bleeding (Heddle 2009; Slichter 2010). A meta- analysis was performed that compared low dose versus standard dose platelet transfusions and no significant difference was seen (RR 1.33, 95\% CI 0.91 to 1.92). In Slichter 2010, no significant difference was seen between high dose and standard dose platelet transfusions in the incidence of grade 3 and 4 bleeding (RR 1.11, 95\% CI 0.73 to 1.68 ).

Three of the studies reported the number of patients who could be classified as having grade 4 bleeding (Heddle 2009; Slichter 2010; Tinmouth 2004). A meta-analysis was performed that compared low dose versus standard dose platelet transfusions and no significant difference was seen (RR 1.87, 95\% CI 0.86 to 4.08) (Figure 10). In Slichter 2010, no significant difference was seen between high dose and standard dose platelet transfusions in the incidence of grade 4 bleeding (RR 1.10, 95\% CI 0.43 to 2.83). 
Figure 10. Forest plot of comparison: 3 Prophylactic platelet transfusion with one dose schedule versus another dose schedule, outcome: 3.6 Number of participants with WHO grade 4 bleeding.

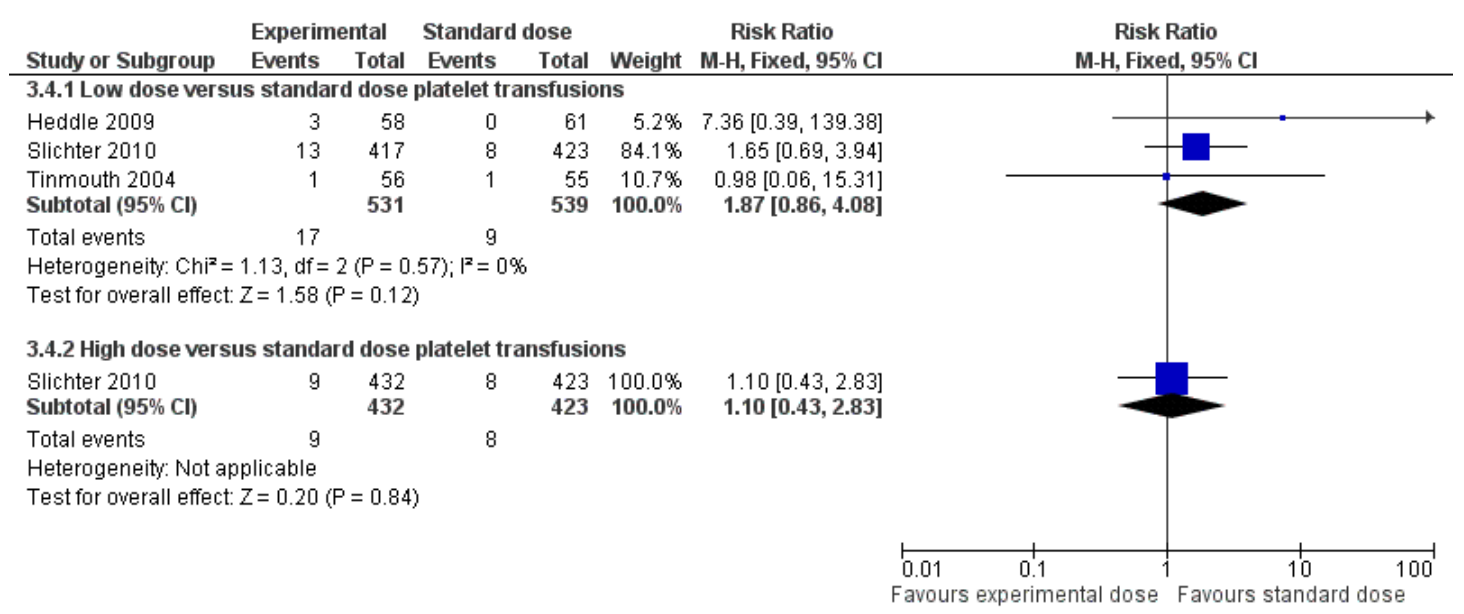

One of the studies reported the number of patients with bleeding that required a red cell transfusion (Heddle 2009). There was no statistically significant difference between the two arms of the study (RR $0.86,95 \%$ CI 0.25 to 3.0 ).

\section{Mortality}

\section{All-cause mortality}

Data on all-cause mortality was available for four of the studies. In two of these studies this was published data (Sensebe 2004; Slichter 2010), and in the other two studies this was unpublished data (Heddle 2009; Tinmouth 2004). In Sensebe 2004, three deaths occurred over both arms of the study, all in patients with acute leukaemia, but no further details were given. In the other three studies there was no significant difference in the mortality rates between the low dosage versus standard dosage arms (RR 2.04, 95\% CI 0.70 to 5.93). In Slichter 2010, there was no difference between the high dosage versus standard dosage arms of the study (RR $1.71,95 \%$ CI 0.51 to 5.81 ).

\section{Mortality secondary to bleeding}

Four of the six studies reported mortality secondary to bleeding (Heddle 2009; Sensebe 2004; Slichter 2010; Tinmouth 2004). The mortality rate secondary to bleeding was very low. In all four studies there was only one death attributable to bleeding (Slichter 2010), this was a patient in the high platelet dosage arm who died secondary to a pulmonary haemorrhage.

\section{Number of platelet transfusions}

All of the studies reported on the number of platelet transfusions (Table 9), however a meta-analysis could not be performed because the data were reported in different ways. Two of the three studies comparing a low dose versus standard dosage platelet transfusion showed a significantly smaller number of platelet transfusion episodes in the standard dosage arm (Heddle 2009; Slichter 2010). Only two of the four studies comparing a high dosage versus standard dosage platelet transfusion reported P values (Sensebe 2004; Slichter 2010). Sensebe 2004 showed a significant difference in the number of platelet transfusion episodes, whereas Slichter 2010 did not. Overall, it appears that higher platelet doses led to fewer platelet transfusion episodes.

Five of the six studies reported on the total platelet utilisation, and the other study reported the number of donor exposures (Table 9), a meta-analysis could not be performed because the data were reported in different ways. Two of the three studies comparing a low dose versus standard dose platelet transfusion strategy showed a significant reduction in the total amount of platelets used (Slichter 2010; Tinmouth 2004). Only two of the four studies comparing a high dosage versus standard dosage platelet transfusion reported $\mathrm{P}$ values (Sensebe 2004; Slichter 2010). Slichter 2010 showed a significant difference in the total platelet utilisation, whereas Sensebe 2004 did not. Overall, it appears that higher platelet doses led to a higher total platelet utilisation.

\section{Number of red cell transfusions}

Three of the six studies reported on the number of red cell transfusions (Heddle 2009; Slichter 2010; Tinmouth 2004) (Table 9). A meta-analysis could not be performed because the data were

Prophylactic platelet transfusion for prevention of bleeding in patients with haematological disorders after chemotherapy and stem cell 30 transplantation (Review) 
reported in different ways. In Heddle 2009, the mean difference in red cell transfusions per thrombocytopenic day was reported and showed no significant difference between low versus standard dosage platelet transfusions (Table 9). In Slichter 2010, no significant difference was seen between the various arms of the study in the number of red cell transfusions patients received (Table 9). In Tinmouth 2004, no formal statistical analysis was reported.

\section{Disease free survival}

None of the six studies reported disease free or all cause survival rates.

\section{Complete remission}

None of the six studies reported complete or partial remission rates.

\section{Time in hospital}

None of the six studies reported the length of time that the patients were in hospital.

\section{Adverse events}

\section{Transfusion reactions}

Only Slichter 2010 reported on transfusion reactions secondary to platelet transfusions (Analysis 3.10), and a large number of events that occurred during or within four hours of a platelet transfusion were documented. Wheezing was the only adverse event that occurred significantly more frequently in the high dosage arm of the study compared to the standard dosage arm of the study (RR $6.85,95 \%$ CI 1.57 to 29.98). However, there was no significant difference in the frequency of wheezing when the low dosage arm of the study was compared with the high dosage arm (RR 0.52, $95 \%$ CI 0.21 to 1.27 ) therefore there is the possibility that this a type I error (i.e. a false positive).

\section{Thromboembolic disease}

Only one study reported on thromboembolic disease (Slichter 2010). Slichter 2010 reported three episodes of venous thromboembolism in the low dosage platelet transfusion arm, with no thrombotic episodes reported in the standard or high dosage platelet transfusion arms. There was no significant difference between the arms of the study in the frequency of thromboembolic disease. Slichter 2010 also reported veno-occlusive disease (VOD) of the liver, with six cases in the low dosage arm, five cases in the standard dosage arm and two cases in the high dosage arm. There was no significant difference in the frequency of VOD between the low dosage and standard dosage arms of the study nor was any significant difference seen between the standard and high dosage arms of the study.

\section{HLA antibodies/platelet refractoriness}

None of the six studies reported on the development of HLA antibodies or platelet refractoriness.

\section{Pre-specified subgroup analysis}

\section{Treatment and diagnostic subgroups}

Two of the studies commented on disease or treatment subgroup and bleeding risk (Slichter 2010; Tinmouth 2004). In Tinmouth 2004, 8 out of 34 acute leukaemia patients had significant bleeding, whereas only 2 out of 77 patients receiving an autologous transplant had significant bleeding (both of these patients bled when the platelet counts were $>100 \times 10^{9} / \mathrm{L}$ ). In Slichter 2010, bleeding of WHO grade 2 or greater occurred in $79 \%$ of recipients of allogeneic stem cell transplants (413 patients), $73 \%$ of patients with haematological cancers receiving chemotherapy (228 patients), and $57 \%$ of patients undergoing autologous or syngeneic stem cell transplantation ( 245 patients). There was significant heterogeneity between the two studies $\left(\mathrm{I}^{2}=70 \%\right)$, this is likely to be secondary to the different ways in which bleeding was documented and graded between the two studies leading to a much lower rate of significant bleeding in Tinmouth 2004. A meta-analysis was performed because the heterogeneity could be explained, this showed a significantly lower risk of bleeding for autologous transplant patients compared to patients receiving intensive chemotherapy or an allogeneic stem cell transplant (RR 0.73, 95\% CI 0.65 to 0.82 ). There was no heterogeneity between the intensive chemotherapy and allogeneic subgroups $\left(\mathrm{P}=0.97 ; \mathrm{I}^{2}=0 \%\right)$.

\section{Fever}

None of the studies commented on an association between fever and bleeding risk.

\section{Prophylactic platelet transfusions versus alternative treatments (such as artificial platelet substitutes/platelet- poor plasma/ rFVIla/ fibrinogen)}

Number and severity of bleeding episodes 
There was only one study in this type of platelet transfusion study (Higby 1974).

\section{Number of participants with a significant bleeding event}

The risk of a significant bleed was decreased in the prophylactic platelet transfusion arm (RR $0.47,95 \%$ CI 0.23 to 0.95 ) and this was statistically significant.

\section{Number of days with a significant bleeding event}

This was not reported by this study.

\section{Time to first significant bleeding event}

There was no difference between the two arms of the study in the time to first bleed (MD (fixed-effects) $0.00,95 \% \mathrm{CI}-7.57$ to 7.57).

\section{Severity of bleeding}

There was no statistically significant difference in the number of patients with bleeding that required a red cell transfusion (RR $0.38,95 \%$ CI 0.13 to 1.11 ).

There was no statistically significant difference in the number of patients with bleeding that caused cardiovascular compromise (RR $0.75,95 \%$ CI 0.05 to 10.44 )

\section{Mortality}

\section{All-cause mortality}

All cause mortality was not reported.

\section{Mortality secondary to bleeding}

There was no evidence for a difference in the mortality rate due to bleeding between the two arms of the study (RR 2.31, 95\% CI 0.1 to 50.85$)$.

\section{Number of platelet transfusions and red cell transfusions}

Neither the number of platelet transfusions per patient nor the number of red cell transfusions per patient were reported in the original study.

\section{Complete remission}

The rates of complete remission were lower in the prophylactic platelet arm, but this was not a statistically significant finding (RR $0.50,95 \%$ CI 0.2 to 1.26 ).

\section{Disease free survival}

Survival rates were not reported in the study.

\section{Time in hospital}

The length of in-patient stay was not reported in the study.

\section{Adverse events}

This study did not report on transfusion reactions secondary to platelet transfusions, nor did it comment on any thromboembolic side-effects.

\section{Transfusion reactions}

Not reported in this study.

\section{Thromboembolic disease}

Not reported in this study.

\section{HLA antibodies/platelet refractoriness}

The number of patients who developed HLA antibodies was lower in the prophylactic platelet arm, however there was no evidence for a difference between the two arms of the study (RR 0.38, 95\% CI 0.09 to 1.62 ).

\section{Pre-specified subgroup analysis}

\section{Treatment and diagnostic subgroups}

This type of subgroup analysis was not performed in the study.

\section{Fever}

Four out of the five patients who bled in the prophylactic platelet arm had a fever prior to bleeding and six out of the eight patients who bled in the platelet-poor plasma arm had a fever prior to the bleed. In all of these cases this fever was still present at the time of the bleed. 


\begin{tabular}{|c|c|c|c|c|c|c|c|}
\hline \multicolumn{8}{|c|}{ O F F I N D I N G S [Explanation] } \\
\hline 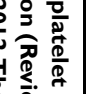 & \multicolumn{7}{|c|}{$\begin{array}{l}\text { Prophylactic platelet transfusion at threshold of } 10,000 \text { compared to Higher transfusion threshold }(20,000 \text { or } 30,000) \text { for prevention of haemorrhage after chemotherapy and stem } \\
\text { cell transplantation }\end{array}$} \\
\hline 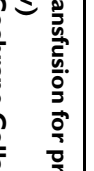 & \multicolumn{7}{|c|}{$\begin{array}{l}\text { Patient or population: Patients with a haematological disorder } \\
\text { Settings: Receiving intensive chemotherapy or a stem cell transplant } \\
\text { Intervention: Prophylactic platelet transfusion at threshold of } 10,000 \\
\text { Comparison: Higher transfusion threshold }(20,000 \text { or } 30,000)\end{array}$} \\
\hline 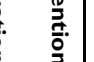 & \multirow[t]{3}{*}{ Outcomes } & \multicolumn{2}{|c|}{ Illustrative comparative risks* $(95 \% \mathrm{Cl})$} & \multirow{3}{*}{$\begin{array}{l}\text { Relative effect } \\
(95 \% \text { Cl) }\end{array}$} & \multirow{3}{*}{$\begin{array}{l}\text { No of Participants } \\
\text { (studies) }\end{array}$} & \multirow{3}{*}{$\begin{array}{l}\text { Quality of the evidence } \\
\text { (GRADE) }\end{array}$} & \multirow[t]{3}{*}{ Comments } \\
\hline $\begin{array}{l}\frac{\bar{D}}{0} \\
\stackrel{0}{g}\end{array}$ & & Assumed risk & Corresponding risk & & & & \\
\hline 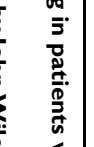 & & $\begin{array}{l}\text { Higher transfusion } \\
\text { threshold }(20,000 \text { or } 30 \text {, } \\
000)\end{array}$ & $\begin{array}{l}\text { Prophylactic platelet } \\
\text { transfusion at threshold } \\
\text { of } 10,000\end{array}$ & & & & \\
\hline 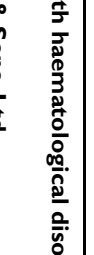 & $\begin{array}{l}\text { Bleeding: Numbers of } \\
\text { patients with at least } \\
\text { one significant bleeding } \\
\text { event }\end{array}$ & 177 per 1000 & $\begin{array}{l}239 \text { per } 1000 \\
(168 \text { to } 336)\end{array}$ & $\begin{array}{l}\text { RR } 1.35 \\
(0.95 \text { to } 1.9)\end{array}$ & $\begin{array}{l}499 \\
\text { (3 studies) }\end{array}$ & $\begin{array}{l}\oplus \oplus \oplus \bigcirc \\
\text { moderate }^{1}\end{array}$ & $\begin{array}{l}\text { The definition of clinically } \\
\text { significant bleeding var- } \\
\text { ied between studies, be- } \\
\text { cause there were differ- } \\
\text { ences in the way bleeding } \\
\text { was graded }\end{array}$ \\
\hline 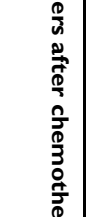 & $\begin{array}{l}\text { Bleeding: Number of } \\
\text { days on which clinically } \\
\text { significant bleeding oc- } \\
\text { curred }^{5}\end{array}$ & 20 per $1000^{5}$ & $\begin{array}{l}34 \text { per } 1000^{5} \\
(27 \text { to } 44)\end{array}$ & $\begin{array}{l}\text { RR } 1.72 \\
(1.33 \text { to } 2.22)\end{array}$ & $\begin{array}{l}9420^{5} \\
\text { (2 studies) }\end{array}$ & $\begin{array}{l}\oplus \oplus \oplus \bigcirc \\
\text { moderate }\end{array}$ & $\begin{array}{l}\text { This reported the total } \\
\text { number of days with clin- } \\
\text { ically significant bleeding } \\
\text { in either arm of the stud- } \\
\text { ies }\end{array}$ \\
\hline 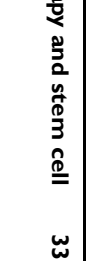 & $\begin{array}{l}\text { Mortality: secondary to } \\
\text { bleeding }\end{array}$ & 0 per 1000 & $\begin{array}{l}\text { O per } 1000 \\
(0 \text { to } 0)\end{array}$ & $\begin{array}{l}\text { RR } 2.67 \\
\text { (0.11 to } 64.91)\end{array}$ & $\begin{array}{l}499 \\
\text { (3 studies) }\end{array}$ & $\begin{array}{l}\oplus \oplus \bigcirc \bigcirc \\
\text { low }^{1,2,4}\end{array}$ & $\begin{array}{l}\text { There was only } 1 \text { death } \\
\text { reported in all three stud- } \\
\text { ies. Although two deaths } \\
\text { due to bleeding within the } \\
\text { Rebulla study were ex- } \\
\text { cluded from the analysis }\end{array}$ \\
\hline
\end{tabular}




$\begin{array}{llll}\begin{array}{l}\text { Number of platelet } \\ \text { transfusions per patient }\end{array} & \begin{array}{l}\text { The mean Number of } \\ \text { platelet transfusions per } \\ \text { patient in the intervention }\end{array} & \begin{array}{l}333 \\ \text { (2 studies) }\end{array} & \begin{array}{l}\oplus \oplus \oplus \bigcirc \\ \text { moderate }\end{array} \\ & \text { groups was } & \\ & \mathbf{2 . 0 9} \text { lower } \\ & (3.2 \text { to } 0.99 \text { lower) } & \\ \end{array}$

*The basis for the assumed risk (e.g. the median control group risk across studies) is provided in footnotes. The corresponding risk (and its $95 \%$ confidence interval) is based on the assumed risk in the comparison group and the relative effect of the intervention (and its $95 \% \mathrm{Cl}$ ).

Cl: Confidence interval; RR: Risk ratio;

\section{GRADE Working Group grades of evidence}

High quality: Further research is very unlikely to change our confidence in the estimate of effect.

Moderate quality: Further research is likely to have an important impact on our confidence in the estimate of effect and may change the estimate.

Low quality: Further research is very likely to have an important impact on our confidence in the estimate of effect and is likely to change the estimate.

Very low quality: We are very uncertain about the estimate.

${ }^{1}$ The number of participants from all three studies may not be large enough to detect a clinically significant difference. The confidence

intervals are wide and there is therefore uncertainty about the result.

2 The Rebulla study did not perform an intention to treat analysis and excluded two patients who died within 24 hours of entering the

study

${ }^{3}$ More protocol violations occurred in the lower threshold arm.

${ }^{4}$ The number of events were very small leading to imprecision

5 This was the total number of days recorded within the study rather than participants 
Prophylactic platelet transfusion with one dose schedule compared to prophylactic platelet transfusions with another dose schedule for prevention of haemorrhage after chemotherapy and stem cell transplantation

Patient or population: Patients with a haematological disorder

Settings: After chemotherapy or a stem cell transplant

Intervention: Prophylactic platelet transfusion with one dose schedule

Comparison: Prophylactic platelet transfusions with another dose schedule

\begin{tabular}{|c|c|c|c|c|c|c|}
\hline \multirow[t]{3}{*}{ Outcomes } & \multicolumn{2}{|c|}{ Illustrative comparative risks* $(95 \%$ Cl) } & \multirow{3}{*}{$\begin{array}{l}\text { Relative effect } \\
(95 \% \mathrm{CI})\end{array}$} & \multirow{3}{*}{$\begin{array}{l}\text { No of Participants } \\
\text { (studies) }\end{array}$} & \multirow{3}{*}{$\begin{array}{l}\text { Quality of the evidence } \\
\text { (GRADE) }\end{array}$} & \multirow[t]{3}{*}{ Comments } \\
\hline & Assumed risk & Corresponding risk & & & & \\
\hline & $\begin{array}{l}\text { prophy- } \\
\text { lactic platelet transfu- } \\
\text { sions with another dose } \\
\text { schedule }\end{array}$ & $\begin{array}{l}\text { Prophylactic } \\
\text { platelet transfusion with } \\
\text { one dose schedule }\end{array}$ & & & & \\
\hline $\begin{array}{l}\text { Bleed- } \\
\text { ing: Number of partici- } \\
\text { pants with a significant } \\
\text { bleeding event - Low } \\
\text { dosage platelet transfu- } \\
\text { sions versus standard } \\
\text { dosage platelet transfu- } \\
\text { sions }\end{array}$ & 605 per 1000 & $\begin{array}{l}\mathbf{6 2 9} \text { per } \mathbf{1 0 0 0} \\
(575 \text { to } 684)\end{array}$ & $\begin{array}{l}\text { RR } 1.04 \\
(0.95 \text { to } 1.13)\end{array}$ & $\begin{array}{l}1070 \\
\text { (3 studies) }\end{array}$ & 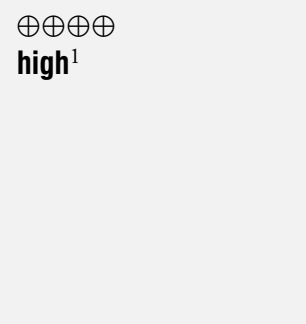 & \\
\hline $\begin{array}{l}\text { Bleeding Number of par- } \\
\text { ticipants with a signif- } \\
\text { icant bleeding event - } \\
\text { High } \\
\text { dosage platelet transfu- } \\
\text { sions versus standard } \\
\text { dosage platelet transfu- } \\
\text { sions }\end{array}$ & 624 per 1000 & $\begin{array}{l}\mathbf{6 3 6} \text { per } \mathbf{1 0 0 0} \\
\text { (580 to } 693)\end{array}$ & $\begin{array}{l}\text { RR } 1.02 \\
(0.93 \text { to } 1.11)\end{array}$ & $\begin{array}{l}951 \\
\text { (2 studies) }\end{array}$ & 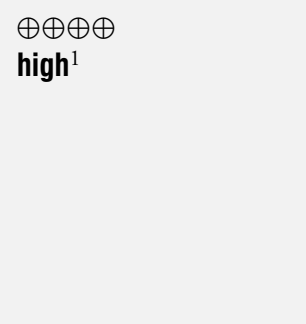 & \\
\hline
\end{tabular}




\begin{tabular}{|c|c|c|c|c|c|c|}
\hline $\begin{array}{l}\text { Bleeding } \\
\text { Number of days with sig- } \\
\text { nificant bleeding - Low } \\
\text { dosage platelet transfu- } \\
\text { sions versus standard } \\
\text { dosage platelet transfu- } \\
\text { sions }\end{array}$ & See comment & See comment & Not estimable & (3 studies) & See comment & $\begin{array}{l}\text { Slichter reported no. of } \\
\text { days with significant } \\
\text { bleeding/patient and no } \\
\text { difference was seen be- } \\
\text { tween low dose and } \\
\text { standard dose. Unpub- } \\
\text { lished data from Tin- } \\
\text { mouth showed no dif- } \\
\text { ference between low } \\
\text { dose and standard dose } \\
\text { platelets. Heddle } 2009 \\
\text { showed a higher number } \\
\text { of days with significant } \\
\text { bleeding. }\end{array}$ \\
\hline $\begin{array}{l}\text { Bleeding: } \\
\text { Number of days with sig- } \\
\text { nificant bleeding - High } \\
\text { dosage platelet transfu- } \\
\text { sions versus standard } \\
\text { dosage platelet transfu- } \\
\text { sions }\end{array}$ & See comment & See comment & Not estimable & $\begin{array}{l}0 \\
\text { (2 studies) }\end{array}$ & See comment & $\begin{array}{l}\text { Slichter } 2010 \text { reported } \\
\text { number of days with sig- } \\
\text { nificant bleeding/patient. } \\
\text { No difference was seen } \\
\text { between high dosage and } \\
\text { standard dosage platelet } \\
\text { transfusions. Roy } 1973 \\
\text { reported no difference in } \\
\text { the number of days with } \\
\text { significant bleeding }\end{array}$ \\
\hline $\begin{array}{l}\text { Mortality:sec- } \\
\text { ondary to bleeding - Low } \\
\text { dosage platelet transfu- } \\
\text { sions versus standard } \\
\text { dose platelet transfu- } \\
\text { sions }\end{array}$ & See comment & See comment & Not estimable & $\begin{array}{l}859 \\
\text { (3 studies) }\end{array}$ & $\begin{array}{l}\oplus \oplus \bigcirc \bigcirc \\
\text { low }^{2,3}\end{array}$ & $\begin{array}{l}\text { No deaths due to bleeding } \\
\text { were reported in any of } \\
\text { the studies }\end{array}$ \\
\hline $\begin{array}{l}\text { Mortality: secondary to } \\
\text { bleeding - High dosage } \\
\text { platelet transfusions } \\
\text { versus standard dosage }\end{array}$ & 0 per 1000 & $\begin{array}{l}\text { O per } 1000 \\
(0 \text { to } 0)\end{array}$ & $\begin{array}{l}\text { RR } 1.47 \\
(0.06 \text { to } 35.9)\end{array}$ & $\begin{array}{l}739 \\
\text { (2 studies) }\end{array}$ & $\begin{array}{l}\oplus \oplus \oplus \bigcirc \\
\text { moderate } 3\end{array}$ & $\begin{array}{l}\text { Only one death due to } \\
\text { bleeding was reported in } \\
\text { the high dosage arm of } \\
\text { the Slichter study }\end{array}$ \\
\hline
\end{tabular}


${ }^{*}$ The basis for the assumed risk (e.g. the median control group risk across studies) is provided in footnotes. The corresponding risk (and its $95 \%$ confidence interval) is based on the assumed risk in the comparison group and the relative effect of the intervention (and its $95 \% \mathrm{Cl}$ ).

Cl: Confidence interval; RR: Risk ratio;

GRADE Working Group grades of evidence

High quality: Further research is very unlikely to change our confidence in the estimate of effect.

Moderate quality: Further research is likely to have an important impact on our confidence in the estimate of effect and may change the estimate.

Low quality: Further research is very likely to have an important impact on our confidence in the estimate of effect and is likely to change the estimate.

Very low quality: We are very uncertain about the estimate.

Although all the studies had limitations and were at risk of bias the authors did not feel that the largest study (Slichter 2010) which was much larger than any of the other studies was at sufficient risk of bias to down-grade the evidence

${ }^{2}$ The study had many protocol violations that meant patients in the low dose arm were transfused at higher thresholds. However, this should have decreased any difference between the two arms of the study.

3 The number of cases was very low 
Prophylactic platelet transfusion compared to platelet-poor plasma for prevention of haemorrhage after chemotherapy and stem cell transplantation

Patient or population: Patients with a haematological disorde

Settings: Patients receiving intensive chemotherapy or a stem cell transplant

Intervention: Prophylactic platelet transfusion

Comparison: Platelet-poor plasma

\begin{tabular}{|c|c|c|c|c|c|c|}
\hline \multirow[t]{3}{*}{ Outcomes } & \multicolumn{2}{|c|}{ Illustrative comparative risks* $(95 \% \mathrm{CI})$} & \multirow{3}{*}{$\begin{array}{l}\text { Relative effect } \\
\text { (95\% CI) }\end{array}$} & \multirow{3}{*}{$\begin{array}{l}\text { No of Participants } \\
\text { (studies) }\end{array}$} & \multirow{3}{*}{$\begin{array}{l}\text { Quality of the evidence } \\
\text { (GRADE) }\end{array}$} & \multirow[t]{3}{*}{ Comments } \\
\hline & Assumed risk & Corresponding risk & & & & \\
\hline & Platelet-poor plasma & $\begin{array}{l}\text { Prophylactic platelet } \\
\text { transfusion }\end{array}$ & & & & \\
\hline $\begin{array}{l}\text { Number of participants } \\
\text { with a significant bleed- } \\
\text { ing event }\end{array}$ & 889 per 1000 & $\begin{array}{l}\mathbf{4 1 8} \text { per } \mathbf{1 0 0 0} \\
\text { (204 to } 845)\end{array}$ & $\begin{array}{l}\text { RR } \mathbf{0 . 4 7} \\
(0.23 \text { to } 0.95)\end{array}$ & $\begin{array}{l}21 \\
\text { (1 study) }\end{array}$ & $\begin{array}{l}\oplus \bigcirc \bigcirc \bigcirc \\
\text { very low }\end{array}$ & \\
\hline $\begin{array}{l}\text { Mortality: secondary to } \\
\text { bleeding }\end{array}$ & 0 per 1000 & $\begin{array}{l}\mathbf{0} \text { per } 1000 \\
(0 \text { to } 0)\end{array}$ & $\begin{array}{l}\text { RR } 2.31 \\
\text { (0.1 to } 50.85)\end{array}$ & $\begin{array}{l}21 \\
\text { (1 study) }\end{array}$ & $\begin{array}{l}\oplus \bigcirc \bigcirc \bigcirc \\
\text { very low } \text { low }^{1,2}\end{array}$ & \\
\hline $\begin{array}{l}\text { Number of platelet } \\
\text { transfusions }\end{array}$ & See comment & See comment & Not estimable & $\begin{array}{l}0 \\
\text { (1 study) }\end{array}$ & $\begin{array}{l}\oplus \bigcirc \bigcirc \bigcirc \\
\text { very low }{ }^{3}\end{array}$ & $\begin{array}{l}\text { This was not reported on } \\
\text { in the original study }\end{array}$ \\
\hline
\end{tabular}

*The basis for the assumed risk (e.g. the median control group risk across studies) is provided in footnotes. The corresponding risk (and its $95 \%$ confidence interval) is based on the assumed risk in the comparison group and the relative effect of the intervention (and its $95 \% \mathrm{Cl}$ ).

Cl: Confidence interval; RR: Risk ratio;

GRADE Working Group grades of evidence

High quality: Further research is very unlikely to change our confidence in the estimate of effect.

Moderate quality: Further research is likely to have an important impact on our confidence in the estimate of effect and may change the estimate.

Low quality: Further research is very likely to have an important impact on our confidence in the estimate of effect and is likely to change the estimate.

Very low quality: We are very uncertain about the estimate.

${ }^{1}$ This was a very small study performed more than 35 years ago. There have significant changes in patient care since his time

2 The quality of platelet components may have changed since this trial was performed 


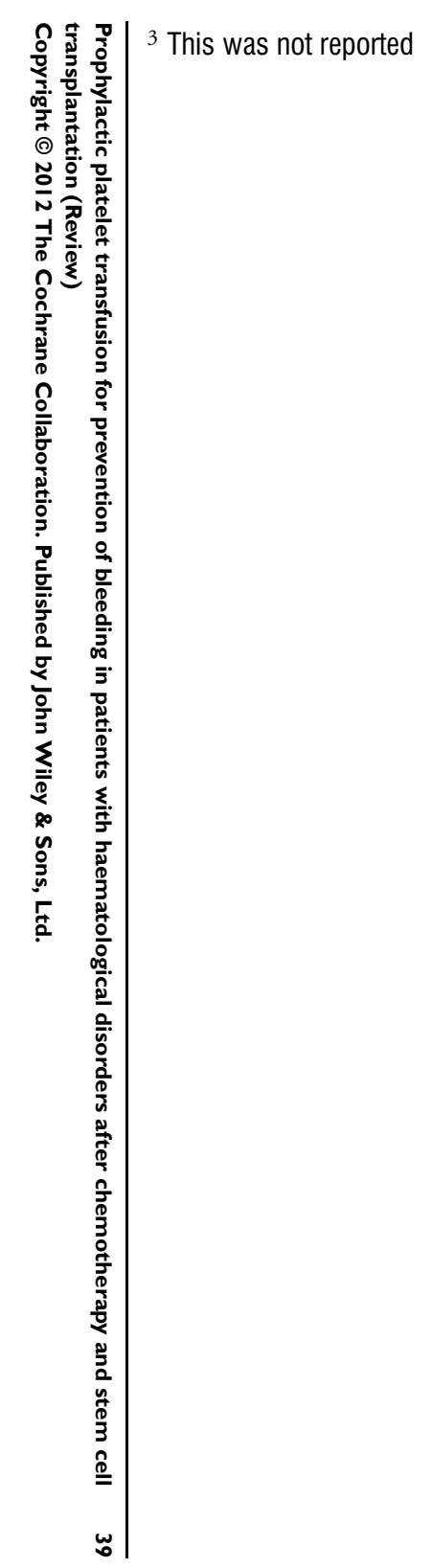




\section{I S C U S S I O N}

The main objective of this review of prophylactic platelet transfusions was to answer certain questions that continue to cause debate.

Firstly, are prophylactic platelet transfusions superior to therapeutic platelet transfusions for the prevention and/or control of lifethreatening thrombocytopenic bleeding?

(Studies from the sub-categories of prophylactic platelet transfusions versus therapeutic platelet transfusions and prophylactic platelet transfusions versus alternative treatments will be used to answer this question).

Secondly, which threshold should be used to trigger the transfusion of prophylactic platelets?

Thirdly, what is the optimal prophylactic platelet dose to prevent thrombocytopenic bleeding?

The Authors' conclusions provide our answers to these questions.

\section{Summary of main results}

Eighteen studies met the inclusion criteria for the review, five of these were ongoing studies and thirteen had data available.

\section{Prophylactic platelet transfusions versus therapeutic platelet transfusions}

Three trials that compared the effect of a prophylactic versus therapeutic platelet transfusion policy were included in the review, but only two of these studies contained separate data for each arm of the study. All of these studies were at risk of bias mainly due to lack of clarity on the methods of randomisation.

There was no significant difference in the number of participants with clinically significant bleeding. The time to first significant bleed was significantly shorter in the therapeutic arm than the prophylactic arm. There was a significant reduction in the number of platelet units required in the therapeutic transfusion arm. There was no statistically significant effect seen on overall mortality, mortality due to bleeding, red cell transfusion requirements, remission rates, or incidence of platelet refractoriness. However, due to the size of the studies they would not be adequately powered to detect important differences and this was reflected in the wide confidence intervals for any comparison.

\section{Prophylactic platelet transfusion with one trigger level versus prophylactic platelet transfusion with another trigger level}

Three trials that compared the effect of platelet transfusions at one platelet count trigger level versus another were included in this review. All of the studies were at risk of bias.

No difference was seen in the number of participants with significant bleeding between the two threshold levels, however this result may have been affected by the greater number of protocol violations in the lower threshold arm of at least two of the studies. When the number of days with significant bleeding was analysed, there was a significant increase in the number of days with significant bleeding in the group of patients transfused at the lower platelet count threshold. There was no difference seen in the number of patients with severe or life-threatening bleeding between the two threshold levels but the confidence intervals were wide $(0.52$ to 1.88 ).

There was a statistically significant reduction in the number of platelet transfusions required using a threshold of $10 \times 10^{9} / \mathrm{L}$.

There were no statistically significant differences between the groups with regards to mortality, red cell transfusion requirements, survival, remission rates, hospital stay or adverse events.

The two studies that reported on fever and bleeding risk reached different conclusions.

\section{Prophylactic platelet transfusion with one dose schedule versus prophylactic platelet transfusion with another dose schedule}

Six trials that compared the effect of platelet transfusion dosage were included in the review. Three compared a low dose versus standard dose platelet transfusion, whereas four compared a standard dose versus a high dose platelet transfusion strategy. All of the studies were at risk of bias.

There was no evidence to suggest that using a lower platelet transfusion dose increased the number of participants with clinically significant (WHO grade 2 or above), or life-threatening (WHO grade 4) bleeding.

Although a formal meta-analysis was not performed, two of the three studies did not show an increase in the total number of days with clinically significant bleeding, or an increase in the number of days per patient with clinically significant bleeding (Slichter 2010; Tinmouth 2004).

Overall the trials of platelet dose showed that a low dose transfusion policy reduced patients' total platelet requirements, but at the expense of a higher number of platelet transfusions.

There were no statistically significant differences between the groups with regards to mortality, red cell transfusion requirements, survival, remission rates or hospital stay. The only adverse event that showed a significant difference between standard and high dose platelet transfusions (wheezing) was not seen when low dose and high dose platelet transfusions were compared and is therefore likely to be a type I error (i.e. a false positive).

Of interest, in those studies that reported treatment subgroups autologous transplantation was associated with a lower risk of clinically significant bleeding compared to those patients receiving myelosuppressive chemotherapy or allogeneic transplantation. However, this is an additional finding and not the focus of this review. 
Prophylactic platelet transfusions versus alternative treatments (such as artificial platelet substitutes/platelet-poor plasma/ rFVIla/ fibrinogen)

This small study was at risk of bias due to differences in the baseline characteristics of the patients as well as lack of clarity on the method of randomisation (Higby 1974). It showed a reduction in the rate of significant bleeding in those patients receiving prophylactic platelet transfusions. There was no significant difference in any of the other outcomes, including adverse events, within this comparison. In this study, fever was associated with an increased risk of bleeding. However, aspirin was still used in the 1970s as an anti-pyretic (because its anti-platelet effects were unknown at that time) and therefore this may have been a confounding factor in this study.

\section{Overall completeness and applicability of evidence}

Are prophylactic platelet transfusions superior to therapeutic platelet transfusions for the prevention and/or control of life-threatening thrombocytopenic bleeding?

\section{Studies of prophylactic platelet transfusions versus} therapeutic platelet transfusions

The two reports of controlled trials that addressed the question of a prophylactic versus therapeutic platelet transfusion policy contained small numbers of patients and were undertaken over 30 years ago. These studies were performed at a time when different quality control measures for the platelet product were applied. The possibility that the platelets in use in the 1970's would have differed in quality from those in use today does need to be considered if attempting to generalise results to the present day. Other factors that also need to be taken in to consideration are that the patients in these studies probably received less optimal supportive therapy (e.g. prophylaxis and treatment of infection), and may have received aspirin and other compounds for fever that affect platelet function (potentially increasing the risk of bleeding).

Also, one studymay not actually represent a strict comparison of prophylactic versus therapeutic platelet transfusions because platelet transfusions were also given if there had been a significant reduction in the platelet count on the preceding day (Solomon 1978).

Studies of prophylactic platelet transfusions versus alternative treatments (such as artificial platelet substitutes/platelet-poor plasma/ rFVIla/ fibrinogen)

One small study that compared prophylactic platelet transfusions versus platelet-poor plasma was conducted over 35 years ago
(Higby 1974). As in the other older studies there is concern over the ability to generalise the findings from this study to the present day. This is due to potential differences in the quality of the platelets and changes in the management of patients with haematological malignancies. It is very unlikely that a similar study will be performed again due to the fact that the control arm was still exposing patients to a transfusion product that might harm the patient but was not expected to benefit the patient and hence would be ethically unacceptable. Newer studies instead compare a therapeutic versus prophylactic platelet transfusion policy.

We are therefore unable to answer this question at the moment.

\section{Which threshold should be used to trigger the transfusion of prophylactic platelets?}

\section{Studies of prophylactic platelet transfusion with one trigger level versus prophylactic platelet transfusion with another trigger level}

No statistically significant difference was demonstrated in the number of participants with clinically significant bleeding, but the $95 \%$ confidence interval (0.95 to 1.9) demonstrates that a clinically important difference in the proportion of patients with bleeding could have been missed. The studies, when combined, were not adequately powered to detect a difference. In Rebulla 1997, which included 255 patients, the power calculations were based on the assumption that the rate of WHO grade 2 or above bleeding was $30 \%$, but the actual rate in this study was $20 \%$. If we assume the rate of bleeding was similar in all three studies, to detect a $50 \%$ increase in the rate of bleeding (i.e. from $20 \%$ to $30 \%$ ) with $80 \%$ power would require 293 participants per arm of the study (586 in total) and to detect a $25 \%$ increase in the rate of bleeding (i.e. from $20 \%$ to $25 \%$ ) with $80 \%$ power would require 1098 participants per arm of the study (2196 in total). As there were only 499 participants within all three studies, the meta-analysis would not be sufficiently powered to detect a $50 \%$ increase in the rate of bleeding in the restrictive transfusion arm. Additionally, there were important differences between the studies that might affect the degree of confidence that can be placed on the assertion of equivalence between liberal $\left(20\right.$ or $\left.30 \times 10^{9} / \mathrm{L}\right)$ and restrictive $\left(10 \times 10^{9} / \mathrm{L}\right)$ platelet count thresholds for prophylactic platelet transfusions. The treatment protocols for administration of platelets varied, particularly the circumstances for which platelet transfusions could be given. In Rebulla 1997, platelets could be given to patients in the $10 \times 10^{9} / \mathrm{L}$ threshold arm if the platelet count was in the range of 10 to $20 \times 10^{9} / \mathrm{L}$ and the patient's temperature was above $38^{\circ} \mathrm{C}$. This meant that $22.6 \%$ of platelet transfusions were given above the threshold of $10 \times 10^{9} / \mathrm{L}$. In Diedrich 2005 and Heckman 1997, there were no changes in the transfusion threshold in the presence of fever. 
What is the optimal prophylactic platelet dose to prevent thrombocytopenic bleeding?

Studies of prophylactic platelet transfusion with one dose schedule versus prophylactic platelet transfusion with another dose schedule

The large number of patients within these studies provided strong evidence that there was no difference in the proportion of participants with bleeding between low dose, standard dose and high dose platelet transfusions. This was reflected in the narrow confidence intervals around the point estimates.

Although Heddle 2009 did not demonstrate any difference in donor exposures between the two arms of the trial, caution needs to be taken when drawing conclusions from this trial. This is because of the large number of protocol deviations within the trial. Patients in the low dose arm were transfused at higher platelet counts, and this may explain why there was no difference in the number of donor exposures.

Also, although Heddle 2009 and Slichter 2010 both used a WHO grading system for bleeding the categorisation of bleeding varied between the studies. In Slichter 2010, less severe bleeding was categorised as Grade 2. For example, in Heddle 2009 epistaxis that lasted for more than an hour or required packing was classed as grade 2 bleeding, whereas in Slichter 2010 if a patient had epistaxis that lasted for more than 30 minutes in any given 24 hour period it was classified as grade 2 bleeding. Also, in Heddle 2009 , ecchymoses larger than $10 \mathrm{~cm}$ in size were classified as grade 2 bleeding, whereas in Slichter 2010 purpura greater than $2.54 \mathrm{~cm}$ ( 1 inch) in diameter were classified as grade 2 bleeding.

\section{Quality of the evidence}

The ability to assess the quality of the evidence was limited by most of the studies not reporting study methodology in adequate detail. For example, allocation concealment was adequate in four studies and unclear in nine studies.

Two of the four studies that blinded the bleeding assessor documented compromise to the blinding process (Heddle 2009; Slichter 2010). This is likely to reflect the inherent difficulties with blinding platelet transfusion trials. Platelet dose trials have difficulties with blinding due to the different volumes of platelets to be transfused. Obviously, trials that compare therapeutic versus prophylactic transfusions or differing transfusion thresholds cannot blind the medical staff caring for the patient.

Overall, the highest quality of evidence was from the platelet dose study sub-category (Summary of findings 3 ). We felt that evidence from future trials would be likely to affect the results in all other sub-categories (Summary of findings for the main comparison; Summary of findings 2; Summary of findings 4).

\section{Potential biases in the review process}

There were no obvious biases within the review process. A wide search was conducted, the relevance of each paper identified was carefully assessed, and no restrictions were made for the language in which the paper was originally published.

\section{A U THORS' CONCLUSIONS}

\section{Implications for practice}

\section{Are prophylactic platelet transfusions superior to therapeutic platelet transfusions for the prevention and/or control of life-threatening thrombocytopenic bleeding?}

We are still unable to answer this question. There is no evidence to change current practice at the moment, and the results from the trials that have just completed recruitment are awaited (Stanworth 2010; Wandt 2009).

\section{Which threshold should be used to trigger the transfusion of prophylactic platelets?}

The evidence does not clearly show equivalence of a threshold of $10 \times 10^{9} / \mathrm{L}$ or $20 \times 10^{9} / \mathrm{L}$. However, without further evidence it is reasonable to continue with the current practice of a platelet transfusion threshold of $10 \times 10^{9} / \mathrm{L}$ in the absence of other risk factors for bleeding. This practice reduces platelet utilisation and donor exposure.

\section{What is the optimal prophylactic platelet dose to prevent thrombocytopenic bleeding?}

Most published guidelines do not suggest an optimal platelet dose for transfusion. The use of low dose prophylactic platelet transfusions for intensively treated in-patients and medium to high dose for outpatients could be considered. This would decrease the total platelet utilisation for inpatients. For out-patients it would decrease the frequency of day-unit attendances for transfusions, which could not only improve a patient's quality of life but also have resource and budget implications.

\section{Implications for research}

Are prophylactic platelet transfusions superior to therapeutic platelet transfusions for the prevention and/or control of life-threatening thrombocytopenic bleeding? 
We are awaiting evidence from the two trials in progress at the moment that compare a therapeutic versus prophylactic transfusion policy (Stanworth 2010; Wandt 2009). It is unlikely that any future trials will compare a policy of prophylactic platelet transfusions versus platelet-poor plasma.

\section{Which threshold should be used to trigger the transfusion of prophylactic platelets?}

The evidence for use of a platelet count threshold of $10 \times 10^{9} /$ $\mathrm{L}$ needs to be re-addressed. Conclusions on the non-inferiority of a platelet count threshold of $10 \times 10^{9} / \mathrm{L}$ compared to $20 \times 10$ $9 / \mathrm{L}$ or $30 \times 10^{9} / \mathrm{L}$ have been based on under-powered studies. However, whether the morning platelet count should be used to guide prophylactic platelet transfusions at all has recently been brought into question (Gerday 2009). Friedmann 2002 performed a large retrospective analysis that demonstrated no relationship between morning platelet count and bleeding risk and in the recent PLADO study the number of days on which WHO grade 2 or above bleeding occurred was similar (17\%) at platelet counts between $6 \times 10^{9} / \mathrm{L}$ and $80 \times 10^{9} / \mathrm{L}$.

\section{What is the optimal prophylactic platelet dose to prevent thrombocytopenic bleeding?}

If possible, further data are required from Slichter 2010 to assess whether there is an increase in the number of days with clinically significant bleeding at a low platelet transfusion dose. If this confirms that there is no difference in the number of days with bleeding overall and the mean number of days with bleeding per patient then no further studies are required.

\section{Assessment of bleeding in future trials}

One of the difficulties within this review was the variability between studies in assessing and grading bleeding. The WHO classification of bleeding, although widely used, has never been validated, and therefore the assumption that all grade 2 bleeding is clinically significant has been brought into question. For future studies an agreed international consensus on assessing and grading bleeding would greatly enhance the ability to compare platelet transfusion trials. This would need to be validated and to take into account the impact bleeding has upon the patient from both a medical perspective and with regard to their quality of life.

It is acknowledged that blinding in platelet transfusion trials is difficult. However, whenever possible, the bleeding assessor should be blinded to the intervention.

\section{ACKNOWLEDGEMENTS}

The editorial base of the Cochrane Haematological Malignancies Group.

We thank the study authors who provided unpublished data or who kindly searched for data but it was no longer available: $\mathrm{B}$ Diedrich; K Heckman; N Heddle; P Rebulla; K Sintnicolaas; A Tinmouth; M Zumberg.

We thank the authors on the previous review: S Brunskill; C Hyde; P Rebulla.

\section{R E F E R E N C E S}

\section{References to studies included in this review}

Diedrich 2005 \{published data only (unpublished sought but not used)\}

Diedrich B, Remberger M, Shanwell A, Svahn BM, Ringden O. A prospective randomised trial of a prophylactic platelet transfusion trigger of $10 \times 10^{9}$ per L versus $30 \times 10^{9}$ per $\mathrm{L}$ in allogeneic hematopoietic progenitor cell transplant recipients. Transfusion 2005;45:1064-72.

Heckman 1997 \{published and unpublished data\}

Heckman K, Weiner GJ, Strauss RG, Jones MP, Burns CP.

Randomized evaluation of the optimal platelet count for prophylactic platelet transfusions in patients undergoing induction therapy for acute leukaemia [American Society of Hematology 35th Annual Meeting]. Blood. 1993; Vol. 82, issue Abstract:192a.

* Heckman KD, Weiner GJ, Davis CS, Strauss RG, Jones MP, Burns CP. Randomized study of prophylactic platelet transfusion threshold during induction therapy for adult acute leukaemia: $10 \times 10^{9} / \mathrm{L}$ versus $20 \times 10^{9} / \mathrm{L}$. Journal of Clinical Oncology 1997;15:1143-9.

Heddle 2009 \{published and unpublished data\}

* Heddle NM, Cook RJ, Tinmouth A, Kouroukis CT,

Hervig T, Klapper E, et al.A randomized controlled trial comparing standard and low dose strategies for transfusion of platelets (SToP) to patients with thrombocytopenia. Blood 2009;113(7):1564-73.

Heddle NM, Wu C, Vassallo R, Carey P, Arnold D, Lozano $\mathrm{M}$, et al.Adjudicating bleeding events in a platelet dose study: impact on outcome results and challenges. Transfusion 2011;51:2304-10.

NCT00420914. Strategies for Transfusion of Platelets (SToP). http://clinicaltrials.gov/show/NCT00420914 (accessed September 15 2009).

Higby 1974 \{published data only\} Higby DJ, Cohen E, Holland JF, Sinks L. The prophylactic treatment of thrombocytopenic leukemic patients with platelets: a double blind study. Transfusion 1974;14:440-5.

Prophylactic platelet transfusion for prevention of bleeding in patients with haematological disorders after chemotherapy and stem cell 43 transplantation (Review) 
Murphy 1982 \{published data only\}

Murphy S, Litwin S, Herring LM, Koch P, Remischovky $\mathrm{J}$, Donaldson $\mathrm{MH}$, et al.Indications for platelet transfusion in children with acute leukemia. American Journal of Hematology 1982;12:347-56.

Rebulla 1997 \{published and unpublished data\} Cook RJ, Heddle NM, Rebulla P, Sigouin CS, Webert KE. Methods for the analysis of bleeding outcomes in randomised trials of platelet transfusion triggers. Transfusion 2004;44:1135-42.

GIMMEMA Group. Interim report from the platelet transfusion trigger trial (PTTT): a prospective controlled study on bleeding risk in acute myeloid leukaemia (AML) patients randomized to be transfused at 10 versus $20 \times 10^{9} /$ L platelets. Blood 1996;88(10):443a.

Heddle NM, Cook RJ, Sigouin C, Slichter SJ, Murphy M, Rebulla P. A descriptive analysis of international transfusion practice and bleeding outcomes in patients with acute leukaemia. Transfusion 2006;46:903-11.

* Rebulla P, Finazzi G, Marangoni F, Avvisati G, Gugliotta L, Tognoni G, et al.The threshold for prophylactic platelet transfusions in adults with acute myeloid leukaemia. New England Journal of Medicine 1997;337;337:1870-5. Webert KE, Cook RJ, Sigouin CS, Rebulla P, Heddle NM. The risk of bleeding in thrombocytopenic patients with acute myeloid leukaemia. Haematologica 2006;91(11): 1530-7.

Roy 1973 \{published data only\} Roy AJ, Jaffe N, Djerassi I. Prophylactic platelet transfusion in children with acute leukemia: A dose response study. Transfusion 1973;13(5):283-90.

Sensebe 2004 \{published data only (unpublished sought but not used)\} Sensebe L, Giraudeau B, Bardiaux L, Deconninck E, Ifrah $\mathrm{N}$, Bidet $\mathrm{M}-\mathrm{L}$, et al.Increasing dose improves the platelet transfusions: results of a prospective multicentre randomised study. Blood 2002;100:(Abstract 2789) 708a. * Sensebe L, Giraudeau B, Baridaux L, Deconinck E, Schmidt A, Bidet ML, et al.The efficiency of transfusing high doses of platelets in hematologic patients with thrombocytopenia: results of a prospective, randomized, open, blinded end point (PROBE) study. Blood 2004;105: 862-4.

Sintnicolaas 1982 \{published data only (unpublished sought but not used)\}

Sintnicolaas K, Velden K, Sizoo W, Haije WG, Abels J, Lowenberg B. Comparison of prophylactic and therapeutic single-donor platelet transfusions in patients with acute leukaemia.. British Journal of Haematology 1982;50:684.

Slichter 2010 \{published and unpublished data\}

Josephson C, Sloan S, Granger S, Castillejo M, Strauss RG, Slichter $S$, et al.Increased incidence of Grade 2 and higher bleeding in pediatric PLADO trial patients. Transfusion 2009;49(S3):19A-20A.

NCT00128713. Optimal platelet dose strategy for management of thrombocytopenia. http://clinicaltrials.gov/ show/NCT00128713. Accessed April 16th 2010. Slichter SJ. Background, rationale, and design of a clinical trial to Assess the effects of platelet dose on bleeding risk in thrombocytopenic patients. Journal of Clinical Apheresis 2006;21:78-84.

* Slichter SJ, Kaufman RM, Assmann SF, McCullough J, Triulzi DJ, Strauss RG, et al.Dose of prophylactic platelet transfusions and prevention of haemorrhage. New England Journal of Medicine 2010;362:600-13.

Slichter SJ, Kaufman RM, Assman SF, Brecher ME, Gernsheimer T, Hillyer CD, et al.Effects of prophylactic platelet (Plt) dose on transfusion (Tx) outcomes (PLADO trial). [50th Annual Meeting of the American Society of Hematology]. Blood 2008;112(11):Abstract 285.

Solomon 1978 \{published data only\}

Solomon J, Bofenkamp T, Fahey JL, Chillar RK, Beutler E. Platelet prophylaxis in acute non-lymphoblastic leukemia. The Lancet 1978;1 (8058): 267.

Steffens 2002 \{published data only (unpublished sought but not used)\} Steffens I, Harrison JF, Taylor CPF. A dose response study of platelet transfusion: comparison between triple dose apheresis platelet transfusion and three split standard transfusions. Haematologica 2002;87(Suppl 1):Various.

Tinmouth 2004 \{published and unpublished data\} Tinmouth A, Kotchetkova N, Tomlinson G, Crump M, Brandwein J, Tannock I, Sutton D. A randomised phase II trial of low dose and standard dose platelet transfusions during induction therapy for acute leukemia or autologous stem cell transplantation. Vox Sanguinis 2002;83 (Suppl 1): 8.

Tinmouth A, Tannock IF, Crump M, Tomlinson G, Brandwein J, Minden M, Sutton D. Low-dose prophylactic platelet transfusions in recipients of an autologous peripheral blood progenitor transplant and patients with acute leukaemia: a randomized controlled trial with a sequential Bayesian design. Transfusion Medicine 2004;44:1711-9.

\section{References to studies excluded from this review}

Aderka 1986 \{published data only\}

Aderka D, Praff G, Santo M, Weinberger A, Pinkhas J. Bleeding due to thrombocytopenia in acute leukaemias and reevaluation of the prophylactic platelet transfusion policy. American Journal of the Medical Sciences 1986;291:147-51.

\section{Agliastro 2006 \{published data only\}}

Agliastro RE, De Francisci G, Bonaccorso R, Spicola D, Ziino $\mathrm{O}$, Arico $\mathrm{M}$, et al.Clinical study in pediatric hematooncology patients:efficacy of pathogen inactivated platelets versus apheresis platelets. Transfusion 2006;46(9S):117A.

Akkök 2007 \{published data only\} Akkök CA, Brinch L, Lauritzsen GF, Solheim BG, KjelsdenKragh J. Clinical effect of buffy-coat vs. apheresis platelet concentrates in patients with severe thrombocytopenia after intensive chemotherapy. Vox Sanguinis 2007;93(1):42-8.

Anderson 1997 \{published data only\}

Anderson N A, Gray S, Copplestone JA, Chan DC, Hamon M, Prentice AG, et al.A prospective randomized study of three types of platelet concentrates in patients with haematological malignancy: corrected platelet count 
increments and frequency of nonhaemolytic febrile transfusion reactions. Transfusion Medicine 1997;7:33-9.

\section{Andrew 1993 \{published data only\}}

Andrew M, Vegh P, Caco C, Kirpalani H, Jefferies A, Ohlsson A, et al.A randomized controlled trial of platelet transfusions in thrombocytopenic premature infants. Journal of Pediatrics 1993;123(2):285-91.

Arnold 2004 \{published data only\} Arnold DM, Heddle NM, Carruthers J, Kulczycky M, Sigouin C, Blajchman MA. A randomized crossover trial comparing in-vivo platelet recovery and survival of leukoreduced apheresis and whole blood derived platelets. Transfusion 2004;44(supplement):1A.

\section{Arnold 2006 \{published data only\}}

Arnold DM, Crowther MA, Cook RJ, Sigouin C, Heddle NM, Molnar L, et al.Utilization of platelet transfusions in the intensive care unit: Indications, transfusion triggers, and platelet count responses. Transfusion 2006;46(8):1286-91.

Bai 2004 \{published data only\} Bai CM, Xu GX, Zhao YQ, Han SM, Shan YD. A multi-centre clinical trial of recombinant human thrombopoietin in the treatment of chemotherapy-induced thrombocytopenia in patients with solid tumor. Zhongguo Yi Xue Ke Xue Yuan Xue Bao Acta Academiae Medicinae Sinicae 2004;26(4):437-41.

\section{Bentley 2000 \{published data only\}}

Bentley M, Taylor K, Kelly C, Taylor D, Leach B, Rodwell $\mathrm{R}$, et al.Thrombopoietin derived autologous cryopreserved platelet support for peripheral blood progenitor cell transplantation. Haematology Society of Australia and New Zealand Annual Scientific Meeting. Perth, 2000.

\section{Blumberg 2002 \{published data only\}}

Blumberg N, Heal JM, Rowe JM. Platelet transfusion and clinical outcome in acute leukemia in adults. Transfusion 2002;42(9S):5S

\section{Blundell 1996 \{published data only\}}

Blundell EL, Pamphilon DH, Fraser ID, Kagen L, Menitove $\mathrm{JE}$, Aster RH, et al.A prospective randomised study of platelet concentrates irradiated with ultraviolet (UV)-B light in patients with high grade haematological malignancy. Blood 1992;80(10):215A.

Blundell EL, Pamphilon DH, Fraser ID, Menitove JE, Greeenwalt TJ, Snyder EL, et al.A prospective, randomized study of the use of platelet concentrates irradiated with ultraviolet-B light in patients with hematologic malignancy. Transfusion 1996;36(4):296-302.

\section{Callow 2002 \{published data only\}}

Callow CR, Swindell R, Randall W, Chopra R. The frequency of bleeding complications in patients with haematological malignancy following the introduction of a stringent prophylactic platelet transfusion policy. British Journal of Haematology 2002;118:677-82.
Cameron 2007 \{published data only\}

Cameron B, Rock G, Olberg B, Neurath D. Evaluation of platelet transfusion triggers in a tertiary-care hospital. Transfusion 2007;47(2):206-11.

\section{Carr 1990 \{published data only\}}

Carr R, Hutton JL, Jenkins JA, Lucas GF, Amphlett NW. Transfusion of ABO-mismatched platelets leads to early platelet refractoriness. British Journal of Haematology 1990; 75:408-13.

\section{Chaoui 2005 \{published data only\}} Chaoui D, Chakroun T, Robert F, Rio B, Belhocine R, Legrand $\mathrm{O}$, et al.Reticulated platelets: a reliable measure to reduce prophylactic platelet transfusions after intensive chemotherapy. Transfusion 2005;45(5):766-72.

\section{Cid 2007 \{published data only\}}

Cid J, Lozano M. Lower or higher doses for prophylactic platelet transfusions: results of a meta-analysis of randomized controlled trials. Transfusion 2007;47:464-70.

\section{Couban 2002 \{published data only\}}

Couban S, Carruthers J, Andreou P, Klama LN, Barr R, Kelton JG, et al.Platelet transfusions in children: results of a randomised prospective cross-over trial of plasma removal and a prospective audit of WBC reduction. Transfusion 2002;42:753-8.

Decaudin 2004 \{published data only\}

Decaudin D, Vantelon JM, Bourhis JH, Farace F, Bonnet ML, Guillier M, et al.Ex vivo expansion of megakaryocyte precursor cells in autologous stem cell transplantation for relapsed malignant lymphoma. Bone Marrow Transplantation 2004;34(12):1089-93.

de Wildt-Eggen 2000 \{published data only\} De Wildt-Eggen J, Nauta S, Schrijver JG, van Marwijk KM, Bins M, van Prooijen HC, et al.Reactions and platelet increments after transfusion of platelet concentrates in plasma or an additive solution: a prospective, randomized study. Transfusion 2000;40(4):398-403.

\section{Diedrich 2009 \{published data only\}}

Diedrich B, Ringden O, Watz E, Shanwell A. A randomised study of buffy coat platelets in platelet additive solution 1-5 versus 6-7 days prior to prophylactic transfusion of allogeneic haematopoietic cell transplant recipients. Vox Sanguinis 2009;97(3):254-9.

Diedrich B, Watz E, Ringden O, Shanwell A. A randomized study in allogeneic haematopoietic stem cell transplant recipients comparing prophylactic transfusion of buffy coat platelets stored for 1-5 vs. 6-7 days. Vox Sanguinis 2008;95 (Supp 1):Abstract.

\section{Dumont 2011 \{published data only\}}

Dumont LJ, Dumont DF, Unger ZM, Siegel A, Szczepiorkowski ZM, Corson JS, et al.A randomized controlled trial comparing autologous radiolabeled in vivo platelet(plt) recoveries and survivals of 7-day-stored pltrich plasma and buffy coat plts from the same subjects. Transfusion 51;6:1241-8. 
Eder 2007 \{published data only\}

Eder AF, Kennedy JM, Dy BA, Notari EP, Weiss JW, Fang CT, et al.Bacterial screening of apheresis platelets and the residual risk of septic transfusion reactions: The American Red Cross Experience (2004-2006). Transfusion 2007;47 (7):1134-42.

Elting 2002 \{published data only\}

Elting LS, Martin CG, Kurtin DJ, Cantor SB, Rubenstein $\mathrm{EB}$, Rodirguez $\mathrm{S}$, et al.The bleeding risk index: a clinical prediction rule to guide the prophylactic use of platelet transfusions in patients with lymphoma or solid tumors. Cancer 2002;94(12):3252-62.

Elting 2003 \{published data only\}

Elting LS, Cantor SB, Martin CG, Hamblin L, Kurtin D, Rivera E, et al.Cost of chemotherapy-induced thrombocytopenia among patients with lymphoma or solid tumors. Cancer 2003;97(6):1541-50.

Fanning 1995 \{published data only\}

Fanning J, Hilgers RD, Murray KP, Bolt K, Aughenbaugh DM. Conservative management of chemotherapy-induced thrombocytopenia in women with gynecological cancers. Gynecologic Oncology 1995;59:191-3.

Follea 2004 \{published data only\} Follea G. Homologous platelet concentrates: products available and utilisation rules in oncology and haematology. Hematologie 2004;10(3):233-44.

Friedmann 2002 \{published data only\} Friedmann AM, Sengul H, Lehmann H, Schwartz C, Goodman S. Do basic laboratory tests or clinical observations predict bleeding in thrombocytopenic oncology patients?. Transfusion Medicine Reviews 2002;16: $34-45$.

Gajic 2006 \{published data only\}

Gajic O, Dzik WH, Toy P. Fresh frozen plasma and platelet transfusion for non-bleeding patients in the intensive care unit: Benefit or harm?. Critical Care Medicine 2006;35(5 Suppl):S170-3.

Gerday 2009 \{published data only\} Gerday E, Baer VL, Lambert DK, Pau DA, Sola-Visner MC, Pysher TJ, et al.Testing Platelet mass versus platelet count to guide platelet transfusions in the neonatal intensive care unit. Transfusion 2009;49:2034-9.

Gil-Fernandez 1996 \{published data only\}

Gil-Fernandez JJ, Alegre A, Fernandez-Villalta MJ, Pinilla I, Gomez Garcia V, Martinez C, et al.Clinical results of a stringent policy on prophylactic platelet transfusion: nonrandomized comparative analysis in 190 bone marrow transplant patients from a single institution. Bone Marrow Transplantation 1996;18:931-5.

Gmur 1983 \{published data only\}

Gmur J, von Felten A, Osterwalder B, Honegger H, Hermann A, Sauter C, et al.Delayed alloimmunization using random single donor platelet transfusions: a prospective study in thrombocytopenic patients with acute leukemia. Blood 1983;62(2):473-9.
Gmur 1991 \{published data only\}

Gmür J, Burger J, Schanz U, Fehr J, Schaffner A. Safety of stringent prophylactic platelet transfusion policy for patients with acute leukaemia. The Lancet 1991;338:1223-6.

Goodnough 2001 \{published data only\} Goodnough LT, Kuter DJ, McCullough J, Slichter SJ, DiPersio J, Romo J, et al.Prophylactic platelet transfusions from healthy apheresis platelet donors undergoing treatment with thrombopoietin.. Blood 2001;98(5):1346-51.

Goodrich 2008 \{published data only\}

Goodrich R, Follua G, Roberts T. Clinical evaluation of Mirasol PRT treated apheresis platelets in thrombocytopenic patients. Transfusion 2008;48(S2):20A.

Greeno 2007 \{published data only\}

Greeno E, McCullough J, Weisdorf D. Platelet utilisation and the transfusion trigger: A prospective analysis. Transfusion 2007;72(2):201-5.

Gurkan 2007 \{published data only\} Gurkan E, Patah PA, Saliba RM, Ramos CA, Anderson $\mathrm{BS}$, Champlin R, et al.Efficacy of prophylactic transfusions using single donor apheresis platelets versus pooled platelet concentrates in AML/MDS patients receiving allogeneic hematopoietic stem cell transplantation. Bone Marrow Transplantation 2007;40(5):461-4.

Hardan 1994 \{published data only\} Hardan I, Sofer O, Shpilberg O, Ra’anani P, Ben-Bassat I. Safety of stringent prophylactic platelet transfusion (PT) policy for lymphoma patients treated by high dose chemotherapy (HDC) and autologous stem cell support. [20th Annual Meeting of the European Group for Bone Marrow Transplantation and 10th Meeting of the Nurses Group.]. Bone Marrow Transplant 1994;14(Supplement): Abstract 330.

\section{Harrup 1999 \{published data only\}} Harrup RA, Kennedy JT, Kiss J, Daniels B. Randomised blinded comparison of buffy coat plasma or T-sol supported platelet transfusions. Haematology Society of Australia and New Zealand Annual Scientific Meeting. Hobart; Tasmania, 1999.

Heal 1993 \{published data only\}

Heal J, Kemmotsu N, Rowe J, Blumberg N. A survival advantage in leukaemics receiving $\mathrm{ABO}$ identical platelets. Blood 1991;78:349a.

Heal J, Rowe J, Blumberg N. The importance of ABO identical platelet transfusions. Blood 1991;78:348a. Heal J, Rowe J, McMican A, Finke K, Blumberg N. A randomised trial of $\mathrm{ABO}$ identical versus $\mathrm{ABO}$ unmatched platelet transfusions. Blood 1989;74(7 Supp 1):215a. ${ }^{*}$ Heal JM, Rowe JM, McMican A, Masel D, Finke C, Blumberg $\mathrm{N}$. The role of $\mathrm{ABO}$ matching in platelet transfusion. European Journal of Haematology 1993;50: $110-7$.

Heddle 1994 \{published data only\} Heddle NM, Klama L, Singer J, Richards C, Fedak P, Walker I, et al.The role of the plasma from platelet 
concentrates in transfusion reactions. New England Journal of Medicine 1994;331(10):625-8.

Heddle 1999 \{published data only\}

Heddle NM, Klama L, Meyer R, Walker I, Boshkov L, Roberts $\mathrm{R}$, et al.A randomized controlled trial comparing plasma removal with white cell reduction to prevent reactions to platelets. Transfusion 1999;39(3):231-8.

Heddle 2002 \{published data only\}

Heddle NM, Blajchman MA, Meyer RM, Lipton JH, Walker IR, Sher GD, et al.A randomized controlled trial comparing the frequency of acute reactions to plasmaremoved platelets and prestorage WBC-reduced platelets. Transfusion 2002;42(5):556-566.

\section{Heddle 2003 \{published data only\}}

Heddle NM, Cook RJ, Webert KE, Sigouin C, Rebulla P. Methodologic issues in the use of bleeding as an outcome in transfusion medicine studies. Transfusion 2003;43:742-52.

Hilbom 2008 \{published data only\}

Hillbom ME. Platelet Transfusion in Acute Intracerebral Haemorrhage. Clinical Trials.gov 2008; Vol. NA, issue NA: webpage.

ISRCTN49080246 \{published data only\}

ISRCTN49080246. Platelet Process Improvement Project. http://www.controlled-trials.com/ISRCTN49080246.

Johansson 2007 \{published data only\}

Johansson PI, Stensballe J, Rosenberg I, Hisløv TL, Jørgensen L, Secher NH. Proactive administration of platelets and plasma for patients with a ruptured abdominal aortic aneurysm: evaluating a change in transfusion practice. Transfusion 2007;47(4):593-8.

Julmy 2009 \{published data only\}

Julmy F, Ammann RA, Taleghani BM, Fontana S, Hirt A, Leibundgut K. Transfusion efficacy of ABO majormismatched platelets (PLTS) in children is inferior to that of ABO-identical platelets. Transfusion 2009;91(1):21-33.

Kakaiya 1981 \{published data only\}

Kakiya RM, Hezzey AJ, Bove JR, Katz AJ, Genco PV, Buchholz DH, et al.Alloimmunization following apheresis platelets vs. pooled platelet concentrates. A prospective randomized study. Transfusion 1981;21(5):600.

Kerkhoffs 2010 \{published data only\}

Kerkhoffs JH, Novotny VM, Te Boekhorst PA, Schipperus MR, Zwaginga JJ, van Pampus I, et al.Clinical effectiveness and safety of pooled, random donor platelet concentrates, leucoreduced and stored up to seven days in either plasma or additive solution with and without pathogen reduction in hemato-oncological patients. Transfusion 2009;49(s3):2A. Kerkhoffs JL, van Putten WL, Novotny VM, Te Boekhorst PA, Schipperus MR, Zwaginga JJ, et al.Clinical effectiveness of leucoreduced, pooled donor platelet concentrates, stored in plasma or additive solution with and without pathogen reduction. British Journal of Haematology 2010;150(2): 209-17.
Klumpp 1999 \{published data only\}

Ackerman SJ, Klumpp TR, Guzman GI, Herman JH, Gaughan JP, Bleecker GC, et al.Economic consequences of alterations in platelet transfusion dose: analysis of a prospective, randomized, double-blind trial. Transfusion 2000;40(12):1457-62.

Hermann JH, Klumpp TR, Christman RA, Russo RR, Goldberg SL, Mangan KF. The effect of platelet dose on the outcome of prophylactic platelet transfusion. 48th Annual Meeting of the American Association of Blood Banks November 1995;35(10s):46S.

Klumpp TR, Herman JH, Gaughan JP, Russo RR, Christman RA, Goldberg SL, et al.Clinical consequences of alterations in platelet dose: a prospective, randomized, double-blind trial. Transfusion 1999;39:674-81.

Lapierre 2003 \{published data only\}

Lapierre V, Benhamou E, Tramalloni D, Brault P, ValteauCouanet D, Ducourtieux M, et al.A randomised trial of platelet transfusion policies after blood stem cell transplantation in young children: reduction of number of single platelet concentrate donors per child. European Group for Blood and Bone Marrow Transplantation Annual Congress. Istanbul, Turkey, 2003:P756.

Lawrence 2001 \{published data only\}

Lawrence JB, Yomtovian RA, Hammons T, Masarik SR, Chongkolwatana V, Cregar RJ, et al.Lowering the prophylactic platelet transfusion threshold: a prospective analysis. Leukemia \& Lymphoma 2001;41:67-76.

Leach 1991 \{published data only\} Leach MF, Fairweather RB, Aubuchon JP. Use of warmed single donor platelets in autologous bone marrow transplant patients. Transfusion 1991;31(Suppl):20S.

Lee 1989 \{published data only\}

Lee EJ, Schiffer CA. ABO compatibility can influence the results of platelet transfusion. Results of a randomized trial. Transfusion 1989;29(5):384-9.

\section{Lozano 2010 \{published data only\}}

Lozano M, Knutson F, Tardivel R, Cid J, Maymó R, Löf H, et al.Frequency of prophylactic transfusion failure: a novel outcome to evaluate platelet components stored more than 5 days. Transfusion 2010;50(Supp 2):25A-26A.

Lozano 2011 \{published data only\}

Lozano M, Knutson F, Tardivel R, Cid J, Maymó RM, Löf $\mathrm{H}$, et al.A multi-centre study of therapeutic efficacy and safety of platelet components treated with amotsalen and ultraviolet A pathogen inactivation stored for 6 or $7 \mathrm{~d}$ prior to transfusion. British Journal of Haematology 2011;153(3): 393-401.

McCullough 2004 \{published data only\} Benjamin RJ, Goodnough LT, Lopez-Perez I, Strauss R, McCullough J, Slichter $S$, et al.Fresh (1-2 day-old) vs. aged (4-5 day-old) INTERCEPT platelets and conventional platelets provide comparable count increments. However

Prophylactic platelet transfusion for prevention of bleeding in patients with haematological disorders after chemotherapy and stem cell 
fresh platelets result in superior hemostasis: results of the SPRINT trial. Transfusion 2003;43(9S):9A.

Goodnough LT, McCullough J, Slichter S, Strauss R, Lin J, Conlan M. A platelet transfusion threshold of $20 \times 10^{9} /$ $\mathrm{L}$ compared to $10 \times 10^{9} / \mathrm{L}$ is associated with increased pretransfusion bleeding and increased platelet transfusions: results of the SPRINT study. Transfusion 2002;42(9S):17S. Kluter H, Chapuis B, Cazenave J, Hastka J, Beris P, Dufour $\mathrm{P}$, et al.Apheresis platelets treated with the INTERCEPT Blood System for pathogen inactivation provide platelet count increments and hemostasis comparable to conventional platelets. Vox Sanguinis 2002;83(Suppl 1): 110a.

* McCullough J, Vesole DH, Benjamin RJ, Slichter SJ, Pineda A, Synder E, et al.Therapeutic efficacy and safety of platelets treated with a photochemical process for pathogen inactivation: the SPRINT Trial. Blood 2004;104(5): 1534-41.

Murphy S, Slichter S, McCullough J, Strauss R, Wood L, Lin J, et al.INTERCEPT platelets are hemostatically as effective as conventional platelet in the prophylaxis and treatment of bleeding: results of the SPRINT trial. Vox Sanguinis 2002;83(109):Abstract.

Murphy S, Synder E, Cable R, Slichter SJ, Strauss RG, McCullough J, et al.Platelet dose consistency and its effect on the number of platelet transfusions for support of thrombocytopenia: an analysis of the SPRINT trial of platelets photochemically treated with amotosalen $\mathrm{HCl}$ and ultraviolet A light. Transfusion 2006;46(1):24-33. Slichter SJ, Murphy S, Buchholz D, Lin J, Corash L, Conlan M. INTERCEPT platelets (plts) and conventional plts provide comparable hemostatic response in thrombocytopenic patients: the SPRINT trial. Blood 2002 2002;11(Pt 2): 141 b.

Strauss RG, Slichter S, Lopez-Plaza I, Goodnough LT, McCullough J, Lin J, et al.Intercept platelets exhibit immunological refractoriness comparable to conventional platelets. Haematologica 2004;89(Suppl 1):Various.

Messerschmidt 1988 \{published data only\} Messerschmidt GL, Makuch R, Appelbaum F, Ungerleider RS, Abrams R, O'Donnell J, et al.A prospective randomized trial of HLA-matched versus mismatched single-donor platelet transfusions in cancer patients. Cancer 1988;62(4): 795-801.

Mirasol 2010 \{published data only\}

The Mirasol Clinical Evaluation Study Group. A randomized controlled clinical trial evaluating the performance and safety of platelets treated with MIRASOL pathogen reduction technology. Transfusion 2010;50: 2362-2375.

Murphy 1986 \{published data only\}

Murphy MF, Metcalfe P, Thomas H, Eve J, Ord J, Lister TA, et al.Use of leucocyte-poor blood components and HLAmatched-platelet donors to prevent HLA alloimmunization. British Journal of Haematology 1986;62:529-34.

Navarro 1998 \{published data only\}

Navarro J-T, Hernandez J-A, Ribera J-M, Sancho J-M,
Oriol A, Pujol M, Milla F, Feliu E. Prophylactic platelet transfusion threshold during therapy for adult acute myeloid leukemia: 10,000/mL. Haematologica 1998;83:998-1000.

Nevo 2007 \{published data only\}

Nevo S, Fuller AK, Borinsky ME, Vogelsang GB. Acute Bleeding Complications in patients after haematopoietic stem cell transplantation triggers of $10 \times 10^{9}$ and $20 \times 10^{9}$ per L. Transfusion 2007;47:801-12.

Norol 1998 \{published data only\} Norol F, Bierling P, Roudot-Thoraval F, Ferrer Le Coeur F, Rieux C, Lavaux A, et al.Platelet transfusion: a dose response study. Blood 1998;92:1448-53.

\section{Oksanen 1991 \{published data only\}}

Oksanen K, Kekomaki R, Ruutu T, Koskimies S, Myllyla G. Prevention of alloimmunization in patients with acute leukemia by use of white cell-reduced blood components: A randomized trial. Transfusion 1991;31:588-94.

\section{Oksanen 1994 \{published data only\}} Oksanen K, Ebeling F, Kekomäki R, Elonen E, Sahlstedt L, Volin L, et al.Adverse reactions to platelet transfusions are reduced by use of platelet concentrates derived from buffy coat. Vox Sanguinis 1994;67(4):356-61.

\section{Paananen 2009 \{published data only\}}

Paananen P, Arola MO, Pelliniemi TT, Salmi TT, Lähteenmäki PM. Evaluation of the effects of different transfusion trigger levels during the treatment of childhood acute lymphoblastic leukemia. Journal of Pediatric Haematology/Oncology 2009;31(10):745-9.

Qureshi 2007 \{published data only\} Qureshi H, Lowe D, Dobson P, Grant-Casey J, Parris E, Dalton D, et al.National comparative audit of the use of platelet transfusions in the UK. Transfusion Clinique Et Biologique 2007;14(6):509-13.

\section{Rabinowitz 2010 \{published data only\}} Rabinowitz I. Dose of prophylactic platelet transfusions did not affect bleeding incidence or severity. ACP Journal Club 2010;152(6): 11 .

Reed 1986 \{published data only\}

Reed RL, Ciavarella D, Heimbach DM, Baron L, Pavlin E, Counts RB, et al.Prophylactic platelet administration during massive transfusion. A prospective, randomized, double-blind clinical study. Annals of Surgery 1986;203(1): $40-8$.

\section{Sagmeister 1999 \{published data only\}}

Sagmeister M, Oec L, Gmur J. A restrictive platelet transfusion policy allowing long term support of outpatients with severe aplastic anaemia. Blood 1999;93:3124-26.

\section{Samama 2005 \{published data only\}}

* Samama CM, Djoudi R, Lecompte T, Nathan DN, Schved JF. Perioperative platelet transfusion: recommendations of the Agence Francaise de Securite Sanitaire des Produits de Sante (AFSSaPS) 2003. Canadian Journal of Anaesthesia 2005;52(1):30-7.

Samama CM, Djoudi R, Lecompte T, Nathan N, Schved JF. Perioperative platelet transfusion. Recommendations 
of the French Health Products Safety Agency (AFSSAPS) 2003. Minerva Anestesiologica 2006;72(6):447-52.

\section{Schiffer 1983 \{published data only\}}

Schiffer CA, Dutcher JP, Aisner J, Hogge D, Wiernik PH, Reilly JP, et al.A randomized trial of leukocyte-depleted platelet transfusion to modify alloimmunization in patients with leukemia. Blood 1983;62:815-20.

Shanwell 1992 \{published data only\}

Shanwell A, Larsson S, Aschan J, Ringden O. A randomized trial comparing the use of fresh and stored platelets in the treatment of bone marrow transplant recipients. European Journal of Haematology 1992;49(2):77-81.

Shehata 2009 \{published data only\}

Shehata, N, Tinmouth, A, Naglie, G, Freedman, J, Wilson, $\mathrm{K}$. ABO-identical versus non-identical platelet transfusion: a systematic review. Transfusion 2009;49:2442-53.

Singer 1988 \{published data only\}

Singer J, Ali AM, Warkentin TE, Blajchman MA, Kelton JG. A prospective randomized study of platelet support in leukemic patients. Transfusion 1988;72(5 Supp):285A.

Sintnicolaas 1995 \{published data only\}

Sintnicolaas K, van Marwijk Kooij M, van Prooijen H C, van Dijk BA, van Putten WL, Claas FH, et al.Leukocyte depletion of random single-donor platelet transfusions does not prevent secondary human leukocyte antigenalloimmunization and refractoriness: A randomized prospective study. Blood 1995;85:824-8.

Slichter 2006 \{published data only\}

Slichter SJ, Raife TJ, Davis K, Rheinschmidt M, Buchholz $\mathrm{DH}$, Corash L, et al.Platelets photochemically treated with amotsalen $\mathrm{HCl}$ and ultraviolet A light correct prolonged bleeding times in patients with thrombocytopenia. Transfusion 2006;46(5):731-40.

Speiss 2004 \{published data only\}

Spiess BD, Royston D, Levy JH, Fitch J, Dietrich W, Body $S$, et al.Platelet transfusions during coronary artery bypass graft surgery are associated with serious adverse outcomes. Transfusion 2004;44(8):1143-8.

Strindberg 1996 \{published data only\}

Strindberg J, Berlin G. Transfusion of platelet concentratesclinical evaluation of two preparations. European Journal of Haematology 1996;57(4):307-11.

\section{Sweeney 2000 \{published data only\}} Sweeney JD, Kouttab NM, Penn CL, McHugh KE, Nelson EJ, Oblon DJ. A comparison of prestorage WBC-reduced whole blood derived platelets in autologous progenitor cell transplant. Transfusion 2000;40(7):794-800.

Tosetto 2009 \{published data only\}

Tosetto A, Balduini CL, Cattaneo M, De Candia E, Mariani G, Molman AC, et al.Management of bleeding and of invasive procedures in patients with platelet disorders and/ or thrombocytopenia: Guidelines of the Italian Society for Haemostasis and Thrombosis (SISET). Thrombosis Research 2009;125(5):e13-8.

\section{TRAP 1997 \{published data only\}}

Enright H, Davis K, Gernsheimer T, McCullough JJ, Woodson R, Slichter SJ. Factors influencing moderate to severe reactions to PLT transfusions: experience of the TRAP multicenter clinical trial.. Transfusion 2003;43(11): $1545-52$.

* The Trial to Reduce Alloimmunization to Platelets Study Group. Leukocyte reduction and ultraviolet B irradiation of platelets to prevent alloimmunization and refractoriness to platelet transfusions. New England Journal of Medicine 1997;337:1861-70.

\section{Vadhan-Raj 2002 \{published data only\}}

Vadhan-Raj S, Kavanagh JJ, Freedman RS, et al.Safety and efficacy of transfusions of autologous cryopreserved platelets derived from recombinant human thrombopoietin to support chemotherapy-associated severe thrombocytopenia: a randomised cross-over study. Lancet 2002;359:2145-52.

Van Marwijk 1991 \{published data only\}

Van Marwijk KM, van Prooijen HC, Moes M, Bosmastants I, Akkerman JW, et al.Use of leukocyte-depleted platelet concentrates for the prevention of refractoriness and primary HLA alloimmunization: A prospective, randomized trial. Blood 1991;77:201-5.

\section{van Rhenen 2003 \{published data only\}}

Cazenave JP, Davis K, Corash L. Design of clinical trials to evaluate the efficacy of platelet transfusion: the euroSPRITE trial for components treated with Helinx technology. Seminars in Hematology 2001;38(4 Supp 11):46-54. Cazenave JP, van Rhenen D, Gulliksson H, Pamphilon $\mathrm{D}$, Ljungman P, Davis K, et al.INTERCEPT buffy coat platelets (IPC) are effective during multiple episodes of thrombocytopenia: the EUROSPRITE trial. Transfusion Clinique et Biologique 2001;8(Supp 1):Various.

Ljungman P, van Rhenen D, Pamphilon D, Metzel P, Marblie S, Lin J, et al.Results of the EUROSPRITE phase III trial: INTERCEPT buffy coat platelet concentrates (IPC) provide effective hemostasis for thrombocytopenic (TCP) patients (PTS). Transfusion Clinique et Biologique 2001;8(Supp 1):100s.

Pamphilon D, Buchholz DH, Cazenave JP, Conlan M, Corash L, Davis K, et al.The EUROSPRITE phase III trial of INTERCEPT buffy coat platelet concentrates (IPC) demonstrates IPC are safe when transfused to thrombocytopenic (TCP) patients (PTS). Transfusion Clinique et Biologique 2001;8(Supp 1):100-1s. * van Rhenen D, Gulliksson H, Cazenave JP, Pamphilon D, Ljungman P, Kluter H, et al.Transfusion of pooled buffy coat platelet components prepared with photochemical pathogen inactivation treatment: the euroSPRITE trial. Blood 2003;101(6):2426-33.

Verma 2008 \{published data only\}

Verma A, Pandey P, Khetan D, Chaudhary R. Platelet transfusions in clinical practice at a multidisciplinary hospital in North India. Transfusion and Apheresis Science 2008;39(1):29-35. 
Wandt 1998 \{published data only\}

* Wandt H, Frank M, Ehninger G, Schneider C, Brack N, Daoud A, et al.Safety and cost effectiveness of a $10 \times 10^{9} / \mathrm{L}$ trigger for prophylactic platelet transfusions compared with the traditional $20 \times 10^{9} / \mathrm{L}$ trigger: a prospective comparative trial in 105 patients with acute myeloid leukaemia. Blood 1998;91:3601-6.

Wandt H, Frank M, Link H, Schneider C, Brack N, Daoud A, et al.The 10/NL trigger for prophylactic platelet transfusion in AML: a prospective comparative multicenter study. Annals of Hematology 1995;70(Suppl 1):A140.

Wandt 2005 \{published data only\}

Wandt H, Frank M, Schaefer-Eckart K, Wilhelm M. Routine prophylactic platelet transfusions Are not necessary in patients with acute myeloid leukaemia. A therapeutic transfusion strategy is safe. Blood 2005;106(11):Abstract. Wandt H, Reinel H, Schaefer-Eckart K, Wilhelmi M, Birkmann J, Gallmeier WM. New strategy for platelet transfusion for patients with acute myeloid leukaemia: routine prophylactic transfusion replaced by therapeutic transfusion. Blood 2002;100((Abstract 2782)):706a.

\section{Wandt 2006 \{published data only\}}

Wandt H, Schaefer-Eckart K, Frank M, Birkmann J, Wilhelm M. A therapeutic platelet transfusion strategy is safe and feasible in patients after autologous peripheral blood stem cell transplantation. Bone Marrow Transplant 2006;37(4):387-92.

\section{Wang 2002 \{published data only\}}

Wang SE, Lara PN, Lee OA, Reed J, Wang LR, Palmer P, et al.Acetaminophen and diphenhydramine as premedication for platelet transfusions: a prospective randomized double-blind placebo-controlled trial. American Journal of Hematology 2002;70(3):191-4.

Weigand 2009 \{published data only\}

Weigand K, Encke J, Meyer FJ, Hinkel UP, Munder M, et al.Low levels of prothrombin (INR) and platelets do not increase the risk of significant bleeding when placing central venous catheters. Medizinische Klinik 2009;104(5):331-5.

Williamson 1994 \{published data only\}

Williamson LM, Wimperis JZ, Williamson P, Copplestone JA, Gooi HC, Morgenstern GR, et al.Bedside filtration of blood products in the prevention of HLA alloimmunization: A prospective randomized study. Alloimmunization Study Group. Blood 1994;83:3028-35.

Zahur 2002 \{published data only\}

Zahur UR, Alam M. Platelet transfusion practice in a tertiary care hospital. Medical Forum Monthly 2002;13(7): 27-9.

Zhao 2002 \{published data only\}

Zhao SM, Cheng XL, Hu J, Xiang GC, Zhang JS, Li RQ. Clinical assessment of preventing febrile nonhemolytic transfusion reaction by leucocyte depleted blood transfusion. Zhongguo Shi Yan Xue Ye Xue Za Zhi 2002;10(6):568-70.

Zumberg 2002 \{published and unpublished data\} Zumberg MS, del Roario ML, Nejame CF, Pollock BH, Garzarella L, Kao KJ, et al.A prospective randomized trial of prophylactic platelet transfusion and bleeding incidence in hematopoietic stem cell transplant Recipients: 10,000/ $\mu \mathrm{L}$ versus $20,000 / \mu \mathrm{L}$ Trigger. Biology of Blood and Marrow Transplantation 2002;8:569-76.

\section{References to ongoing studies}

Franklin 1995 \{published data only\}

Franklin IM. Clinical efficacy of platelet transfusions. Within previous version of this cochrane review. Stanworth 2004.

Lu 2011 \{published data only\}

Lu FQ, Wang WM, Yu M. Effect of reducing prophylactic platelet transfusion dose on bleeding in thrombocytopenic patients. Vox Sanguinis 2011;101(S1):310 (P-577).

\section{NCT00180986 \{published data only\}}

NCT00180986. Randomized trial of platelet transfusion policies after blood stem cells transplantation In young children: Reduction of number of single platelet concentrate donors per child. http://clinicaltrials.gov/show/ NCT00180986. Accessed March 5th 2010.

\section{Stanworth 2010 \{published data only\}}

ISRCTN08758735. A randomised controlled trial of prophylactic versus no-prophylactic platelet transfusions in patients with haematological malignancies. http:// www.controlled-trials.com/ISRCTN08758735. Accessed February 6th 2010

* Stanworth SJ, Dyer C, Choo L, Bakrania L, Copplestone A, Llewelyn C, et al.Do all patients with hematologic malignancies and severe thrombocytopenia need prophylactic platelet transfusions? Background, rationale, and design of a clinical trial (trial of platelet prophylaxis) to assess the effectiveness of prophylactic platelet transfusions. Transfusion Medicine Reviews 2010;24(3):163-71.

\section{Wandt 2009 \{published data only\}}

NCT00521664. A Trial Comparing a Prophylactic With a Therapeutic Platelet Strategy in Two Groups. http:// clinicaltrials.gov/show/NCT00521664. Accessed January 4th 2010.

Schaefer-Eckart K, Wendelin K, Wilhelm M, Mahlknecht $\mathrm{U}$, Conradi R, Schaich M, et al.Interim analysis of a prospective randomised study comparing a therapeutic platelet strategy with the prophylactic platelet transfusion standard in patients after autologous peripheral stem cell transplantation (ASCT) [48th Annual Meeting of the American Society of Hematology]. Blood 2006;108(11): (Abstract).

Wandt H, Schaefer-Eckart K, Pilz B, Thalheimer M, Ho A, Schaich M, et al.Experience with a therapeutic platelet transfusion strategy in patients with acute myeloid leukemia. Final results of a randomized multicenter study comparing a prophylactic with a therapeutic transfusion strategy. Onkologie 2010;33(6):(Abstract).

Wandt H, Schaefer-Eckart K, Pilz B, Thalheimer M, Ho AD, Schaich M, et al.Experience with a therapeutic platelet transfusion strategy in acute myeloid leukaemia: Preliminary results of a randomised multicenter study 
after enrolment of 175 patients [51st ASH Meeting and Exposition]. Blood 2009;11(Supplement):(Abstract). * Wandt H, Schäfer-Eckart K, Wendelin K, Rottmann M, Thalmeimer M, Schubert MS, et al.A therapeutic platelet transfusion strategy without routine prophylactic transfusion is feasible and safe and reduces platelet transfusion numbers significantly: final analysis of a randomised study after high-dose chemotherapy and PBSCT. Bone Marrow Transplantation 2009;43 Supp 1: S23.

Wandt H, Wendelin K, Schaefer-Eckart K, Thalheimer M, Schubert MS, Conradi R, et al.Therapeutic platelet transfusion strategy without routine prophylactic transfusion Is feasible and safe and reduces platelet transfusion numbers significantly: preliminary analysis of a randomized study in patients after high dose chemotherapy and autologous peripheral blood stem cell transplantation. Blood (ASH Annual Meeting Abstracts) 2008;112:Abstract 286.

\section{Additional references}

\section{Ajani 1990}

Ajani JA, Welsh SR, Raber MN. Comprehensive criteria for assessing therapy-induced toxicity. Cancer Investigation 1990;8:141-53.

\section{BCSH 2003}

British Committee for Standards in Haematology (BCSH). Guidelines for the use of platelet transfusions. British Journal of Haematology 2003;122:10-23.

\section{Beutler 1993}

Beutler E. Platelet transfusions: the $20,000 / \mu \mathrm{L}$ trigger. Blood 1993;81:1411-3.

\section{Blajchman 1981}

Blajchman MA, Senyi AF, Hirsh J, Genton E, George JN. Hemostatic function, survival, and membrane glycoprotein changes in young versus old rabbit platelets. Journal of Clinical Investigation 1981;68:1289-94.

Blajchman 2008

Blajchman MA, Slichter SJ, Heddle NM, Murphy MF. New Strategies for the Optimal Use of Platelet Transfusions. Hematology (American Society of Hematology Education Program) 2008:198-204.

\section{Cook 2004}

Cook RJ, Heddle NM, Rebulla P, Sigouin CS, Webert KE. Methods for the analysis of bleeding outcomes in randomized trials of platelet transfusion triggers. Transfusion 2004;44:1135-42.

\section{Deeks 2011}

Deeks JJ, Higgins JPT, Altman DG (editors). Chapter 9: Analysing data and undertaking meta-analyses. In: Higgins JPT, Green S (editors). Cochrane Handbook for Systematic Reviews of Interventions Version 5.1.0 (updated March 2011). The Cochrane Collaboration, 2011. Available from www.cochrane-handbook.org.

\section{Duke 1910}

Duke WW. The relation of blood platelets to hemorrhagic disease. Description of a method for determining the bleeding time and coagulation time and report of 3 cases of hemorrhagic disease relieved by transfusion. Journal of the American Medical Association 1910;55:1185-92.

\section{Estcourt 2011a}

Estcourt LJ, Birchall J, Lowe D, Grant-Casey J, Rowley M, Murphy MF. Analysis of current patterns of utilisation of platelet transfusion components in hematology patients. Transfusion 2011;51(Supplement):188A.

\section{Estcourt 2011b}

Estcourt LJ, Stanworth SJ, Murphy MF. Platelet transfusions for patients with haematological malignancies: who needs them?. British Journal of Haematology 2011;154(4):425-40.

\section{Gaydos 1962}

Gaydos LA, Freireich EJ, Mantel N. The quantitative relation between platelet count and hemorrhage in patients with acute leukaemia. New England Journal of Medicine 1962;266:905-9.

\section{Hanson 1985}

Hanson SR, Slichter SJ. Platelet kinetics in patients with bone marrow hypoplasia: evidence for a fixed platelet requirement. Blood 1985;66:1105-9.

\section{Heddle 2008}

Heddle, NM, Arnold, DM, Boye, D, Webert, KE, Resz, I, Dumont, LJ. Comparing the efficacy and safety of apheresis and whole blood-derived platelet transfusions: a systematic review. Transfusion 2008;48(7):1447-58.

\section{Hersh 1998}

Hersh JK, Hom EG, Brecher ME. Mathematical modelling of platelet survival with implications for optimal transfusion practice in the chronically platelet transfusion-dependent patient. Transfusion 1998;38:637-644.

\section{Higgins 2011a}

Higgins JPT, Deeks JJ (editors). Chapter 7: Selecting studies and collecting data. In: Higgins JPT, Green S (editors), Cochrane Handbook for Systematic Reviews of Interventions Version 5.1.0 (updated March 2011). The Cochrane Collaboration, 2011. Available from www.cochrane-handbook.org.

\section{Higgins 2011b}

Higgins JPT, Deeks JJ, Altman DG (editors). Chapter 16: Special topics in Statistics. In: Higgins JPT, Green S (editors), Cochrane Handbook for Systematic Reviews of Interventions Version 5.1.0 (updated March 2011). The Cochrane Collaboration, 2011. Available from www.cochrane-handbook.org.

\section{Higgins 2011c}

Higgins JPT, Altman DG, Sterne JAC (editors). Chapter 8: Assessing risk of bias in included studies. In: Higgins JPT, Green S (editors). Cochrane Handbook for Systematic Reviews of Interventions Version 5.1.0 (updated March 2011). The Cochrane Collaboration, 2011. Available from www.cochrane-handbook.org. 


\section{Kitchens 1975}

Kitchens CS, Weiss L. Ultrastructural changes of endothelium associated with thrombocytopenia. Blood 1975;46:567-78

\section{Koreth 2004}

Koreth R, Weinert C, Weisdorf DJ, Key NS. Measurement of bleeding severity: a critical review. Transfusion 2004;44: 605-17.

\section{Lefebvre 2011}

Lefebvre C, Manheimer E, Glanville J. Chapter 6: Searching for studies. In: Higgins JPT, Green S (editors). Cochrane Handbook for Systematic Reviews of Interventions Version 5.1.0 (updated March 2011). The Cochrane Collaboration, 2011. Available from www.cochrane-handbook.org.

\section{Nachman 2008}

Nachman RL, Rafii S. Platelets, petechiae and preservation of the vascular wall. New England Journal of Medicine 2008; 359:1261-1270

\section{Pendry 2011}

Pendry K, Davies T. An audit of use and wastage in the north west of England and North Wales: where have all the platelets gone?. Blood and Transplant Matters 2011;34: 17-9.

\section{Review Manager 2011}

The Nordic Cochrane Centre. Review Manager (RevMan). Version 5.1. Copenhagen: The Cochrane Collaboration, 2011.

\section{Schiffer 200}

Schiffer CA, Anderson KC, Bennett CL, Bernstein S, Elting LS, Goldsmith M, et al.Platelet transfusion for patients with cancer: Clinical practice guidelines of the American Society of Clinical Oncology. Journal of Clinical Oncology 2001;19: 1519-38.

\section{Schünemann 2011}

Schünemann HJ, Oxman AD, Higgins JPT, Vist GE, Glasziou P, Guyatt GH. Chapter 11: Presenting results and 'Summary of findings' tables. In: Higgins JPT, Green $S$ (editors), Cochrane Handbook for Systematic Reviews of Interventions Version 5.1.0 (updated March 2011). The Cochrane Collaboration, 2011. Available from www.cochrane-handbook.org.

\section{Segal 2005}

Segal HC, Briggs C, Kunka S, Casbard A, Harrison P, Machin SJ, et al.Accuracy of platelet counting haematology analysers in severe thrombocytopenia and potential impact on platelet transfusion. British Journal of Haematology 2005; 128: $520-5$.

\section{Slichter 1978}

Slichter SJ, Harker LA. Thrombocytopenia: mechanisms and management of defects in platelet production. Clinical Haematology 1978;7:523-39.

\section{Slichter 1980}

Slichter SJ. Controversies in platelet transfusion therapy. Annual Reviews of Medicine 1980;31:509-40.

Slichter 2007

Slichter SJ. Evidence-based platelet transfusion guidelines. Hematology (American Society of Hematology Education Program) 2007:172-8.

\section{Stanworth 2005}

Stanworth SJ, Hyde C, Brunskill S, Murphy MF. Platelet transfusion prophylaxis for patients with haematological malignancies: where to now?. British Journal of Haematology 2005;131:588-95.

\section{Sterne 2011}

Sterne JAC, Egger M, Moher D (editors). Chapter 10: Addressing reporting biases. In: Higgins JPT, Green S (editors). Cochrane Handbook for Systematic Reviews of Intervention. Version 5.1.0 (updated March 2011). The Cochrane Collaboration, 2011. Available from www.cochrane-handbook.org.

\section{Sullivan 2002}

Sullivan MT, McCullough J, Schreiber GB, Wallace EL. Blood Collection and transfusion in the United States in 1997. Transfusion 2002;42(10):1253-60.

Taylor 2010

Taylor C (Ed.), Cohen H, Mold D, Jones H, et al.on behalf of the Serious Hazards of Transfusion (SHOT) Steering Group. The 2009 Annual SHOT Report. SHOT Steering Group, 2010.

Tinmouth 2003

Tinmouth AT, Freedman J. Prophylactic platelet transfusions: which dose is the best dose? A review of the literature. Transfusion Medicine Reviews 2003;17(3): $181-93$.

Webert 2006

Webert KE, Cook RJ, Sigouin CS, Rebulla P, Heddle NM. The risk of bleeding in thrombocytopenic patients with acute myeloid leukaemia. Haematologica 2006;91(11): $1530-7$.

WHO 1979

WHO. WHO Handbook for Reporting Results of Cancer Treatment. WHO Offset publication No. 48. Geneva: World Health Organisation, 1979.

\section{References to other published versions of this review}

\section{Stanworth 2004}

Stanworth SJ, Hyde C, Heddle N, Rebulla P, Brunskill S, Murphy MF. Prophylactic platelet transfusion for haemorrhage after chemotherapy and stem cell transplantation. Cochrane Database of Systematic Reviews 2004, Issue 4. [DOI: 10.1002/14651858.CD004269.pub2]

* Indicates the major publication for the study 
CHARACTERISTICS OF STUDIES

Characteristics of included studies [ordered by study ID]

Diedrich 2005

Methods Parallel RCT (enrolled September 1996 to September 2001). Single centre. Sweden
Outcomes
Inclusion criteria: Patients undergoing an allogeneic haematopoietic stem cell transplant. All ages

Exclusion criteria: Patients with a known bleeding disorder or coagulopathy $\mathrm{N}=166$ (All included in analysis)

Arm $1 \mathrm{~N}=79$ (acute leukaemia $\mathrm{N}=47$; chronic leukaemia $\mathrm{N}=20$; non-malignant haematological disorder $\mathrm{N}=4$; other malignancy $\mathrm{N}=8$ )

Arm $2 \mathrm{~N}=87$ (acute leukaemia $\mathrm{N}=36$; chronic leukaemia $\mathrm{N}=24$; non-malignant haematological disorder $\mathrm{N}=11$; other malignancy $\mathrm{N}=16$ )

\begin{tabular}{l} 
Comparison between prophylactic platelets with different transfusion triggers \\
Arm 1 (Low transfusion trigger): If platelet count $<10 \times 10^{9} / \mathrm{L}$ \\
Arm 2 (High transfusion trigger): If platelet count $<30 \times 10^{9} / \mathrm{L}$ \\
In both arms prior to an operation or a biopsy, a platelet count $>50 \times 10^{9} / \mathrm{L}$ was aimed \\
for. \\
$\begin{array}{l}\text { Platelet dose (mean } \pm \text { S.D.): } \\
\text { - (buffy coat) approximately } 410 \times 10^{9} \pm 20 \times 10^{9} \\
\text { Platelet type: } \text { pooled random donor platelets (buffy coat) } 85 \% \text { of platelet transfusions } \\
\text { given; apheresis } 15 \% \text { of platelet transfusions given. All were ABO matched, irradiated } \\
\text { and leuco depleted }\end{array}$ \\
\hline
\end{tabular}

Primary outcome: - Number of platelet transfusions Secondary outcomes included:

- RBC transfusions

- Haemorrhages

- GvHD

- Transplantation related mortality

- Survival

Average number of days patients on study

Not reported

Risk of bias

Patients randomised: documentation for study started 7 days prior to transplant Follow-up: until 30 days post stem cell transplant.

Stopping rules: not reported

\begin{tabular}{|c|c|c|}
\hline Bias & Authors' judgement & Support for judgement \\
\hline $\begin{array}{l}\text { Random sequence generation (selection } \\
\text { bias) }\end{array}$ & Unclear risk & $\begin{array}{l}\text { Patients were randomised after stratifica- } \\
\text { tion, method of randomisation not stated }\end{array}$ \\
\hline
\end{tabular}


Diedrich 2005 (Continued)

\begin{tabular}{|c|c|c|}
\hline Allocation concealment (selection bias) & Unclear risk & $\begin{array}{l}\text { Patients were randomised after stratifica- } \\
\text { tion, method of allocation concealment not } \\
\text { stated }\end{array}$ \\
\hline $\begin{array}{l}\text { Blinding (performance bias and detection } \\
\text { bias) } \\
\text { Assessor of bleeding assessment }\end{array}$ & Low risk & $\begin{array}{l}\text { Nurses from the ward, blinded to treatment } \\
\text { arm, performed daily (inpatients) or twice } \\
\text { a week (outpatients) bleeding assessment } \\
\text { and reported this. A special research nurse } \\
\text { collected all data for the study }\end{array}$ \\
\hline $\begin{array}{l}\text { Blinding (performance bias and detection } \\
\text { bias) } \\
\text { Physician/Medical Staff }\end{array}$ & High risk & $\begin{array}{l}\text { All platelet units were ordered by a differ- } \\
\text { ent nurse in charge of and responsible for } \\
\text { the patient. He or she was not blinded, for } \\
\text { practical reasons, to the treatment arm }\end{array}$ \\
\hline $\begin{array}{l}\text { Incomplete outcome data (attrition bias) } \\
\text { All outcomes }\end{array}$ & Unclear risk & $\begin{array}{l}\text { Insufficient information to make an assess- } \\
\text { ment }\end{array}$ \\
\hline Selective reporting (reporting bias) & Unclear risk & $\begin{array}{l}\text { No protocol available to assess whether all } \\
\text { pre-specified outcomes have been reported }\end{array}$ \\
\hline Other bias & Low risk & $\begin{array}{l}\text { The study appears to be free of other } \\
\text { sources of bias }\end{array}$ \\
\hline Protocol Deviation balanced? & Unclear risk & $\begin{array}{l}\text { In patients with WHO grade } 2-4 \text { bleed- } \\
\text { ing, violations of the protocol occurred in } \\
4 / 14 \text { patients in Arm } 1 \text { and } 3 / 13 \text { patients } \\
\text { in Arm } 2 \text {. The number of transfusions in } \\
\text { which a protocol deviation occurred was } \\
\text { not reported. Whether there were any pro- } \\
\text { tocol deviations in those patients that did } \\
\text { not bleed was not reported }\end{array}$ \\
\hline
\end{tabular}

Heckman 1997

Methods

Participants
Parallel RCT (enrolled April 1991 to November 1995). Single centre. USA

Inclusion criteria: - Unequivocal diagnosis of acute leukaemia (AML, ALL in relapse, acute undifferentiated leukaemia or MDS transformed to AML). Age > 17yrs. Patient undergoing initial induction chemotherapy, or re-induction following relapse

Exclusion criteria: - APL. Inherited clotting disorder. Uncontrolled infection at randomisation. History of a bleeding diathesis. DIC at randomisation into the study. Prior entry into the study. Concomitant malignancy or AIDs diagnosis. History of platelet refractory status

$\mathrm{N}=82$ entered into study; 4 ineligible ( 2 delayed cytogenetic diagnosis of APL. 2 not assessable, transferred to ITU within 24 hrs of registration with severe infections).

Arm 1: $N=37$

Arm 2: $\mathrm{N}=41$ 
Heckman 1997 (Continued)

$\begin{array}{ll}\text { Interventions } & \text { Comparison between prophylactic platelets with different transfusion triggers } \\ \text { Arm } 1 \text { (Low transfusion trigger). If platelet count } \leq 10 \times 10^{9} / \mathrm{L} \\ \text { Arm } 2 \text { (High transfusion trigger). If platelet count } \leq 20 \times 10^{9} / \mathrm{L} \\ \text { Platelets given in both arms if serious or life-threatening bleeding and for procedures at } \\ \text { discretion of physician } \\ \text { Platelet dose: } 1 \text { apheresis unit (approximately } 4-4.9 \times 10^{11} \text { of platelets) } \\ \text { Platelet type: } \text { apheresis. Leucodepleted. }\end{array}$

\begin{tabular}{l|l}
\hline Outcomes & Main or primary outcome not stated \\
& Outcomes mentioned \\
& - Survival (at time of analysis) \\
- Remission rates (time period not stated) \\
- Bleeding episodes per patient \\
- Transfusion requirements (platelets, red cells) \\
- Hospital stay \\
- Adverse events \\
Number of days patients on study (median): \\
Arm $1: 24$ days \\
Arm $2: 24$ days
\end{tabular}

Risk of bias

\begin{tabular}{|c|c|c|}
\hline Bias & Authors' judgement & Support for judgement \\
\hline $\begin{array}{l}\text { Random sequence generation (selection } \\
\text { bias) }\end{array}$ & Unclear risk & $\begin{array}{l}\text { Random allocation "by selecting ran- } \\
\text { domised cards from envelopes". No com- } \\
\text { ment on how cards were randomised } \\
\text { Randomisation stratified by four groups } \\
\text { [new diagnosis }<60 \mathrm{y} \text {; new diagnosis }=60 \\
\text { y; relapse }<60 \mathrm{y} \text {; relapse }=60 \mathrm{y} \text { ] }\end{array}$ \\
\hline Allocation concealment (selection bias) & Unclear risk & $\begin{array}{l}\text { Attempt to conceal allocation not de- } \\
\text { scribed. It was not mentioned whether en- } \\
\text { velopes were opaque or sealed }\end{array}$ \\
\hline $\begin{array}{l}\text { Blinding (performance bias and detection } \\
\text { bias) } \\
\text { Assessor of bleeding assessment }\end{array}$ & High risk & $\begin{array}{l}\text { Assessor of bleeding was variable. Doctors } \\
\text { and nurses would know randomisation be- } \\
\text { cause of having to treat depending on a } \\
\text { threshold }\end{array}$ \\
\hline $\begin{array}{l}\text { Blinding (performance bias and detection } \\
\text { bias) } \\
\text { Physician/Medical Staff }\end{array}$ & High risk & $\begin{array}{l}\text { Authors felt doctors may be more prone to } \\
\text { treat minor bleeding with platelet transfu- } \\
\text { sions in }<10,000 \text { group }\end{array}$ \\
\hline
\end{tabular}


Heckman 1997 (Continued)

\begin{tabular}{|c|c|c|}
\hline $\begin{array}{l}\text { Incomplete outcome data (attrition bias) } \\
\text { All outcomes }\end{array}$ & Unclear risk & Insufficient reporting to allow assessment. \\
\hline Selective reporting (reporting bias) & Unclear risk & $\begin{array}{l}\text { No study protocol available and outcomes } \\
\text { not clearly stated. }\end{array}$ \\
\hline Other bias & Unclear risk & Insufficient information to assess. \\
\hline Protocol Deviation balanced? & High risk & $\begin{array}{l}\text { In Arm } 130 / 311 \text { transfusions deviated } \\
\text { from the protocol whereas in Arm } 2 \text { only } \\
7 / 457 \text { transfusions deviated from the pro- } \\
\text { tocol This affected } 14 / 37 \text { patients in Arm } \\
1 \text { and } 6 / 41 \text { patients in Arm } 2(P=0.02)\end{array}$ \\
\hline
\end{tabular}

\section{Heddle 2009}

Methods

Participants
Parallel RCT (enrolled October 2003-June 2007). Multi-national study (Canada 3 centres, Norway 1 centre, USA 2 centres)

Inclusion Criteria: Hypoproliferative thrombocytopenia where platelet count was expected to be $<10 \times 10^{9} / \mathrm{L}$ for $\geq 10$ days; receiving treatment as an in-patient; weight between $40-100 \mathrm{~kg}$; minimum age $17 \mathrm{yrs}$

Exclusion Criteria: APL; pregnant; history or current diagnosis of ITP, TTP or HUS; evidence of $\geq \mathrm{WHO}$ grade 2 bleeding at time of study assessment; indication for bedside leukoreduced platelet components

$\mathrm{N}=129$ randomised;119 included in analysis (6 did not require platelet transfusions; 1 withdrew from trial before receiving platelets; 3 no bleeding assessment data)

Arm $1 \mathrm{~N}=58$ (acute leukaemia $\mathrm{N}=51$; lymphoma $\mathrm{N}=4$; carcinoma $\mathrm{N}=1$; $\mathrm{MDS} \mathrm{N}$ $=1$; plasma cell dyscrasia $\mathrm{N}=1$ )

$N=7$ withdrew early (1 patient decision; 6 physician decision)

Arm $2 \mathrm{~N}=61$ (acute leukaemia $\mathrm{N}=52$; chronic leukaemia $\mathrm{N}=2$; lymphoma $\mathrm{N}=3$; MDS $\mathrm{N}=2$; plasma cell dyscrasia $\mathrm{N}=1$; other $\mathrm{N}=1$ )

$N=3$ withdrew early (2 patient decision; 1 physician decision)
Comparison between prophylactic platelet transfusions with different platelet dosages Arm 1 Low dose (1.5 to $3.0 \times 10^{11}$ platelets/product) Arm 2 Standard dose (3.0 to $6.0 \times 10^{11}$ platelets/product)

Transfusion thresholds: Prophylactic platelet transfusion threshold depended on local transfusion trigger. Most centres used trigger of $10 \times 10^{9} / \mathrm{L}$. Higher triggers were used in special circumstances (e.g. sepsis) at the discretion of the treating physician Type of platelet transfusion: Both US sites used leucodepleted apheresis platelets. Canadian sites used both apheresis and random donor pooled platelets (both leucodepleted). Norwegian site used apheresis and random donor pooled platelets

Outcomes
Primary outcome: -Occurrence of a WHO grade 2 or higher bleed Secondary outcomes:

- Frequency of individual grades of bleeding (grades 1-4)

- Time to first bleed 
Heddle 2009 (Continued)

\begin{tabular}{|l}
\hline - Duration of thrombocytopenia \\
- Platelet transfusions requirements \\
- Red cell transfusion requirements \\
- Interval between platelet transfusions \\
- Modeling the recurrent event analysis to determine the mean number of bleeding \\
days over time per 100 patients \\
Number of days of thrombocytopenia (mean \pm SD) \\
Arm $1=15.8 \pm 9.3$ \\
Arm $2=14.0 \pm 9.0$ \\
\hline
\end{tabular}

Notes

Patients randomised at: time of first prophylactic platelet transfusion. (usually when platelet count $<10 \times 10^{9} / \mathrm{L}$ - depended on local trigger).

Followed up of patients: until bone marrow recovery (unsupported platelet count > $50 \times 10^{9} / \mathrm{L}$ ) OR 30 days from randomisation OR discharge from hospital OR patient withdrawal OR death

Stopping guideline: Study to be stopped if difference in the proportion of grade 4 bleeding between the 2 treatment arms exceeded $5 \%$ at any time after 50 patients had been enrolled per arm

Risk of bias

\begin{tabular}{|c|c|c|}
\hline Bias & Authors' judgement & Support for judgement \\
\hline $\begin{array}{l}\text { Random sequence generation (selection } \\
\text { bias) }\end{array}$ & Low risk & $\begin{array}{l}\text { Computer generated, stratified by centre } \\
\text { and diagnostic group. Block randomisation } \\
\text { was used with variable block sizes within } \\
\text { strata to help conceal treatment allocation }\end{array}$ \\
\hline
\end{tabular}

Allocation concealment (selection bias) Low risk

Allocated through a secure central webbased randomisation system. Block randomisation was used with variable block sizes within strata to help conceal treatment allocation

Blinding (performance bias and detection Low risk bias)

Assessor of bleeding assessment

Blinding (performance bias and detection High risk bias)

Physician/Medical Staff

Incomplete outcome data (attrition bias)

High risk

All outcomes
Bleeding assessment was performed each morning during the period of thrombocytopenia by personnel who were blinded to the platelet dose assigned to the patient

Although study was meant to be blinded authors were concerned that this was not always the case. 7 patients withdrawn from the study early 1 in standard dose arm and 6 in low dose arm

2 patients in standard group and 1 patient in low risk group had missing data (not included in analysis). 10 patients withdrew from the study early for the following rea- 
Heddle 2009 (Continued)

\begin{tabular}{|c|c|c|}
\hline & & $\begin{array}{l}\text { sons: patient decision to withdraw ( } \mathrm{N}=3: 2 \\
\text { standard dose; } 1 \text { low dose); physician deci- } \\
\text { sion to withdraw ( } \mathrm{N}=7: 1 \text { standard dose; } 6 \\
\text { low dose). Therefore early withdrawal un- } \\
\text { balanced between the two groups }\end{array}$ \\
\hline Selective reporting (reporting bias) & High risk & $\begin{array}{l}\text { Not all of the pre-specified outcomes were } \\
\text { reported. Including platelet response; pre } \\
\text { and post transfusion bleeding grade in } \\
\text { response to dose of therapeutic platelets } \\
\text { transfused; cost analysis }\end{array}$ \\
\hline Other bias & High risk & $\begin{array}{l}\text { Discrepancies in adjudication of bleeding } \\
\text { grade between the first } 2 \text { adjudicators in } \\
39 \%(433 / 1150) \text { of the bleeding days ad- } \\
\text { judicated. However, through consensus, } \\
\text { agreement could be reached. Most of the } \\
\text { discrepancies occurred between the grade } 1 \\
\text { and grade } 2 \text { classifications } \\
\text { Trial stopped early due to a pre-specified } \\
\text { stopping guideline. Higher rate of grade } 4 \\
\text { bleeding in patients receiving low dose pro- } \\
\text { phylactic platelet transfusions. Frequency } \\
\text { of grade } 4 \text { bleeding } 5.2 \%(3 / 58) \text { in low dose } \\
\text { arm and } 0 \%(0 / 61) \text { in standard-dose arm. } \\
\text { Risk of incomplete randomisation blocks }\end{array}$ \\
\hline Protocol Deviation balanced? & High risk & $\begin{array}{l}\text { The triggers used for prophylactic platelet } \\
\text { transfusions tended to be higher in the low- } \\
\text { dose treatment group with } 35.9 \% \text { of trans- } \\
\text { fusions }(158 / 440) \text { given at a trigger of } 16 \times \\
10^{9} / \mathrm{L} \text { or more compared with } 24.7 \%(66 / \\
267) \text { in the standard dose group } \\
\text { In the low dose arm } 27.4 \% \text { of the prophy- } \\
\text { lactic platelet transfusions were outside the } \\
\text { predesignated range: } 2.7 \% \text { below } 150 \times 10^{9} \\
\text { platelets/product }(\mathrm{n}=10) \text { and } 24.7 \% \text { above } \\
300 \times 10^{9} \text { platelets/product }(\mathrm{N}=91) \\
\text { In the standard dose arm } 20 \% \text { of the pro- } \\
\text { phylactic platelet transfusions were outside } \\
\text { the predesignated range: } 6.7 \% \text { below } 300 \times \\
10^{9} \text { platelets/product }(\mathrm{n}=17) \text { and } 13.3 \% \\
\text { above } 600 \times 10^{9} \text { platelets/product }(\mathrm{N}=34)\end{array}$ \\
\hline
\end{tabular}


Higby 1974

\begin{tabular}{|c|c|}
\hline Methods & Parallel RCT (enrolment period not stated). Single centre. USA \\
\hline Participants & $\begin{array}{l}\text { Inclusion Criteria: - Afebrile; thrombocytopenic - platelet count }<30 \times 10^{9} / \mathrm{L} \text {; patients } \\
\text { with Acute Myeloid Leukaemia (adults) } \\
\text { Exclusion Criteria: - Haematological remission of leukaemia; evidence of bleeding; } \\
\text { evidence of haemolysis } \\
\mathrm{N}=21 \text { participants, } 24 \text { episodes of chemotherapy induced thrombocytopenia. (18 pa- } \\
\text { tients randomised once; } 3 \text { randomised twice) } \\
\text { Arm 1: } \mathrm{N}=12 \text { episodes; } 12 \text { patients } \\
\text { Arm 2: } \mathrm{N}=12 \text { episodes; } 12 \text { patients, } 3 \text { not entered into analysis (recovered from throm- } \\
\text { bocytopenia within } 48 \mathrm{hrs} \text { of entry into trial) }\end{array}$ \\
\hline Interventions & $\begin{array}{l}\text { Comparison between prophylactic platelet transfusions and platelet-poor plasma } \\
\text { Arm } 1 \text { (Prophylactic). Platelets ( } 3 \text { units } / \mathrm{m}^{2} \text { body surface area = approximately } 3 \times 10^{11} \\
\text { platelets } / \mathrm{m}^{2} \text { ) } \\
\text { Arm } 2 \text { (Placebo). Plasma infusion (platelet-poor) of equal volume } \\
\text { Platelets or platelet-poor plasma given twice weekly. } \\
\text { Type of platelet transfusion: random donor pooled platelets }\end{array}$ \\
\hline Outcomes & $\begin{array}{l}\text { Main or primary outcome not stated } \\
\text { Outcomes mentioned } \\
\text { - Frequency of haemorrhage } \\
\text { - Average platelet count } \\
\text { Number of days patients on study (mean } \pm \text { SD): } \\
\text { Arm 1: } 12.3 \pm 6.9 \\
\text { Arm 2: } 14.9 \pm 10.8\end{array}$ \\
\hline Notes & $\begin{array}{l}\text { Patients randomised at: platelet count }<30 \times 10^{9} / \mathrm{L} \\
\text { Follow-up of patients: until unsupported platelet count }>30 \times 10^{9} / \mathrm{L} \text { for } 2 \text { days; OR } \\
\text { patient had a significant haemorrhage; OR patient developed septic shock/ significant } \\
\text { sepsis } \\
\text { Stopping guidelines: not reported }\end{array}$ \\
\hline
\end{tabular}

\section{Risk of bias}

\begin{tabular}{|c|c|c|}
\hline Bias & Authors' judgement & Support for judgement \\
\hline $\begin{array}{l}\text { Random sequence generation (selection } \\
\text { bias) }\end{array}$ & Unclear risk & $\begin{array}{l}\text { Patients "were assigned at random to one of } \\
\text { two groups" Insufficient information about } \\
\text { the sequence generation process to permit } \\
\text { judgement of 'Yes' or 'No' }\end{array}$ \\
\hline Allocation concealment (selection bias) & Low risk & $\begin{array}{l}\text { "Eligible patients were allocated to treat- } \\
\text { ment regimen in the blood bank and with- } \\
\text { out knowledge of the attending physicians" }\end{array}$ \\
\hline
\end{tabular}


Higby 1974 (Continued)

\begin{tabular}{|c|c|c|}
\hline $\begin{array}{l}\text { Blinding (performance bias and detection } \\
\text { bias) } \\
\text { Assessor of bleeding assessment }\end{array}$ & Unclear risk & $\begin{array}{l}\text { The method of performing the bleeding } \\
\text { assessment and the person performing the } \\
\text { bleeding assessment were not stated }\end{array}$ \\
\hline $\begin{array}{l}\text { Blinding (performance bias and detection } \\
\text { bias) } \\
\text { Physician/Medical Staff }\end{array}$ & Low risk & $\begin{array}{l}\text { "Eligible patients were allocated to a treat- } \\
\text { ment regimen in the blood bank and were } \\
\text { treated in the manner assigned without the } \\
\text { knowledge of the attending physicians" }\end{array}$ \\
\hline $\begin{array}{l}\text { Incomplete outcome data (attrition bias) } \\
\text { All outcomes }\end{array}$ & Low risk & $\begin{array}{l}\text { "as treated analysis. No missing outcome } \\
\text { data" }\end{array}$ \\
\hline Selective reporting (reporting bias) & Unclear risk & Protocol not available to make assessment. \\
\hline Other bias & High risk & $\begin{array}{l}\text { There was a significant difference between } \\
\text { the ages of the patients in the two groups } \\
(\text { mean } \pm \text { SD) } 53.3 \pm 18.5(\mathrm{arm} 1) \text { vs. } 43.8 \pm \\
19.4(\operatorname{arm} 2)(\mathrm{P}<0.05 \text { (t-test) })\end{array}$ \\
\hline Protocol Deviation balanced? & Unclear risk & Not stated \\
\hline
\end{tabular}

\section{Murphy 1982}

\begin{tabular}{|c|c|}
\hline Methods & Parallel RCT (conducted from July 1st 1972 to Jan 1st 1976). Single Centre. USA \\
\hline Participants & $\begin{array}{l}\text { Inclusion criteria: Children with previously untreated acute leukaemia cared for at the } \\
\text { Children's Hospital of Philadelphia } \\
\text { Exclusion criteria: Not stated. } \\
\mathrm{N}=56 \text { children } \\
\text { Arm 1: N=35 (Acute lymphocytic leukaemia (ALL) }=28 \text {, Acute leukaemia excluding } \\
\text { ALL (AnonLL) }=7 \text { ) } \\
\text { Arm 2: } N=21(A L L=15 \text {, AnonLL=6) }\end{array}$ \\
\hline Interventions & $\begin{array}{l}\text { Comparison between prophylactic and therapeutic platelet transfusions } \\
\text { Arm } 1 \text { (Prophylactic): Aim to maintain platelet count above } 20 \times 10^{9} / \mathrm{L} \\
\text { Arm } 2 \text { (Therapeutic): Only given platelets in presence of five clinical indications } \\
\text { 1. Epistaxis not controlled by initial packing } \\
\text { 2. Gross gastrointestinal bleeding } \\
\text { 3. Gross genitourinary tract bleeding } \\
\text { 4. Any central nervous system bleeding } \\
\text { 5. Any bleeding episode felt to be life- threatening } \\
\text { Unclear whether platelets were given in both arms if clinical indications occurred and } \\
\text { platelet count }>20 \times 10^{9} / \mathrm{L} \\
\text { Platelet dose: } 4 \text { units } / \mathrm{m}^{2} \text {. Number of platelets/unit not stated. } \\
\text { Platelet type: pooled random donor platelets }\end{array}$ \\
\hline
\end{tabular}


Murphy 1982 (Continued)

\begin{tabular}{|c|c|c|}
\hline Outcomes & \multicolumn{2}{|c|}{$\begin{array}{l}\text { Primary outcome: Survival } \\
\text { Secondary outcomes } \\
\text { - Number, duration and dates of serious bleeding events (bleeds) during study. } \\
\text { - Total number of days on which bleeding was present. } \\
\text { - Platelet transfusion requirements in first } 10 \text { months (number of patients } \\
\text { transfused; number of transfusions given; number of units given; number of patients } \\
\text { bleeding; number of days with bleeding) } \\
\text { Number of months patients on study } \\
\text { Arm 1: Mean length of follow-up } 19.9 \text { months (ALL = } 20.7 \text { months; AnonLL = } 16.6 \\
\text { months) } \\
\text { Arm 2: Mean length of follow-up } 20.4 \text { months (ALL = } 21.6 \text { months; AnonLL = } 17.7 \\
\text { months) }\end{array}$} \\
\hline Notes & \multicolumn{2}{|c|}{$\begin{array}{l}\text { Patients randomised at: not reported } \\
\text { Follow-up of patients: until death or until 1st July } 1976 . \\
\text { Stopping guidelines: not reported }\end{array}$} \\
\hline \multicolumn{3}{|l|}{ Risk of bias } \\
\hline Bias & Authors' judgement & Support for judgement \\
\hline $\begin{array}{l}\text { Random sequence generation (selection } \\
\text { bias) }\end{array}$ & Unclear risk & $\begin{array}{l}\text { Method of random allocation not de- } \\
\text { scribed. Randomisation was performed } \\
\text { separately for acute lymphoblastic and } \\
\text { acute non lymphoblastic leukaemia. Ini- } \\
\text { tially randomisation } 1: 1 \text {; changed to } 2: 1 \\
\text { after interim analysis } 2 \text { years after start of } \\
\text { trial, since a preliminary analysis indicated } \\
\text { that "the incidence of bleeding might be re- } \\
\text { duced in the prophylactic group" (further } \\
\text { details of numbers enrolled prior to change } \\
\text { in method of allocation not provided) }\end{array}$ \\
\hline Allocation concealment (selection bias) & Unclear risk & $\begin{array}{l}\text { Attempt to conceal allocation not men- } \\
\text { tioned. }\end{array}$ \\
\hline $\begin{array}{l}\text { Blinding (performance bias and detection } \\
\text { bias) } \\
\text { Assessor of bleeding assessment }\end{array}$ & Unclear risk & $\begin{array}{l}\text { No mechanisms mentioned to blind out- } \\
\text { come assessors (presumed also to be clini- } \\
\text { cians) to treatment after allocation }\end{array}$ \\
\hline $\begin{array}{l}\text { Blinding (performance bias and detection } \\
\text { bias) } \\
\text { Physician/Medical Staff }\end{array}$ & Unclear risk & $\begin{array}{l}\text { No mechanisms mentioned to blind physi- } \\
\text { cians to treatment. }\end{array}$ \\
\hline $\begin{array}{l}\text { Incomplete outcome data (attrition bias) } \\
\text { All outcomes }\end{array}$ & Unclear risk & Insufficient reporting to allow assessment \\
\hline
\end{tabular}


Murphy 1982 (Continued)

\begin{tabular}{l|l|l}
\hline Selective reporting (reporting bias) & High risk & $\begin{array}{l}\text { Reported in text that there was "no correla- } \\
\text { tion of the incidence of bleeding with sex, } \\
\text { pre-transfusion haematocrit, concomitant } \\
\text { corticosteroid therapy or the use of specific } \\
\text { antineoplastic drugs". None of these were } \\
\text { reported further }\end{array}$ \\
\hline Other bias & High risk & $\begin{array}{l}\text { Unbalanced numbers between groups with } \\
\text { a greater proportion of AnonLL in thera- } \\
\text { peutic group. Age and gender of patients } \\
\text { not reported for each group }\end{array}$ \\
\hline Protocol Deviation balanced? & Unclear risk & Not reported \\
\hline
\end{tabular}

Rebulla 1997

Methods

Parallel RCT (enrolled from March 1994 to March 1996). Multi-centre study (21 centres). Italy Inclusion Criteria: Patients with acute myeloid leukaemia (AML); adolescents and
adults (aged $16-70 \mathrm{yrs})$; admitted to hospital for 1 st course of induction chemotherapy
Exclusion Criteria: Patients diagnosed with promyelocytic leukaemia or secondary
AML; patients who had received a blood transfusion prior to diagnosis of AML
$\mathrm{N}=329$ patients screened for trial. 276 randomised. (37 secondary leukaemia; 10 blood
transfusion prior to diagnosis; 4 did not meet age criteria; 2 declined to give consent)
Arm 1: $\mathrm{N}=144 ; 9$ not included in analysis; 8 alive at discharge (no study records received)
$; 1$ death on day 5 (cerebral haemorrhage) (no study records received)
Arm $2: \mathrm{N}=132 ; 12$ not included in analysis; 8 alive at discharge (no study records
received); 2 died within 24 hours of admission (1 cerebral haemorrhage, 1 cardiac arrest)
$; 2$ received non-myeloablative course of chemotherapy

\begin{tabular}{|c|c|}
\hline Interventions & $\begin{array}{l}\text { Comparison between prophylactic platelets with different tr } \\
\text { Arm } 1 \text { (Low transfusion trigger). If platelet count }<10 \times 10 \\
{ }^{\circ} \mathrm{C} \text {, OR } 10 \text { to } 20 \times 10^{9} / \mathrm{L} \text { if } \mathrm{T}>38^{\circ} \mathrm{C} \text { or in presence of ma } \\
\text { invasive procedures were necessary } \\
\text { Arm } 2 \text { (High transfusion trigger). If platelet count }<20 \times 1 \\
\text { Platelet dose: } 1 \text { unit of platelet rich plasma or buffy coat } \\
\text { weight or } 1 \text { apheresis concentrate given. Number of platelet } \\
\text { median } 280 \times 10^{9} \text { (range } 110 \text { to } 588 \text { ), pooled concentrate } \mathrm{m} \\
\text { to } 555 \text { ) } \\
\text { Platelet type: Apheresis platelets given to } 50 \% \text { of patients in } \\
\text { in Arm } 2\end{array}$ \\
\hline Outcomes & $\begin{array}{l}\text { Primary outcome: Frequency and severity of haemorrhage } \\
\text { Secondary outcomes: } \\
\text { - Mortality rates } \\
\text { - Rates of complete remission } \\
\text { - Number of red cell transfusions }\end{array}$ \\
\hline
\end{tabular}

Prophylactic platelet transfusion for prevention of bleeding in patients with haematological disorders after chemotherapy and stem cell 
Rebulla 1997 (Continued)

- Number of platelet transfusions

All outcomes measured to end of study

Number of days patients on study (mean)

Arm $1=29.7$ days

Arm $2=27.8$ days

\begin{tabular}{ll}
\hline Notes & Patients randomised at: diagnosis \\
& Follow-up of patients: until platelet count $>100 \times 10^{9} / \mathrm{L}$ OR discharge from hospital \\
OR occurrence of complete remission OR resistance to chemotherapy OR death \\
Stopping guidelines: The trial was scheduled to be stopped if the rate of outcome events \\
reached statistical significance $(\mathrm{P}<0.01$ by the chi-square test $)$ \\
Acetaminophen was used as an anti-pyretic agent
\end{tabular}

Risk of bias

\begin{tabular}{|c|c|c|}
\hline Bias & Authors' judgement & Support for judgement \\
\hline $\begin{array}{l}\text { Random sequence generation (selection } \\
\text { bias) }\end{array}$ & Low risk & $\begin{array}{l}\text { Patients underwent randomisation as soon } \\
\text { as the diagnosis and other inclusion cri- } \\
\text { teria were communicated by telephone to } \\
\text { the central randomisation centre at the } \\
\text { GIMEMA secretariat in Rome. A random } \\
\text { permutated block design was used in the } \\
\text { individual centres }\end{array}$ \\
\hline
\end{tabular}

Allocation concealment (selection bias) Low risk

The people who handled randomisation, data management, and statistical analysis were not involved in the treatment of the patients

Blinding (performance bias and detection High risk bias)

Assessor of bleeding assessment

Bleeding assessors were not blinded to the intervention (unpublished, supplied by the author)

Blinding (performance bias and detection High risk bias)

Medical staff routinely involved in the care of the patient were the bleeding assessors and were not blinded to the intervention (unpublished, supplied by the author)

Incomplete outcome data (attrition bias) Low risk All outcomes

Missing outcome data balanced in numbers across intervention groups, with similar reasons for missing data across groups

\begin{tabular}{l|l|l} 
Selective reporting (reporting bias) & Unclear risk & $\begin{array}{l}\text { Study protocol not available to allow judge- } \\
\text { ment. }\end{array}$ \\
\hline Other bias & Low risk & $\begin{array}{l}\text { The study appears to be free of other } \\
\text { sources of bias. }\end{array}$
\end{tabular}


Rebulla 1997 (Continued)

Protocol Deviation balanced? High risk

\begin{tabular}{|c|c|}
\hline Methods & Parallel RCT (enrolment period not stated). SIngle centre. USA \\
\hline Participants & $\begin{array}{l}\text { Inclusion Criteria: Hospitalised leukaemia patients (paediatric); platelet count } \leq 25 \mathrm{x} \\
10^{9} / \mathrm{L} \text {; no active bleeding within the previous } 5 \text { days } \\
\text { Exclusion Criteria: Not stated } \\
\mathrm{N}=62 \text { patients } \\
\text { Arm } 1: \mathrm{N}=30 \text { patients having } 167 \text { transfusion episodes (age } 0-4 \mathrm{yrs}=14 \text {; age } 5-9 \mathrm{yrs}= \\
14 \text {; age } 10-14 \text { yrs }=2 \text { ) } \\
\text { Arm } 2: \mathrm{N}=32 \text { patients having } 141 \text { transfusion episodes (age } 0-4 \text { yrs = 5; age } 5-9 \mathrm{yrs}= \\
12 \text {; age } 10-14 \text { yrs }=15 \text { ) }\end{array}$ \\
\hline Interventions & $\begin{array}{l}\text { Comparison between prophylactic platelet transfusions with different platelet dosages } \\
\text { Arm 1. 'higher dose' platelets (dose: } 0.06-0.07 \text { units } / \mathrm{lb} \text { ) }=0.9 \text { to } 1.1 \times 10^{11} \text { platelets/ } \\
10 \mathrm{~kg} \\
\text { Arm 2. 'lower dose' platelets (dose: } 0.03 \text { units } / \mathrm{lb})=0.46 \times 10^{11} \text { platelets } / 10 \mathrm{~kg} \\
\text { (the average platelet yield reported in the study was } 7 \times 10^{10} \text { platelets per unit) } \\
\text { Transfusion thresholds: Prophylactic platelet transfusions given when platelet count } \leq \\
25 \times 10^{9} / \mathrm{L} \\
\text { When bleeding occurred despite prophylaxis, the patient was treated with larger platelet } \\
\text { transfusions until all bleeding was arrested } \\
\text { Platelet transfusion type: } \mathrm{ABO} \text { identical pooled platelets }\end{array}$ \\
\hline
\end{tabular}

Outcomes

Main or Primary outcome not stated.

Aims of the trial: -

- To assess the dose-response relationship between transfused platelets and prevention of haemorrhage

- To investigate the needs and desirability of prophylactic platelet transfusion Number of days on study

Patients were followed up for 24 hours after platelet transfusion

Notes

Patients randomised at: platelet count $\leq 25 \times 10^{9} / \mathrm{L}$

Follow up of patients: for 24 hours after platelet transfusion.

Stopping guideline: not reported

If patient required further platelet transfusions during the same hospital admission patient kept initial randomisation. On re-admission to hospital patients were re-randomised

Risk of bias

Bias

Authors' judgement

Support for judgement 
Roy 1973 (Continued)

\begin{tabular}{|c|c|c|}
\hline $\begin{array}{l}\text { Random sequence generation (selection } \\
\text { bias) }\end{array}$ & Unclear risk & $\begin{array}{l}\text { Patients were assigned randomly to either } \\
\text { dosage group by drawing sealed envelopes. } \\
\text { Does not say how patients were randomised }\end{array}$ \\
\hline Allocation concealment (selection bias) & Unclear risk & $\begin{array}{l}\text { Patients were assigned randomly to ei- } \\
\text { ther dosage group by drawing sealed en- } \\
\text { velopes. Does not say whether envelopes } \\
\text { were opaque }\end{array}$ \\
\hline
\end{tabular}

Blinding (performance bias and detection Low risk

bias)

They were studied over each 24 hours fol-

Assessor of bleeding assessment

lowing transfusion for signs of bleeding by

an investigator who was unaware of the platelet dosage received

Blinding (performance bias and detection Unclear risk

Not reported

bias)

Physician/Medical Staff

\begin{tabular}{l|l|l}
\hline $\begin{array}{l}\text { Incomplete outcome data (attrition bias) } \\
\text { All outcomes }\end{array}$ & Low risk & No patients lost to follow-up \\
\hline Selective reporting (reporting bias) & High risk & $\begin{array}{l}\text { No protocol available to assess this, but in } \\
\text { the report a lot of data has been collected } \\
\text { but not reported on. "No correlation of the } \\
\text { incidence of bleeding with sex, pre-trans- } \\
\text { fusion haematocrit, concomitant corticos- } \\
\text { teroid therapy or the use of anti-neoplas- } \\
\text { tic drugs was found". None of these results } \\
\text { were reported }\end{array}$ \\
\hline Other bias & High risk & $\begin{array}{l}\text { Marked difference between population age } \\
\text { groups. Other baseline characteristics not } \\
\text { stated adequately to assess }\end{array}$ \\
\hline Protocol Deviation balanced? & Unclear risk & Not reported \\
\hline
\end{tabular}

Sensebe 2004

Methods

Parallel RCT (enrolled from May 1999 - October 2001). Multicentre (4 centres). France

Participants

Inclusion criteria: Patients who had not undergone transfusion who had acute leukaemia undergoing first line treatment; Patients undergoing autologous hematopoietic stem cell transplantation without criteria impairing platelet efficiency

Exclusion criteria: Patients diagnosed with AML M3

$\mathrm{N}=101$ patients randomised (98 included in analysis; 5 patients never transfused)

Arm $1=50$ (acute leukaemia $(\mathrm{AL})=17$; autologous transplant $($ AT $)=33)(2$ AT never transfused)

Arm 2 = $51(\mathrm{AL}=14 ; \mathrm{AT}=37)(2 \mathrm{AL}$ never transfused; 1 AT never transfused $)$ 


\begin{tabular}{|c|c|}
\hline Interventions & $\begin{array}{l}\text { Comparison between prophylactic platelet transfusions with different platelet dosages } \\
\text { Arm 1: Single dose }\left(0.5 \times 10^{11} / 10 \mathrm{~kg}\right) \\
\text { Arm 2: Double dose }\left(1.0 \times 10^{11} / 10 \mathrm{~kg}\right) \\
\text { Platelet transfusion thresholds: Prophylactic platelet transfusions given if platelet count } \\
<20 \times 10^{9} / \mathrm{L} \text {. Therapeutic platelet transfusion trigger not stated. } \\
\text { Platelet transfusion type: Leucodepleted, ABO compatible apheresis platelets }\end{array}$ \\
\hline Outcomes & $\begin{array}{l}\text { Primary outcome: Time between first transfusion and daily platelet reaching } 20 \times 10 \\
9 / \mathrm{L} \text { (allowed for calculating the risk of re-transfusion and theoretical time between first } \\
\text { and second transfusions } \\
\text { Secondary outcomes: } \\
\text { - Corrected count increment }(\mathrm{CCI}) \text { calculated as: } \\
\quad \quad \quad \text { (post-transfusion count - pre-transfusion count x body surface area }\left(\mathrm{m}^{2}\right) / \\
\text { platelet dose }\left(\mathrm{x} 10^{11}\right) \\
\text { - Number of transfusions } \\
\text { - Number of transfused platelets } \\
\text { Number of days on study } \\
\text { Not reported }\end{array}$ \\
\hline Notes & $\begin{array}{l}\text { Patients randomised at: not reported } \\
\text { Follow-up of patients: until platelet count }>25 \times 10^{9} / \mathrm{L} \text { and stable OR discharge from } \\
\text { hospital OR death } \\
\text { Stopping guideline: not reported }\end{array}$ \\
\hline
\end{tabular}

\section{Risk of bias}

\begin{tabular}{|c|c|c|}
\hline Bias & Authors' judgement & Support for judgement \\
\hline $\begin{array}{l}\text { Random sequence generation (selection } \\
\text { bias) }\end{array}$ & Unclear risk & $\begin{array}{l}\text { Method of sequence generation not com- } \\
\text { mented on. }\end{array}$ \\
\hline Allocation concealment (selection bias) & Unclear risk & $\begin{array}{l}\text { Method of allocation concealment not } \\
\text { commented on. }\end{array}$ \\
\hline $\begin{array}{l}\text { Blinding (performance bias and detection } \\
\text { bias) } \\
\text { Assessor of bleeding assessment }\end{array}$ & Unclear risk & $\begin{array}{l}\text { Bleeding was assessed daily, but it was not } \\
\text { stated how bleeding was assessed not who } \\
\text { assessed the bleeding }\end{array}$ \\
\hline $\begin{array}{l}\text { Blinding (performance bias and detection } \\
\text { bias) } \\
\text { Physician/Medical Staff }\end{array}$ & High risk & $\begin{array}{l}\text { Physicians and patients were not blinded to } \\
\text { the randomisation arm }\end{array}$ \\
\hline $\begin{array}{l}\text { Incomplete outcome data (attrition bias) } \\
\text { All outcomes }\end{array}$ & Low risk & No missing outcome data \\
\hline Selective reporting (reporting bias) & Unclear risk & $\begin{array}{l}\text { Insufficient information to say. No proto- } \\
\text { col available }\end{array}$ \\
\hline
\end{tabular}




\begin{tabular}{|c|c|c|}
\hline Other bias & Low risk & $\begin{array}{l}\text { The study appears to be free of other } \\
\text { sources of biases. }\end{array}$ \\
\hline Protocol Deviation balanced? & Unclear risk & $\begin{array}{l}\text { Protocol deviations or violations were not } \\
\text { commented on. }\end{array}$ \\
\hline
\end{tabular}

Sintnicolaas 1982

\begin{tabular}{ll}
\hline Methods & $\begin{array}{l}\text { Randomised (enrolment period not reported). Study performed by haematological sup- } \\
\text { portive care group in Netherlands }\end{array}$ \\
\hline Participants & $\begin{array}{l}\text { Inclusion criteria: patients with acute leukaemia and severe thrombocytopenia } \\
\mathrm{N}=12\end{array}$ \\
\hline Interventions & $\begin{array}{l}\text { Comparison between prophylactic and therapeutic platelet regimens } \\
\text { Arm 1: Prophylactic platelets to maintain platelet count above } 20 \times 10^{9} / \mathrm{L} \\
\text { Arm 2: Transfusion for 'haemorrhage only' } \\
\text { Platelet dose } 4 \mathrm{x} 10^{11} \text { platelets/transfusion }\end{array}$ \\
\hline Outcomes & $\begin{array}{l}\text { No primary or secondary outcomes reported. } \\
\text { Reported decreased morbidity in the prophylactic group (no deaths due to bleeding) } \\
\text { Reported } 2 \text { patients became refractory to platelets (1 in each arm) }\end{array}$ \\
\hline Notes & Published in abstract form only \\
\hline
\end{tabular}

\section{Risk of bias}

\begin{tabular}{|c|c|c|}
\hline Bias & Authors' judgement & Support for judgement \\
\hline $\begin{array}{l}\text { Random sequence generation (selection } \\
\text { bias) }\end{array}$ & Unclear risk & Method of randomisation not reported \\
\hline Allocation concealment (selection bias) & Unclear risk & $\begin{array}{l}\text { Method of allocation concealment not re- } \\
\text { ported }\end{array}$ \\
\hline $\begin{array}{l}\text { Blinding (performance bias and detection } \\
\text { bias) } \\
\text { Assessor of bleeding assessment }\end{array}$ & Unclear risk & Not reported \\
\hline $\begin{array}{l}\text { Blinding (performance bias and detection } \\
\text { bias) } \\
\text { Physician/Medical Staff }\end{array}$ & Unclear risk & Not reported \\
\hline $\begin{array}{l}\text { Incomplete outcome data (attrition bias) } \\
\text { All outcomes }\end{array}$ & Unclear risk & Only reported as an abstract \\
\hline Selective reporting (reporting bias) & Unclear risk & Only reported as an abstract \\
\hline
\end{tabular}


Sintnicolaas 1982 (Continued)

\begin{tabular}{lll}
\hline Other bias & Unclear risk & Only reported as an abstract \\
\hline Protocol Deviation balanced? & Unclear risk & Not reported \\
\hline
\end{tabular}

Slichter 2010

\begin{tabular}{|c|c|}
\hline Methods & Parallel RCT (enrolled from 2004-2007). Multicentre (26 centres). USA \\
\hline Participants & 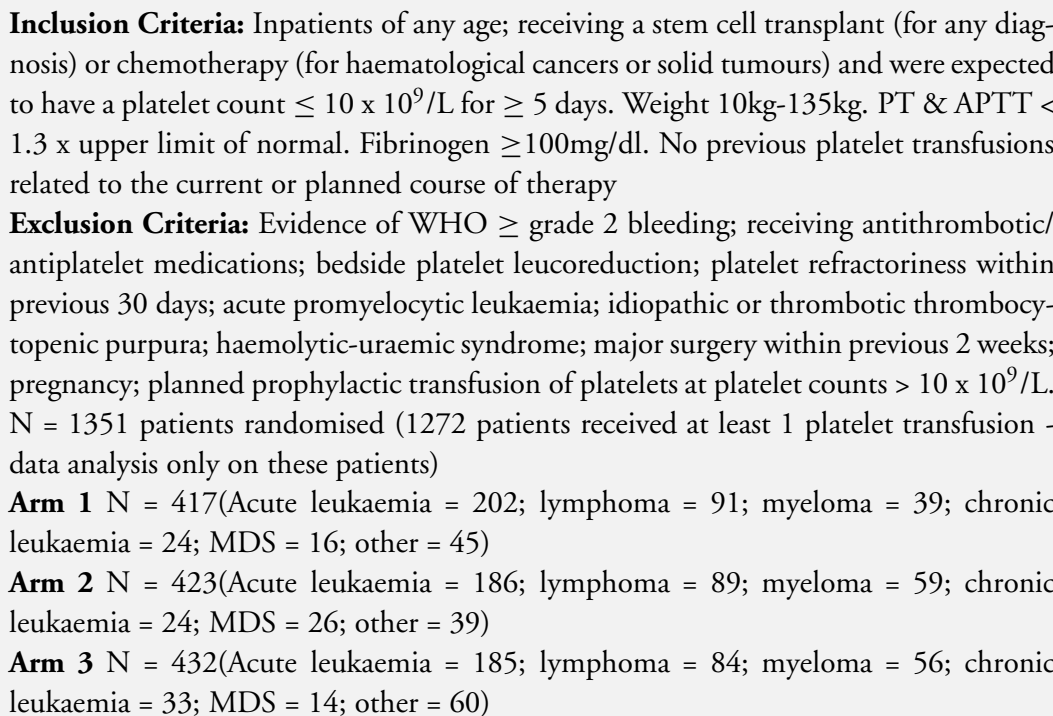 \\
\hline
\end{tabular}

Interventions

Comparison between prophylactic platelet transfusions with different platelet dosages

Arm 1: $1.1 \times 10^{11} / \mathrm{m}^{2}$ body surface area/transfusion $\pm 25 \%$

Arm 2: $2.2 \times 10^{11} / \mathrm{m}^{2}$ body surface area/transfusion $\pm 25 \%$

Arm 3: $4.4 \times 10^{11} / \mathrm{m}^{2}$ body surface area/transfusion $\pm 25 \%$

Platelet transfusion thresholds: Prophylactic platelet transfusions given when platelet count $\leq 10 \times 10^{9} / \mathrm{L}$. Patient's physician could alter transfusion trigger or threshold if required by clinical indications. Therapeutic platelet transfusion trigger not reported

Platelet transfusion type: apheresis and random donor pooled products

Outcomes

Primary outcome: Grade 2 or higher bleeding as determined by the Platelet Dose Trial Bleeding Scale

Secondary outcomes:

- Platelet utilisation rates (total number of platelets transfused x $10^{11}$ )

- Number of platelet transfusion events (frequency of transfusions)

- Highest category of bleeding during time of study

- Bleeding severity based on number of days with bleeding, intensity of bleeding, and number of sites with bleeding

Number of days on study

1272 patients were observed for a total of 24,309 days. Mean number of days 19.1 
Slichter 2010 (Continued)

$\begin{array}{ll}\text { Notes } & \text { Patients randomised at: not reported } \\ \text { Follow-up of patients: until a } 10 \text { day period without a platelet transfusion OR } 30 \text { days } \\ \text { from first platelet transfusion OR discharge from hospital OR withdrawal from study } \\ \text { OR death } \\ \text { Stopping guideline: Stopping boundaries for the comparison of the primary end-point } \\ \text { between each pair of treatment groups were calculated with the use of an alpha spending } \\ \text { function similar to OBrien-Fleming boundaries }\end{array}$

\section{Risk of bias}

\begin{tabular}{|c|c|c|}
\hline Bias & Authors' judgement & Support for judgement \\
\hline $\begin{array}{l}\text { Random sequence generation (selection } \\
\text { bias) }\end{array}$ & Low risk & $\begin{array}{l}\text { Patients were randomly assigned in a } 1: 1 \text { : } \\
1 \text { ratio, by means of computer-generated } \\
\text { permuted blocks, to receive platelets at one } \\
\text { of three doses. Treatment groups were bal- } \\
\text { anced within trial sites with the use of dy- } \\
\text { namic balancing }\end{array}$ \\
\hline Allocation concealment (selection bias) & Unclear risk & Not explicitly reported \\
\hline $\begin{array}{l}\text { Blinding (performance bias and detection } \\
\text { bias) } \\
\text { Assessor of bleeding assessment }\end{array}$ & High risk & $\begin{array}{l}\text { Site staff were not told the patient's assigned } \\
\text { dose but differences in transfusion vol- } \\
\text { ume prevented complete blinding. How- } \\
\text { ever, a computer algorithm assigned the fi- } \\
\text { nal bleeding grade from the collected data, } \\
\text { and this part of the process was at a low risk } \\
\text { of bias }\end{array}$ \\
\hline
\end{tabular}

Blinding (performance bias and detection High risk bias)

Physician/Medical Staff

Incomplete outcome data (attrition bias) High risk All outcomes
Site staff were not told the patient's assigned dose but differences in transfusion volume prevented complete blinding

Analysis of the number of platelet transfusions per patient was limited to patients who had no missing data on the number of transfusion events and number of platelets transfused $(71 \%, 82 \%$ and $83 \%$ of data were complete on low, medium and high dose patients respectively)

Selective reporting (reporting bias) Low risk

Low risk

Study protocol is available and has been reported in the prespecified way

Other bias
The study appears to be free of other sources of bias 
Slichter 2010 (Continued)

\begin{tabular}{|c|c|c|}
\hline Protocol Deviation balanced? & High risk & $\begin{array}{l}\text { A significantly smaller proportion of trans- } \\
\text { fusions were within the assigned dose range } \\
\text { when the "at-issue" platelet counts were } \\
\text { compared between low dose and medium } \\
\text { dose groups }(71 \% \text { vs. } 80 \%(P=0.007)) \\
\text { and between high dose and medium dose } \\
\text { groups }(70 \% \text { vs. } 80 \%(P<0.001)\end{array}$ \\
\hline
\end{tabular}

\section{Solomon 1978}

Methods

Participants

Parallel RCT (period of enrolment not reported). Single centre. USA

Inclusion Criteria: previously untreated non-lymphoblastic acute leukaemia (adults) Exclusion Criteria: promyelocytic leukaemia

$\mathrm{N}=31$ successive patients receiving induction chemotherapy

Arm 1: $\mathrm{N}=19$ patients; 17 patients included in analyses ( 2 died on day 1 of study from cerebral haemorrhage)

Arm 2: N=12 patients receiving 17 courses of chemotherapy

Interventions Comparison of a prophylactic platelet regime versus a therapeutic platelet regime

Arm 1 (Prophylactic):If platelet count $<20 \times 10^{9} / \mathrm{L}$

Arm 2 (Specific indications): clinically significant bleeding or $50 \%$ fall in platelets to below $20 \times 10^{9} / \mathrm{L}$ occurred over 24 hrs.

Both arms received platelets when there was clinically significant bleeding

Platelet dose: not reported

Platelet type: random donor pooled platelets

\begin{tabular}{l|l}
\hline Outcomes & $\begin{array}{l}\text { Primary outcome not reported } \\
\text { Outcomes reported } \\
\text { - Deaths (within 1 month of chemotherapy course) } \\
\text { - Deaths due to bleeding (within 1 month of chemotherapy course) } \\
\text { - Complete remission rates (time period not stated) } \\
\text { - Transfusion requirements (platelets, red cells) per course of chemotherapy } \\
\text { Number of days on study } \\
\text { Not reported. }\end{array}$ \\
\hline Notes & $\begin{array}{l}\text { Patients randomised at: not reported } \\
\text { Follow-up of patients: not reported } \\
\text { Stopping guideline: not reported } \\
\text { Main author died before full publication }\end{array}$ \\
\hline
\end{tabular}

\section{Risk of bias}

Bias

Authors' judgement

Support for judgement

Prophylactic platelet transfusion for prevention of bleeding in patients with haematological disorders after chemotherapy and stem cell 
Solomon 1978 (Continued)

\begin{tabular}{|c|c|c|}
\hline $\begin{array}{l}\text { Random sequence generation (selection } \\
\text { bias) }\end{array}$ & Unclear risk & $\begin{array}{l}\text { Method of random allocation not de- } \\
\text { scribed - " } 17 \text { randomly selected patients } \\
\text { were given platelet transfusions .." }\end{array}$ \\
\hline Allocation concealment (selection bias) & Unclear risk & $\begin{array}{l}\text { Attempt to conceal allocation not men- } \\
\text { tioned. }\end{array}$ \\
\hline $\begin{array}{l}\text { Blinding (performance bias and detection } \\
\text { bias) } \\
\text { Assessor of bleeding assessment }\end{array}$ & Unclear risk & $\begin{array}{l}\text { No mechanisms mentioned to blind out- } \\
\text { come assessors (presumed also to be clini- } \\
\text { cians) to treatment after allocation }\end{array}$ \\
\hline $\begin{array}{l}\text { Blinding (performance bias and detection } \\
\text { bias) } \\
\text { Physician/Medical Staff }\end{array}$ & Unclear risk & $\begin{array}{l}\text { No mechanisms mentioned to blind clini- } \\
\text { cians }\end{array}$ \\
\hline $\begin{array}{l}\text { Incomplete outcome data (attrition bias) } \\
\text { All outcomes }\end{array}$ & Unclear risk & Study not sufficiently reported \\
\hline Selective reporting (reporting bias) & Unclear risk & No protocol available \\
\hline Other bias & Unclear risk & Not enough information to assess \\
\hline Protocol Deviation balanced? & Unclear risk & Not reported \\
\hline
\end{tabular}

Steffens 2002

\begin{tabular}{l|l}
\hline Methods & Parallel RCT (period of enrolment not stated). Single centre. UK \\
\hline Participants & $\begin{array}{l}\text { Inclusion criteria: Patients aged }>16 y r s \text { receiving intensive chemotherapy for AML and } \\
\text { SCT conditioning for allogeneic SCT }\end{array}$ \\
\hline $\begin{array}{l}\text { Exclusion criteria: Patients with HLA antibodies } \\
\text { Patients with cardiovascular disease unable to tolerate a volume load }\end{array}$ & $\begin{array}{l}\mathrm{N}=54 \\
\text { Arm 1: } \mathrm{N}=28 \text { patients. AML }(21) \text { Allogeneic stem cell transplant }(7)\end{array}$ \\
\hline Arm 2: $\mathrm{N}=26$ patients. AML $(19)$ Allogeneic stem cell transplant $(7)$
\end{tabular}

Type of platelet transfusion: single donor apheresis platelets 
Steffens 2002 (Continued)

\begin{tabular}{|c|c|c|}
\hline Outcomes & \multicolumn{2}{|c|}{$\begin{array}{l}\text { No primary or secondary outcomes stated. } \\
\text { Aim: compare the efficacy of single donor platelets given as either a single adult dose or } \\
\text { a triple adult dose }\end{array}$} \\
\hline Notes & \multicolumn{2}{|c|}{$\begin{array}{l}\text { Patients randomised at : initiation of chemotherapy } \\
\text { Patients followed up until: platelet transfusion independent (not further defined) } \\
\text { Stopping guideline: not reported }\end{array}$} \\
\hline \multicolumn{3}{|l|}{ Risk of bias } \\
\hline Bias & Authors' judgement & Support for judgement \\
\hline $\begin{array}{l}\text { Random sequence generation (selection } \\
\text { bias) }\end{array}$ & Unclear risk & Method of random allocation not reported \\
\hline Allocation concealment (selection bias) & Unclear risk & $\begin{array}{l}\text { Method of allocation concealment not re- } \\
\text { ported }\end{array}$ \\
\hline $\begin{array}{l}\text { Blinding (performance bias and detection } \\
\text { bias) } \\
\text { Assessor of bleeding assessment }\end{array}$ & Unclear risk & Method of blinding assessor not reported \\
\hline $\begin{array}{l}\text { Blinding (performance bias and detection } \\
\text { bias) } \\
\text { Physician/Medical Staff }\end{array}$ & Unclear risk & Method of blinding clinician not reported \\
\hline $\begin{array}{l}\text { Incomplete outcome data (attrition bias) } \\
\text { All outcomes }\end{array}$ & Unclear risk & $\begin{array}{l}\text { Insufficiently reported to allow an assess- } \\
\text { ment to be made }\end{array}$ \\
\hline Selective reporting (reporting bias) & High risk & $\begin{array}{l}\text { No protocol available. However mentions } \\
\text { study will reported in more detail in fu- } \\
\text { ture including clinical efficacy, bleeding } \\
\text { episodes, red cell requirements and compli- } \\
\text { cation }\end{array}$ \\
\hline Other bias & Unclear risk & $\begin{array}{l}\text { Study not reported sufficiently to enable a } \\
\text { comment to be made }\end{array}$ \\
\hline Protocol Deviation balanced? & Unclear risk & Not reported \\
\hline
\end{tabular}


Tinmouth 2004

\begin{tabular}{|c|c|}
\hline Methods & $\begin{array}{l}\text { Phase II Bayesian approach study (Feb } 2001 \text { to Mar } 2002 \text { (unpublished)). Single centre. } \\
\text { Canada }\end{array}$ \\
\hline Participants & $\begin{array}{l}\text { Inclusion Criteria: Consecutive patients > } 16 \text { yrs of age. Undergoing autologous stem } \\
\text { cell transplant or induction chemotherapy for ALL or AML } \\
\text { Exclusion Criteria: APL, active bleeding, abnormal coagulation tests, history of a bleed- } \\
\text { ing diathesis, ITP, refractory to platelet transfusions, receiving anticoagulants, antifibri- } \\
\text { nolytics, desmopressin or antiplatelet medication } \\
\mathrm{N}=111 \text { patients enrolled } \\
\text { Arm 1: } \mathrm{N}=56 \text {. Acute leukaemia (17); Autologous transplant (39) } \\
55 \text { patients completed assessment ( } 1 \text { allergic transfusion reaction). } 14 \text { patients did not } \\
\text { require any platelet transfusions } \\
\text { Arm 2: } \mathrm{N}=55 \text {. Acute leukaemia (17); Autologous transplant (38). } \\
51 \text { patients completed assessment ( } 2 \text { withdrawn when required antifibrinolytic or anti- } \\
\text { coagulant; } 2 \text { withdrawn when bleeding initially categorised as major was reclassified as } \\
\text { minor). } 10 \text { patients did not require any platelet transfusions }\end{array}$ \\
\hline Interventions & $\begin{array}{l}\text { Comparison between prophylactic platelet transfusions with different platelet dosages } \\
\text { Arm 1: } 3 \text { units/half single apheresis unit }=1.9-2.5 \times 10^{11} \text { platelets/transfusion } \\
\text { Arm 2: } 5 \text { units/full single apheresis unit }=3.4-4.4 \times 10^{11} \text { platelets/transfusion } \\
\text { Platelet yields were } 6.73 \times 10^{10} \text { to } 8.5 \times 10^{10} \text { per whole blood derived platelet unit and } \\
3.85 \times 10^{11} \text { to } 4.06 \times 10^{11} \text { per apheresis platelet unit } \\
\text { Platelet transfusion thresholds: Prophylactic platelet threshold }<10 \times 10^{9} / \mathrm{L} \text {. } \\
\text { If minor bleeding platelet threshold }<20 \times 10^{9} / \mathrm{L} \text {. Prior to invasive procedures platelet } \\
\text { threshold }<50 \times 10^{9} / \mathrm{L} \text {. } \\
\text { Platelet transfusion type: Random donor pooled platelets (PRP method). Leucode- } \\
\text { pleted. Apheresis platelets only used if no whole blood derived platelets available }\end{array}$ \\
\hline Outcomes & $\begin{array}{l}\text { Hypothesis: Lower dose of platelets would be safe and effective in preventing major } \\
\text { bleeding events and would decrease total utilisation of platelets } \\
\text { Stopping criteria: } \\
\text { Absolute increase in major bleeding in the low-dose group of } \leq 10 \% \text { was considered the } \\
\text { range of equivalence } \\
\text { 1) a high probability (greater than } 80 \% \text { ) of equivalence (i.e., the increase in major } \\
\text { bleeding events with low-dose PLT transfusions was less than } 10 \% \text { ) } \\
\text { 2) a moderately high probability (greater than } 60 \% \text { ) of nonequivalence (i.e., that the } \\
\text { increase in major bleeding events was greater than } 10 \% \text { ) } \\
\text { Number of days on study } \\
\text { Median time from start of chemotherapy to termination of the transfusion protocol was } \\
15 \text { days }\end{array}$ \\
\hline Notes & $\begin{array}{l}\text { Patient randomisation: within } 72 \text { hours of starting chemotherapy } \\
\text { Follow up of patients: until platelet count }>20 \times 10^{9} / \mathrm{L} \text { for } 2 \text { days spontaneously OR } \\
\text { major bleeding event (determined by treating physician) OR refractoriness to platelet } \\
\text { transfusions OR discharge from hospital OR transfer to intensive care unit OR admin- } \\
\text { istration of further chemotherapy OR failure of engraftment OR death }\end{array}$ \\
\hline
\end{tabular}

Risk of bias

Prophylactic platelet transfusion for prevention of bleeding in patients with haematological disorders after chemotherapy and stem cell 
Tinmouth 2004 (Continued)

\begin{tabular}{|c|c|c|}
\hline Bias & Authors' judgement & Support for judgement \\
\hline $\begin{array}{l}\text { Random sequence generation (selection } \\
\text { bias) }\end{array}$ & Low risk & $\begin{array}{l}\text { Computer generated, stratified by diagnos- } \\
\text { tic group. Block randomisation was used } \\
\text { with variable block sizes within strata to } \\
\text { help conceal treatment allocation (unpub- } \\
\text { lished, information supplied by the author) }\end{array}$ \\
\hline Allocation concealment (selection bias) & Low risk & $\begin{array}{l}\text { Sealed, consecutively numbered envelopes } \\
\text { containing information about the platelet } \\
\text { dose group were opened by the hospital } \\
\text { blood bank staff who were not involved in } \\
\text { the study design, clinical management or } \\
\text { data collection for the trial (unpublished, } \\
\text { information supplied by the author) }\end{array}$ \\
\hline $\begin{array}{l}\text { Blinding (performance bias and detection } \\
\text { bias) } \\
\text { Assessor of bleeding assessment }\end{array}$ & High risk & $\begin{array}{l}\text { Clinicians collected the data on bleed- } \\
\text { ing and they were unblinded to the dose } \\
\text { of platelets transfused. "Ajudication com- } \\
\text { mittee of three physicians blinded to the } \\
\text { platelet dose and physician assigned bleed- } \\
\text { ing grade independently reviewed all bleed- } \\
\text { ing events and assigned the final bleeding } \\
\text { grade." Therefore the allocation of a bleed- } \\
\text { ing grade was at a low risk of bias }\end{array}$ \\
\hline $\begin{array}{l}\text { Blinding (performance bias and detection } \\
\text { bias) } \\
\text { Physician/Medical Staff }\end{array}$ & High risk & $\begin{array}{l}\text { Medical and nursing staff were not blinded } \\
\text { to the dose of platelet transfused }\end{array}$ \\
\hline $\begin{array}{l}\text { Incomplete outcome data (attrition bias) } \\
\text { All outcomes }\end{array}$ & Low risk & Balanced withdrawal across groups \\
\hline Selective reporting (reporting bias) & Unclear risk & No protocol available to assess \\
\hline Other bias & Low risk & $\begin{array}{l}\text { The study appears to be free of other } \\
\text { sources of bias }\end{array}$ \\
\hline Protocol Deviation balanced? & High risk & $\begin{array}{l}\text { 15/164 transfusions contravened protocol } \\
\text { in Arm } 1 \\
3 / 147 \text { transfusions contravened protocol in } \\
\text { Arm } 2\end{array}$ \\
\hline
\end{tabular}


Characteristics of excluded studies [ordered by study ID]

\begin{tabular}{|c|c|}
\hline Study & Reason for exclusion \\
\hline Aderka 1986 & A non-randomised retrospective study \\
\hline Agliastro 2006 & Comparison of apheresis vs. buffy coat platelet transfusions (Abstract) \\
\hline Akkök 2007 & Comparison of apheresis vs. buffy coat platelet transfusions \\
\hline Anderson 1997 & Comparison of apheresis versus buffy coat derived versus platelet rich plasma derived platelet products \\
\hline Andrew 1993 & Wrong patient group - premature infants \\
\hline Arnold 2004 & Comparison of apheresis versus whole blood derived platelet transfusions \\
\hline Arnold 2006 & Wrong patient group - ITU \\
\hline Bai 2004 & Wrong patient group - solid tumours \\
\hline Bentley 2000 & Comparison of autologous versus allogeneic platelet transfusions \\
\hline Blumberg 2002 & Comparison of washed versus standard platelet transfusions \\
\hline Blundell 1996 & Comparison of standard versus pathogen inactivated platelets \\
\hline Callow 2002 & A non-randomised prospective study with historical control \\
\hline Cameron 2007 & A non-randomised prospective study \\
\hline Carr 1990 & Comparison of $\mathrm{ABO}$-matched versus mismatched platelet products \\
\hline Chaoui 2005 & Observational prospective study \\
\hline Cid 2007 & Systematic review of differing platelet transfusion doses \\
\hline Couban 2002 & Comparison of plasma reduction and leucodepletion \\
\hline de Wildt-Eggen 2000 & Comparison of platelet concentrates in plasma versus additive solution \\
\hline Decaudin 2004 & Non-randomised prospective study \\
\hline Diedrich 2009 & Comparison of platelet products stored $1-5$ versus 6-7 days \\
\hline Dumont 2011 & Comparison of buffy coat versus platelet rich plasma platelet concentrates \\
\hline Eder 2007 & Non-randomised observational study \\
\hline
\end{tabular}

Prophylactic platelet transfusion for prevention of bleeding in patients with haematological disorders after chemotherapy and stem cell 75 
(Continued)

\begin{tabular}{|c|c|}
\hline Elting 2002 & Retrospective analysis - lymphoma and solid tumours \\
\hline Elting 2003 & Non-randomised retrospective cohort - lymphoma and solid tumours \\
\hline Fanning 1995 & Wrong patient group - gynaecological cancer \\
\hline Follea 2004 & Guideline \\
\hline Friedmann 2002 & A non-randomised retrospective analysis \\
\hline Gajic 2006 & Wrong patient group - ITU \\
\hline Gerday 2009 & Wrong patient group - neonates \\
\hline Gil-Fernandez 1996 & A non-randomised retrospective historical control study (different platelet transfusion thresholds) \\
\hline Gmur 1983 & Comparison of single donor versus pooled platelet products \\
\hline Gmur 1991 & A non-randomised prospective cohort observational study (different platelet transfusion thresholds) \\
\hline Goodnough 2001 & Fewer than $80 \%$ of patients diagnosed with a haematological disorder - different platelet doses \\
\hline Goodrich 2008 & Comparison of pathogen inactivated versus standard apheresis platelets \\
\hline Greeno 2007 & A non-randomised prospective observational study (different platelet transfusion thresholds) \\
\hline Gurkan 2007 & Comparison of apheresis vs. pooled platelet products \\
\hline Hardan 1994 & $\begin{array}{l}\text { A non-randomised observational study, (therapeutic platelets only), historical control reported only as an } \\
\text { abstract }\end{array}$ \\
\hline Harrup 1999 & Comparison of buffy coat plasma or T-sol platelet transfusions \\
\hline Heal 1993 & Comparison of $\mathrm{ABO}$ compatible versus mismatched platelet transfusions \\
\hline Heddle 1994 & Comparison of plasma from platelet concentrates versus platelets \\
\hline Heddle 1999 & Comparison of plasma removal versus leucodepletion \\
\hline Heddle 2002 & Comparison of plasma removal versus leucodepletion \\
\hline Heddle 2003 & Systematic review - methods of assessing bleeding outcome \\
\hline Hilbom 2008 & Wrong patient group - intracerebral haemorrhage \\
\hline ISRCTN49080246 & Comparison of $1-5$ vs. 6-7 day old platelet transfusions \\
\hline
\end{tabular}

Prophylactic platelet transfusion for prevention of bleeding in patients with haematological disorders after chemotherapy and stem cell 76 
(Continued)

\begin{tabular}{|c|c|}
\hline Johansson 2007 & Wrong patient group - ruptured abdominal aortic aneurysm \\
\hline Julmy 2009 & Wrong patient group - ruptured abdominal aortic aneurysm \\
\hline Kakaiya 1981 & Comparison of apheresis versus pooled platelet concentrates \\
\hline Kerkhoffs 2010 & Comparison of standard platelets versus pathogen inactivated platelets versus platelets stored in PAS II media \\
\hline Klumpp 1999 & $\begin{array}{l}\text { A randomised cross-over study. This study was included within the previous systematic review. However } \\
\text { because of stricter inclusion/exclusion criteria this study has now been excluded from the review } \\
\text { Only laboratory outcomes were reported. } \\
37 \% \text { of patients had a non-haematological malignancy (breast cancer) }\end{array}$ \\
\hline Lapierre 2003 & Comparison of standard apheresis platelet products versus a donor reduction policy \\
\hline Lawrence 2001 & A non-randomised retrospective historical control study (different platelet transfusion thresholds) \\
\hline Leach 1991 & Comparison of warmed versus standard platelet transfusions \\
\hline Lee 1989 & Comparison of $\mathrm{ABO}$ matched versus mis-matched platelet transfusions \\
\hline Lozano 2010 & Efficacy of older platelet transfusions \\
\hline Lozano 2011 & Comparison of pathogen inactivated vs. conventional platelet products \\
\hline McCullough 2004 & Comparison of pathogen inactivated vs conventional apheresis platelets \\
\hline Messerschmidt 1988 & Comparison of HLA matched versus mismatched platelet transfusions \\
\hline Mirasol 2010 & Comparison of pathogen inactivated vs. conventional platelet products \\
\hline Murphy 1986 & Comparison of HLA matched and leucodepleted blood products \\
\hline Navarro 1998 & $\begin{array}{l}\text { A non-randomised retrospective historical control observational study (different platelet transfusion thresh- } \\
\text { olds) }\end{array}$ \\
\hline Nevo 2007 & A non-randomised retrospective analysis (different platelet thresholds) \\
\hline Norol 1998 & A non-randomised prospective comparison (three different doses of platelets) \\
\hline Oksanen 1991 & Comparison of pre versus post storage leucodepletion of PRP derived platelet transfusions \\
\hline Oksanen 1994 & Comparison of leucodepleted buffy coat derived platelet transfusions versus historical control \\
\hline Paananen 2009 & Non-randomised study (unclear whether prospective or retrospective) \\
\hline Qureshi 2007 & Audit of platelet transfusions in the UK \\
\hline
\end{tabular}

Prophylactic platelet transfusion for prevention of bleeding in patients with haematological disorders after chemotherapy and stem cell 77 transplantation (Review)

Copyright (? 2012 The Cochrane Collaboration. Published by John Wiley \& Sons, Ltd. 
(Continued)

\begin{tabular}{|c|c|}
\hline Rabinowitz 2010 & Review \\
\hline Reed 1986 & Wrong patient group - massive transfusion \\
\hline Sagmeister 1999 & A non-randomised retrospective study (aplastic anaemia) \\
\hline Samama 2005 & Guideline \\
\hline Schiffer 1983 & Comparison of leucodepleted versus standard platelet concentrates \\
\hline Shanwell 1992 & Comparison of fresh versus stored platelets \\
\hline Shehata 2009 & Systematic review - ABO identical versus non-identical platelet transfusions \\
\hline Singer 1988 & Single donor HLA matched versus random donor platelets \\
\hline Sintnicolaas 1995 & Comparison of leucocyte depleted versus standard platelets \\
\hline Slichter 2006 & Comparison of pathogen inactivated vs conventional apheresis platelets \\
\hline Speiss 2004 & Wrong patient group - cardiac \\
\hline Strindberg 1996 & Comparison of apheresis versus buffy coat platelet products \\
\hline Sweeney 2000 & Comparison of pre-storage leucodepleted versus bed-side leucodepleted platelets \\
\hline Tosetto 2009 & Guideline \\
\hline TRAP 1997 & $\begin{array}{l}\text { Comparison of standard pooled platelet product vs. irradiated pooled platelet product vs. leucodepleted } \\
\text { pooled platelet product vs. apheresis platelet product }\end{array}$ \\
\hline Vadhan-Raj 2002 & Wrong patient group - gynaecological malignancy \\
\hline Van Marwijk 1991 & Comparison of leucodepleted platelet products prepared by filtration or centrifugation \\
\hline van Rhenen 2003 & Comparison of pathogen inactivated versus standard buffy coat derived platelet transfusions \\
\hline Verma 2008 & A non-randomised observational study \\
\hline Wandt 1998 & A non-randomised prospective cohort study (not randomised at the participant level) \\
\hline Wandt 2005 & $\begin{array}{l}\text { A non-randomised prospective study with an historical case control (therapeutic vs. prophylactic platelet } \\
\text { transfusions) }\end{array}$ \\
\hline Wandt 2006 & $\begin{array}{l}\text { A non-randomised prospective study with an historical case control (therapeutic vs. prophylactic platelet } \\
\text { transfusions) }\end{array}$ \\
\hline
\end{tabular}


(Continued)

\begin{tabular}{ll}
\hline Wang 2002 & A comparison of acetaminophen and diphenhydramine vs. placebo as premedication for platelet transfusions \\
\hline Weigand 2009 & Prospective observational study \\
\hline Williamson 1994 & Comparison of standard versus bedside leucodepleted platelet products \\
\hline Zahur 2002 & Prospective observational study \\
\hline Zhao 2002 & Comparison of leucodepleted versus standard platelet transfusions \\
\hline Zumberg 2002 & $\begin{array}{l}\text { This study was included within the previous systematic review. However because of stricter inclusion/ } \\
\text { exclusion criteria this study has now been excluded from the review } \\
\text { 31\% of patients had a non-haematological malignancy (breast cancer) }\end{array}$ \\
\hline
\end{tabular}

\section{Characteristics of ongoing studies [ordered by study ID]}

\section{Franklin 1995}

\begin{tabular}{ll}
\hline Trial name or title & Clinical efficacy of platelet transfusions in relation to platelet dose given \\
\hline Methods & Open versus blinded study (unknown). Single centre versus multicentre (unknown) \\
\hline Participants & Patients undergoing BMT \\
\hline Interventions & Response to platelets \\
\hline Outcomes & 1995 \\
\hline Starting date & Prof I Franklin, Glasgow, UK \\
\hline Contact information & $\begin{array}{l}\text { Not actively recruiting patients at the moment } \\
\text { Author contacted but did not supply any further information. }\end{array}$ \\
\hline Notes &
\end{tabular}

\section{Lu 2011}

\begin{tabular}{ll} 
Trial name or title & Effect of reducing prophylactic platelet transfusion dose on bleeding in thrombocytopenic patients \\
\hline Methods & Single centre. Randomised Controlled Trial. Open versus blinded study (unknown) \\
\hline Participants & $\begin{array}{l}\text { Hospitalised patients undergoing haematopoietic stem-cell transplantation or chemotherapy for haematolog- } \\
\text { ical cancers or solid tumours }\end{array}$
\end{tabular}




\section{Lu 2011 (Continued)}

\begin{tabular}{ll}
\hline Interventions & $\begin{array}{l}\text { Eligible patients randomised to receive low dose }\left(1.1 \times 10^{11} / \mathrm{m}^{2}\right) \text { or standard dose }\left(2.2 \times 10^{11} / \mathrm{m}^{2}\right) \text { prophylactic } \\
\text { platelet transfusions when the morning platelet count was } \leq 10 \times 10^{9} / \mathrm{L}\end{array}$ \\
\hline Outcomes & $\begin{array}{l}\text { Primary outcome: percentage of patients with bleeding of grade } 2 \text { or higher (as defined on the basis of World } \\
\text { Health Organization criteria) } \\
\text { Secondary outcomes: incidence of higher grades of bleeding; number of platelet transfusions/patient; number } \\
\text { of platelets/patient }\end{array}$ \\
\hline Starting date & Not reported \\
\hline Contact information & Dr Fa Qiang Lu faqianglu@yahoo.com \\
\hline Notes & Study completed but not published \\
Author contacted but did not supply any further information.
\end{tabular}

\section{NCT00180986}

Trial name or title Randomized Trial Of Platelet Transfusion Policies After Blood Stem Cells Transplantation In Young Children: Reduction Of Number Of Single Platelet Concentrate Donors Per Child

\begin{tabular}{ll}
\hline Methods & Open-label, parallel, randomised controlled trial. Single centre versus multicentre (unknown) \\
\hline Participants & $\begin{array}{l}\text { Children weighing } 30 \mathrm{~kg} \text { or less with a diagnosis of haematological malignancy or solid tumour, who were } \\
\text { candidates for HSCT were eligible for inclusion in the study. Children were excluded if they had an anti-HLA } \\
\text { and/or anti-HPA antibody, if they were prior included in this study or if the parents declined to participate }\end{array}$ \\
\hline Interventions & Different platelet transfusion policies \\
\hline Outcomes & $\begin{array}{l}\text { The primary end point of the study was to compare the number of platelet concentrates donors who were } \\
\text { implicated in platelet transfusion supportive after HSCT }\end{array}$ \\
\hline Starting date & October 1995 \\
\hline Contact information & $\begin{array}{l}\text { NCT00180986 } \\
\text { Not actively recruiting but ongoing } \\
\text { Author contacted but did not supply any further information. }\end{array}$ \\
\hline Notes & \begin{tabular}{l} 
Ond \\
\hline
\end{tabular}
\end{tabular}

\section{Stanworth 2010}

Trial name or title A randomised controlled trial of prophylactic versus no-prophylactic platelet transfusions in patients with haematological malignancies

Methods

Open-label, parallel, multicentre, randomised controlled trial 


Participants
lignancy; they are receiving or are going to receive myelosuppressive chemotherapy on this hospital admission
with or without haematopoietic stem cell support (this includes patients undergoing haemopoietic stem cell
transplantation - autograft or allograft); they are thrombocytopenic or expected to become thrombocytopenic
with a platelet count of less than $50 \times 10^{9} / \mathrm{L}$ for at least five days; they are able to comply with treatment and
monitoring
Exclusion Criteria: They have had a World Health Organisation (WHO) Grade three or four bleed (refer to
Modified WHO Bleeding Criteria) during any stage of their treatment to date; during the current admission,
they have experienced or are currently experiencing a WHO Grade two or greater bleed; they have any
inherited clotting disorder (e.g. haemophilia); they need to remain on regular aspirin (or related drugs), or will
require regular therapeutic doses of anticoagulants (heparin), during the whole period of thrombocytopenia;
they have acute promyelocytic leukaemia; they have known HLA antibodies; they are pregnant; they have
previously been randomised in this trial at any stage of their treatment

Interventions $\quad$ Eligible patients will be randomised to receive either prophylactic platelet transfusions if the platelet count is less than $10 \times 10^{\wedge} 9 / \mathrm{L}$, or no prophylaxis with therapeutic transfusions given only after documented signs or symptoms of bleeding

Outcomes

Primary outcome: percentage of patients who develop a WHO Grade two, three or four bleeding event up to 30 days from randomisation. The percentage of patients a WHO Grade two, three or four bleed by day 30 will be calculated for each arm

Secondary outcomes: Logistic regression for proportion developing grade 3 or 4 bleed - subsidiary outcome measure: Cox proportional hazards regression model for time to first WHO grade two, three, or four bleed; time from randomisation to second grade two bleed; period in hospital; poisson regression for the rate of bleeding events

\begin{tabular}{ll} 
Starting date & July 2006 \\
\hline Contact information & $\begin{array}{l}\text { Dr Simon Stanworth } \\
\text { simon.stanworth@nhsbt.nhs.uk }\end{array}$ \\
\hline Notes & $\begin{array}{l}\text { ISRCTN08758735 } \\
\text { Study completed but not published }\end{array}$ \\
\hline
\end{tabular}

\section{Wandt 2009}

Trial name or title

Prospective Randomized Trial Comparing a Prophylactic With a Therapeutic Platelet Transfusion Strategy in Two Groups:1) In Patients With Acute Myeloid Leukemia After Intensive Chemotherapy and 2) After Autologous Blood Stem Cell Transplantation

Methods Open-label, parallel, multicentre, randomised controlled trial

Participants

\section{Inclusion Criteria}

(AML Group): Inclusion in studies of the DSIL or OSHO group for AML; AML M3/M3v can be included only when in complete remission; age 16 - 80 years

(Autologous Group): AML and ALL patients in first or second remission; low grade or high grade NonHodgkin lymphoma or morbus Hodgkin or multiple myeloma; conditioning regime: TBI 8-12 Gy/Cy 120 or BEAM or BU/CY or Melphalan $140-200 \mathrm{mg} / \mathrm{m} 2$ or a similarly intensive chemotherapy regime; age 16 -

Prophylactic platelet transfusion for prevention of bleeding in patients with haematological disorders after chemotherapy and stem cell 8 transplantation (Review)

Copyright $\odot 2012$ The Cochrane Collaboration. Published by John Wiley \& Sons, Ltd. 
Wandt 2009 (Continued)

\begin{tabular}{|c|c|}
\hline & $\begin{array}{l}65 \text { years } \\
\text { Exclusion Criteria } \\
\text { (Both Groups): known refractoriness to platelet transfusion; known major bleeding with thrombocytopenia } \\
\text { when the reason for bleeding is still ongoing known plasmatic coagulation disorder; patient unable to give } \\
\text { informed consent } \\
\text { (Autologous Group): patients with pulmonal or cerebral lesions due to infection or neoplasm; patients with } \\
\text { AL-amyloidosis }\end{array}$ \\
\hline Interventions & $\begin{array}{l}\text { In the therapeutic platelet transfusion arm: platelet transfusion is only required if bleeding occurs (more than } \\
\text { petechial)or in case of pulmonary infections with or without sepsis } \\
\text { In the prophylactic platelet transfusion arm: platelet transfusion has to be performed when platelet count is } \\
\text { below } 10,000 / \mu \mathrm{L} \text { in any case and when bleeding (more than petechial) occurs }\end{array}$ \\
\hline Outcomes & $\begin{array}{l}\text { Primary Outcome: reduction in numbers of platelet transfusion by } 25 \% \text { in the experimental arm (therapeutic } \\
\text { transfusion strategy)compared with the standard arm (prophylactic transfusion strategy) } \\
\text { Secondary Outcomes: incidence and duration of clinically relevant bleeding - numbers of red blood cell } \\
\text { transfusion - side effects of transfusions - duration of thrombocytopenia below } 10,000 / \mu \mathrm{L} \text { and below } 20,000 / \\
\mu \mathrm{L} \text { - duration of hospitalisation }\end{array}$ \\
\hline Starting date & September 2004 \\
\hline Contact information & $\begin{array}{l}\text { Hannes Wandt, Dr. MD wandt@klinikum-nuernberg.de } \\
\text { Kerstin Schäfer-Eckart, Dr. schaefer@klinikum-nuernberg.de }\end{array}$ \\
\hline Notes & $\begin{array}{l}\text { NCT00521664 } \\
\text { Study completed but not published }\end{array}$ \\
\hline
\end{tabular}


DATA AND ANALYSES

Comparison 1. Prophylactic platelet transfusion versus non prophylactic or therapeutic transfusion

\begin{tabular}{|c|c|c|c|c|}
\hline Outcome or subgroup title & $\begin{array}{l}\text { No. of } \\
\text { studies }\end{array}$ & $\begin{array}{c}\text { No. of } \\
\text { participants }\end{array}$ & Statistical method & Effect size \\
\hline $\begin{array}{l}1 \text { Numbers of participants with a } \\
\text { significant bleeding event }\end{array}$ & 1 & 56 & Risk Ratio (M-H, Fixed, 95\% CI) & $1.66[0.90,3.04]$ \\
\hline 1.1 Patients with ALL & 1 & 43 & Risk Ratio (M-H, Fixed, 95\% CI) & $2.61[1.00,6.83]$ \\
\hline 1.2 Patients with AML & 1 & 13 & Risk Ratio (M-H, Fixed, 95\% CI) & $0.93[0.45,1.95]$ \\
\hline $\begin{array}{l}2 \text { Number of days with significant } \\
\text { bleeding }\end{array}$ & 1 & 34213 & Risk Ratio (M-H, Fixed, 95\% CI) & $0.90[0.62,1.32]$ \\
\hline 2.1 Patients with ALL & 1 & 27516 & Risk Ratio (M-H, Fixed, 95\% CI) & $0.81[0.43,1.52]$ \\
\hline 2.2 Patients with AML & 1 & 6697 & Risk Ratio (M-H, Fixed, 95\% CI) & $0.96[0.60,1.54]$ \\
\hline 3 Mortality from all causes & 2 & 85 & Risk Ratio (M-H, Fixed, 95\% CI) & $0.97[0.48,1.93]$ \\
\hline 4 Mortality from bleeding & 2 & 85 & Risk Ratio (M-H, Fixed, 95\% CI) & $1.08[0.23,5.06]$ \\
\hline $\begin{array}{l}5 \text { Mean number of platelet } \\
\text { transfusions per course of } \\
\text { chemotherapy }\end{array}$ & 2 & 85 & Mean Difference (IV, Fixed, 95\% CI) & $\begin{array}{l}-15.80[-19.20,-12 . \\
40]\end{array}$ \\
\hline $\begin{array}{l}6 \text { Mean number of red cell } \\
\text { transfusions per patient }\end{array}$ & 1 & 29 & Mean Difference (IV, Fixed, 95\% CI) & $0.60[-0.14,1.34]$ \\
\hline 7 Remission rates & 1 & 29 & Risk Ratio (M-H, Fixed, 95\% CI) & $1.06[0.50,2.27]$ \\
\hline $\begin{array}{l}8 \text { Number of participants with } \\
\text { platelet refractoriness }\end{array}$ & 1 & 56 & Risk Ratio (M-H, Fixed, 95\% CI) & $0.33[0.04,2.66]$ \\
\hline
\end{tabular}

Comparison 2. Prophylactic platelet transfusion at one trigger level versus another trigger level

\begin{tabular}{|c|c|c|c|c|}
\hline Outcome or subgroup title & $\begin{array}{l}\text { No. of } \\
\text { studies }\end{array}$ & $\begin{array}{c}\text { No. of } \\
\text { participants }\end{array}$ & Statistical method & Effect size \\
\hline $\begin{array}{l}1 \text { Number of participants with any } \\
\text { bleeding event }\end{array}$ & 1 & 78 & Risk Ratio (M-H, Fixed, 95\% CI) & $1.05[0.92,1.19]$ \\
\hline $\begin{array}{l}2 \text { Numbers of participants with a } \\
\text { significant bleeding event }\end{array}$ & 3 & 499 & Risk Ratio (M-H, Fixed, 95\% CI) & $1.35[0.95,1.90]$ \\
\hline $\begin{array}{l}2.1 \text { Platelet threshold }<10 \text { vs. } \\
<20\end{array}$ & 2 & 333 & Risk Ratio (M-H, Fixed, 95\% CI) & $1.41[0.95,2.10]$ \\
\hline $\begin{array}{l}2.2 \text { Platelet threshold }<10 \text { vs. } \\
<30\end{array}$ & 1 & 166 & Risk Ratio (M-H, Fixed, 95\% CI) & $1.19[0.59,2.37]$ \\
\hline $\begin{array}{l}3 \text { Number of participants with } \\
\text { WHO Grade } 3 \text { or } 4 \text { bleeding }\end{array}$ & 2 & 421 & Risk Ratio (M-H, Fixed, 95\% CI) & $0.99[0.52,1.88]$ \\
\hline $\begin{array}{l}3.1 \text { Platelet threshold }<10 \text { vs. } \\
<20\end{array}$ & 1 & 255 & Risk Ratio (M-H, Fixed, 95\% CI) & $1.21[0.58,2.54]$ \\
\hline $\begin{array}{l}3.2 \text { Platelet threshold }<10 \text { vs. } \\
<30\end{array}$ & 1 & 166 & Risk Ratio (M-H, Fixed, 95\% CI) & $0.55[0.14,2.13]$ \\
\hline
\end{tabular}

Prophylactic platelet transfusion for prevention of bleeding in patients with haematological disorders after chemotherapy and stem cell 83 transplantation (Review)

Copyright ( 2012 The Cochrane Collaboration. Published by John Wiley \& Sons, Ltd. 
bleeding requiring a red cell transfusion

5 Number of days with any bleeding

6 Number of days with a significant bleed

7 Mortality from all causes

8 Mortality from bleeding

9 Mean number of platelet transfusions per patient

10 Mean number of red cell transfusions per patient

11 Remission rates

12 Numbers of participants with platelet transfusion reactions

13 Number of participants with thromboembolic disease

14 Number of participants requiring HLA-matched platelets

15 Number of participants with platelet refractoriness

\section{Comparison 3. Prophylactic platelet transfusion with one dose schedule versus another dose schedule}

\begin{tabular}{|c|c|c|c|c|}
\hline Outcome or subgroup title & $\begin{array}{l}\text { No. of } \\
\text { studies }\end{array}$ & $\begin{array}{l}\text { No. of } \\
\text { participants }\end{array}$ & Statistical method & Effect size \\
\hline $\begin{array}{l}1 \text { Number of participants with any } \\
\text { bleeding event }\end{array}$ & 2 & & Risk Ratio (M-H, Fixed, 95\% CI) & Subtotals only \\
\hline $\begin{array}{l}\text { 1.1 Low dosage platelet } \\
\text { transfusion versus standard } \\
\text { dose platelet transfusions }\end{array}$ & 1 & 119 & Risk Ratio (M-H, Fixed, 95\% CI) & $1.16[1.00,1.35]$ \\
\hline $\begin{array}{l}\text { 1.2 High dosage platelet } \\
\text { transfusion versus standard } \\
\text { dose platelet transfusion }\end{array}$ & 1 & 96 & Risk Ratio (M-H, Fixed, 95\% CI) & $0.56[0.20,1.54]$ \\
\hline $\begin{array}{l}2 \text { Number of participants with a } \\
\text { significant bleeding event }\end{array}$ & 4 & & Risk Ratio (M-H, Fixed, 95\% CI) & Subtotals only \\
\hline $\begin{array}{l}\text { 2.1 Low dosage platelet } \\
\text { transfusions versus standard } \\
\text { dosage platelet transfusions }\end{array}$ & 3 & 1070 & Risk Ratio (M-H, Fixed, 95\% CI) & $1.04[0.95,1.13]$ \\
\hline $\begin{array}{l}\text { 2.2 High dosage platelet } \\
\text { transfusions versus standard } \\
\text { dosage platelet transfusions }\end{array}$ & 2 & 951 & Risk Ratio (M-H, Fixed, 95\% CI) & $1.02[0.93,1.11]$ \\
\hline $\begin{array}{l}3 \text { Number of participants with } \\
\text { WHO Grade } 3 \text { or } 4 \text { bleeding }\end{array}$ & 2 & & Risk Ratio (M-H, Fixed, 95\% CI) & Subtotals only \\
\hline $\begin{array}{l}\text { 3.1 Low dose vs. standard } \\
\text { dose }\end{array}$ & 2 & 959 & Risk Ratio (M-H, Fixed, 95\% CI) & $1.33[0.91,1.92]$ \\
\hline
\end{tabular}

Prophylactic platelet transfusion for prevention of bleeding in patients with haematological disorders after chemotherapy and stem cell transplantation (Review) 


\subsection{High dose vs. Standard} dose

4 Number of participants with WHO grade 4 bleeding

4.1 Low dose versus standard dose platelet transfusions

4.2 High dose versus standard dose platelet transfusions

5 Number of participants with bleeding requiring a red cell transfusion

6 Number of participants with bleeding causing cardiovascular compromise

7 Number of days with significant bleeding

7.1 Low dose versus standard dose platelet transfusions

7.2 High dose versus standard dose platelet transfusions

8 Mortality from all causes 8.1 Low dose vs. standard dose

8.2 High dose vs. standard dose

9 Mortality from bleeding 9.1 Low dosage platelet transfusions versus standard dose platelet transfusions 9.2 High dosage platelet transfusions versus standard dosage platelet transfusions

10 Number of participants with platelet transfusion reactions

10.1 Allergic reaction or hypersensitivity: Low dosage platelet transfusions versus standard dosage platelet transfusions

10.2 Allergic reaction or hypersensitivity: High dosage platelet transfusions versus standard dosage platelet transfusions

10.3 Hypotension: Low dosage platelet transfusions versus standard dosage platelet transfusions
Subtotals only

$1.87[0.86,4.08]$

$1.10[0.43,2.83]$

$0.88[0.28,2.72]$

$2.95[0.12,70.82]$

Risk Ratio (M-H, Fixed, 95\% CI)

Subtotals only

$1.16[0.91,1.47]$

$1.13[0.26,4.95]$

Subtotals only $2.04[0.70,5.93]$

Risk Ratio (M-H, Fixed, 95\% CI)

1070 Risk Ratio (M-H, Fixed, 95\% CI)

Risk Ratio (M-H, Fixed, 95\% CI)

$1.71[0.51,5.81]$

Risk Ratio (M-H, Fixed, 95\% CI)

859 Risk Ratio (M-H, Fixed, 95\% CI)

Subtotals only $0.0[0.0,0.0]$

$1.47[0.06,35.90]$

Subtotals only

Risk Ratio (M-H, Fixed, 95\% CI)

$0.83[0.55,1.26]$

1 840

Risk Ratio (M-H, Fixed, 95\% CI)

$1.24[0.86,1.79]$

Prophylactic platelet transfusion for prevention of bleeding in patients with haematological disorders after chemotherapy and stem cell 
platelet transfusions versu

standard dosage platelet

transfusions

10.6 Dyspnoea: High dosage

platelet transfusions versus

standard dosage platelet

transfusions

10.7 Hypoxia: Low dosage

platelet transfusions versus

standard dosage platelet

transfusions

10.8 Hypoxia: High dosage transfusions

10.9 Wheezing: Low dosage

standard dosage platelet

transfusions

10.10 Wheezing: High dosage platelet transfusions versus standard dosage platelet transfusions

10.11 Wheezing: Low dosage platelet transfusions versus high dosage platelet transfusions

10.12 Haemolysis: Low dosage platelet transfusions versus standard dosage platelet transfusions

10.13 Haemolysis: High dosage platelet transfusions versus standard dosage platelet transfusions

10.14 Rigors or chills: Low

versus standard dosage platelet transfusions transfusions 
10.17 Fever: High dosage platelet transfusions versus standard dosage platelet transfusions

10.18 Infection: Low dosage platelet transfusions versus standard dosage platelet transfusions

10.19 Infection: High dosage platelet transfusions versus standard dosage platelet transfusions

11 Thromboembolic disease 11.1 Low dosage platelet transfusions versus standard dose platelet transfusions 11.2 High dosage platelet transfusions versus standard dosage platelet transfusions

12 Number of participants with a significant bleeding episode

12.1 Autologous

transplantation versus

chemotherapy

12.2 Autologous

transplantation versus

Allogeneic transplantation

13 Time to first significant bleeding event

14 Number of days with WHO grade 2 or above bleeding per patient

\section{Comparison 4. Prophylactic platelet transfusion versus platelet-poor plasma}

\begin{tabular}{lcccc} 
Outcome or subgroup title & $\begin{array}{c}\text { No. of } \\
\text { studies }\end{array}$ & $\begin{array}{c}\text { No. of } \\
\text { participants }\end{array}$ & Statistical method & Effect size \\
\hline $\begin{array}{l}\text { 1 Number of participants with a } \\
\quad \text { significant bleeding event }\end{array}$ & 1 & 21 & Risk Ratio (M-H, Fixed, 95\% CI) & $0.47[0.23,0.95]$ \\
2 Time to first bleed & 1 & 21 & Mean Difference (IV, Fixed, 95\% CI) & $0.0[-7.57,7.57]$ \\
$\begin{array}{l}\text { Number of participants with } \\
\quad \text { bleeding requiring a red cell }\end{array}$ & 1 & 21 & Risk Ratio (M-H, Fixed, 95\% CI) & $0.38[0.13,1.11]$ \\
$\quad$ transfusion & & & & \\
4 Number of participants with & 1 & 21 & Risk Ratio (M-H, Fixed, 95\% CI) & $0.75[0.05,10.44]$ \\
$\quad \begin{array}{l}\text { bleeding causing cardiovascular } \\
\text { compromise }\end{array}$ & & & & \\
$\begin{array}{l}\text { 5 Mortality from bleeding } \\
\text { 6 Complete remission }\end{array}$ & 1 & 21 & Risk Ratio (M-H, Fixed, 95\% CI) & $2.31[0.10,50.85]$ \\
\hline
\end{tabular}

Prophylactic platelet transfusion for prevention of bleeding in patients with haematological disorders after chemotherapy and stem cell 87 transplantation (Review) 


\section{Analysis I.I. Comparison I Prophylactic platelet transfusion versus non prophylactic or therapeutic} transfusion, Outcome I Numbers of participants with a significant bleeding event.

Review: Prophylactic platelet transfusion for prevention of bleeding in patients with haematological disorders after chemotherapy and stem cell transplantation

Comparison: I Prophylactic platelet transfusion versus non prophylactic or therapeutic transfusion

Outcome: I Numbers of participants with a significant bleeding event

\begin{tabular}{|c|c|c|c|c|c|}
\hline \multirow[t]{2}{*}{ Study or subgroup } & Therapeutic & Prophylactic & Risk Ratio & \multirow[t]{2}{*}{ Weight } & \multirow{2}{*}{$\begin{array}{r}\text { Risk Ratio } \\
\text { M-H,Fixed,95\% Cl }\end{array}$} \\
\hline & $\mathrm{n} / \mathrm{N}$ & $\mathrm{n} / \mathrm{N}$ & M-H,Fixed,95\% Cl & & \\
\hline \multicolumn{6}{|l|}{ I Patients with ALL } \\
\hline Murphy 1982 & $7 / 15$ & $5 / 28$ & 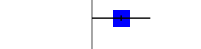 & $43.0 \%$ & $2.61[1.00,6.83]$ \\
\hline Subtotal (95\% CI) & 15 & 28 & & $43.0 \%$ & $2.61[1.00,6.83]$ \\
\hline \multicolumn{6}{|c|}{ Total events: 7 (Therapeutic), 5 (Prophylactic) } \\
\hline \multicolumn{6}{|c|}{ Heterogeneity: not applicable } \\
\hline \multicolumn{6}{|c|}{ Test for overall effect: $Z=1.96(P=0.050)$} \\
\hline \multicolumn{6}{|c|}{2 Patients with AML } \\
\hline Murphy 1982 & $4 / 6$ & $5 / 7$ & & $57.0 \%$ & $0.93[0.45,1.95]$ \\
\hline Subtotal (95\% CI) & 6 & 7 & & $57.0 \%$ & $0.93[0.45,1.95]$ \\
\hline \multicolumn{6}{|c|}{ Total events: 4 (Therapeutic), 5 (Prophylactic) } \\
\hline \multicolumn{6}{|c|}{ Heterogeneity: not applicable } \\
\hline \multicolumn{6}{|c|}{ Test for overall effect: $Z=0.18(P=0.85)$} \\
\hline Total (95\% CI) & 21 & 35 & - & $100.0 \%$ & $1.66[0.90,3.04]$ \\
\hline \multicolumn{6}{|c|}{ Total events: II (Therapeutic), I0 (Prophylactic) } \\
\hline \multicolumn{6}{|c|}{ Heterogeneity: Chi $^{2}=3.21, d f=I(P=0.07) ;\left.\right|^{2}=69 \%$} \\
\hline \multicolumn{6}{|c|}{ Test for overall effect: $Z=1.63(P=0.10)$} \\
\hline Test for subgroup differenc & $i^{2}=2.78, d f=$ & . 10), $\left.\right|^{2}=64 \%$ & & & \\
\hline
\end{tabular}

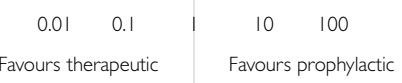


Analysis I.2. Comparison I Prophylactic platelet transfusion versus non prophylactic or therapeutic transfusion, Outcome 2 Number of days with significant bleeding.

Review: Prophylactic platelet transfusion for prevention of bleeding in patients with haematological disorders after chemotherapy and stem cell transplantation

Comparison: I Prophylactic platelet transfusion versus non prophylactic or therapeutic transfusion

Outcome: 2 Number of days with significant bleeding

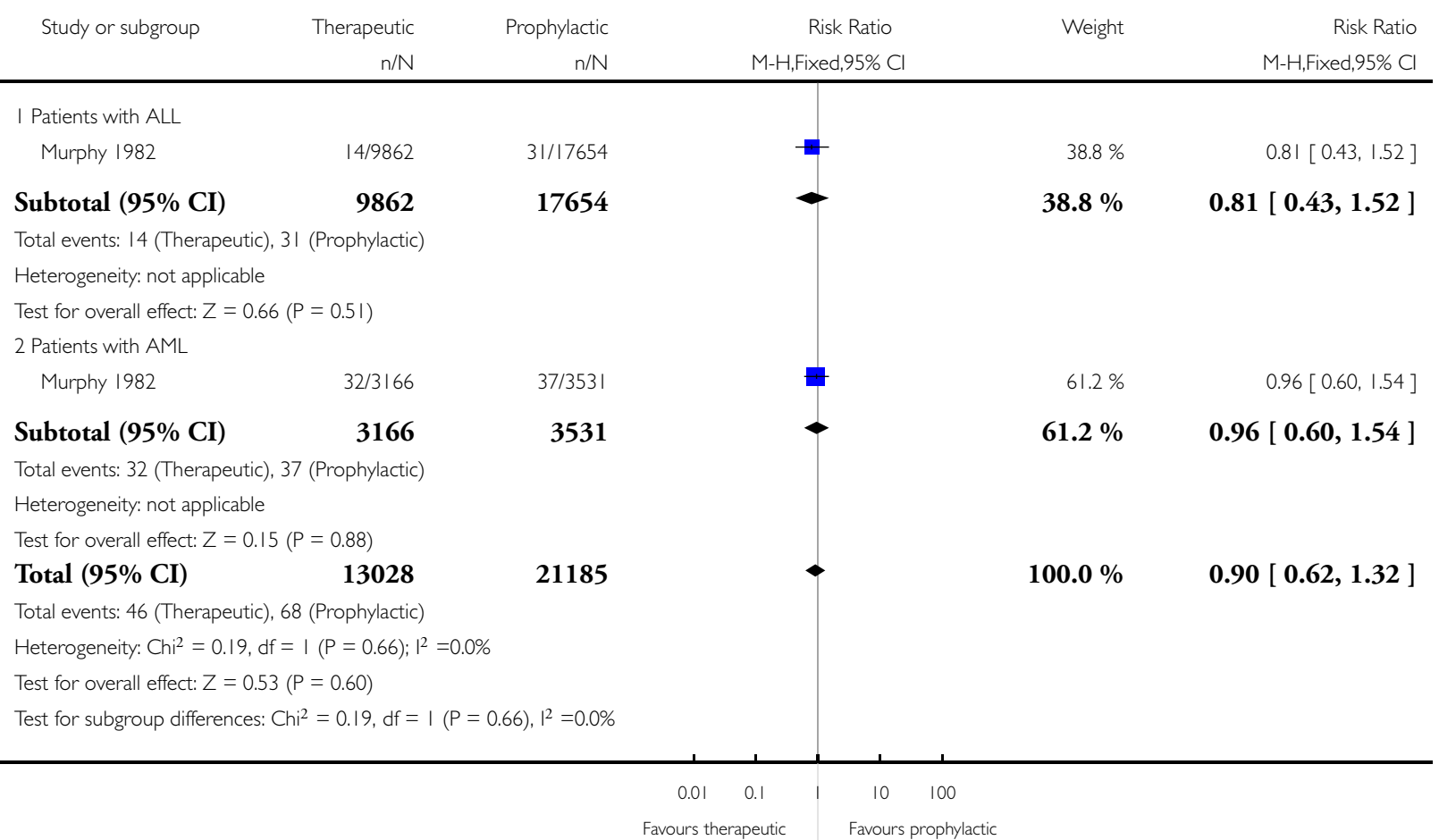


Analysis I.3. Comparison I Prophylactic platelet transfusion versus non prophylactic or therapeutic transfusion, Outcome 3 Mortality from all causes.

Review: Prophylactic platelet transfusion for prevention of bleeding in patients with haematological disorders after chemotherapy and stem cell transplantation

Comparison: I Prophylactic platelet transfusion versus non prophylactic or therapeutic transfusion

Outcome: 3 Mortality from all causes

\begin{tabular}{|c|c|c|c|c|c|}
\hline \multirow[t]{2}{*}{ Study or subgroup } & Therapeutic & \multicolumn{2}{|l|}{ Prophylactic } & \multirow[t]{2}{*}{ Weight } & \multirow{2}{*}{$\begin{array}{r}\text { Risk Ratio } \\
\text { M-H,Fixed,95\% C }\end{array}$} \\
\hline & $\mathrm{n} / \mathrm{N}$ & $n / N$ & M-H,Fixed,95\% Cl & & \\
\hline Murphy 1982 & $7 / 21$ & $12 / 35$ & & $78.4 \%$ & $0.97[0.46,2.08]$ \\
\hline Solomon 1978 & $2 / 12$ & $3 / 17$ & & $21.6 \%$ & $0.94[0.19,4.82]$ \\
\hline Total $(95 \% \mathrm{CI})$ & 33 & 52 & & $100.0 \%$ & $0.97[0.48,1.93]$ \\
\hline \multicolumn{6}{|c|}{ Total events: 9 (Therapeutic), I5 (Prophylactic) } \\
\hline \multicolumn{6}{|c|}{ Heterogeneity: Chi $^{2}=0.00, d f=I(P=0.97) ;\left.\right|^{2}=0.0 \%$} \\
\hline \multicolumn{6}{|c|}{ Test for overall effect: $Z=0.10(P=0.92)$} \\
\hline \multicolumn{6}{|c|}{ Test for subgroup differences: Not applicable } \\
\hline
\end{tabular}

\section{Analysis 1.4. Comparison I Prophylactic platelet transfusion versus non prophylactic or therapeutic} transfusion, Outcome 4 Mortality from bleeding.

Review: Prophylactic platelet transfusion for prevention of bleeding in patients with haematological disorders after chemotherapy and stem cell transplantation

Comparison: I Prophylactic platelet transfusion versus non prophylactic or therapeutic transfusion

Outcome: 4 Mortality from bleeding

\begin{tabular}{|c|c|c|c|c|c|}
\hline \multirow[t]{2}{*}{ Study or subgroup } & Therapeutic & Prophylactic & Risk Ratio & Weight & \multirow{2}{*}{$\begin{array}{r}\text { Risk Ratio } \\
\text { M-H,Fixed,95\% Cl }\end{array}$} \\
\hline & $\mathrm{n} / \mathrm{N}$ & $n / N$ & \multicolumn{2}{|l|}{ M-H,Fixed,95\% Cl } & \\
\hline Murphy 1982 & $2 / 21$ & $1 / 35$ & $\longrightarrow$ & $26.3 \%$ & $3.33[0.32,34.56]$ \\
\hline Solomon 1978 & $0 / 12$ & $2 / 17$ & & $73.7 \%$ & $0.28[0.01,5.30]$ \\
\hline Total $(95 \% \mathrm{CI})$ & 33 & 52 & & $100.0 \%$ & $1.08[0.23,5.06]$ \\
\hline \multicolumn{6}{|c|}{ Total events: 2 (Therapeutic), 3 (Prophylactic) } \\
\hline \multicolumn{6}{|c|}{ Heterogeneity: $\mathrm{Chi}^{2}=1.71, \mathrm{df}=|(P=0.19) ;|^{2}=41 \%$} \\
\hline \multicolumn{6}{|c|}{ Test for overall effect: $Z=0.10(P=0.92)$} \\
\hline Test for subgroup diff & Not applicable & & & & \\
\hline
\end{tabular}

$\begin{array}{lllllll}0.1 & 0.2 & 0.5 & 1 & 2 & 5 & 10\end{array}$

Favours therapeutic Favours prophylactic 
Analysis I.5. Comparison I Prophylactic platelet transfusion versus non prophylactic or therapeutic transfusion, Outcome 5 Mean number of platelet transfusions per course of chemotherapy.

Review: Prophylactic platelet transfusion for prevention of bleeding in patients with haematological disorders after chemotherapy and stem cell transplantation

Comparison: I Prophylactic platelet transfusion versus non prophylactic or therapeutic transfusion

Outcome: 5 Mean number of platelet transfusions per course of chemotherapy

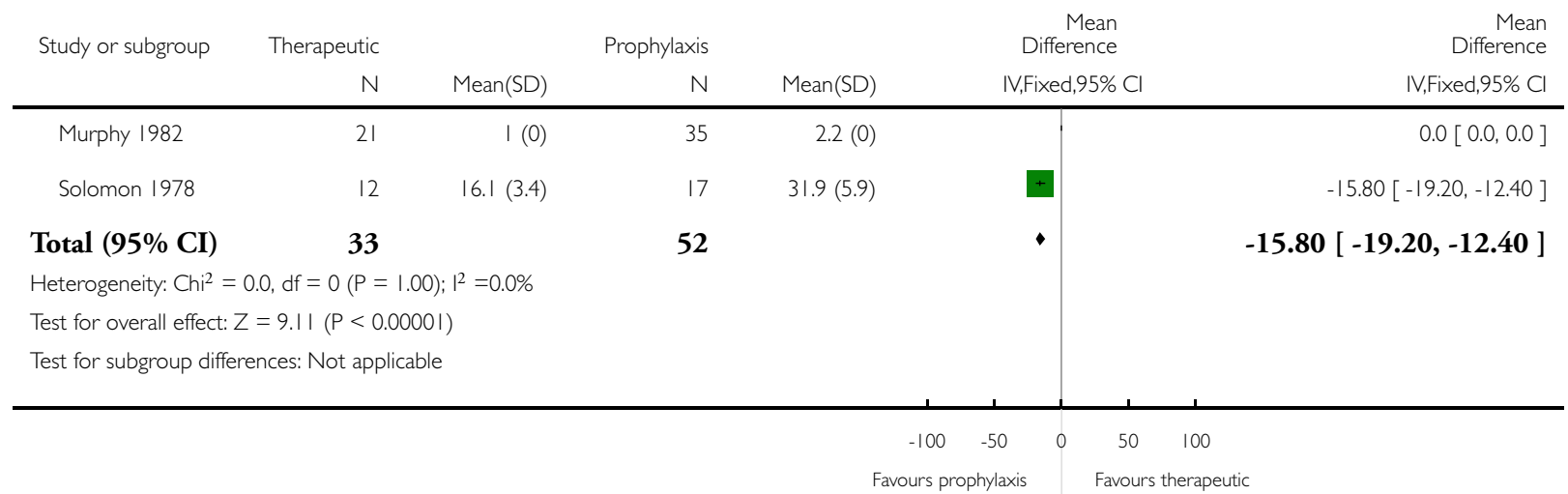

Analysis I.6. Comparison I Prophylactic platelet transfusion versus non prophylactic or therapeutic transfusion, Outcome 6 Mean number of red cell transfusions per patient.

Review: Prophylactic platelet transfusion for prevention of bleeding in patients with haematological disorders after chemotherapy and stem cell transplantation

Comparison: I Prophylactic platelet transfusion versus non prophylactic or therapeutic transfusion

Outcome: 6 Mean number of red cell transfusions per patient

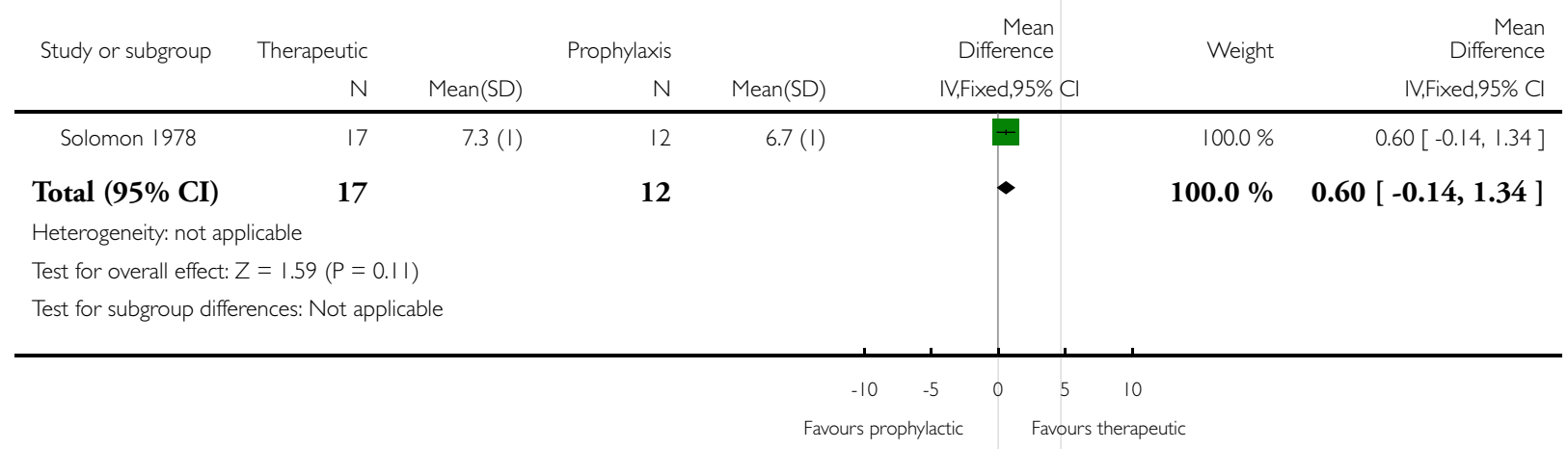

Prophylactic platelet transfusion for prevention of bleeding in patients with haematological disorders after chemotherapy and stem cell 
Analysis I.7. Comparison I Prophylactic platelet transfusion versus non prophylactic or therapeutic transfusion, Outcome 7 Remission rates.

Review: Prophylactic platelet transfusion for prevention of bleeding in patients with haematological disorders after chemotherapy and stem cell transplantation

Comparison: I Prophylactic platelet transfusion versus non prophylactic or therapeutic transfusion

Outcome: 7 Remission rates

\begin{tabular}{|c|c|c|c|c|c|}
\hline \multirow[t]{2}{*}{ Study or subgroup } & Therapeutic & Prophylactic & Risk Ratio & Weight & Risk Ratio \\
\hline & $\mathrm{n} / \mathrm{N}$ & $n / N$ & M-H,Fixed,95\% Cl & & M-H,Fixed,95\% Cl \\
\hline Solomon 1978 & $6 / 12$ & $8 / 17$ & & $100.0 \%$ & $1.06[0.50,2.27]$ \\
\hline Total (95\% CI) & 12 & 17 & & $100.0 \%$ & $1.06[0.50,2.27]$ \\
\hline \multicolumn{6}{|c|}{ Total events: 6 (Therapeutic), 8 (Prophylactic) } \\
\hline \multicolumn{6}{|c|}{ Heterogeneity: not applicable } \\
\hline \multicolumn{6}{|c|}{ Test for overall effect: $Z=0.16(P=0.88)$} \\
\hline Test for subgroup diffe & Not applicable & & & & \\
\hline
\end{tabular}

$\begin{array}{lllllll}0.1 & 0.2 & 0.5 & 1 & 2 & 5 & 10\end{array}$

Favours therapeutic Favours prophylactic

Analysis I.8. Comparison I Prophylactic platelet transfusion versus non prophylactic or therapeutic transfusion, Outcome 8 Number of participants with platelet refractoriness.

Review: Prophylactic platelet transfusion for prevention of bleeding in patients with haematological disorders after chemotherapy and stem cell transplantation

Comparison: I Prophylactic platelet transfusion versus non prophylactic or therapeutic transfusion

Outcome: 8 Number of participants with platelet refractoriness

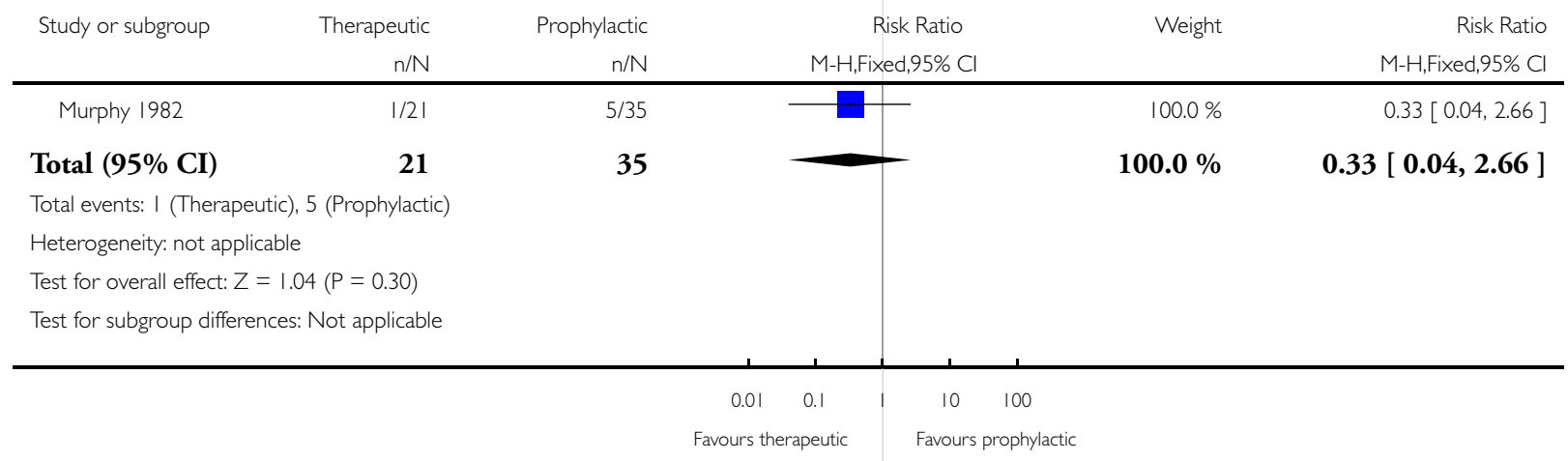

Prophylactic platelet transfusion for prevention of bleeding in patients with haematological disorders after chemotherapy and stem cell 
Analysis 2.1. Comparison 2 Prophylactic platelet transfusion at one trigger level versus another trigger level, Outcome I Number of participants with any bleeding event.

Review: Prophylactic platelet transfusion for prevention of bleeding in patients with haematological disorders after chemotherapy and stem cell transplantation

Comparison: 2 Prophylactic platelet transfusion at one trigger level versus another trigger level

Outcome: I Number of participants with any bleeding event

\begin{tabular}{|c|c|c|c|c|c|}
\hline \multirow[t]{2}{*}{ Study or subgroup } & Lower trigger & Higher trigger & Risk Ratio & \multirow[t]{2}{*}{ Weight } & Risk Ratio \\
\hline & $\mathrm{n} / \mathrm{N}$ & $\mathrm{n} / \mathrm{N}$ & M-H,Fixed,95\% Cl & & M-H,Fixed,95\% Cl \\
\hline Heckman 1997 & $35 / 37$ & $37 / 41$ & & $100.0 \%$ & $1.05[0.92,1.19]$ \\
\hline Total $(95 \% \mathrm{CI})$ & 37 & 41 & 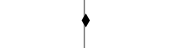 & $100.0 \%$ & $1.05[0.92,1.19]$ \\
\hline \multicolumn{6}{|c|}{ Total events: 35 (Lower trigger), 37 (Higher trigger) } \\
\hline \multicolumn{6}{|c|}{ Heterogeneity: not applicable } \\
\hline \multicolumn{6}{|c|}{ Test for overall effect: $Z=0.73(P=0.47)$} \\
\hline Test for subgroup diff & Not applicable & & & & \\
\hline
\end{tabular}

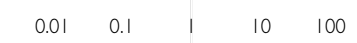

Favours lower trigger Favours higher trigger

Analysis 2.2. Comparison 2 Prophylactic platelet transfusion at one trigger level versus another trigger level, Outcome 2 Numbers of participants with a significant bleeding event.

Review: Prophylactic platelet transfusion for prevention of bleeding in patients with haematological disorders after chemotherapy and stem cell transplantation

Comparison: 2 Prophylactic platelet transfusion at one trigger level versus another trigger level

Outcome: 2 Numbers of participants with a significant bleeding event

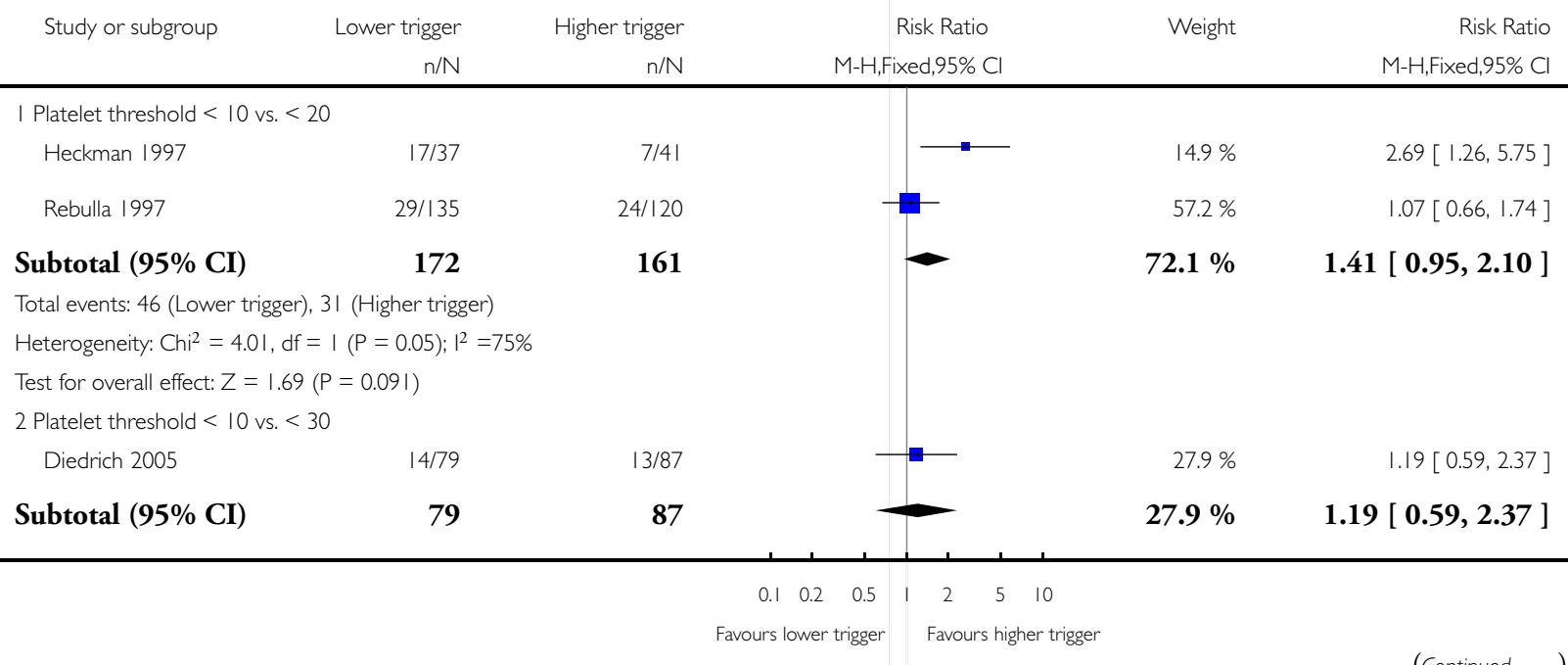

Prophylactic platelet transfusion for prevention of bleeding in patients with haematological disorders after chemotherapy and stem cell 


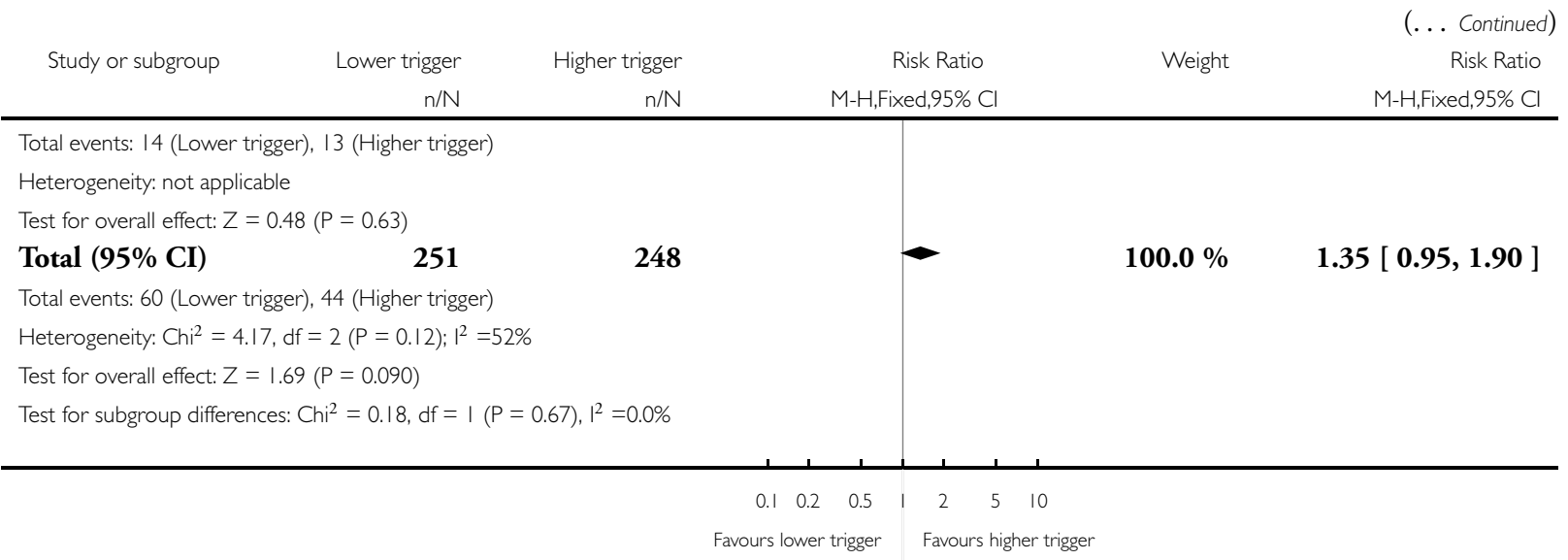

\section{Analysis 2.3. Comparison 2 Prophylactic platelet transfusion at one trigger level versus another trigger} level, Outcome 3 Number of participants with WHO Grade 3 or 4 bleeding.

Review: Prophylactic platelet transfusion for prevention of bleeding in patients with haematological disorders after chemotherapy and stem cell transplantation

Comparison: 2 Prophylactic platelet transfusion at one trigger level versus another trigger level

Outcome: 3 Number of participants with WHO Grade 3 or 4 bleeding

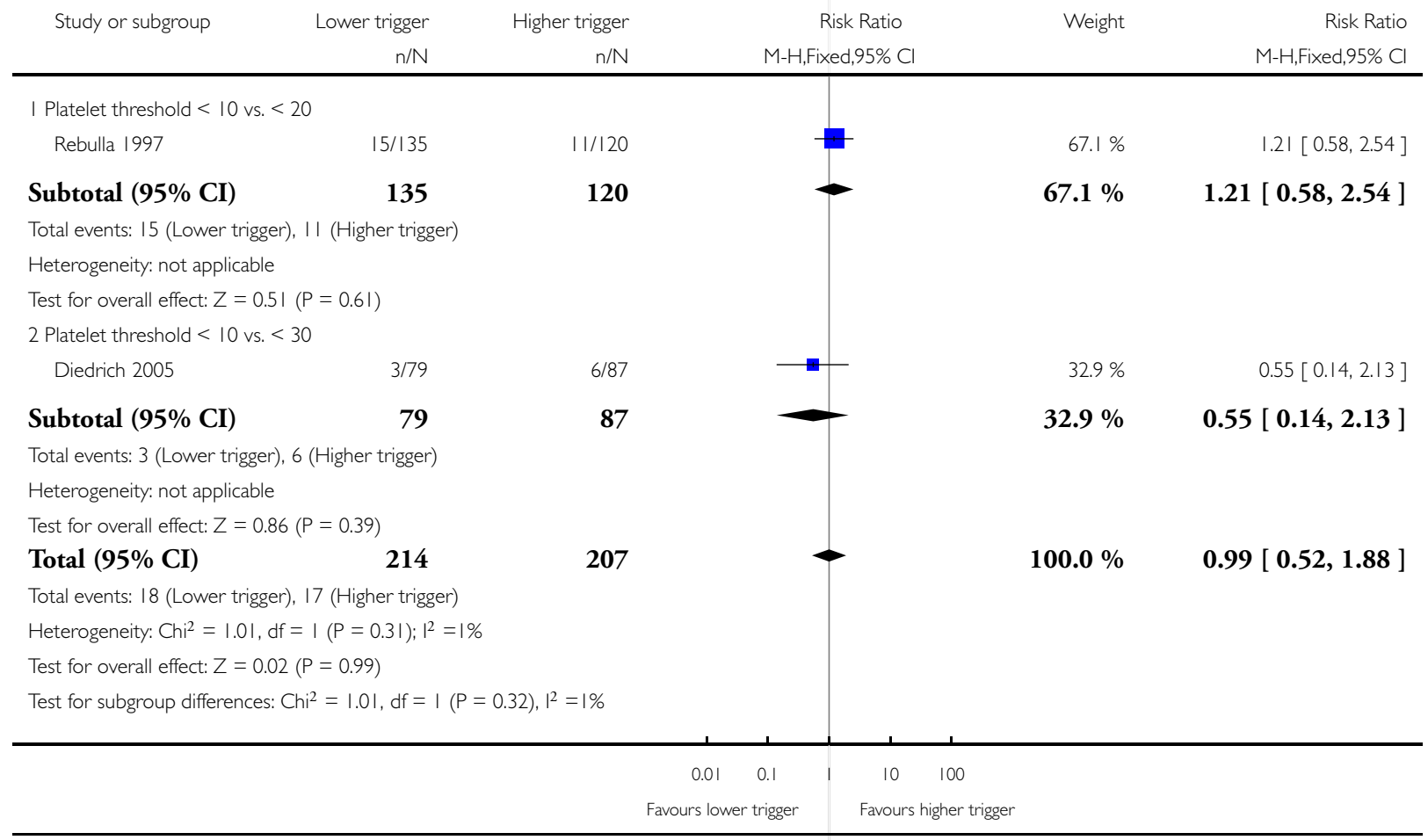

Prophylactic platelet transfusion for prevention of bleeding in patients with haematological disorders after chemotherapy and stem cell 
Analysis 2.4. Comparison 2 Prophylactic platelet transfusion at one trigger level versus another trigger level, Outcome 4 Number of participants with bleeding requiring a red cell transfusion.

Review: Prophylactic platelet transfusion for prevention of bleeding in patients with haematological disorders after chemotherapy and stem cell transplantation

Comparison: 2 Prophylactic platelet transfusion at one trigger level versus another trigger level

Outcome: 4 Number of participants with bleeding requiring a red cell transfusion

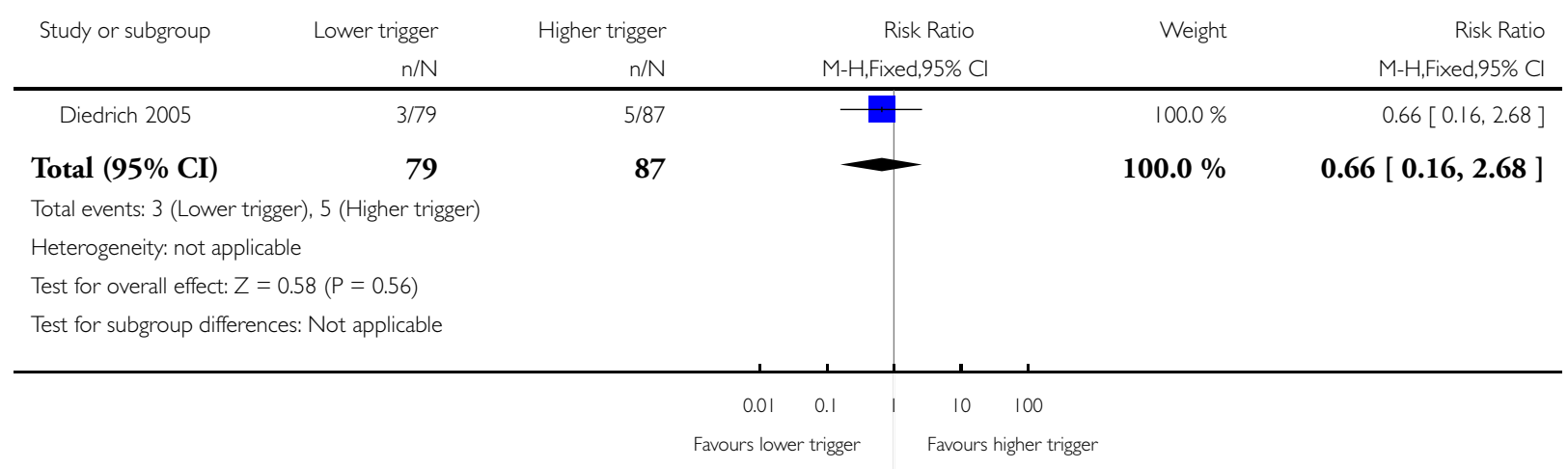

Analysis 2.5. Comparison 2 Prophylactic platelet transfusion at one trigger level versus another trigger level, Outcome 5 Number of days with any bleeding.

Review: Prophylactic platelet transfusion for prevention of bleeding in patients with haematological disorders after chemotherapy and stem cell transplantation

Comparison: 2 Prophylactic platelet transfusion at one trigger level versus another trigger level

Outcome: 5 Number of days with any bleeding

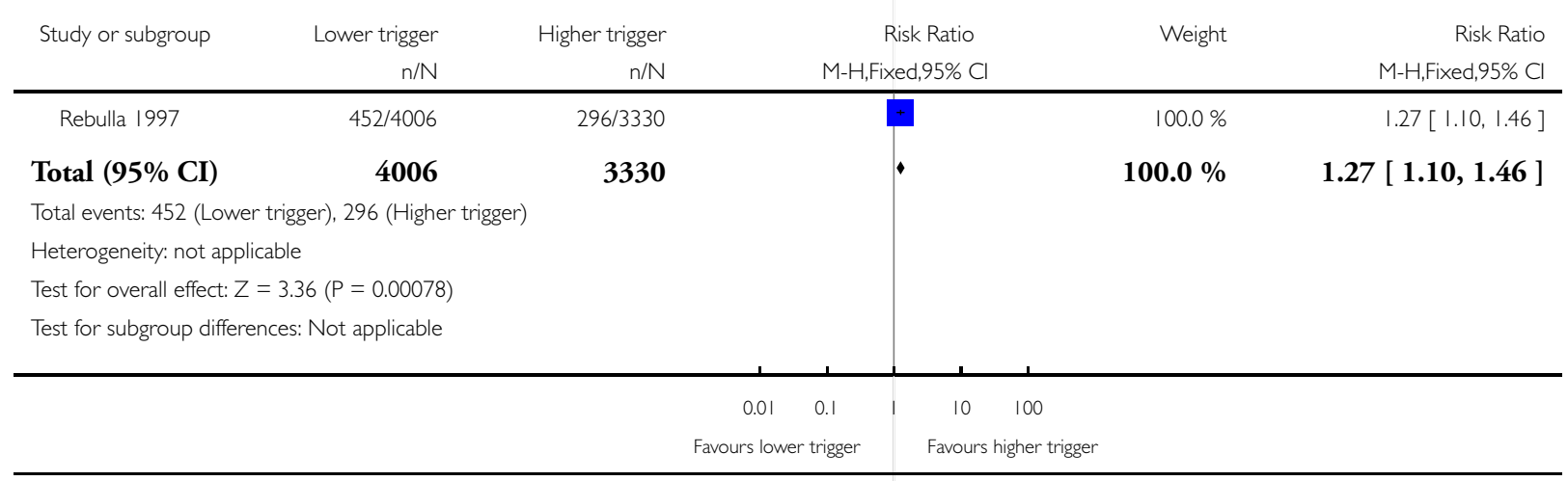

Prophylactic platelet transfusion for prevention of bleeding in patients with haematological disorders after chemotherapy and stem cell 95 transplantation (Review)

Copyright ( 2012 The Cochrane Collaboration. Published by John Wiley \& Sons, Ltd. 


\section{Analysis 2.6. Comparison 2 Prophylactic platelet transfusion at one trigger level versus another trigger}

level, Outcome 6 Number of days with a significant bleed.

Review: Prophylactic platelet transfusion for prevention of bleeding in patients with haematological disorders after chemotherapy and stem cell transplantation

Comparison: 2 Prophylactic platelet transfusion at one trigger level versus another trigger level

Outcome: 6 Number of days with a significant bleed

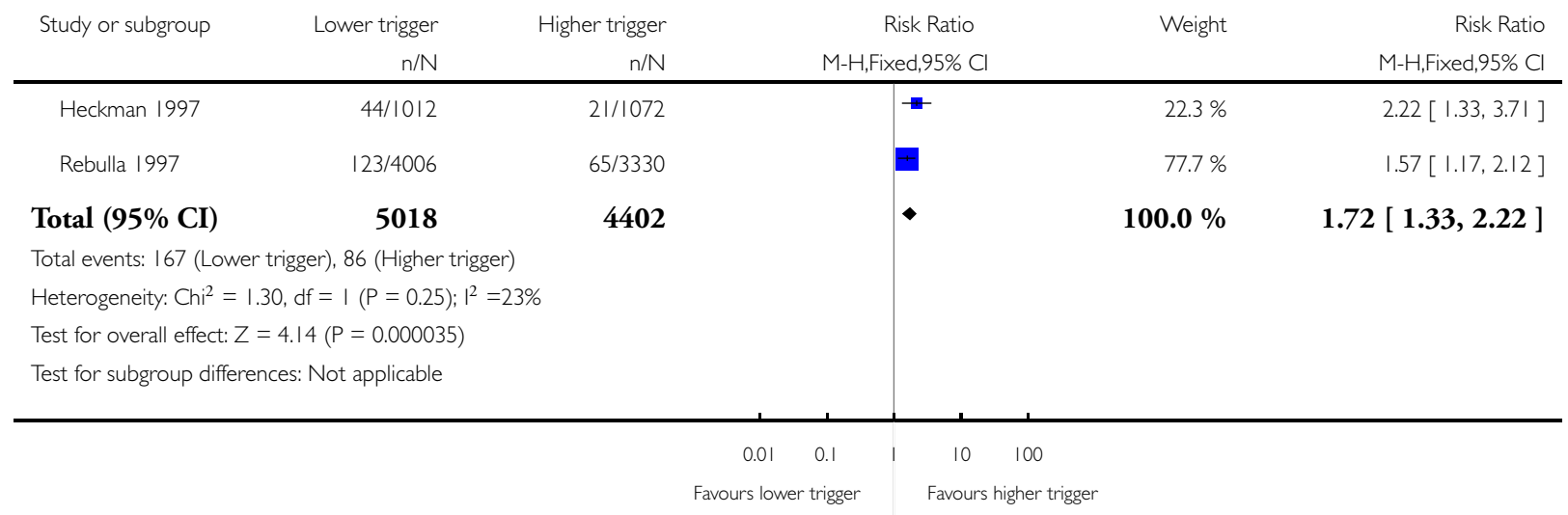


Analysis 2.7. Comparison 2 Prophylactic platelet transfusion at one trigger level versus another trigger level, Outcome 7 Mortality from all causes.

Review: Prophylactic platelet transfusion for prevention of bleeding in patients with haematological disorders after chemotherapy and stem cell transplantation

Comparison: 2 Prophylactic platelet transfusion at one trigger level versus another trigger level

Outcome: 7 Mortality from all causes

\begin{tabular}{|c|c|c|c|c|c|}
\hline Study or subgroup & Lower trigger & Higher trigger & Risk Ratio & Weight & Risk Ratio \\
\hline & $\mathrm{n} / \mathrm{N}$ & $\mathrm{n} / \mathrm{N}$ & M-H,Fixed,95\% Cl & & M-H,Fixed,95\% Cl \\
\hline Heckman 1997 & $25 / 37$ & $29 / 41$ & & $74.3 \%$ & $0.96[0.71,1.29]$ \\
\hline Rebulla 1997 & $18 / 135$ & $9 / 120$ & $=$ & $25.7 \%$ & $1.78[0.83,3.81]$ \\
\hline
\end{tabular}

Total (95\% CI)

172

161

$100.0 \%$

$1.17[0.85,1.60]$

Total events: 43 (Lower trigger), 38 (Higher trigger)

Heterogeneity: $\mathrm{Ch}^{2}=2.91, \mathrm{df}=|(P=0.09) ;|^{2}=66 \%$

Test for overall effect: $Z=0.96(P=0.34)$

Test for subgroup differences: Not applicable

$\begin{array}{lllllll}0.1 & 0.2 & 0.5 & 1 & 2 & 5 & 10\end{array}$

Favours lower trigger Favours higher trigger

Analysis 2.8. Comparison 2 Prophylactic platelet transfusion at one trigger level versus another trigger level, Outcome 8 Mortality from bleeding.

Review: Prophylactic platelet transfusion for prevention of bleeding in patients with haematological disorders after chemotherapy and stem cell transplantation

Comparison: 2 Prophylactic platelet transfusion at one trigger level versus another trigger level

Outcome: 8 Mortality from bleeding

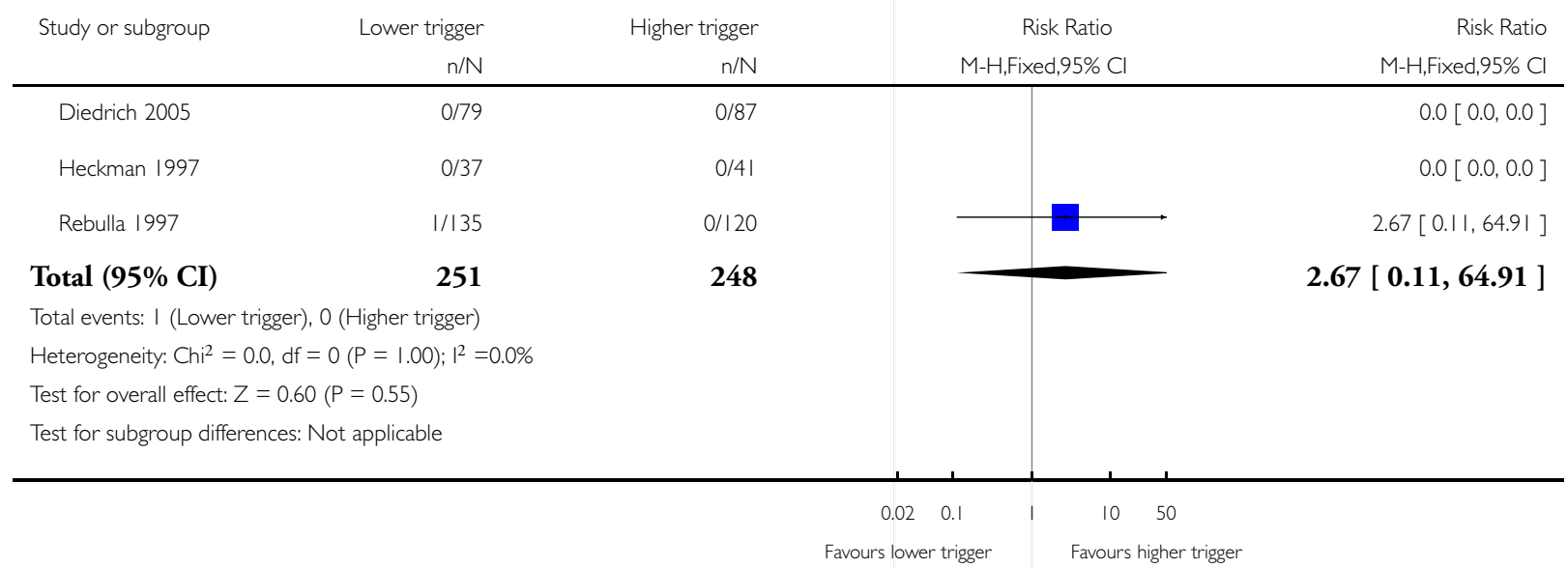

Prophylactic platelet transfusion for prevention of bleeding in patients with haematological disorders after chemotherapy and stem cell 
Analysis 2.9. Comparison 2 Prophylactic platelet transfusion at one trigger level versus another trigger level, Outcome 9 Mean number of platelet transfusions per patient.

Review: Prophylactic platelet transfusion for prevention of bleeding in patients with haematological disorders after chemotherapy and stem cell transplantation

Comparison: 2 Prophylactic platelet transfusion at one trigger level versus another trigger level

Outcome: 9 Mean number of platelet transfusions per patient

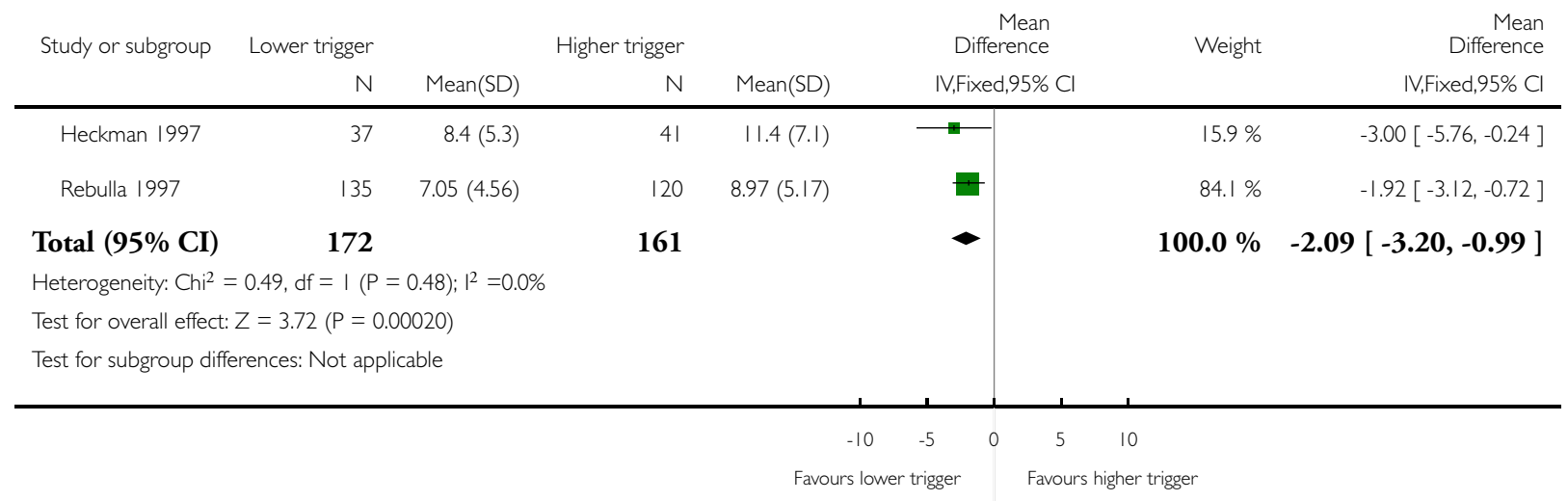

Analysis 2.10. Comparison 2 Prophylactic platelet transfusion at one trigger level versus another trigger level, Outcome 10 Mean number of red cell transfusions per patient.

Review: Prophylactic platelet transfusion for prevention of bleeding in patients with haematological disorders after chemotherapy and stem cell transplantation

Comparison: 2 Prophylactic platelet transfusion at one trigger level versus another trigger level

Outcome: 10 Mean number of red cell transfusions per patient

\begin{tabular}{|c|c|c|c|c|c|c|c|c|}
\hline \multirow[t]{2}{*}{ Study or subgroup } & \multirow{2}{*}{$\begin{array}{r}\text { Lower trigger } \\
\mathrm{N}\end{array}$} & \multicolumn{3}{|c|}{ Higher trigger } & \multirow{2}{*}{\multicolumn{2}{|c|}{$\begin{array}{c}\text { Mean } \\
\text { Difference } \\
\text { IV,Fixed,95\% Cl }\end{array}$}} & \multirow[t]{2}{*}{ Weight } & \multirow{2}{*}{$\begin{array}{r}\text { Mean } \\
\text { Difference } \\
\text { IV,Fixed,95\% Cl }\end{array}$} \\
\hline & & Mean(SD) & N & Mean(SD) & & & & \\
\hline Heckman 1997 & 37 & $12.2(6.9)$ & 41 & $10.7(5.1)$ & & $ד$ & $16.3 \%$ & $1.50[-1.22,4.22]$ \\
\hline Rebulla 1997 & 135 & $9.57(5.18)$ & 120 & $9.07(4.58)$ & & & $83.7 \%$ & $0.50[-0.70,1.70]$ \\
\hline Total (95\% CI) & 172 & & 161 & & & 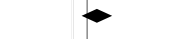 & $100.0 \%$ & $0.66[-0.43,1.76]$ \\
\hline \multicolumn{9}{|c|}{ Heterogeneity: $\mathrm{Chi}^{2}=0.44, \mathrm{df}=\mathrm{I}(\mathrm{P}=0.5 \mathrm{I}) ; \mathrm{I}^{2}=0.0 \%$} \\
\hline \multicolumn{9}{|c|}{ Test for overall effect: $Z=1.19(P=0.24)$} \\
\hline \multicolumn{9}{|c|}{ Test for subgroup differences: Not applicable } \\
\hline & & & & & -10 & -5 & 10 & \\
\hline
\end{tabular}

Prophylactic platelet transfusion for prevention of bleeding in patients with haematological disorders after chemotherapy and stem cell 
Analysis 2.1 I. Comparison 2 Prophylactic platelet transfusion at one trigger level versus another trigger level, Outcome I I Remission rates.

Review: Prophylactic platelet transfusion for prevention of bleeding in patients with haematological disorders after chemotherapy and stem cell transplantation

Comparison: 2 Prophylactic platelet transfusion at one trigger level versus another trigger level

Outcome: II Remission rates

\begin{tabular}{|c|c|c|c|c|c|}
\hline \multirow[t]{2}{*}{ Study or subgroup } & Lower trigger & Higher trigger & Risk Ratio & Weight & Risk Ratio \\
\hline & $\mathrm{n} / \mathrm{N}$ & $\mathrm{n} / \mathrm{N}$ & M-H,Fixed,95\% Cl & & M-H,Fixed,95\% Cl \\
\hline Heckman 1997 & $25 / 37$ & $27 / 41$ & $\rightarrow$ & $24.1 \%$ & $1.03[0.75,1.40]$ \\
\hline Rebulla 1997 & $76 / 135$ & $76 / 120$ & & $75.9 \%$ & $0.89[0.73,1.09]$ \\
\hline
\end{tabular}

\section{Total (95\% CI)}

172

161

$100.0 \%$

$0.92[0.78,1.09]$

Total events: I0I (Lower trigger), I03 (Higher trigger)

Heterogeneity: $\mathrm{Chi}^{2}=0.57, \mathrm{df}=\mathrm{I}(\mathrm{P}=0.45) ; \mathrm{I}^{2}=0.0 \%$

Test for overall effect: $Z=0.94(P=0.35)$

Test for subgroup differences: Not applicable

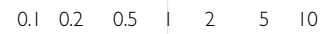

Favours lower trigger Favours higher trigger

Analysis 2.12. Comparison 2 Prophylactic platelet transfusion at one trigger level versus another trigger level, Outcome 12 Numbers of participants with platelet transfusion reactions.

Review: Prophylactic platelet transfusion for prevention of bleeding in patients with haematological disorders after chemotherapy and stem cell transplantation

Comparison: 2 Prophylactic platelet transfusion at one trigger level versus another trigger level

Outcome: 12 Numbers of participants with platelet transfusion reactions

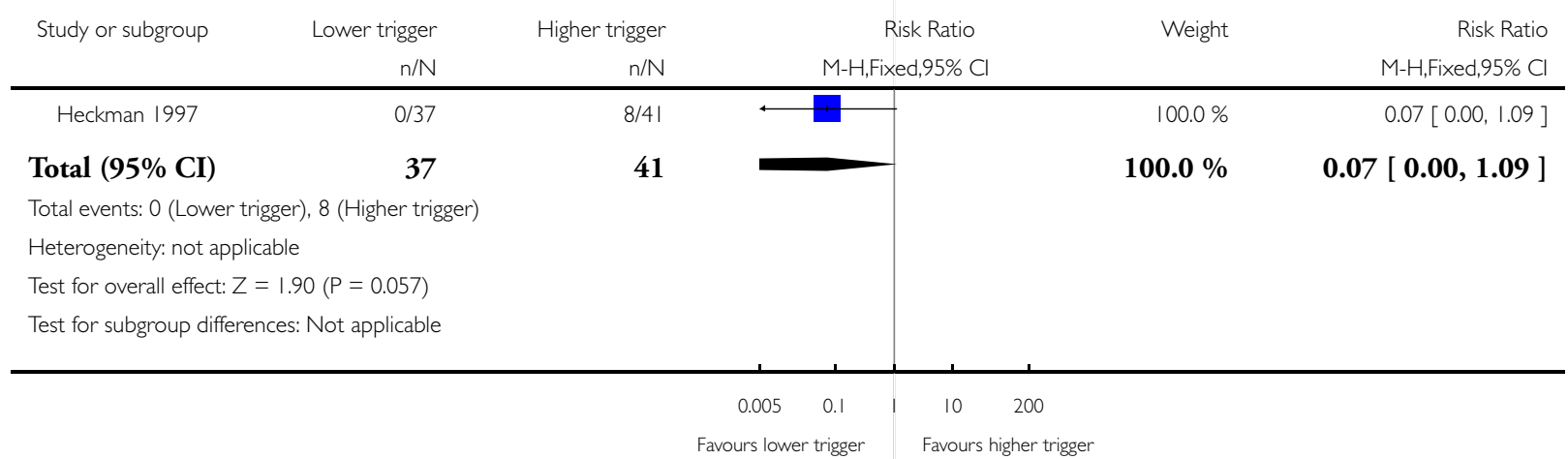


Analysis 2.13. Comparison 2 Prophylactic platelet transfusion at one trigger level versus another trigger level, Outcome 13 Number of participants with thromboembolic disease.

Review: Prophylactic platelet transfusion for prevention of bleeding in patients with haematological disorders after chemotherapy and stem cell transplantation

Comparison: 2 Prophylactic platelet transfusion at one trigger level versus another trigger level

Outcome: 13 Number of participants with thromboembolic disease

\begin{tabular}{|c|c|c|c|c|c|}
\hline \multirow{2}{*}{ Study or subgroup } & Lower trigger & Higher trigger & Risk Ratio & Weight & Risk Ratio \\
\hline & $\mathrm{n} / \mathrm{N}$ & $\mathrm{n} / \mathrm{N}$ & M-H,Fixed,95\% Cl & & M-H,Fixed,95\% Cl \\
\hline Rebulla 1997 & $1 / 135$ & $1 / 120$ & 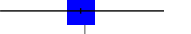 & $100.0 \%$ & $0.89[0.06,14.06]$ \\
\hline
\end{tabular}

Total (95\% CI) 135

Total events: I (Lower trigger), I (Higher trigger)

Heterogeneity: not applicable

Test for overall effect: $Z=0.08(P=0.93)$

Test for subgroup differences: Not applicable

$100.0 \%$

$0.89[0.06,14.06]$

$\begin{array}{cccccc}0.01 & 0.1 & 1 & 10 & 100 \\ \text { Favours lower trigger } & \text { Favours higher trigger }\end{array}$

Analysis 2.14. Comparison 2 Prophylactic platelet transfusion at one trigger level versus another trigger level, Outcome 14 Number of participants requiring HLA-matched platelets.

Review: Prophylactic platelet transfusion for prevention of bleeding in patients with haematological disorders after chemotherapy and stem cell transplantation

Comparison: 2 Prophylactic platelet transfusion at one trigger level versus another trigger level

Outcome: 14 Number of participants requiring HLA-matched platelets

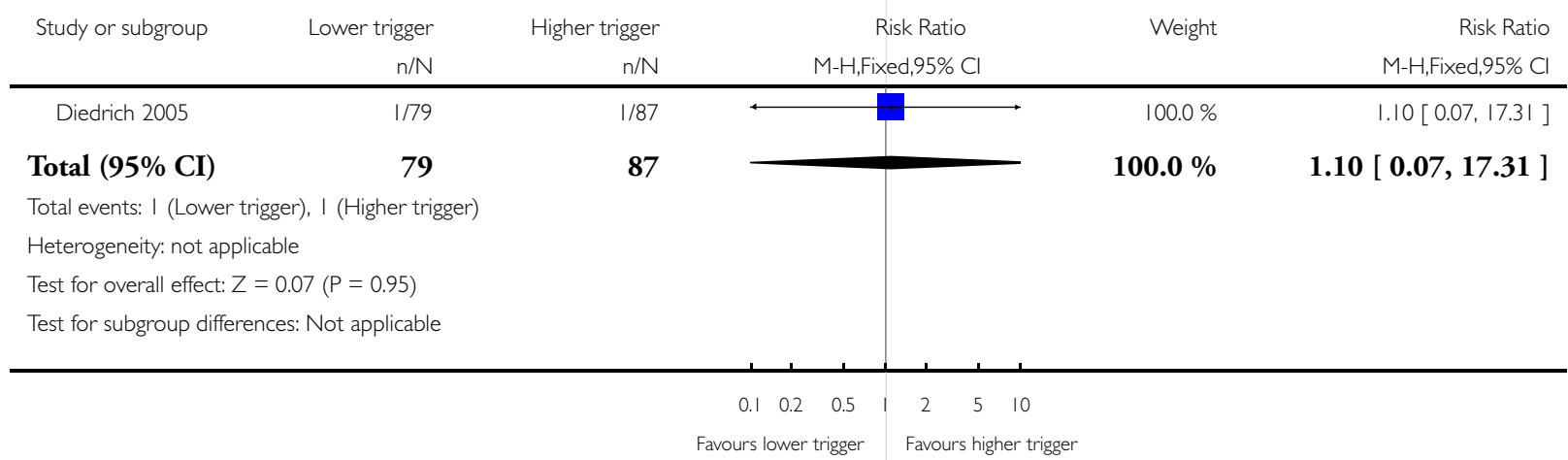

Prophylactic platelet transfusion for prevention of bleeding in patients with haematological disorders after chemotherapy and stem cell $\quad$ I00 transplantation (Review)

Copyright (C) 2012 The Cochrane Collaboration. Published by John Wiley \& Sons, Ltd. 
Analysis 2.15. Comparison 2 Prophylactic platelet transfusion at one trigger level versus another trigger level, Outcome 15 Number of participants with platelet refractoriness.

Review: Prophylactic platelet transfusion for prevention of bleeding in patients with haematological disorders after chemotherapy and stem cell transplantation

Comparison: 2 Prophylactic platelet transfusion at one trigger level versus another trigger level

Outcome: 15 Number of participants with platelet refractoriness

\begin{tabular}{|c|c|c|c|c|c|}
\hline Study or subgroup & Lower trigger & Higher trigger & Risk Ratio & Weight & Risk Ratio \\
\hline & $\mathrm{n} / \mathrm{N}$ & $\mathrm{n} / \mathrm{N}$ & M-H,Fixed,95\% Cl & & M-H,Fixed,95\% Cl \\
\hline Diedrich 2005 & $1 / 79$ & $1 / 87$ & $\longrightarrow$ & $20.1 \%$ & $1.10[0.07,17.31]$ \\
\hline Heckman 1997 & $2 / 37$ & $4 / 41$ & $\square$ & $79.9 \%$ & $0.55[0.11,2.85]$ \\
\hline
\end{tabular}

Total (95\% CI)

116

128

$100.0 \%$

$0.66[0.16,2.67]$

Total events: 3 (Lower trigger), 5 (Higher trigger)

Heterogeneity: $\mathrm{Chi}^{2}=0.18, \mathrm{df}=1(P=0.67) ;\left.\right|^{2}=0.0 \%$

Test for overall effect: $Z=0.58(P=0.56)$

Test for subgroup differences: Not applicable

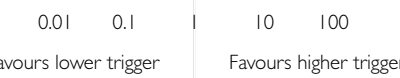

Prophylactic platelet transfusion for prevention of bleeding in patients with haematological disorders after chemotherapy and stem cell $\quad$ I0I transplantation (Review)

Copyright ( 2012 The Cochrane Collaboration. Published by John Wiley \& Sons, Ltd. 
Analysis 3.I. Comparison 3 Prophylactic platelet transfusion with one dose schedule versus another dose schedule, Outcome I Number of participants with any bleeding event.

Review: Prophylactic platelet transfusion for prevention of bleeding in patients with haematological disorders after chemotherapy and stem cell transplantation

Comparison: 3 Prophylactic platelet transfusion with one dose schedule versus another dose schedule

Outcome: I Number of participants with any bleeding event

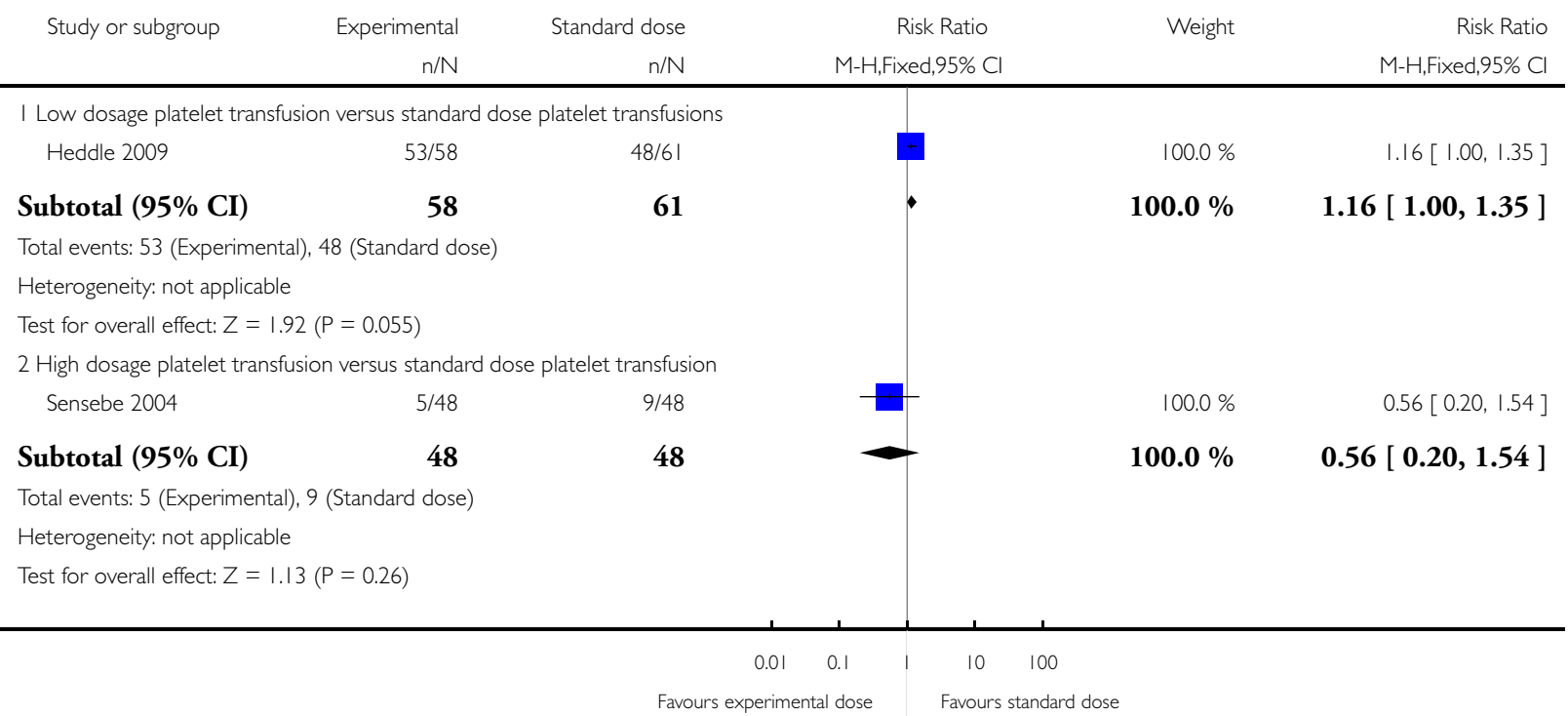

Prophylactic platelet transfusion for prevention of bleeding in patients with haematological disorders after chemotherapy and stem cell 102 transplantation (Review)

Copyright ( 2012 The Cochrane Collaboration. Published by John Wiley \& Sons, Ltd. 
Analysis 3.2. Comparison 3 Prophylactic platelet transfusion with one dose schedule versus another dose schedule, Outcome 2 Number of participants with a significant bleeding event.

Review: Prophylactic platelet transfusion for prevention of bleeding in patients with haematological disorders after chemotherapy and stem cell transplantation

Comparison: 3 Prophylactic platelet transfusion with one dose schedule versus another dose schedule

Outcome: 2 Number of participants with a significant bleeding event

\begin{tabular}{|c|c|c|c|c|c|}
\hline \multirow[t]{2}{*}{ Study or subgroup } & Study dose & Standard dose & Risk Ratio & Weight & Risk Ratio \\
\hline & $\mathrm{n} / \mathrm{N}$ & $\mathrm{n} / \mathrm{N}$ & M-H,Fixed,95\% Cl & & M-H,Fixed, $95 \% \mathrm{Cl}$ \\
\hline \multicolumn{6}{|c|}{ I Low dosage platelet transfusions versus standard dosage platelet transfusions } \\
\hline Heddle 2009 & $30 / 58$ & $30 / 61$ & $\rightarrow$ & $9.0 \%$ & $1.05[0.74,1.50]$ \\
\hline Slichter 2010 & $296 / 417$ & $292 / 423$ & & $89.7 \%$ & $1.03[0.94,1.12]$ \\
\hline Tinmouth 2004 & $6 / 56$ & $4 / 55$ & & $1.2 \%$ & $1.47[0.44,4.94]$ \\
\hline Subtotal $(95 \% \mathrm{CI})$ & 531 & 539 & - & $100.0 \%$ & $1.04[0.95,1.13]$ \\
\hline \multicolumn{6}{|c|}{ Total events: 332 (Study dose), 326 (Standard dose) } \\
\hline \multicolumn{6}{|c|}{ Heterogeneity: $\mathrm{Chi}^{2}=0.36, \mathrm{df}=2(\mathrm{P}=0.84) ; \mathrm{I}^{2}=0.0 \%$} \\
\hline \multicolumn{6}{|c|}{ Test for overall effect: $Z=0.79(P=0.43)$} \\
\hline \multicolumn{6}{|c|}{2 High dosage platelet transfusions versus standard dosage platelet transfusions } \\
\hline Sensebe 2004 & $3 / 48$ & $2 / 48$ & & $0.7 \%$ & $1.50[0.26,8.58]$ \\
\hline Slichter 2010 & $302 / 432$ & $292 / 423$ & & $99.3 \%$ & $1.01[0.93,1.11]$ \\
\hline Subtotal (95\% CI) & 480 & 471 & - & $100.0 \%$ & $1.02[0.93,1.11]$ \\
\hline \multicolumn{6}{|c|}{ Total events: 305 (Study dose), 294 (Standard dose) } \\
\hline \multicolumn{6}{|c|}{ Heterogeneity: $\mathrm{Chi}^{2}=0.20, \mathrm{df}=\mathrm{I}(\mathrm{P}=0.66) ; \mathrm{I}^{2}=0.0 \%$} \\
\hline Test for overall effect: $Z=$ & $P=0.73)$ & & & & \\
\hline
\end{tabular}

$\begin{array}{lllllll}0.1 & 0.2 & 0.5 & 1 & 2 & 5 & 10\end{array}$

Favours experimental dose Favours standard dose

Prophylactic platelet transfusion for prevention of bleeding in patients with haematological disorders after chemotherapy and stem cell 103 transplantation (Review)

Copyright ( 2012 The Cochrane Collaboration. Published by John Wiley \& Sons, Ltd. 
Analysis 3.3. Comparison 3 Prophylactic platelet transfusion with one dose schedule versus another dose schedule, Outcome 3 Number of participants with WHO Grade 3 or 4 bleeding.

Review: Prophylactic platelet transfusion for prevention of bleeding in patients with haematological disorders after chemotherapy and stem cell transplantation

Comparison: 3 Prophylactic platelet transfusion with one dose schedule versus another dose schedule

Outcome: 3 Number of participants with WHO Grade 3 or 4 bleeding

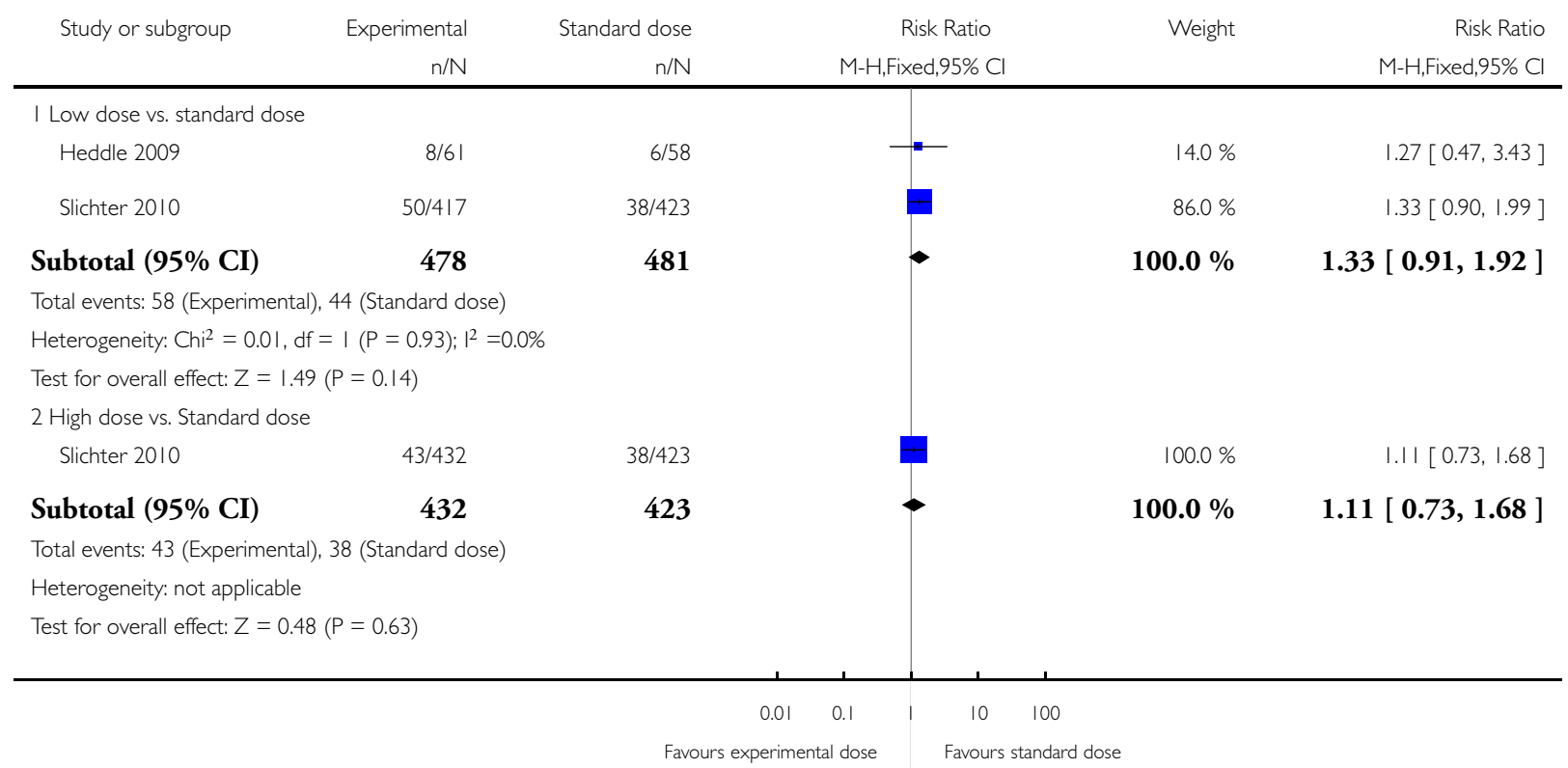

Prophylactic platelet transfusion for prevention of bleeding in patients with haematological disorders after chemotherapy and stem cell $\quad$ I04 transplantation (Review)

Copyright ( 2012 The Cochrane Collaboration. Published by John Wiley \& Sons, Ltd. 
Analysis 3.4. Comparison 3 Prophylactic platelet transfusion with one dose schedule versus another dose schedule, Outcome 4 Number of participants with WHO grade 4 bleeding.

Review: Prophylactic platelet transfusion for prevention of bleeding in patients with haematological disorders after chemotherapy and stem cell transplantation

Comparison: 3 Prophylactic platelet transfusion with one dose schedule versus another dose schedule

Outcome: 4 Number of participants with WHO grade 4 bleeding

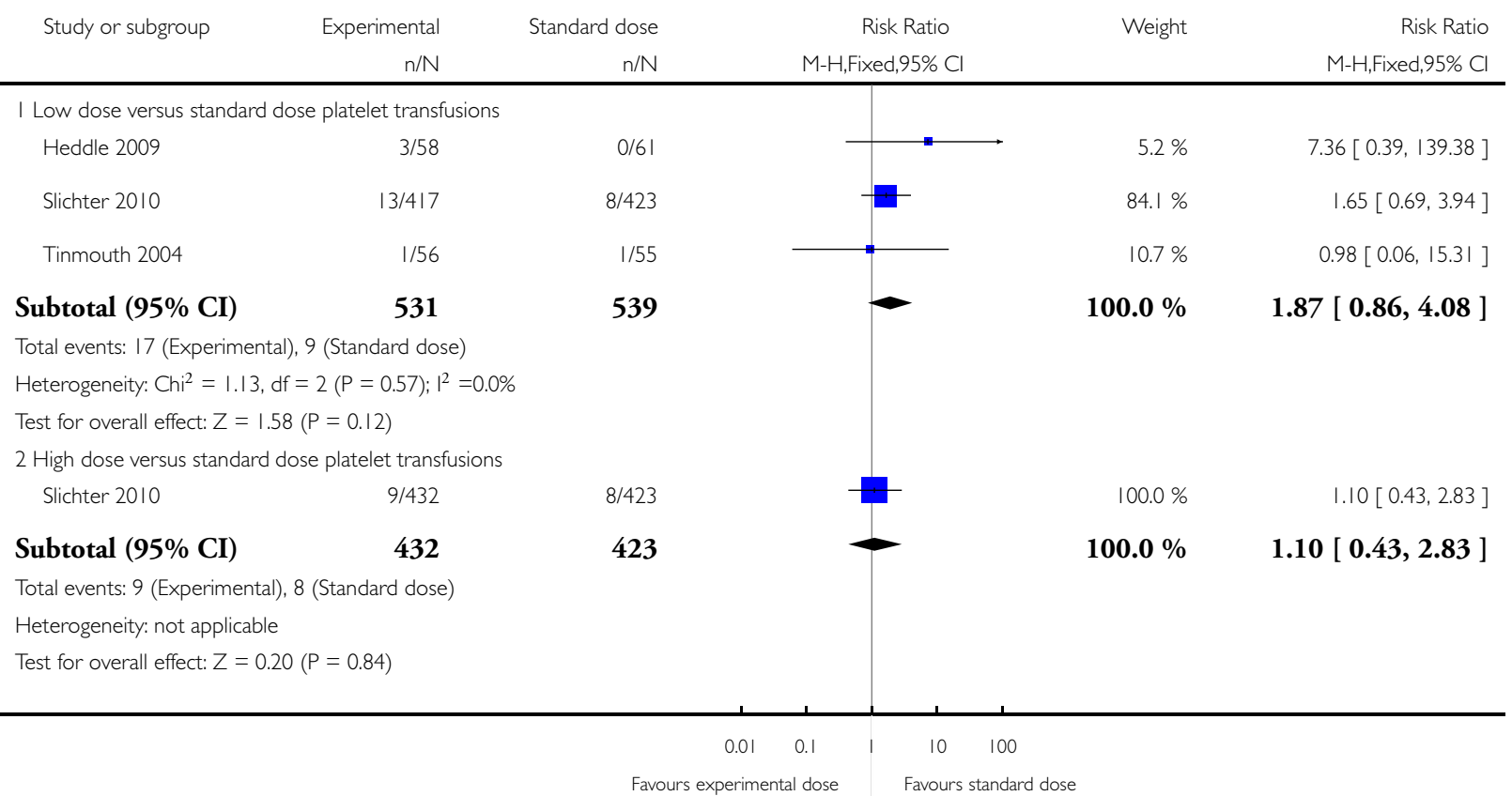

Prophylactic platelet transfusion for prevention of bleeding in patients with haematological disorders after chemotherapy and stem cell $\quad$ I05 transplantation (Review)

Copyright (C) 2012 The Cochrane Collaboration. Published by John Wiley \& Sons, Ltd. 
Analysis 3.5. Comparison 3 Prophylactic platelet transfusion with one dose schedule versus another dose schedule, Outcome 5 Number of participants with bleeding requiring a red cell transfusion.

Review: Prophylactic platelet transfusion for prevention of bleeding in patients with haematological disorders after chemotherapy and stem cell transplantation

Comparison: 3 Prophylactic platelet transfusion with one dose schedule versus another dose schedule

Outcome: 5 Number of participants with bleeding requiring a red cell transfusion

\begin{tabular}{|c|c|c|c|c|c|}
\hline \multirow[t]{2}{*}{ Study or subgroup } & Experimental & Standard dose & Risk Ratio & Weight & Risk Ratio \\
\hline & $\mathrm{n} / \mathrm{N}$ & $\mathrm{n} / \mathrm{N}$ & M-H,Fixed,95\% Cl & & M-H,Fixed,95\% Cl \\
\hline Heddle 2009 & $5 / 58$ & $6 / 61$ & & $100.0 \%$ & $0.88[0.28,2.72]$ \\
\hline Total $(95 \% \mathrm{CI})$ & 58 & 61 & & $100.0 \%$ & $0.88[0.28,2.72]$ \\
\hline \multicolumn{6}{|c|}{ Total events: 5 (Experimental), 6 (Standard dose) } \\
\hline \multicolumn{6}{|c|}{ Heterogeneity: not applicable } \\
\hline \multicolumn{6}{|c|}{ Test for overall effect: $Z=0.23(P=0.82)$} \\
\hline Test for subgroup diff & Not applicable & & & & \\
\hline
\end{tabular}

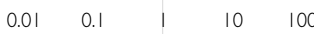

Favours experimental dose Favours standard dose

Analysis 3.6. Comparison 3 Prophylactic platelet transfusion with one dose schedule versus another dose schedule, Outcome 6 Number of participants with bleeding causing cardiovascular compromise.

Review: Prophylactic platelet transfusion for prevention of bleeding in patients with haematological disorders after chemotherapy and stem cell transplantation

Comparison: 3 Prophylactic platelet transfusion with one dose schedule versus another dose schedule

Outcome: 6 Number of participants with bleeding causing cardiovascular compromise

\begin{tabular}{|c|c|c|c|c|c|}
\hline \multirow[t]{2}{*}{ Study or subgroup } & Experimental & Standard dose & Risk Ratio & Weight & Risk Ratio \\
\hline & $\mathrm{n} / \mathrm{N}$ & $\mathrm{n} / \mathrm{N}$ & M-H,Fixed,95\% Cl & & M-H,Fixed,95\% Cl \\
\hline Tinmouth 2004 & $1 / 56$ & $0 / 55$ & & $100.0 \%$ & $2.95[0.12,70.82]$ \\
\hline Total $(95 \%$ CI $)$ & 56 & 55 & & $100.0 \%$ & $2.95[0.12,70.82]$ \\
\hline \multicolumn{6}{|c|}{ Total events: I (Experimental), 0 (Standard dose) } \\
\hline \multicolumn{6}{|c|}{ Heterogeneity: not applicable } \\
\hline \multicolumn{6}{|c|}{ Test for overall effect: $Z=0.67(P=0.5 \mathrm{I})$} \\
\hline Test for subgroup diffe & : Not applicable & & & & \\
\hline
\end{tabular}

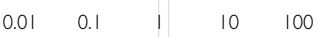

Favours experimental dose Favours standard dose

Prophylactic platelet transfusion for prevention of bleeding in patients with haematological disorders after chemotherapy and stem cell 106 transplantation (Review)

Copyright ( 2012 The Cochrane Collaboration. Published by John Wiley \& Sons, Ltd. 
Analysis 3.7. Comparison 3 Prophylactic platelet transfusion with one dose schedule versus another dose schedule, Outcome 7 Number of days with significant bleeding.

Review: Prophylactic platelet transfusion for prevention of bleeding in patients with haematological disorders after chemotherapy and stem cell transplantation

Comparison: 3 Prophylactic platelet transfusion with one dose schedule versus another dose schedule

Outcome: 7 Number of days with significant bleeding

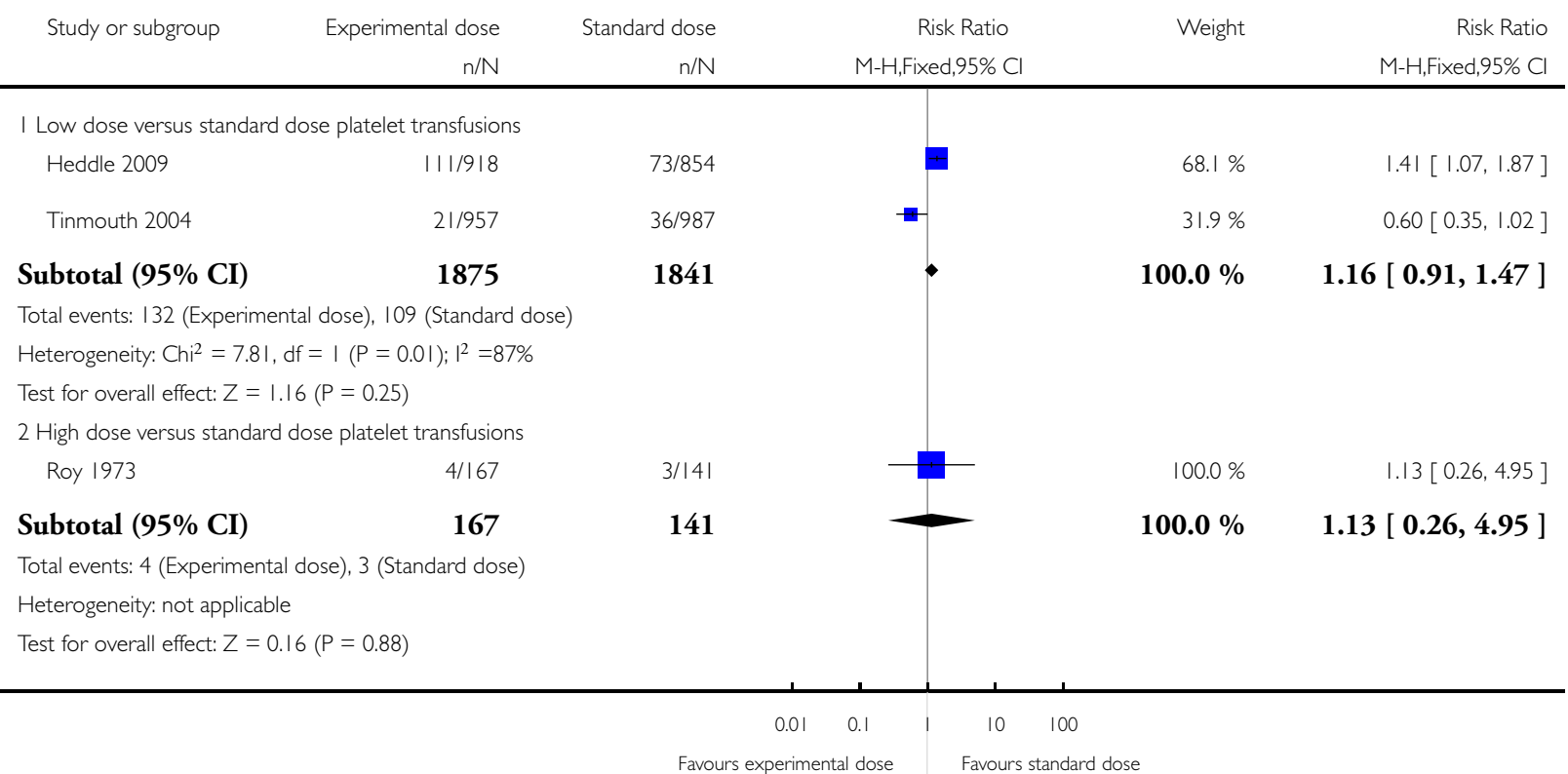

Prophylactic platelet transfusion for prevention of bleeding in patients with haematological disorders after chemotherapy and stem cell $\quad$ I07 transplantation (Review)

Copyright (C) 2012 The Cochrane Collaboration. Published by John Wiley \& Sons, Ltd. 
Analysis 3.8. Comparison 3 Prophylactic platelet transfusion with one dose schedule versus another dose schedule, Outcome 8 Mortality from all causes.

Review: Prophylactic platelet transfusion for prevention of bleeding in patients with haematological disorders after chemotherapy and stem cell transplantation

Comparison: 3 Prophylactic platelet transfusion with one dose schedule versus another dose schedule

Outcome: 8 Mortality from all causes

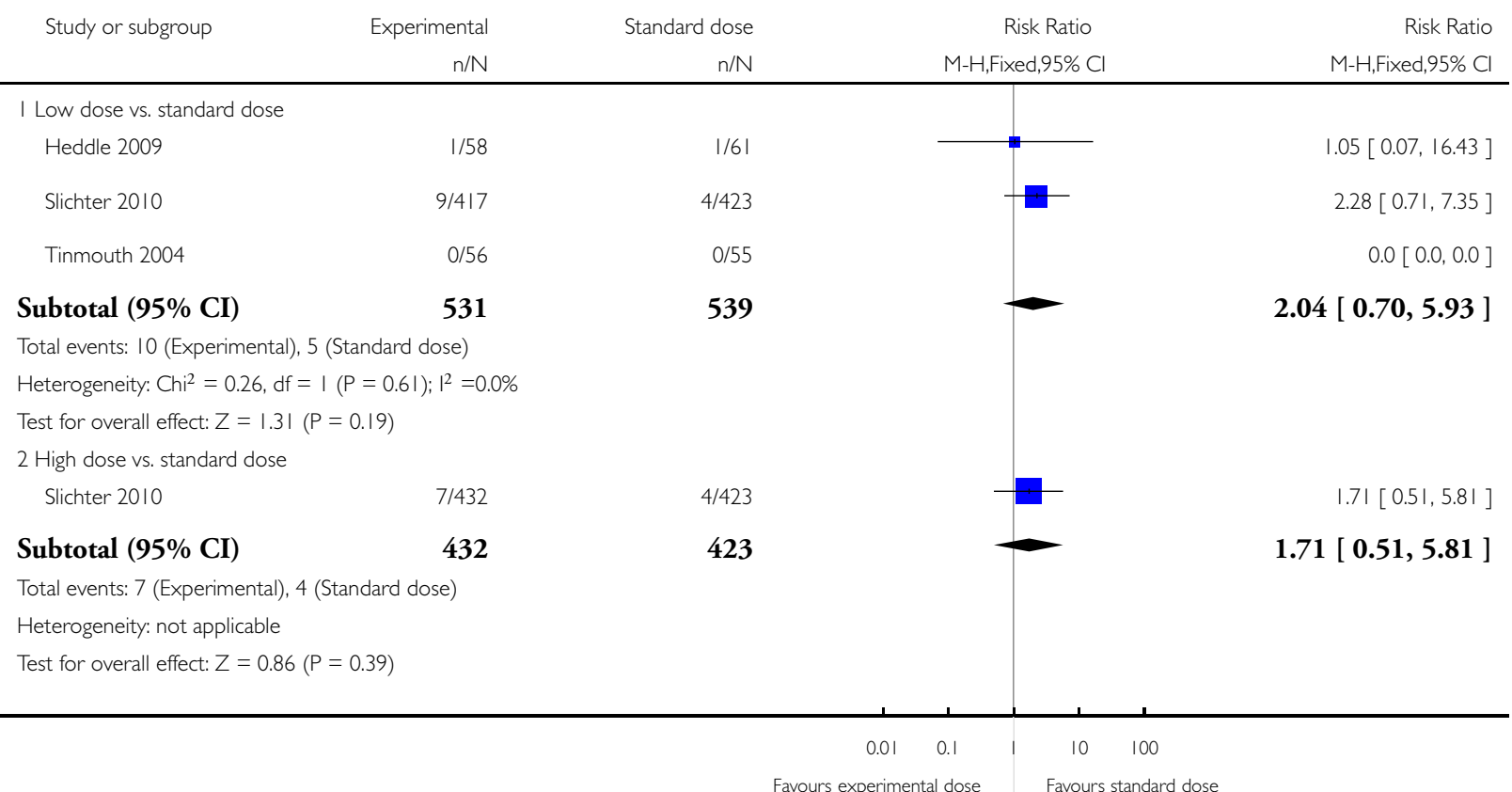

Prophylactic platelet transfusion for prevention of bleeding in patients with haematological disorders after chemotherapy and stem cell $\quad 108$ transplantation (Review)

Copyright (C) 2012 The Cochrane Collaboration. Published by John Wiley \& Sons, Ltd. 
Analysis 3.9. Comparison 3 Prophylactic platelet transfusion with one dose schedule versus another dose schedule, Outcome 9 Mortality from bleeding.

Review: Prophylactic platelet transfusion for prevention of bleeding in patients with haematological disorders after chemotherapy and stem cell transplantation

Comparison: 3 Prophylactic platelet transfusion with one dose schedule versus another dose schedule

Outcome: 9 Mortality from bleeding

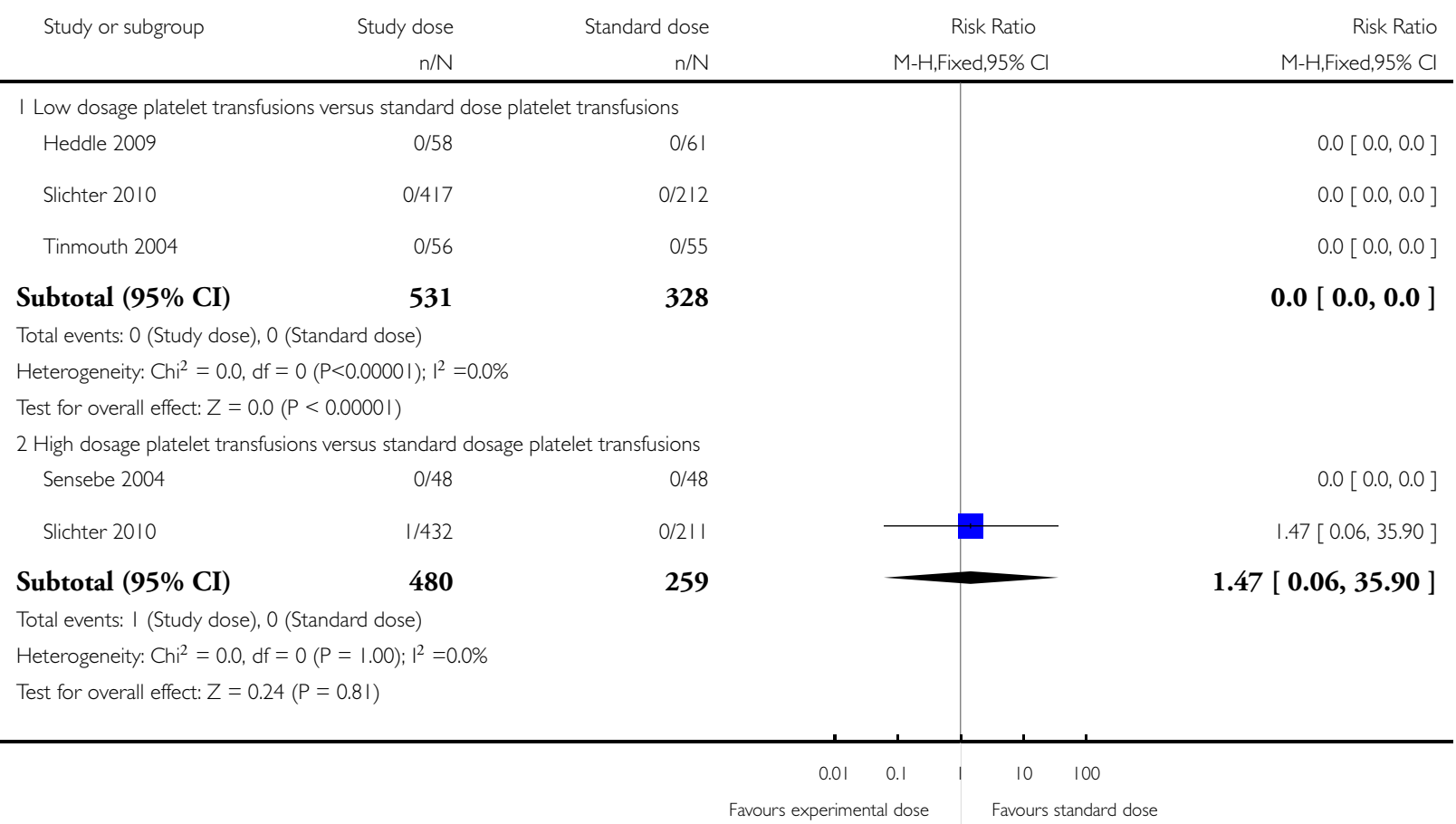

Prophylactic platelet transfusion for prevention of bleeding in patients with haematological disorders after chemotherapy and stem cell $\quad$ I09 transplantation (Review)

Copyright (C) 2012 The Cochrane Collaboration. Published by John Wiley \& Sons, Ltd. 


\section{Analysis 3.10. Comparison 3 Prophylactic platelet transfusion with one dose schedule versus another dose schedule, Outcome 10 Number of participants with platelet transfusion reactions.}

Review: Prophylactic platelet transfusion for prevention of bleeding in patients with haematological disorders after chemotherapy and stem cell transplantation

Comparison: 3 Prophylactic platelet transfusion with one dose schedule versus another dose schedule

Outcome: 10 Number of participants with platelet transfusion reactions

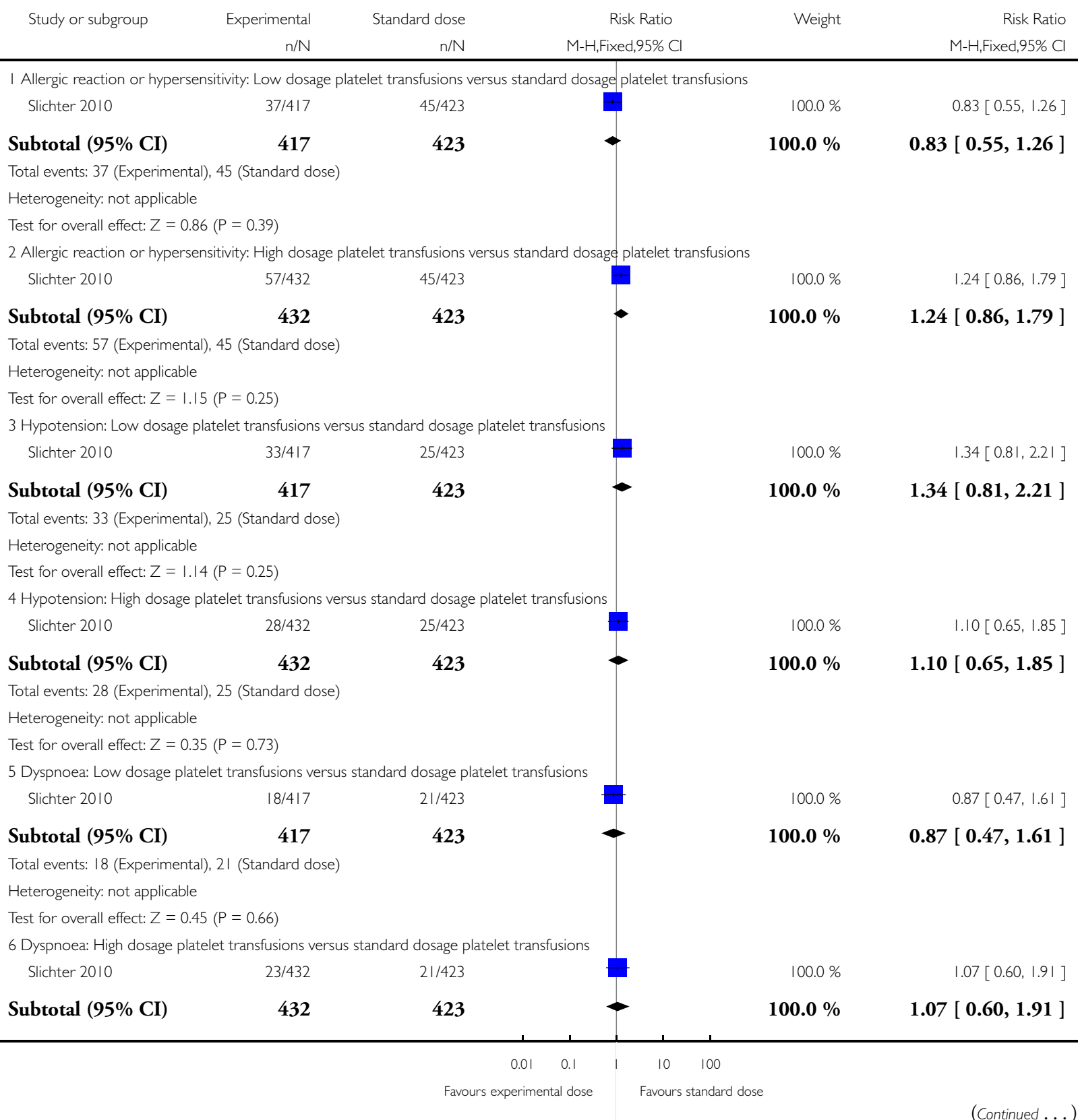




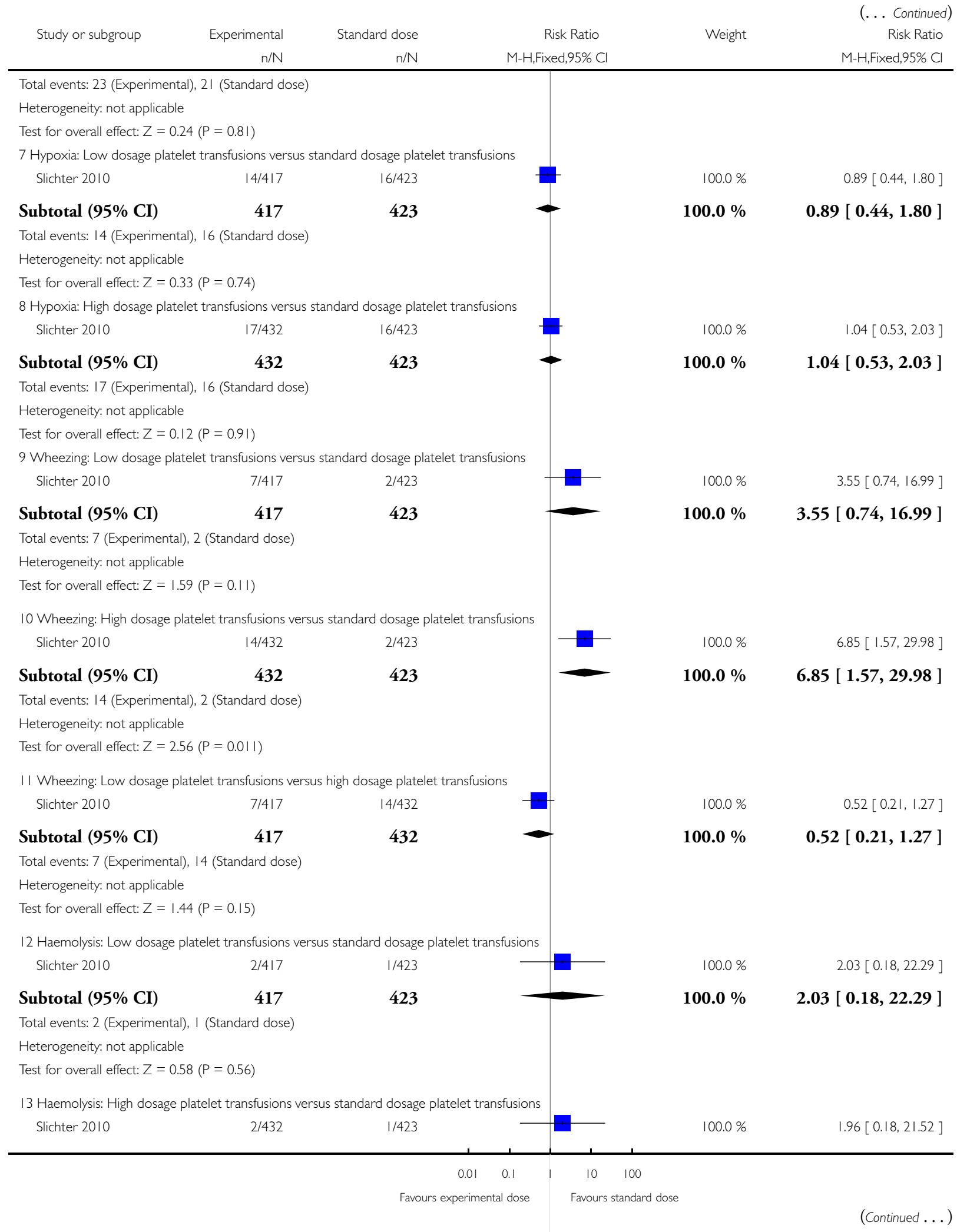

Prophylactic platelet transfusion for prevention of bleeding in patients with haematological disorders after chemotherapy and stem cell II I transplantation (Review)

Copyright (C) 2012 The Cochrane Collaboration. Published by John Wiley \& Sons, Ltd. 


\begin{tabular}{|c|c|c|c|c|c|}
\hline Study or subgroup & $\begin{array}{r}\text { Experimental } \\
\mathrm{n} / \mathrm{N} \\
\end{array}$ & $\begin{array}{r}\text { Standard dose } \\
\mathrm{n} / \mathrm{N} \\
\end{array}$ & M-H,Fixed,95\% Cl & Weight & $\begin{array}{r}\text { Risk Ratio } \\
\text { M-H,Fixed,95\% Cl }\end{array}$ \\
\hline Subtotal (95\% CI) & 432 & 423 & & $100.0 \%$ & $1.96[0.18,21.52]$ \\
\hline \multicolumn{6}{|c|}{ Total events: 2 (Experimental), I (Standard dose) } \\
\hline \multicolumn{6}{|c|}{ Heterogeneity: not applicable } \\
\hline \multicolumn{6}{|c|}{ Test for overall effect: $Z=0.55(P=0.58)$} \\
\hline \multicolumn{6}{|c|}{ I4 Rigors or chills: Low dosage platelet transfusions versus standard dosage platelet transfusions } \\
\hline Slichter 2010 & $37 / 417$ & $43 / 423$ & & $100.0 \%$ & $0.87[0.57,1.33]$ \\
\hline Subtotal (95\% CI) & 417 & 423 & & $100.0 \%$ & $0.87[0.57,1.33]$ \\
\hline \multicolumn{6}{|c|}{ Total events: 37 (Experimental), 43 (Standard dose) } \\
\hline \multicolumn{6}{|c|}{ Heterogeneity: not applicable } \\
\hline \multicolumn{6}{|c|}{ Test for overall effect: $Z=0.64(P=0.52)$} \\
\hline \multicolumn{6}{|c|}{ I5 Rigors or chills: High dosage platelet transfusions versus standard dosage platelet transfusions } \\
\hline Slichter 2010 & $50 / 432$ & $43 / 423$ & & $100.0 \%$ & $1.14[0.77,1.67]$ \\
\hline Subtotal (95\% CI) & 432 & 423 & $\longrightarrow$ & $100.0 \%$ & $1.14[0.77,1.67]$ \\
\hline \multicolumn{6}{|c|}{ Total events: 50 (Experimental), 43 (Standard dose) } \\
\hline \multicolumn{6}{|c|}{ Heterogeneity: not applicable } \\
\hline \multicolumn{6}{|c|}{ Test for overall effect: $Z=0.66(P=0.5 \mathrm{I})$} \\
\hline \multicolumn{6}{|c|}{16 Fever: Low dosage platelet transfusions versus standard dosage platelet transfusions } \\
\hline Slichter 2010 & $149 / 417$ & $132 / 423$ & & $100.0 \%$ & $1.15[0.95,1.39]$ \\
\hline Subtotal (95\% CI) & 417 & 423 & - & $100.0 \%$ & $1.15[0.95,1.39]$ \\
\hline \multicolumn{6}{|c|}{ Total events: I 49 (Experimental), 132 (Standard dose) } \\
\hline \multicolumn{6}{|c|}{ Heterogeneity: not applicable } \\
\hline \multicolumn{6}{|c|}{ Test for overall effect: $Z=1.39(P=0.17)$} \\
\hline \multicolumn{6}{|c|}{ I7 Fever: High dosage platelet transfusions versus standard dosage platelet transfusions } \\
\hline Slichter 2010 & $144 / 432$ & $132 / 423$ & & $100.0 \%$ & $1.07[0.88,1.30]$ \\
\hline Subtotal (95\% CI) & 432 & 423 & $\bullet$ & $100.0 \%$ & $1.07[0.88,1.30]$ \\
\hline \multicolumn{6}{|c|}{ Total events: I 44 (Experimental), I 32 (Standard dose) } \\
\hline \multicolumn{6}{|c|}{ Heterogeneity: not applicable } \\
\hline \multicolumn{6}{|c|}{ Test for overall effect: $Z=0.66(P=0.51)$} \\
\hline \multicolumn{6}{|c|}{ I8 Infection: Low dosage platelet transfusions versus standard dosage platelet transfusions } \\
\hline Slichter 2010 & $5 / 417$ & $5 / 423$ & & $100.0 \%$ & $1.01[0.30,3.48]$ \\
\hline Subtotal (95\% CI) & 417 & 423 & & $100.0 \%$ & $1.01[0.30,3.48]$ \\
\hline \multicolumn{6}{|c|}{ Total events: 5 (Experimental), 5 (Standard dose) } \\
\hline \multicolumn{6}{|c|}{ Heterogeneity: not applicable } \\
\hline \multicolumn{6}{|c|}{ Test for overall effect: $Z=0.02(P=0.98)$} \\
\hline 19 Infection: High dosage & $t$ transfusions ve & andard dosage pla & sions & & \\
\hline Slichter 2010 & $7 / 432$ & $5 / 423$ & & $100.0 \%$ & $1.37[0.44,4.29]$ \\
\hline Subtotal (95\% CI) & 432 & 423 & - & $100.0 \%$ & $1.37[0.44,4.29]$ \\
\hline Total events: 7 (Experimen & (Standard dose) & & & & \\
\hline Heterogeneity: not applica & & & & & \\
\hline Test for overall effect: $Z=$ & $P=0.59)$ & & & & \\
\hline & & & 10 & 100 & \\
\hline & & Favou & Favours & tandard dose & \\
\hline
\end{tabular}

Prophylactic platelet transfusion for prevention of bleeding in patients with haematological disorders after chemotherapy and stem cell II 2 transplantation (Review) 
Analysis 3.1 I. Comparison 3 Prophylactic platelet transfusion with one dose schedule versus another dose schedule, Outcome II Thromboembolic disease.

Review: Prophylactic platelet transfusion for prevention of bleeding in patients with haematological disorders after chemotherapy and stem cell transplantation

Comparison: 3 Prophylactic platelet transfusion with one dose schedule versus another dose schedule

Outcome: II Thromboembolic disease

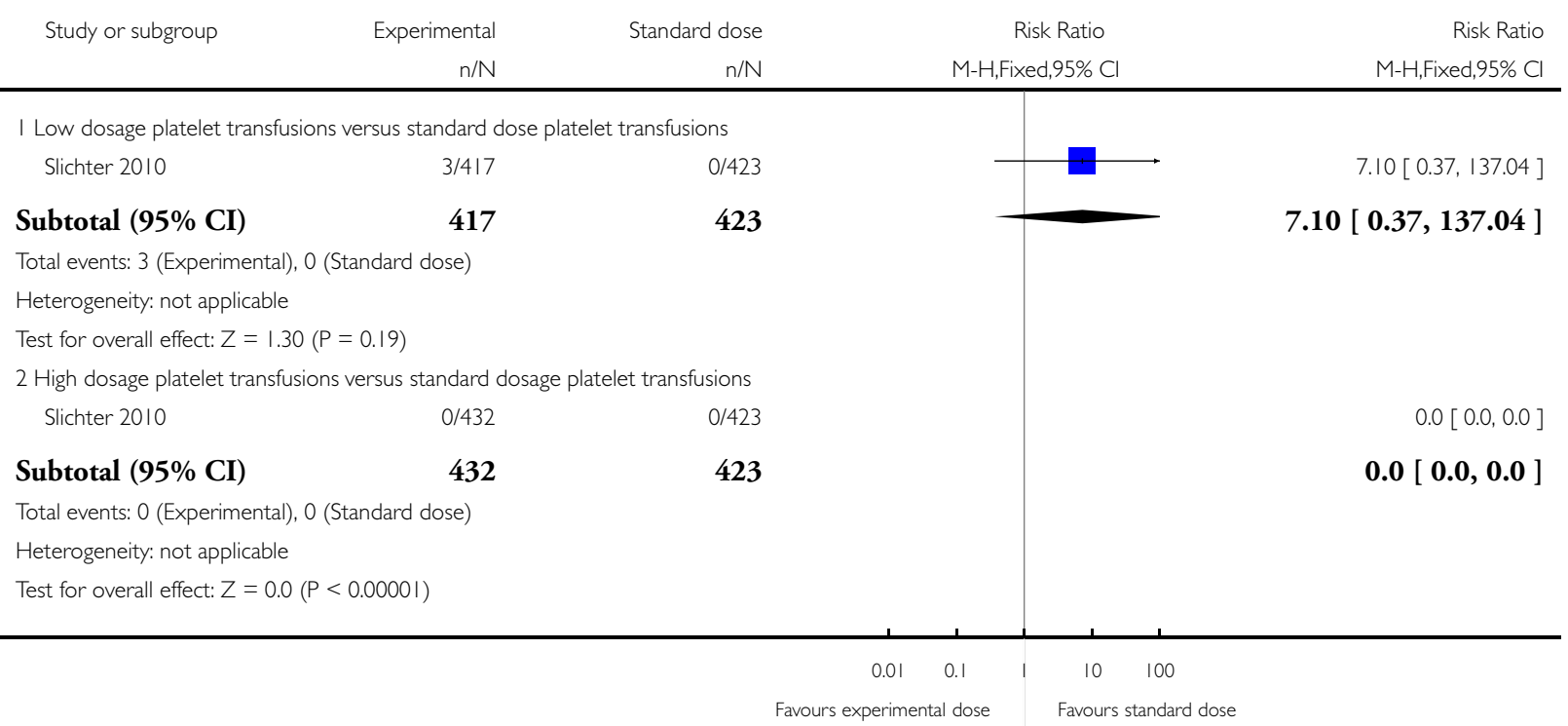

Prophylactic platelet transfusion for prevention of bleeding in patients with haematological disorders after chemotherapy and stem cell $I I 3$ transplantation (Review)

Copyright (? 2012 The Cochrane Collaboration. Published by John Wiley \& Sons, Ltd. 
Analysis 3.12. Comparison 3 Prophylactic platelet transfusion with one dose schedule versus another dose schedule, Outcome 12 Number of participants with a significant bleeding episode.

Review: Prophylactic platelet transfusion for prevention of bleeding in patients with haematological disorders after chemotherapy and stem cell transplantation

Comparison: 3 Prophylactic platelet transfusion with one dose schedule versus another dose schedule

Outcome: 12 Number of participants with a significant bleeding episode

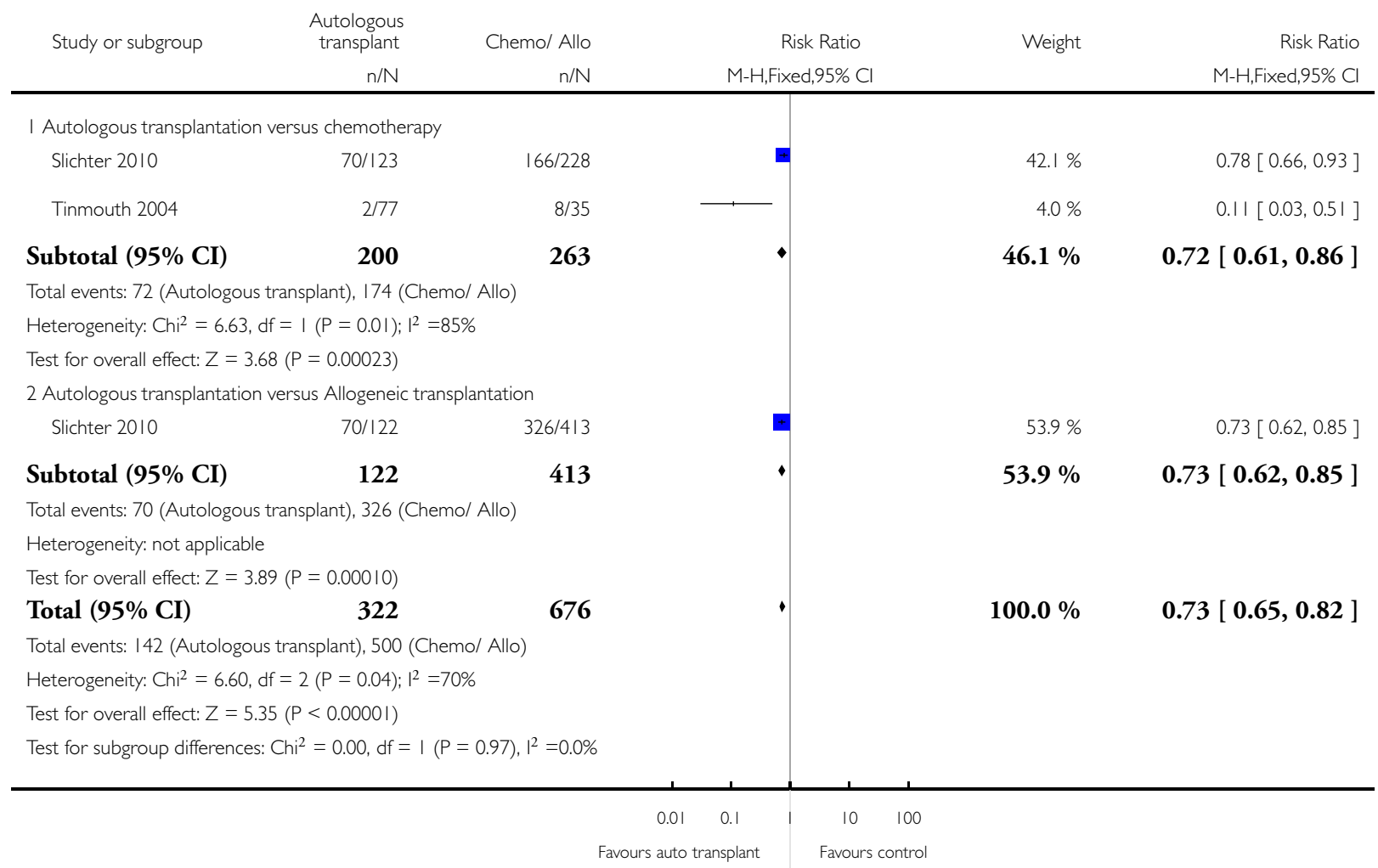

Prophylactic platelet transfusion for prevention of bleeding in patients with haematological disorders after chemotherapy and stem cell II4 transplantation (Review)

Copyright (C) 2012 The Cochrane Collaboration. Published by John Wiley \& Sons, Ltd. 
Analysis 3.13. Comparison 3 Prophylactic platelet transfusion with one dose schedule versus another dose schedule, Outcome 13 Time to first significant bleeding event.

Review: Prophylactic platelet transfusion for prevention of bleeding in patients with haematological disorders after chemotherapy and stem cell transplantation

Comparison: 3 Prophylactic platelet transfusion with one dose schedule versus another dose schedule

Outcome: 13 Time to first significant bleeding event

\begin{tabular}{|c|c|c|c|c|c|c|c|}
\hline \multirow[t]{2}{*}{ Study or subgroup } & Low dosage platelets & & $\begin{array}{r}\text { Standard } \\
\text { dosage } \\
\text { platelets }\end{array}$ & & $\begin{array}{r}\text { Mean } \\
\text { Difference }\end{array}$ & \multirow[t]{2}{*}{ Weight } & \multirow{2}{*}{$\begin{array}{r}\text { Mean } \\
\text { Difference } \\
\text { IV,Fixed,95\% C }\end{array}$} \\
\hline & $N$ & Mean(SD) & N & Mean(SD) & IV,Fixed,95\% Cl & & \\
\hline Heddle 2009 & 58 & $11.2(9.18)$ & 61 & $9.7(8.39)$ & + & $100.0 \%$ & $1.50[-1.66,4.66]$ \\
\hline Total $(95 \%$ CI $)$ & 58 & & 61 & & - & $100.0 \%$ & $1.50[-1.66,4.66]$ \\
\hline \multicolumn{8}{|c|}{ Heterogeneity: not applicable } \\
\hline \multicolumn{8}{|c|}{ Test for overall effect: $Z=0.93(P=0.35)$} \\
\hline \multicolumn{8}{|c|}{ Test for subgroup differences: Not applicable } \\
\hline & & & & -100 & -50 & 100 & \\
\hline
\end{tabular}

Analysis 3.14. Comparison 3 Prophylactic platelet transfusion with one dose schedule versus another dose schedule, Outcome 14 Number of days with WHO grade 2 or above bleeding per patient.

Review: Prophylactic platelet transfusion for prevention of bleeding in patients with haematological disorders after chemotherapy and stem cell transplantation

Comparison: 3 Prophylactic platelet transfusion with one dose schedule versus another dose schedule

Outcome: 14 Number of days with WHO grade 2 or above bleeding per patient

\begin{tabular}{|c|c|c|c|c|c|c|c|}
\hline \multirow[t]{2}{*}{ Study or subgroup } & Low dosage platelets & & $\begin{array}{r}\text { Standard } \\
\text { dosage } \\
\text { platelets }\end{array}$ & & $\begin{array}{r}\text { Mean } \\
\text { Difference }\end{array}$ & \multirow[t]{2}{*}{ Weight } & \multirow{2}{*}{$\begin{array}{r}\text { Mean } \\
\text { Difference } \\
\text { IV,Fixed,95\% Cl }\end{array}$} \\
\hline & $N$ & Mean(SD) & N & Mean(SD) & IV,Fixed,95\% Cl & & \\
\hline Heddle 2009 & 58 & $1.8(3.23)$ & 61 & $1.2(2.02)$ & 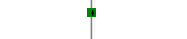 & $11.9 \%$ & $0.60[-0.37,1.57]$ \\
\hline Tinmouth 2004 & 56 & $0.375(0.9256)$ & 55 & $0.65(1)$ & & $88.1 \%$ & $-0.28[-0.64,0.08]$ \\
\hline Total (95\% CI) & 114 & & 116 & & 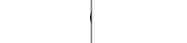 & $100.0 \%$ & $-0.17[-0.51,0.16]$ \\
\hline \multicolumn{8}{|c|}{ Heterogeneity: $\mathrm{Chi}^{2}=2.76, d f=I(P=0.10) ;\left.\right|^{2}=64 \%$} \\
\hline \multicolumn{8}{|c|}{ Test for overall effect: $Z=1.02(P=0.31)$} \\
\hline \multicolumn{8}{|c|}{ Test for subgroup differences: Not applicable } \\
\hline & & & & -100 & -50 & 100 & \\
\hline
\end{tabular}

Prophylactic platelet transfusion for prevention of bleeding in patients with haematological disorders after chemotherapy and stem cell II 5 transplantation (Review)

Copyright ( 2012 The Cochrane Collaboration. Published by John Wiley \& Sons, Ltd. 
Analysis 4.I. Comparison 4 Prophylactic platelet transfusion versus platelet-poor plasma, Outcome I Number of participants with a significant bleeding event.

Review: Prophylactic platelet transfusion for prevention of bleeding in patients with haematological disorders after chemotherapy and stem cell transplantation

Comparison: 4 Prophylactic platelet transfusion versus platelet-poor plasma

Outcome: I Number of participants with a significant bleeding event

\begin{tabular}{crrrr} 
Study or subgroup & Prophylactic platelets & Platelet poor plasma & Risk Ratio & Weight \\
& $n / N$ & $n / N$ & $M-H, F i x e d, 95 \%$ Cl & R-H,Fixed,95\% Cl \\
\hline Higby 1974 & $5 / 12$ & $8 / 9$ & $\mathbf{9}$ & $0.47[0.23,0.95]$ \\
Total (95\% CI) & $\mathbf{1 2}$ & $-\mathbf{1 0 0 . 0} \%$ & $\mathbf{0 . 4 7}[\mathbf{0 . 2 3}, \mathbf{0 . 9 5}]$
\end{tabular}

Total events: 5 (Prophylactic platelets), 8 (Platelet poor plasma)

Heterogeneity: not applicable

Test for overall effect: $Z=2.10(P=0.036)$

Test for subgroup differences: Not applicable

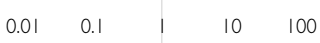

Favours platelets Favours plasma

Analysis 4.2. Comparison 4 Prophylactic platelet transfusion versus platelet-poor plasma, Outcome 2 Time to first bleed.

Review: Prophylactic platelet transfusion for prevention of bleeding in patients with haematological disorders after chemotherapy and stem cell transplantation

Comparison: 4 Prophylactic platelet transfusion versus platelet-poor plasma

Outcome: 2 Time to first bleed

\begin{tabular}{|c|c|c|c|c|c|c|c|}
\hline \multirow[t]{2}{*}{ Study or subgroup } & Prophylactic platelets & & Platelet poor plasma & & $\begin{array}{r}\text { Mean } \\
\text { Difference }\end{array}$ & \multirow[t]{2}{*}{ Weight } & \multirow{2}{*}{$\begin{array}{r}\text { Mear } \\
\text { Difference } \\
\text { IV,Fixed,95\% C }\end{array}$} \\
\hline & $\mathrm{N}$ & Mean(SD) & $\mathrm{N}$ & Mean(SD) & IV,Fixed,95\% Cl & & \\
\hline Higby 1974 & 12 & $13(7.11)$ & 9 & $13(9.82)$ & & $100.0 \%$ & $0.0[-7.57,7.57]$ \\
\hline Total $(95 \% \mathrm{CI})$ & 12 & & 9 & & $\rightarrow$ & $100.0 \%$ & $0.0[-7.57,7.57]$ \\
\hline \multicolumn{8}{|c|}{ Heterogeneity: not applicable } \\
\hline \multicolumn{8}{|c|}{ Test for overall effect: $Z=0.0(P=1.0)$} \\
\hline \multicolumn{8}{|c|}{ Test for subgroup differences: Not applicable } \\
\hline & & & & -100 & -50 & 100 & \\
\hline & & & & Favours & platelets & lasma & \\
\hline
\end{tabular}

Prophylactic platelet transfusion for prevention of bleeding in patients with haematological disorders after chemotherapy and stem cell $\mathbf{I} \mathbf{6}$ transplantation (Review)

Copyright ( 2012 The Cochrane Collaboration. Published by John Wiley \& Sons, Ltd. 
Analysis 4.3. Comparison 4 Prophylactic platelet transfusion versus platelet-poor plasma, Outcome 3 Number of participants with bleeding requiring a red cell transfusion.

Review: Prophylactic platelet transfusion for prevention of bleeding in patients with haematological disorders after chemotherapy and stem cell transplantation

Comparison: 4 Prophylactic platelet transfusion versus platelet-poor plasma

Outcome: 3 Number of participants with bleeding requiring a red cell transfusion

\begin{tabular}{|c|c|c|c|c|c|}
\hline Study or subgroup & Prophylactic platelets & Platelet poor plasma & Risk Ratio & Weight & Risk Ratio \\
\hline & $n / N$ & $\mathrm{n} / \mathrm{N}$ & M-H,Fixed,95\% Cl & & M-H,Fixed,95\% Cl \\
\hline Higby 1974 & $3 / 12$ & $6 / 9$ & 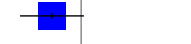 & $100.0 \%$ & $0.38[0.13,1.11]$ \\
\hline Total $(95 \% \mathrm{CI})$ & 12 & 9 & & $100.0 \%$ & $0.38[0.13,1.11]$ \\
\hline
\end{tabular}

Total events: 3 (Prophylactic platelets), 6 (Platelet poor plasma)

Heterogeneity: not applicable

Test for overall effect: $Z=1.77(P=0.076)$

Test for subgroup differences: Not applicable

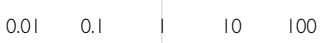

Favours platelets Favours plasma

Analysis 4.4. Comparison 4 Prophylactic platelet transfusion versus platelet-poor plasma, Outcome 4 Number of participants with bleeding causing cardiovascular compromise.

Review: Prophylactic platelet transfusion for prevention of bleeding in patients with haematological disorders after chemotherapy and stem cell transplantation

Comparison: 4 Prophylactic platelet transfusion versus platelet-poor plasma

Outcome: 4 Number of participants with bleeding causing cardiovascular compromise

\begin{tabular}{|c|c|c|c|c|c|}
\hline \multirow[t]{2}{*}{ Study or subgroup } & Prophylactic platelets & Platelet poor plasma & Risk Ratio & Weight & Risk Ratio \\
\hline & $\mathrm{n} / \mathrm{N}$ & $\mathrm{n} / \mathrm{N}$ & M-H,Fixed,95\% Cl & & M-H,Fixed,95\% Cl \\
\hline Higby 1974 & $1 / 12$ & $1 / 9$ & & $100.0 \%$ & $0.75[0.05,10.44]$ \\
\hline Total $(95 \% \mathrm{CI})$ & 12 & 9 & & $100.0 \%$ & $0.75[0.05,10.44]$ \\
\hline \multicolumn{6}{|c|}{ Total events: I (Prophylactic platelets), I (Platelet poor plasma) } \\
\hline \multicolumn{6}{|c|}{ Heterogeneity: not applicable } \\
\hline \multicolumn{6}{|c|}{ Test for overall effect: $Z=0.21(P=0.83)$} \\
\hline Test for subgroup dif & ces: Not applicable & & & & \\
\hline
\end{tabular}

$\begin{array}{lllll}0.01 & 0.1 & 1 & 10 & 100\end{array}$

Favours platelets Favours plasma

Prophylactic platelet transfusion for prevention of bleeding in patients with haematological disorders after chemotherapy and stem cell $\quad$ II transplantation (Review)

Copyright ( 2012 The Cochrane Collaboration. Published by John Wiley \& Sons, Ltd. 
Analysis 4.5. Comparison 4 Prophylactic platelet transfusion versus platelet-poor plasma, Outcome 5 Mortality from bleeding.

Review: Prophylactic platelet transfusion for prevention of bleeding in patients with haematological disorders after chemotherapy and stem cell transplantation

Comparison: 4 Prophylactic platelet transfusion versus platelet-poor plasma

Outcome: 5 Mortality from bleeding

\begin{tabular}{|c|c|c|c|c|c|}
\hline \multirow[t]{2}{*}{ Study or subgroup } & Prophylactic platelets & Platelet poor plasma & Risk Ratio & Weight & Risk Ratio \\
\hline & $\mathrm{n} / \mathrm{N}$ & $\mathrm{n} / \mathrm{N}$ & M-H,Fixed,95\% Cl & & M-H,Fixed,95\% Cl \\
\hline Higby 1974 & $1 / 12$ & $0 / 9$ & & $100.0 \%$ & $2.31[0.10,50.85]$ \\
\hline
\end{tabular}

Total $(95 \% \mathrm{CI})$

12

9

$100.0 \%$

$2.31[0.10,50.85]$

Total events: I (Prophylactic platelets), 0 (Platelet poor plasma)

Heterogeneity: not applicable

Test for overall effect: $Z=0.53(P=0.60)$

Test for subgroup differences: Not applicable

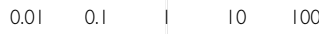

Favours platelets Favours plasma

Analysis 4.6. Comparison 4 Prophylactic platelet transfusion versus platelet-poor plasma, Outcome 6 Complete remission.

Review: Prophylactic platelet transfusion for prevention of bleeding in patients with haematological disorders after chemotherapy and stem cell transplantation

Comparison: 4 Prophylactic platelet transfusion versus platelet-poor plasma

Outcome: 6 Complete remission

\begin{tabular}{|c|c|c|c|c|c|}
\hline \multirow[t]{2}{*}{ Study or subgroup } & Prophylactic platelets & Platelet poor plasma & Risk Ratio & Weight & Risk Ratio \\
\hline & $\mathrm{n} / \mathrm{N}$ & $\mathrm{n} / \mathrm{N}$ & M-H,Fixed,95\% Cl & & M-H,Fixed, $95 \% \mathrm{Cl}$ \\
\hline Higby 1974 & $4 / 12$ & $6 / 9$ & 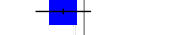 & $100.0 \%$ & $0.50[0.20,1.26]$ \\
\hline
\end{tabular}

Total (95\% CI)

12

9

$100.0 \%$

$0.50[0.20,1.26]$

Total events: 4 (Prophylactic platelets), 6 (Platelet poor plasma)

Heterogeneity: not applicable

Test for overall effect: $Z=1.47(P=0.14)$

Test for subgroup differences: Not applicable

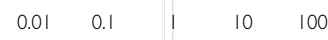

Favours platelets Favours plasma

Prophylactic platelet transfusion for prevention of bleeding in patients with haematological disorders after chemotherapy and stem cell $\quad$ I 8 transplantation (Review)

Copyright (C) 2012 The Cochrane Collaboration. Published by John Wiley \& Sons, Ltd. 


\section{Analysis 4.7. Comparison 4 Prophylactic platelet transfusion versus platelet-poor plasma, Outcome 7 Development of HLA Antibodies.}

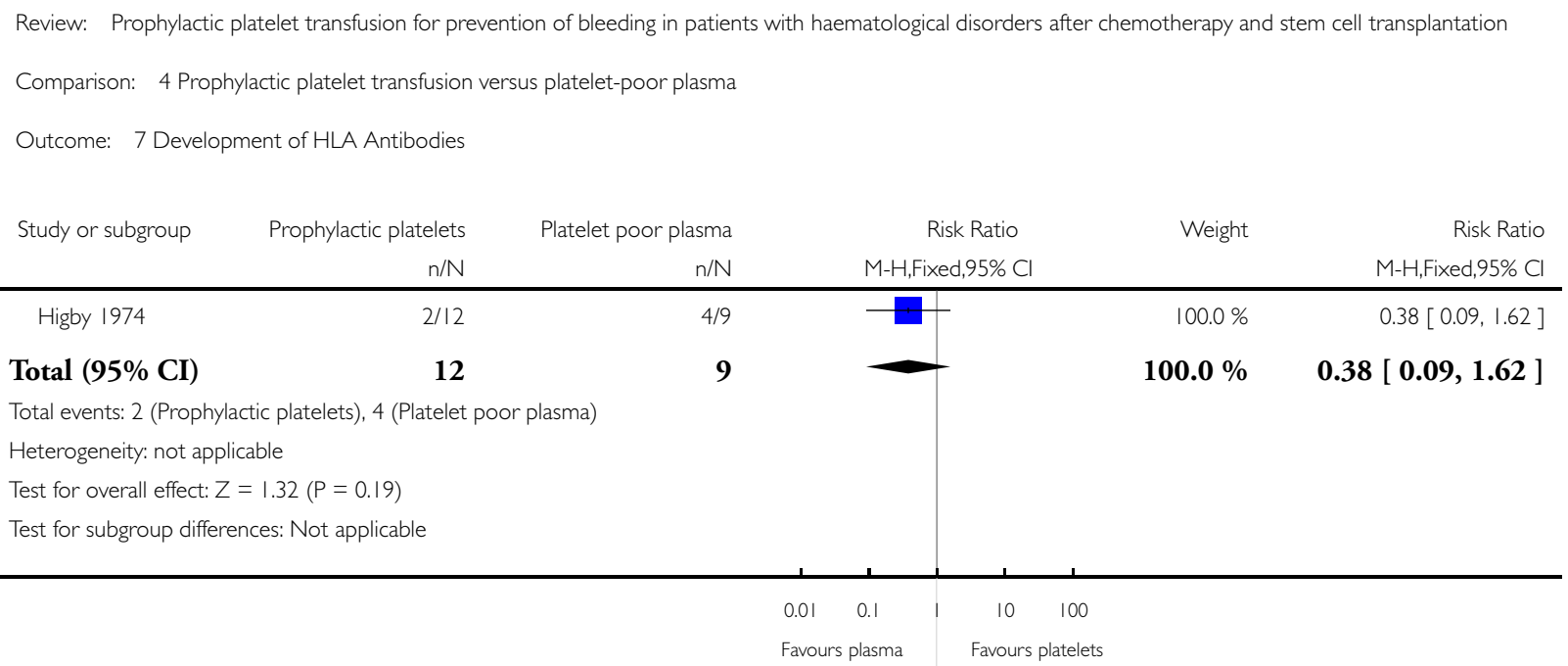

ADDITIONAL TABLES

Table 1. Prophylactic versus Therapeutic Platelet Transfusion Studies - Characteristics of Studies

\begin{tabular}{|c|c|c|c|c|c|c|}
\hline Study & Participants & Number & Intervention & Duration of study & $\begin{array}{l}\text { Type of platelet } \\
\text { product }\end{array}$ & $\begin{array}{l}\text { Primary } \\
\text { Outcome }\end{array}$ \\
\hline Murphy 1982 & $\begin{array}{l}\text { Children with } \\
\text { acute leukaemia }\end{array}$ & 56 & $\begin{array}{l}\text { Pro- } \\
\text { phylactic plt trans- } \\
\text { fusion if plt count } \\
<20 \times 10^{9} / \mathrm{L} \\
\text { versus } \\
\text { Plt transfusion } \\
\text { given in presence } \\
\text { of } 5 \text { clinical indica- } \\
\text { tors of bleeding }\end{array}$ & $\begin{array}{l}19.9 \text { to } 20.4 \\
\text { months }\end{array}$ & Random donor & Survival \\
\hline $\begin{array}{l}\text { Sintnicolaas } \\
1982\end{array}$ & $\begin{array}{l}\text { Patients with } \\
\text { acute leukaemia }\end{array}$ & 12 & $\begin{array}{l}\text { Pro- } \\
\text { phylactic plt trans- } \\
\text { fusion if plt count } \\
<20 \times 10^{9} / \mathrm{L} \\
\text { versus } \\
\mathrm{Plt} \text { transfusion } \\
\text { given in presence } \\
\text { of haemorrhage }\end{array}$ & Not reported & $\begin{array}{l}\text { ABO compatible } \\
\text { Single donor }\end{array}$ & Not reported \\
\hline
\end{tabular}

Prophylactic platelet transfusion for prevention of bleeding in patients with haematological disorders after chemotherapy and stem cell II9 transplantation (Review) 
Table 1. Prophylactic versus Therapeutic Platelet Transfusion Studies - Characteristics of Studies (Continued)

\begin{tabular}{|c|c|c|c|c|c|c|}
\hline Solomon 1978 & $\begin{array}{l}\text { Adults with } \\
\text { AML }\end{array}$ & 31 & $\begin{array}{l}\text { Pro- } \\
\text { phylactic plt trans- } \\
\text { fusion if plt count } \\
<20 \times 10^{9} / \mathrm{L} \\
\text { versus } \\
\text { Plt } \\
\text { transfusion given } \\
\text { if clinically signif- } \\
\text { icant bleeding OR } \\
>50 \% \text { fall in plts } \\
\text { to }<20 \times 10^{9} / \mathrm{L} \text { in } \\
\text { previous } 24 \text { hours }\end{array}$ & Not reported & Random donor & Not reported \\
\hline
\end{tabular}

Table 2. Prophylactic Platelet transfusion Studies with Varying Transfusion Trigger Levels - Characteristics of Studies

\begin{tabular}{|c|c|c|c|c|c|c|}
\hline Study & Participants & Number & Intervention & Duration of study & $\begin{array}{l}\text { Type of platelet } \\
\text { product }\end{array}$ & $\begin{array}{l}\text { Primary } \\
\text { Outcome }\end{array}$ \\
\hline Diedrich 2005 & $\begin{array}{l}\text { All ages under- } \\
\text { going an allo- } \\
\text { geneic stem cell } \\
\text { transplant }\end{array}$ & 166 & $\begin{array}{l}\text { Pro- } \\
\text { phylactic plt trans- } \\
\text { fusion if plt count } \\
<10 \times 10^{9} / \mathrm{L} \\
\text { versus } \\
\text { Pro- } \\
\text { phylactic plt trans- } \\
\text { fusion if plt count } \\
<30 \times 10^{9} / \mathrm{L}\end{array}$ & Not reported & $\begin{array}{l}\text { Leucodepleted } \\
\text { ABO matched Ir- } \\
\text { radiated } \\
\text { Pooled random } \\
\text { donor platelets } \\
\text { (Buffy coat) } 85 \% \\
\text { Apheresis } 15 \%\end{array}$ & $\begin{array}{l}\text { Number of platelet } \\
\text { transfusions }\end{array}$ \\
\hline Heckman 1997 & $\begin{array}{l}\text { Adults with } \\
\text { acute leukaemia }\end{array}$ & 82 & $\begin{array}{l}\text { Pro- } \\
\text { phylactic plt trans- } \\
\text { fusion if plt count } \\
\leq 10 \times 10^{9} / \mathrm{L} \\
\text { versus } \\
\text { Pro- } \\
\text { phylactic plt trans- } \\
\text { fusion if plt count } \\
\leq 20 \times 10^{9} / \mathrm{L}\end{array}$ & Median 24 days & $\begin{array}{l}\text { Leucodepleted } \\
\text { Apheresis }\end{array}$ & Not reported \\
\hline Rebulla 1997 & $\begin{array}{l}\text { Adolescents and } \\
\text { adults with AML }\end{array}$ & 276 & $\begin{array}{l}\text { Pro- } \\
\text { phylactic plt trans- } \\
\text { fusion if plt count } \\
<10 \times 10^{9} / \mathrm{L} \\
\text { versus } \\
\text { Pro- } \\
\text { phylactic plt trans- } \\
\text { fusion if plt count } \\
<20 \times 10^{9} / \mathrm{L}\end{array}$ & Not reported & $\begin{array}{l}\text { Apheresis and } \\
\text { Pooled products }\end{array}$ & $\begin{array}{l}\text { Frequency and } \\
\text { severity of haemor- } \\
\text { rhage }\end{array}$ \\
\hline
\end{tabular}

Prophylactic platelet transfusion for prevention of bleeding in patients with haematological disorders after chemotherapy and stem cell $\quad$ I 20 transplantation (Review)

Copyright @ 2012 The Cochrane Collaboration. Published by John Wiley \& Sons, Ltd. 
Table 3. Prophylactic Platelet Transfusion Studies with Varying Platelet Transfusion Doses - Characteristics of Studies

\begin{tabular}{|c|c|c|c|c|c|c|c|}
\hline Study & Participants & Number & Intervention & $\begin{array}{l}\text { Prophylactic } \\
\text { Platelet trans- } \\
\text { fusion thresh- } \\
\text { old }\end{array}$ & $\begin{array}{l}\text { Duration of } \\
\text { study }\end{array}$ & $\begin{array}{l}\text { Type of } \\
\text { platelet prod- } \\
\text { uct }\end{array}$ & $\begin{array}{l}\text { Primary Out- } \\
\text { come }\end{array}$ \\
\hline Heddle 2009 & $\begin{array}{l}\text { Adults with } \\
\text { hypoprolif- } \\
\text { erative throm- } \\
\text { bocytopenia }\end{array}$ & 129 & $\begin{array}{l}\text { Low dose }(1.5 \\
\text { to } 3.0 \times 10^{11} \\
\text { platelets/ } \\
\text { product) } \\
\text { versus } \\
\text { Standard dose } \\
(3.0 \text { to } 6.0 \times x \\
10^{11} \text { platelets/ } \\
\text { product })\end{array}$ & $\begin{array}{l}\text { De- } \\
\text { pended on lo- } \\
\text { cal transfusion } \\
\text { trigger. Usually } \\
10 \times 10^{9} / \mathrm{L}\end{array}$ & $\begin{array}{l}\text { Mean of } 14 \text { to } \\
15.8 \text { days }\end{array}$ & $\begin{array}{l}\text { Apheresis and } \\
\text { Pooled platelet } \\
\text { products }\end{array}$ & $\begin{array}{l}\text { Occurrence of a } \\
\text { WHO grade } 2 \\
\text { bleed or above }\end{array}$ \\
\hline Roy 1973 & $\begin{array}{l}\text { Children with } \\
\text { acute } \\
\text { leukaemia }\end{array}$ & 62 & $\begin{array}{l}\text { Standard dose } \\
\left(0.46 \times 10^{11}\right. \\
\text { platelets/10kg) } \\
\text { versus } \\
\text { High dose }(0.9 \\
\text { to } 1.1 \times 10^{11} / \\
10 \mathrm{~kg})\end{array}$ & $\begin{array}{l}\text { Plt count } \leq 25 \\
\times 10^{9} / \mathrm{L}\end{array}$ & $\begin{array}{l}\text { Follow-up for } \\
24 \text { hours post } \\
\text { platelet trans- } \\
\text { fusion }\end{array}$ & $\begin{array}{l}\text { ABO identical } \\
\text { Pooled } \\
\text { products }\end{array}$ & Not reported \\
\hline Sensebe 2004 & $\begin{array}{l}\text { Patients with } \\
\text { acute } \\
\text { leukaemia } \\
\text { or patients un- } \\
\text { dergoing au- } \\
\text { tologous SCT }\end{array}$ & 101 & $\begin{array}{l}\text { Standard dose } \\
\left(0.5 \times 10^{11} /\right. \\
10 \mathrm{~kg}) \\
\text { versus } \\
\text { High dose }(1.0 \\
\left.\times 10^{11} / 10 \mathrm{~kg}\right)\end{array}$ & $\begin{array}{l}\text { Plt count }<20 \mathrm{x} \\
10^{9} / \mathrm{L}\end{array}$ & Not stated & $\begin{array}{l}\text { Leucodepleted } \\
\text { ABO compati- } \\
\text { ble Apheresis }\end{array}$ & $\begin{array}{l}\text { Time between } \\
\text { first transfusion } \\
\text { and daily } \\
\text { platelet count } \\
\text { reaching } 20 \mathrm{x} \\
10^{9} / \mathrm{L}\end{array}$ \\
\hline Slichter 2010 & $\begin{array}{l}\text { Patients of any } \\
\text { age } \\
\text { receiving stem } \\
\text { cell transplant } \\
\text { or myeloabla- } \\
\text { tive } \\
\text { chemotherapy }\end{array}$ & 1351 & $\begin{array}{l}\text { Low dose }(1.1 \mathrm{x} \\
\left.10^{11} / \mathrm{m}^{2} \mathrm{BSA}\right) \\
\text { versus } \\
\text { Intermedi- } \\
\text { ate dose }(2.2 \mathrm{x} \\
\left.10^{11} / \mathrm{m}^{2} \mathrm{BSA}\right) \\
\text { versus } \\
\text { High dose }(4 . \\
4 \mathrm{x} 10^{11} / \mathrm{m}^{2} \\
\mathrm{BSA})\end{array}$ & $\begin{array}{l}\text { Plt count } \leq 10 \\
\times 10^{9} / \mathrm{L}\end{array}$ & $\begin{array}{l}\text { Mean number } \\
\text { of days } 19.1\end{array}$ & $\begin{array}{l}\text { Apheresis and } \\
\text { pooled platelet } \\
\text { products }\end{array}$ & $\begin{array}{l}\text { Grade } 2 \text { or } \\
\text { higher bleeding }\end{array}$ \\
\hline Steffens 2002 & $\begin{array}{l}\text { Patients aged } \\
>16 y r s \text { with } \\
\text { AML or un- } \\
\text { der- } \\
\text { going an allo- } \\
\text { geneic SCT }\end{array}$ & 54 & $\begin{array}{l}\text { Standard dose } \\
\text { (single aphere- } \\
\text { sis unit) } \\
\text { versus } \\
\text { High dose } \\
\text { (triple aphere- } \\
\text { sis unit) }\end{array}$ & $\begin{array}{l}\text { Plt count } \leq 10 \\
\times 10^{9} / \mathrm{L}\end{array}$ & $\begin{array}{l}\text { Median } \\
\text { time for AML } \\
\text { patients } 25.1 \text { to } \\
25.8 \text { days } \\
\text { Median time } \\
\text { for SCT } 14.1 \text { to } \\
15.9 \text { days }\end{array}$ & Apheresis & Not reported \\
\hline
\end{tabular}

Prophylactic platelet transfusion for prevention of bleeding in patients with haematological disorders after chemotherapy and stem cell $\mathbf{I 2}$ I 
Table 3. Prophylactic Platelet Transfusion Studies with Varying Platelet Transfusion Doses - Characteristics of Studies (Continued)

\begin{tabular}{|c|c|c|c|c|c|c|c|}
\hline $\begin{array}{l}\text { Tinmouth } \\
2004\end{array}$ & $\begin{array}{l}\text { Patients age > } \\
16 y r s \quad \text { with } \\
\text { acute } \\
\text { leukaemia or } \\
\text { receiv- } \\
\text { ing an autolo- } \\
\text { gous SCT }\end{array}$ & 111 & $\begin{array}{l}\text { Low dose }(1.9 \\
\text { to } 2.5 \times 10^{11} \\
\text { platelets/ } \\
\text { transfusion) } \\
\text { versus } \\
\text { Standard dose } \\
(3.4 \text { to } 4.4 \mathrm{x} \\
10^{11} \text { platelets/ } \\
\text { transfusion) }\end{array}$ & $\begin{array}{l}\text { Plt count }<10 \mathrm{x} \\
10^{9} / \mathrm{L}\end{array}$ & $\begin{array}{l}\text { Median time } \\
15 \text { days }\end{array}$ & $\begin{array}{l}\text { Leucodepleted } \\
\text { Random donor } \\
\text { pooled platelets } \\
\text { (PRP method) }\end{array}$ & $\begin{array}{l}\text { Bayesian } \\
\text { design. Lower } \\
\text { dose of platelets } \\
\text { would be safe } \\
\text { and effective in } \\
\text { preventing ma- } \\
\text { jor bleed- } \\
\text { ing events and } \\
\text { would decrease } \\
\text { total utilisation } \\
\text { of platelets }\end{array}$ \\
\hline
\end{tabular}

$\overline{\mathrm{BSA}}=$ body surface area

SCT $=$ stem cell transplant

Table 4. Studies that reported bleeding as an outcome measure- Bleeding Assessment and Grading

\begin{tabular}{|c|c|c|c|c|c|}
\hline Study & $\begin{array}{l}\text { Bleeding primary } \\
\text { outcome of study }\end{array}$ & $\begin{array}{l}\text { Method of bleed- } \\
\text { ing assessment re- } \\
\text { ported }\end{array}$ & $\begin{array}{l}\text { Bleeding severity } \\
\text { scale used }\end{array}$ & $\begin{array}{l}\text { RBC usage part } \\
\text { of bleeding severity } \\
\text { assessment }\end{array}$ & $\begin{array}{l}\text { RBC transfusion } \\
\text { policy }\end{array}$ \\
\hline Heddle 2009 & Yes & Yes & Adapted WHO & Yes & $\begin{array}{l}\text { Local practice at } \\
\text { each centre } \\
\text { (unpublished) }\end{array}$ \\
\hline Rebulla 1997 & Yes & Yes & $\begin{array}{l}\text { New scale developed } \\
\text { by Rebulla }\end{array}$ & Yes & $\begin{array}{l}\text { Haemoglobin }<80 \mathrm{~g} / \\
\mathrm{L}\end{array}$ \\
\hline Slichter 2010 & Yes & Yes & Adapted WHO & Yes & $\begin{array}{l}\text { Local practice at } \\
\text { each centre }\end{array}$ \\
\hline Tinmouth 2004 & Yes & Yes & Adapted Rebulla & No & Not reported \\
\hline Heckman 1997 & Not reported & Yes & Ajani 1990 & Yes & Not reported \\
\hline Higby 1974 & Not reported & No & Study specific & Yes & Not reported \\
\hline Roy 1973 & Not reported & Yes & Study specific & No & Not reported \\
\hline Diedrich 2005 & No & Yes & WHO 1979 & No & $\begin{array}{l}\text { Haemoglobin }<80 \mathrm{~g} / \\
\mathrm{L}\end{array}$ \\
\hline Murphy 1982 & No & No & Study specific & No & Not reported \\
\hline Sensebe 2004 & No & No & WHO 1979 & No & Not reported \\
\hline
\end{tabular}

Prophylactic platelet transfusion for prevention of bleeding in patients with haematological disorders after chemotherapy and stem cell $\quad 122$ transplantation (Review)

Copyright ( 2012 The Cochrane Collaboration. Published by John Wiley \& Sons, Ltd. 
Table 5. Prophylactic versus Therapeutic Platelet Transfusion Studies - Number of platelet units and red cell transfusions

\begin{tabular}{|c|c|c|c|c|c|c|c|}
\hline Study & Intervention & $\begin{array}{l}\text { Number } \\
\text { of patients in } \\
\text { each arm }\end{array}$ & $\begin{array}{l}\text { Platelet dose/ } \\
\text { transfusion }\end{array}$ & $\begin{array}{l}\text { Number of } \\
\text { platelet units }\end{array}$ & P value & $\begin{array}{l}\text { Num- } \\
\text { ber of red cell } \\
\text { transfusions/ } \\
\text { patient }\end{array}$ & P value \\
\hline \multirow{2}{*}{$\begin{array}{l}\text { Murphy } \\
1982\end{array}$} & Prophylactic & 35 & \multirow[t]{2}{*}{4 units $/ \mathrm{m}^{2}$} & 8.1/ patient* & \multirow[t]{2}{*}{ Not reported } & \multirow[t]{2}{*}{ Not reported } & \multirow[t]{2}{*}{ Not reported } \\
\hline & Therapeutic & 21 & & 4.8/ patient* & & & \\
\hline \multirow[t]{2}{*}{$\begin{array}{l}\text { Solomon } \\
1978\end{array}$} & Prophylactic & 17 & \multirow[t]{2}{*}{ Not reported } & $\begin{array}{l}\text { Mean } 31.9 \text { (S. } \\
\text { D. } \\
\text { 5.9)/ course of } \\
\text { chemotherapy }\end{array}$ & \multirow[t]{2}{*}{ Not reported } & $\begin{array}{l}\text { Mean 6.7 (S. } \\
\text { D. } \pm 1.0)\end{array}$ & \multirow[t]{2}{*}{ Not reported } \\
\hline & Therapeutic & 12 & & $\begin{array}{l}\text { Mean } 16.1 \text { (S. } \\
\text { D. } \\
3.4) / \text { course of } \\
\text { chemotherapy }\end{array}$ & & $\begin{array}{l}\text { Mean } 7.3 \text { (S. } \\
\text { D. } \pm 1.0)\end{array}$ & \\
\hline
\end{tabular}

* = Not specified in article whether this figure is a mean or a median (author has died).

$\mathrm{SD}=$ standard deviation

Table 6. Prophylactic Platelet Transfusion Studies with Varying Platelet Transfusion Thresholds - Duration of Hospital Stay

\begin{tabular}{|c|c|c|c|c|}
\hline Study & $\begin{array}{l}\text { Intervention } \\
\text { (Transfusion threshold) }\end{array}$ & $\begin{array}{l}\text { Number of patients in } \\
\text { each arm }\end{array}$ & $\begin{array}{l}\text { Number of days in hospi- } \\
\text { tal (median) }\end{array}$ & $P$ value \\
\hline \multirow[t]{2}{*}{ Diedrich 2005} & $<10 \times 10^{9} / \mathrm{L}$ & 79 & $\begin{array}{l}23 \\
\text { Range } 9 \text { to } 89\end{array}$ & \multirow[t]{2}{*}{ Not significant } \\
\hline & $<30 \times 10^{9} / \mathrm{L}$ & 87 & $\begin{array}{l}23 \\
\text { Range } 14 \text { to } 140\end{array}$ & \\
\hline \multirow[t]{2}{*}{ Heckman 1997} & $\leq 10 \times 10^{9} / \mathrm{L}$ & 37 & $\begin{array}{l}38 \\
\text { IQR } 30 \text { to } 42\end{array}$ & \multirow[t]{2}{*}{$0.25^{*}$} \\
\hline & $\leq 20 \times 10^{9} / \mathrm{L}$ & 41 & $\begin{array}{l}32 \\
\text { IQR } 27 \text { to } 45\end{array}$ & \\
\hline \multirow[t]{2}{*}{ Rebulla 1997} & $<10 \times 10^{9} / \mathrm{L}$ & 135 & $\begin{array}{l}29 \\
\text { Range } 3 \text { to } 64\end{array}$ & \multirow[t]{2}{*}{ Not reported } \\
\hline & $<20 \times 10^{9} / \mathrm{L}$ & 120 & $\begin{array}{l}28 \\
\text { Range } 4 \text { to } 54\end{array}$ & \\
\hline
\end{tabular}

$\overline{\mathrm{IQR}}=$ Interquartile range

* = P value is not statistically significant

Prophylactic platelet transfusion for prevention of bleeding in patients with haematological disorders after chemotherapy and stem cell $\quad$ I 23 transplantation (Review)

Copyright ( 2012 The Cochrane Collaboration. Published by John Wiley \& Sons, Ltd. 
Table 7. Prophylactic Platelet Transfusion Studies with Varying Platelet Transfusion Dosages - Number of days with a significant bleeding event/patient

\begin{tabular}{|c|c|c|c|c|c|c|c|c|}
\hline \multirow[t]{2}{*}{ Study } & \multicolumn{2}{|l|}{ Low dose } & \multirow{2}{*}{$\begin{array}{l}\text { P value } \\
\text { Low dose } \\
\text { vs. standard } \\
\text { dose }\end{array}$} & \multicolumn{2}{|c|}{ Standard dose } & \multirow{2}{*}{$\begin{array}{l}\text { P value } \\
\text { Standard } \\
\text { dose vs. } \\
\text { high dose }\end{array}$} & \multicolumn{2}{|l|}{ High dose } \\
\hline & $\begin{array}{l}\text { Num- } \\
\text { ber of par- } \\
\text { ticipants }\end{array}$ & Days & & $\begin{array}{l}\text { Num- } \\
\text { ber of par- } \\
\text { ticipants }\end{array}$ & Days & & $\begin{array}{l}\text { Num- } \\
\text { ber of par- } \\
\text { ticipants }\end{array}$ & Days \\
\hline $\begin{array}{l}\text { Heddle } \\
2009\end{array}$ & 58 & $\begin{array}{l}\text { Mean } 1.8 \pm \\
\text { S.D. } 3 \cdot 23^{\#}\end{array}$ & $\begin{array}{l}\text { Not } \\
\text { reported }\end{array}$ & 61 & $\begin{array}{l}\text { Mean } 1.2 \pm \\
\text { S.D. } 2.02^{\#}\end{array}$ & NA & NA & NA \\
\hline $\begin{array}{l}\text { Slichter } \\
2010\end{array}$ & 417 & $\begin{array}{l}\text { Median } 1 \\
\text { IQR } 0 \text { to } 4\end{array}$ & $0.9^{*}$ & 423 & $\begin{array}{l}\text { Median } 1 \\
\text { IQR } 0 \text { to } 4\end{array}$ & $0.91^{*}$ & 432 & $\begin{array}{l}\text { Median } 1 \\
\text { IQR } 0 \text { to } 4\end{array}$ \\
\hline $\begin{array}{l}\text { Tinmouth } \\
2004^{@}\end{array}$ & 56 & $\begin{array}{l}\text { Mean } 0.375 \\
\pm S D 0.93^{\#}\end{array}$ & $\begin{array}{l}\text { Not } \\
\text { reported }\end{array}$ & 55 & $\begin{array}{l}\text { Mean } 0.65 \pm \\
\text { SD } 1.0^{\#}\end{array}$ & NA & NA & NA \\
\hline
\end{tabular}

IQR = Interquartile range

NA = Not applicable

* = $\mathrm{P}$ value is not statistically significant

\# = unpublished data

@ = To improve comparison with the other studies significant bleeding in this analysis was the number of days with bleeding that required a therapeutic platelet transfusion or local intervention. This differs from the study's definition of significant bleeding.

Table 8. Prophylactic Platelet Transfusion Studies with Varying Platelet Transfusion Dosages - Time to first significant bleeding event

\begin{tabular}{|c|c|c|c|c|c|c|c|c|}
\hline \multirow[t]{2}{*}{ Study } & \multicolumn{2}{|l|}{ Low dose } & \multirow{2}{*}{$\begin{array}{l}\text { P value } \\
\text { Low dose } \\
\text { vs. standard } \\
\text { dose }\end{array}$} & \multicolumn{2}{|c|}{ Standard dose } & \multirow{2}{*}{$\begin{array}{l}\text { P value } \\
\text { Standard } \\
\text { dose vs. } \\
\text { high dose }\end{array}$} & \multicolumn{2}{|l|}{ High dose } \\
\hline & $\begin{array}{l}\text { Num- } \\
\text { ber of par- } \\
\text { ticipants }\end{array}$ & Days & & $\begin{array}{l}\text { Num- } \\
\text { ber of par- } \\
\text { ticipants }\end{array}$ & Days & & $\begin{array}{l}\text { Num- } \\
\text { ber of par- } \\
\text { ticipants }\end{array}$ & Days \\
\hline $\begin{array}{l}\text { Heddle } \\
2009\end{array}$ & 58 & $\begin{array}{l}\text { Mean } 11.2 \pm \\
\text { SD } 9.18^{\#}\end{array}$ & $\begin{array}{l}\text { Not } \\
\text { reported }\end{array}$ & 61 & $\begin{array}{l}\text { Mean } 9.7 \pm \\
\text { SD } 8.39^{\#}\end{array}$ & NA & NA & NA \\
\hline $\begin{array}{l}\text { Slichter } \\
2010\end{array}$ & 417 & $\begin{array}{l}\text { Median } 7 \\
\text { IQR } 3 \text { to } 18\end{array}$ & $0.85^{*}$ & 423 & $\begin{array}{l}\text { Median } 7 \\
\text { IQR } 3 \text { to } 19\end{array}$ & $0.66^{*}$ & 432 & $\begin{array}{l}\text { Median } 8 \\
\text { IQR } 3 \text { to } 19\end{array}$ \\
\hline
\end{tabular}

$\overline{\mathrm{IQR}}=$ Interquartile range

NA $=$ Not applicable

* = P value is not statistically significant

${ }^{*}=$ unpublished data 
Table 9. Prophylactic Platelet Transfusion Studies with Varying Platelet Transfusion Doses - Number of platelet transfusions and red cell transfusions

\begin{tabular}{|c|c|c|c|c|c|c|c|c|}
\hline Study & $\begin{array}{l}\text { Interven- } \\
\text { tion }\end{array}$ & $\begin{array}{l}\text { Num- } \\
\text { ber of par- } \\
\text { ticipants }\end{array}$ & $\begin{array}{l}\text { Number of } \\
\text { platelet } \\
\text { transfusion } \\
\text { episodes/ } \\
\text { patient }\end{array}$ & P value & $\begin{array}{l}\text { To- } \\
\text { tal platelet } \\
\text { utilisation }\end{array}$ & P value & $\begin{array}{l}\text { Number of } \\
\text { red cell } \\
\text { transfu- } \\
\text { sions/ } \\
\text { patient }\end{array}$ & P value \\
\hline
\end{tabular}

Low dosage versus standard dosage platelets

\begin{tabular}{|c|c|c|c|c|c|c|c|c|}
\hline \multirow[t]{2}{*}{$\begin{array}{l}\text { Heddle } \\
2009\end{array}$} & $\begin{array}{l}\text { Low dose } \\
\mathbf{1 . 5}-\mathbf{3} \times 10 \\
11 \text { platelets/ } \\
\text { transfusion }\end{array}$ & 58 & $\begin{array}{l}\text { Mean } 9.5 \pm \\
\text { SD } 7.8\end{array}$ & \multirow[t]{2}{*}{$<0.001$} & \multirow{2}{*}{$\begin{array}{l}\text { Number of } \\
\text { donor expo- } \\
\text { sures } \\
\text { MD } \\
4.1 ; 95 \% \text { CI } \\
-4.3 \text { to } 12.4\end{array}$} & \multirow[t]{2}{*}{$0.335^{*}$} & $\begin{array}{l}\text { Mean } 6.1 \pm \\
\operatorname{SD~} 4.19^{\#}\end{array}$ & \multirow[t]{2}{*}{$\begin{array}{l}\text { Not } \\
\text { reported }\end{array}$} \\
\hline & $\begin{array}{l}\text { Standard } \\
\text { dose } \\
\mathbf{3}-\mathbf{6} \times 10 \\
11 \text { platelets/ } \\
\text { transfusion }\end{array}$ & 61 & $\begin{array}{l}\text { Mean } 5.3 \pm \\
\text { SD } 3.2\end{array}$ & & & & $\begin{array}{l}\text { Mean } 5.23 \pm \\
\text { SD } 3.58^{\#}\end{array}$ & \\
\hline \multirow[t]{2}{*}{$\begin{array}{l}\text { Slichter } \\
2010\end{array}$} & $\begin{array}{l}\text { Low dose } \\
\mathbf{1 . 1} \times \mathbf{x} \quad \mathbf{1 0} \\
{ }^{11} \text { platelets/ } \\
\mathbf{m}^{2} \pm 25 \%\end{array}$ & 417 & $\begin{array}{l}\text { Median } 5 \\
\text { IQR } 3 \text { to } 9\end{array}$ & \multirow[t]{2}{*}{$<0.001$} & $\begin{array}{l}\text { Median } 9.3 \\
\times 10^{11} \\
\text { IQR } 4.9 \text { to } \\
17.9\end{array}$ & \multirow[t]{2}{*}{0.002} & $\begin{array}{l}\text { Median } 4 \\
\text { IQR } 2 \text { to } 8\end{array}$ & \multirow[t]{2}{*}{$0.62^{*}$} \\
\hline & $\begin{array}{l}\text { Standard } \\
\text { dose } \\
2.2 \quad \text { x } \quad 10 \\
11 \text { platelets/ } \\
\mathbf{m}^{2} \pm 25 \%\end{array}$ & 423 & $\begin{array}{l}\text { Median } 3 \\
\text { IQR } 2 \text { to } 6\end{array}$ & & $\begin{array}{l}\text { Median } 11 . \\
3 \times 10^{11} \\
\text { IQR } 7.0 \text { to } \\
22.8\end{array}$ & & $\begin{array}{l}\text { Median } 4 \\
\text { IQR } 2 \text { to } 8\end{array}$ & \\
\hline \multirow[t]{2}{*}{$\begin{array}{l}\text { Tinmouth } \\
2004\end{array}$} & $\begin{array}{l}\text { Low dose } \\
\mathbf{1 .} \\
9-2.6 \times 10 \\
11 \text { platelets/ } \\
\text { transfusion }\end{array}$ & 56 & $\begin{array}{l}\text { Median } 1 \\
\text { IQR } 0.75 \text { to } \\
5\end{array}$ & \multirow[t]{2}{*}{$\begin{array}{l}\text { Not } \\
\text { reported }\end{array}$} & $\begin{array}{l}\text { Median } 3 \\
\text { WBD units } \\
\text { Range } 0 \text { to } \\
49\end{array}$ & \multirow{2}{*}{$\begin{array}{l}\text { Bayesian } \\
\text { analysis } \\
89 \% \text { prob- } \\
\text { ability low- } \\
\text { dose } \\
\text { platelets re- } \\
\text { duce total } \\
\text { number of } \\
\text { units } \\
\text { transfused } \\
\text { per patient. }\end{array}$} & $\begin{array}{l}\text { Median } 4.5 \\
\text { Range } 0 \text { to } \\
16\end{array}$ & \multirow[t]{2}{*}{$\begin{array}{l}\text { Not } \\
\text { reported }\end{array}$} \\
\hline & $\begin{array}{l}\text { Standard } \\
\text { dose } \\
3 . \\
4-4.4 \times 10 \\
{ }^{11} \text { platelets/ } \\
\text { transfusion }\end{array}$ & 55 & $\begin{array}{l}\text { Median } 1 \\
\text { IQR } 1 \text { to } 4\end{array}$ & & $\begin{array}{l}\text { Median } 5 \\
\text { WBD units } \\
\text { Range } 0 \text { to } \\
110\end{array}$ & & $\begin{array}{l}\text { Median } 4 \\
\text { Range } 0 \text { to } \\
12\end{array}$ & \\
\hline
\end{tabular}

Standard dosage versus High dosage platelets

\begin{tabular}{|c|c|c|c|c|c|c|c|c|}
\hline Roy 1973 & $\begin{array}{l}\text { Standard } \\
\text { dose } \\
0.46 \text { x } 10 \\
11 \text { platelets/ }\end{array}$ & 32 & Mean 4.4 & $\begin{array}{l}\text { Not } \\
\text { reported }\end{array}$ & $\begin{array}{l}\text { Mean } 11.5 \\
\text { WBD units }\end{array}$ & $\begin{array}{l}\text { Not } \\
\text { reported }\end{array}$ & $\begin{array}{l}\text { Not } \\
\text { reported }\end{array}$ & $\begin{array}{l}\text { Not } \\
\text { reported }\end{array}$ \\
\hline
\end{tabular}

Prophylactic platelet transfusion for prevention of bleeding in patients with haematological disorders after chemotherapy and stem cell $\quad$ I 25 transplantation (Review)

Copyright ( 2012 The Cochrane Collaboration. Published by John Wiley \& Sons, Ltd. 
Table 9. Prophylactic Platelet Transfusion Studies with Varying Platelet Transfusion Doses - Number of platelet transfusions and red cell transfusions (Continued)

\begin{tabular}{|c|c|c|c|c|c|c|c|c|}
\hline & \multicolumn{3}{|l|}{$10 \mathrm{~kg}$} & & \multirow[b]{2}{*}{$\begin{array}{l}\text { Mean } 19.0 \\
\text { WBD units }\end{array}$} & & \multirow[b]{2}{*}{$\begin{array}{l}\text { Not } \\
\text { reported }\end{array}$} & \\
\hline & $\begin{array}{l}\text { High dose } \\
0 . \\
9-1.1 \times 10 \\
11 \text { platelets/ } \\
10 \mathrm{~kg}\end{array}$ & 30 & Mean 5.6 & & & & & \\
\hline \multirow[t]{2}{*}{$\begin{array}{l}\text { Sensebe } \\
2004\end{array}$} & $\begin{array}{l}\text { Standard } \\
\text { dose } \\
0.5 \text { x } 10 \\
11 \text { platelets/ } \\
10 \mathrm{~kg}\end{array}$ & 48 & $\begin{array}{l}\text { Median } 3 \\
\text { Range } 1 \text { to } \\
12\end{array}$ & \multirow[t]{2}{*}{0.037} & $\begin{array}{l}\text { Mean } 14.9 x \\
10^{11}\end{array}$ & \multirow[t]{2}{*}{$0.156^{*}$} & $\begin{array}{l}\text { Not } \\
\text { reported }\end{array}$ & \multirow[t]{2}{*}{$\begin{array}{l}\text { Not } \\
\text { reportec }\end{array}$} \\
\hline & $\begin{array}{l}\text { High dose } \\
1.0 \times 10 \\
11 \text { platelets/ } \\
10 \mathrm{~kg}\end{array}$ & 48 & $\begin{array}{l}\text { Median } 2 \\
\text { Range } 1 \text { to } \\
13\end{array}$ & & $\begin{array}{l}\text { Mean } 18.5 \mathrm{x} \\
10^{11}\end{array}$ & & $\begin{array}{l}\text { Not } \\
\text { reported }\end{array}$ & \\
\hline \multirow[t]{2}{*}{$\begin{array}{l}\text { Slichter } \\
2010\end{array}$} & $\begin{array}{l}\text { Standard } \\
\text { dose } \\
2.2 \text { x } 10 \\
{ }^{11} \text { platelets/ } \\
\mathbf{m}^{2} \pm 25 \%\end{array}$ & 423 & $\begin{array}{l}\text { Median } 3 \\
\text { IQR } 2 \text { to } 6\end{array}$ & \multirow[t]{2}{*}{$0.09^{*}$} & $\begin{array}{l}\text { Median } 11 \\
3 \times 10^{11} \\
\text { IQR } 7.0 \text { to } \\
22.8\end{array}$ & \multirow[t]{2}{*}{$<0.001$} & $\begin{array}{l}\text { Median } 4 \\
\text { IQR } 2 \text { to } 8\end{array}$ & \multirow[t]{2}{*}{$0.70^{*}$} \\
\hline & $\begin{array}{l}\text { High dose } \\
4.4 \times 10 \\
11 \text { platelets/ } \\
\mathbf{m}^{2} \pm 25 \%\end{array}$ & 432 & $\begin{array}{l}\text { Median } 3 \\
\text { IQR } 2 \text { to } 6\end{array}$ & & $\begin{array}{l}\text { Median } 19 . \\
6 \times 10^{11} \\
\text { IQR } 10.6 \text { to } \\
37.4\end{array}$ & & $\begin{array}{l}\text { Median } 4 \\
\text { IQR } 2 \text { to } 8\end{array}$ & \\
\hline \multirow[t]{2}{*}{$\begin{array}{l}\text { Steffens } \\
2002\end{array}$} & $\begin{array}{l}\text { Standard } \\
\text { dose } \\
\text { (Sin- } \\
\text { gle aphere- } \\
\text { sis unit) }\end{array}$ & 28 & $\begin{array}{l}\text { Median } 6 \\
\text { Range } 1 \text { to } \\
14\end{array}$ & \multirow[t]{2}{*}{$\begin{array}{l}\text { Not } \\
\text { reported }\end{array}$} & $\begin{array}{l}\text { Mean } 6.0 \\
\text { units } \\
\text { Range } 1 \text { to } \\
14\end{array}$ & \multirow[t]{2}{*}{$\begin{array}{l}\text { Not } \\
\text { reported }\end{array}$} & $\begin{array}{l}\text { Not } \\
\text { reported }\end{array}$ & \multirow[t]{2}{*}{$\begin{array}{l}\text { Not } \\
\text { reportec }\end{array}$} \\
\hline & $\begin{array}{l}\text { High dose } \\
\text { (Triple } \\
\text { apheresis } \\
\text { unit) }\end{array}$ & 26 & $\begin{array}{l}\text { Median } 3 . \\
23 \\
\text { Range } 1 \text { to } 8\end{array}$ & & $\begin{array}{l}\text { Mean } 9.7 \\
\text { units } \\
\text { Range } 3 \text { to } \\
23\end{array}$ & & $\begin{array}{l}\text { Not } \\
\text { reported }\end{array}$ & \\
\hline
\end{tabular}

$\overline{\mathrm{IQR}}=$ Interquartile range

$\mathrm{MD}=$ mean difference

$\mathrm{SD}=$ standard deviation

$\mathrm{WBD}=$ whole blood derived

$*=$ P value is not statistically significant

\# = unpublished data 


\section{A P P E N D I CES}

\section{Appendix I. MEDLINE search strategy (1996 to Jan 2002)}

1. Platelet Transfusion.mh.

2. platelet $\$$ adj10 (substitute $\$$ or transfusion $\$$ or prophyla $\$$ ).tw.

3. 1 or 2

4. haemorrhage.mh

5. platelet\$.tw.

6. 4 and 5

7. exp Blood Transfusion/

8.5 and 7

9. 3 or 6 or 8

10. randomised controlled trial.pt.

11. controlled clinical trial.pt.

12. randomised controlled trials/

13. random allocation/

14. double blind method/

15. single blind method/

16. clinical trial.pt.

17. exp clinical trials/

18. (clinic\$ adj25 trial\$).ti, ab.

19. cross-over studies/

20. (crossover or cross-over or cross over).tw.

21. ((singl\$ or doubl\$ or trebl\$ or tripl\$) adj25 (blind $\$$ or mask $\$)$ ).ti, ab.

22. placebos/

23. placebo $\$ . t i, a b$.

24. random\$.ti, ab.

25. research design/

26. or/10-25

27. 9 and 26

28. animal/ not (animal/ and human/)

29. 27 not 28

Appendix 2. MEDLINE (Ovid) search strategy (Jan 2002-Nov 20II)

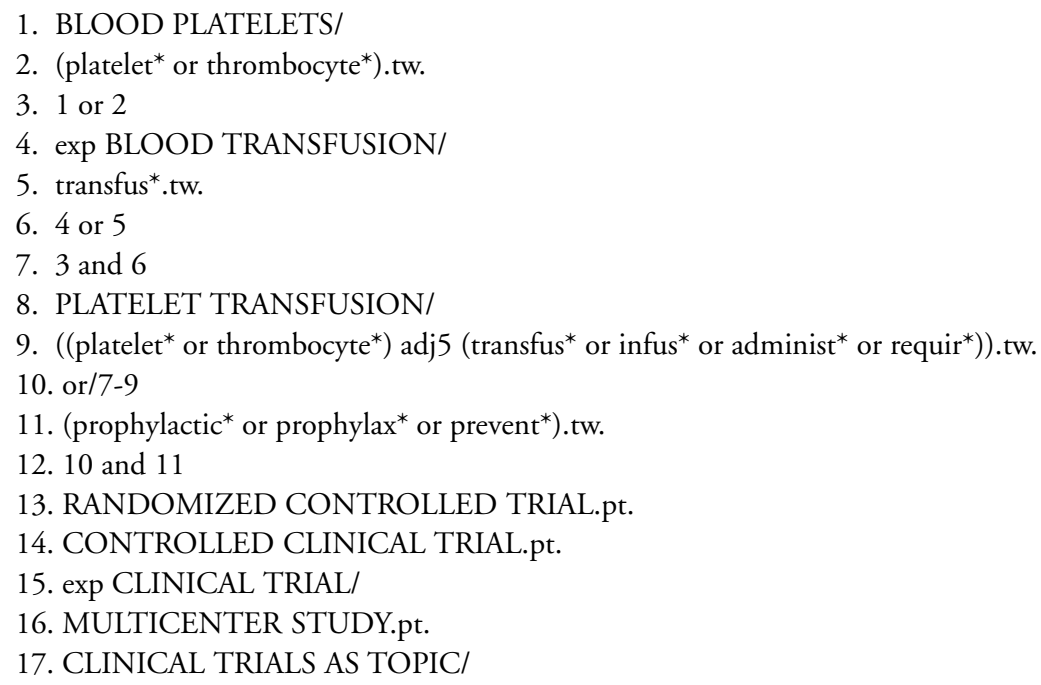

2. (platelet* or thrombocyte*).tw.

3. 1 or 2

4. exp BLOOD TRANSFUSION/

5. transfus*.tw.

6. 4 or 5

7. 3 and 6

8. PLATELET TRANSFUSION/

9. ((platelet* or thrombocyte*) adj5 (transfus* or infus* or administ* or requir*)).tw.

10. or/7-9

11. (prophylactic* or prophylax* or prevent ${ }^{*}$ ).tw.

12. 10 and 11

13. RANDOMIZED CONTROLLED TRIAL.pt.

14. CONTROLLED CLINICAL TRIAL.pt.

15. exp CLINICAL TRIAL/

16. MULTICENTER STUDY.pt.

17. CLINICAL TRIALS AS TOPIC/

Prophylactic platelet transfusion for prevention of bleeding in patients with haematological disorders after chemotherapy and stem cell 
18. CLINICAL TRIALS PHASE III AS TOPIC/

19. CLINICAL TRIALS PHASE IV AS TOPIC/

20. exp CONTROLLED CLINICAL TRIALS AS TOPIC/

21. RANDOM ALLOCATION/

22. DOUBLE BLIND METHOD/

23. SINGLE BLIND METHOD/

24. CROSSOVER STUDIES/

25. PLACEBOS/

26. or/13-25

27. (controlled adj3 (trial* or stud*)).ti,ab.

28. (blind* or mask*).ti,ab.

29. (placebo* or random* or factorial*).ti,ab.

30. (crossover or (cross adj over)).ti,ab.

31. aleatori*.ti,ab.

32. (treatment adj $\left.\operatorname{arm}^{*}\right)$.ti,ab.

33. ((phase adj iii) or (phase adj three) or (phase adj '3')).ti,ab.

34. (latin adj square).ti,ab.

35. or/27-34

36. 26 or 35

37. ANIMALS/ NOT (HUMANS/ AND ANIMALS/)

38. 36 not 37

39. 12 AND 38

Appendix 3. EMBASE (Ovid) search strategy (1980 to Jan 2002)

1. random\$.ti,ab.

2. factorial\$.ti,ab.

3. (crossover $\$$ or crossover $\$$ or crossover $\$$ ).ti,ab.

4. placebo\$.ti,ab.

5. (double $\$$ adj blind $\$$ ).ti,ab.

6. (singl\$ adj blind $\$$ ).ti,ab.

7. assign\$.ti,ab.

8. allocat\$.ti,ab.

9. volunteer\$.ti,ab.

10. CROSSOVER PROCEDURE.sh.

11. DOUBLE-BLIND PROCEDURE.sh.

12. RANDOMIZED CONTROLLED TRIAL.sh.

13. SINGLE-BLIND PROCEDURE.sh

14. versus.ti,ab,sh.

15. factorial.ti,ab.

16. latin square design.sh.

17. latine square.mp.

18. aleatoric.ab.

19. aleatory.ti,ab.

20. aleatorized.ab.

21. aleatorily.ab.

22. multicenter.ti,ab.

23. multicenter study.sh.

24. multicentered.ti,ab.

25. multicenters.ti,ab.

26. multicenterstudy.ti,ab.

27. multicenterstudie.ti.

Prophylactic platelet transfusion for prevention of bleeding in patients with haematological disorders after chemotherapy and stem cell 


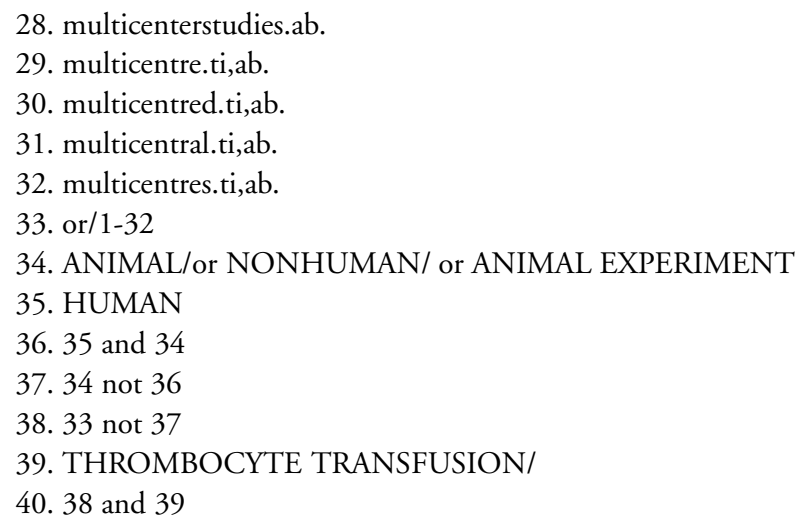

Appendix 4. EMBASE (Ovid) search strategy (Jan 2002-Nov 20II)

1. THROMBOCYTE/

2. (platelet* or thrombocyte*).tw.

3. 1 or 2

4. exp BLOOD TRANSFUSION/

5. transfus*.tw.

6. 4 or 5

7. 3 and 6

8. THROMBOCYTE TRANSFUSION/

9. ((platelet* or thrombocyte*) adj5 (transfus* or infus* or administ* or requir*)).tw. 10. or/7-9

11. (prophylactic* or prophylax* or prevent*).tw.

12. 10 and 11

11. random*.ti,ab.

12. factorial*.ti,ab.

13. (crossover* OR cross over* OR cross-over*).ti,ab.

14. placebo*.ti,ab.

15. (double* adj blind*).ti,ab.

16. (singl ${ }^{*}$ adj blind ${ }^{*}$.ti,ab.

17. (assign* or allocat*).ti,ab.

18. (latin square or aleator*).ti.ab.

19. volunteer*.ti,ab.

20. CROSSOVER PROCEDURE/

21. DOUBLE BLIND PROCEDURE/

22. RANDOMIZED CONTROLLED TRIAL/

23. SINGLE BLIND PROCEDURE/

24. or/11-23

25. $\exp$ ANIMAL/ OR NONHUMAN/ OR exp ANIMAL EXPERIMENT/

26. $\exp$ HUMAN/

27. 25 NOT 26

28. 24 NOT 27

29. 12 AND 28

Prophylactic platelet transfusion for prevention of bleeding in patients with haematological disorders after chemotherapy and stem cell 


\section{Appendix 5. CENTRAL search strategy (Issue 4, 20 I I)}

\#1 MeSH descriptor Blood Platelets explode all trees

\#2 platelet* $^{*}$ or thrombocyte*

\#3 (\#1 OR \#2)

\#4 MeSH descriptor Blood Transfusion explode all trees

$\# 5$ transfus*

\#6 (\#4 OR \#5)

\#7 (\#3 AND \#6)

\#8 MeSH descriptor Platelet Transfusion explode all trees

\#9 (platelet* or thrombocyte*) NEAR/5 (transfus* or infus* or administ* or requir*)

\#10 (\#7 OR \#8 OR \#9)

\#11 prophylactic* or prophylax* or prevent*

\#12 (\#10 AND \#11)

\section{Appendix 6. CINAHL (NHS Evidence) search strategy (Jan 2002-Nov 20 II)}

1. BLOOD PLATELETS/

2. (platelet* or thrombocyte*).ti,ab

3. 1 or 2

4. exp BLOOD TRANSFUSION/

5. transfus*.ti,ab

6. 4 or 5

7. 3 and 6

8. PLATELET TRANSFUSION/

9. ((platelet* adj5 transfus*) or (platelet* adj5 infus*) or (platelet* adj5 administ*) or (platelet* adj5 requir*).ti,ab

10. ((thrombocyte* adj5 transfus*) or (thrombocyte* adj5 infus* ${ }^{*}$ or (thrombocyte* adj5 administ* $^{*}$ ) or (thrombocyte* adj5 requir $\left.^{*}\right)$ ).ti,ab

11.7 or 8 or 9 or 10

12. (prophylactic* or prophylax* or prevent*).ti,ab

13. 11 and 12

14. "CLINICAL TRIAL"/

15. ((controlled adj trial*) OR (clinical adj trial*)).ti,ab

16. ((singl* adj blind $\left.{ }^{*}\right)$ OR (doubl* adj blind*) OR (trebl* adj blind*) OR (singl* adj mask*) OR (doubl* adj mask*) OR (tripl* adj mask $\left.^{*}\right)$ ).ti,ab

randomi*.ti,ab

17. RANDOM ASSIGNMENT/

18. ("phase III" OR "phase 3" OR “phase three").ti,ab

19. (random* adj1 allocat*).ti,ab

20. (random* adj1 assign*).ti,ab

21. PLACEBOS/

22. 14 OR 15 OR 16 OR 17 OR 18 OR 19 OR 20 OR 21

23. 13 AND 22 


\section{Appendix 7. Free text search strategy for other databases}

(platelet* OR thrombocyte*) AND (transfus* OR infus* OR administ* OR requir*) AND (prophylactic* OR prophylaxis OR prevent OR prevention OR preventing)

\section{WHAT'S NEW}

Last assessed as up-to-date: 14 November 2011.

\begin{tabular}{l|l|l}
\hline Date & Event & Description \\
\hline 14 November 2011 & New citation required and conclusions have changed & $\begin{array}{l}\text { Authors changed (new authors S Hopewell and A Tin- } \\
\text { mouth) } \\
\text { Outcomes are now divided into primary and sec- } \\
\text { ondary outcomes. Bleeding is the primary outcome } \\
\text { Pre-specified subgroup analyses (type of disease and } \\
\text { treatment) and fever }\end{array}$ \\
\hline 10 November 2011 & New search has been performed & $\begin{array}{l}\text { New search } \\
\text { Inclusion/exclusion criteria altered - only includes } \\
\text { studies that contain at least 80\% haematology patients } \\
\text { or a subgroup of haematology patients can be identi- } \\
\text { fied }\end{array}$ \\
\hline
\end{tabular}

\section{H IS T O R Y}

Protocol first published: Issue 3, 2003

Review first published: Issue 4, 2004

\section{CONTRIBUTIONS OFAUTHORS}

Lise Estcourt: protocol development, searching, selection of studies, eligibility and quality assessment, data extraction and analysis and content expert.

Simon Stanworth: protocol development, searching, selection of studies, eligibility and quality assessment, data extraction and analysis and content expert.

Carolyn Doree: protocol development, searching and selection of studies

Sally Hopewell: protocol development and methodological expert.

Mike Murphy: protocol development and content expert.

Alan Tinmouth: content expert.

Nancy Heddle: protocol development and content expert.

All review authors contributed to the preparation of the final review. 


\section{DECLARATIONS OF INTEREST}

Lise Estcourt: none declared

Simon Stanworth: none declared

Carolyn Doree: none declared

Sally Hopewell: none declared

Mike Murphy: none declared

Alan Tinmouth: none declared

Nancy Heddle:none declared

\section{SOURCES OF SUPPORT}

\section{Internal sources}

- NHS Blood and Transplant, Research and Development, UK.

\section{External sources}

- German Ministry of Education and Research (BMBF) towards support of the Cochrane Haematological Malignancies Group, Germany.

\section{DIFFERENCES BETWEEN PROTOCOL AND REVIEW}

This updated review has changed from the previous review (Stanworth 2004). The inclusion/exclusion criteria are more restrictive so that only studies that include at least $80 \%$ haematology patients were included in the review. This led to the exclusion of two studies that were included in the previous review (Klumpp 1999; Zumberg 2002). A primary outcome was pre-specified prior to performing the updated review, to comply with the current Cochrane recommendations. One of the secondary outcomes, cost of treatments, was no longer included in the updated review because none of the studies in the original review reported this outcome. Two subgroup analyses were pre-specified prior to updating the review, these were fever and patients diagnostic and treatment subgroups.

\section{N DEX TERMS}

\section{Medical Subject Headings (MeSH)}

*Platelet Transfusion; *Stem Cell Transplantation; Hemorrhage [prevention \& control; *therapy]; Randomized Controlled Trials as Topic; Thrombocytopenia [* ${ }^{*}$ complications] 


\section{MeSH check words}

Humans

Prophylactic platelet transfusion for prevention of bleeding in patients with haematological disorders after chemotherapy and stem cell 133 transplantation (Review)

Copyright (? 2012 The Cochrane Collaboration. Published by John Wiley \& Sons, Ltd. 